Portland State University

PDXScholar

Spring 5-24-2016

\title{
Developing a Hierarchical Decision Model to Evaluate Nuclear Power Plant Alternative Siting Technologies
}

Marwan Mossa Lingga

Portland State University

Follow this and additional works at: https://pdxscholar.library.pdx.edu/open_access_etds

Part of the Operations Research, Systems Engineering and Industrial Engineering Commons Let us know how access to this document benefits you.

Recommended Citation

Lingga, Marwan Mossa, "Developing a Hierarchical Decision Model to Evaluate Nuclear Power Plant Alternative Siting Technologies" (2016). Dissertations and Theses. Paper 2943.

https://doi.org/10.15760/etd.2938

This Dissertation is brought to you for free and open access. It has been accepted for inclusion in Dissertations and Theses by an authorized administrator of PDXScholar. Please contact us if we can make this document more accessible: pdxscholar@pdx.edu. 
Developing a Hierarchical Decision Model to Evaluate Nuclear Power Plant Alternative Siting Technologies

by
Marwan Mossa Lingga

A dissertation submitted in partial fulfillment of the requirements for the degree of

\author{
Doctor of Philosophy \\ in \\ Technology Management
}

Dissertation Committee:

Dundar F. Kocaoglu, Chair

Tugrul U. Daim

Loren Lutzenhiser

Brian G. Woods

Portland State University

2016 
(C) 2016 Marwan Mossa Lingga 


\begin{abstract}
A strong trend of returning to nuclear power is evident in different places in the world. Forty-five countries are planning to add nuclear power to their grids and more than 66 nuclear power plants are under construction.

Nuclear power plants that generate electricity and steam need to improve safety to become more acceptable to governments and the public. One novel practical solution to increase nuclear power plants' safety factor is to build them away from urban areas, such as offshore or underground. To date, Land-Based siting is the dominant option for siting all commercial operational nuclear power plants. However, the literature reveals several options for building nuclear power plants in safer sitings than Land-Based siting.
\end{abstract}

The alternatives are several and each has advantages and disadvantages, and it is difficult to distinguish among them and choose the best for a specific project. In this research, we recall the old idea of using the alternatives of offshore and underground sitings for new nuclear power plants and propose a tool to help in choosing the best siting technology.

This research involved the development of a decision model for evaluating several potential nuclear power plant siting technologies, both those that are currently available and future ones. The decision model was developed based on the Hierarchical Decision Modeling (HDM) methodology. The model considers five 
major dimensions, social, technical, economic, environmental, and political (STEEP), and their related criteria and sub-criteria. The model was designed and developed by the author, and its elements' validation and evaluation were done by a large number of experts in the field of nuclear energy.

The decision model was applied in evaluating five potential siting technologies and ranked the Natural Island as the best in comparison to LandBased, Floating Plant, Artificial Island, and Semi-Embedded plant. 


\section{DEDICATION}

To my partner, best friend, beloved beautiful wife, Doaa Mohammad Behairi. 


\section{ACKNOWLEDGMENTS}

At first, I need to say "Alhumdo Lellah" Thank God for your infinite graces, bounties, and support throughout my life and for all successes and this ultimate achievement.

Second, I want to express my gratefulness to the Saudi government and the unforgettable man who deserves the acknowledgments and continuous prayers of mercy from thousands of Saudi students, King Abdulla bin Abdulaziz Al Saud, for his generous international scholarship program.

Third, over the past eight years, I have been inspired and received support and encouragement from a large number of people. I would like to begin with my teacher, adviser, and dissertation committee chair, Professor Dundar F. Kocaoglu, for his wisdom, guidance, patience, and unlimited support that made this research work a thoughtful and rewarding journey. He is my source of inspiration and role model of a genuine professor. His willingness to share valuable knowledge, time, and experience has been deeply appreciated. Thank you Dr. Kocaoglu.

I would like to express my deep appreciation to my dissertation committee members, Professor Tugrul U. Daim, Dr. Loren Lutzenhiser, and Dr. Brian G. Woods for their constructive suggestions and continuous support over the past two years as I moved from an idea to a completed study. 
I would like to send a special gratitude and appreciation to a person who is more than a friend, brother, mentor, or relative. The man who has helped me to achieve my master degree in Industrial Engineering fifteen years ago and who motivated me to pursue the PhD, Sheikh Mohammad Thabet Alhalabi. He has all beholden all the time for his honest love and decent friendship.

I would like to thank Dr. Mohammed A. Aleissa, the Cultural Attaché in the US, for his understanding, support, and wise-decision that extended my scholarship beyond the norm and helped me accomplish my ambition.

I am particularly grateful to my classmate and close friend, Dr. Nasir J. Sheikh, for his concern and advice at difficult times of data collection and evaluation. His long distance calls and hours of discussion were very supportive.

I would like to offer special thanks to all 53 experts who participated in my research for their patient, time, dedicated involvement, and useful critiques of this research work.

I am very thankful to my comprehensive exam committee members, Prof. Dundar F. Kocaoglu, Prof. Tugrul U. Daim, Dr. Timothy R. Anderson, Dr. Antonie J. Jetter, for their valuable comments and honest advices during the comprehensive exam process that helped me to proceed and focus in my endeavor. 
I would like to express my gratitude to all Engineering and Technology Management department's faculty members, in particular Prof. Paul R. Newman for his style of teaching, staff, classmates, and all students for making the ETM a family department and my PhD journey very pleasant.

I am truly thankful to all people whom I met at PSU from first day as an international student, especially Christina Luther, the director of NAFSA International Student and Scholar for her assistance at hard times, and as an IELP student who starts learning the English language by wonderful teachers, then as a graduate student in the College of Engineering.

Words are not enough to express my great gratitude for the role and help of my family during my study. I am very pleased, honored, and humbled to express my unlimited thanks to my beloved great mother, Aziz; my darling sisters, Hind, Doaa, Dina, and Eman; my close friends and brothers, Hassan, Yasser, and Khalid; my lovely wife, Doaa; and my wonderful children, Needa, Moayad, Mohammad, and little Dona for their constant blessings, sincere support, and patience during all these years.

Finally yet importantly, I would like to thank, Jacqueline Ramey, a professional editor, for her remarkable editorial work that made this dissertation readable. 


\section{TABLE OF CONTENTS}

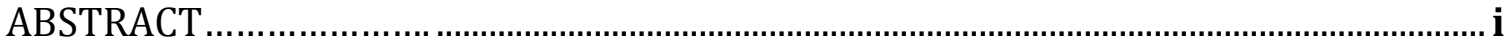

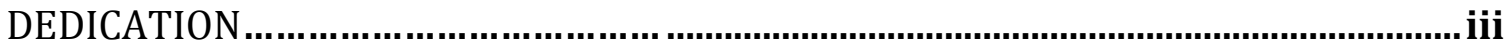

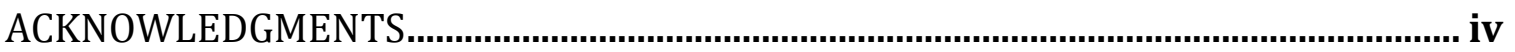

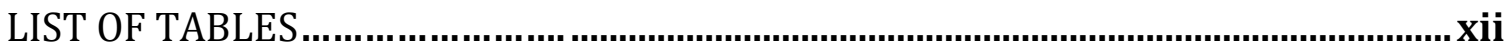

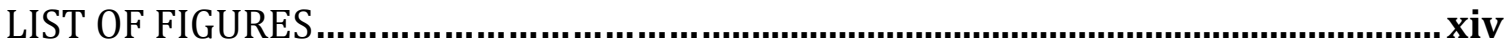

CHAPTER 1: BACKGROUND............................................................................................. 1

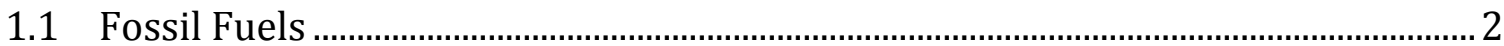

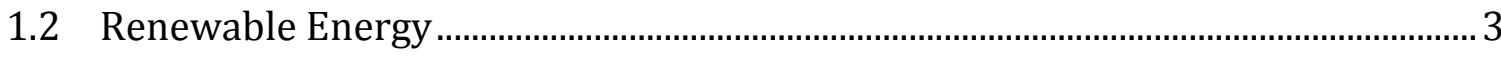

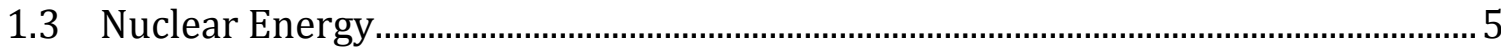

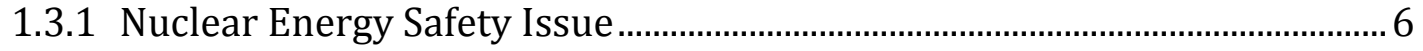

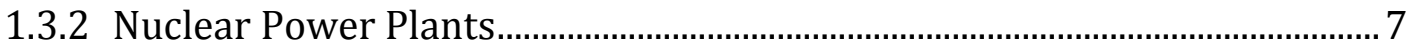

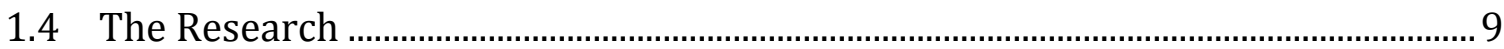

CHAPTER 2： LITERATURE REVIEW

2.1 Preface

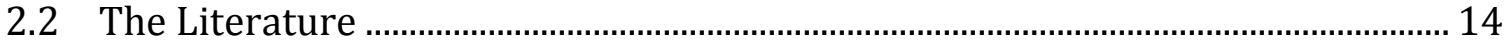

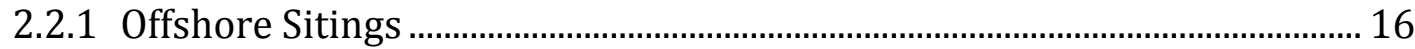

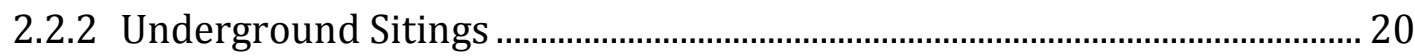

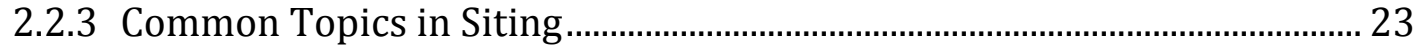

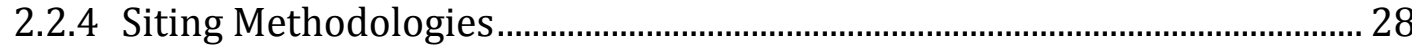

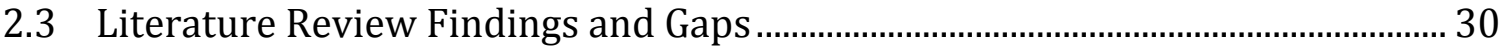

CHAPTER 3: RESEARCH FUNDAMENTALS .............................................................. 37

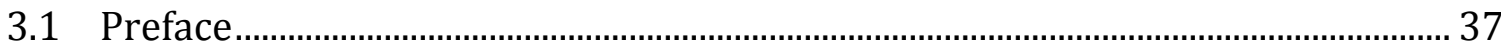

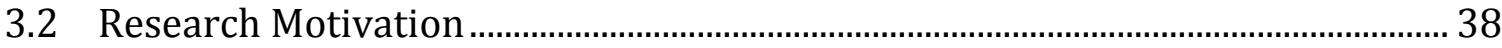

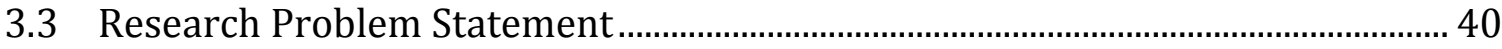

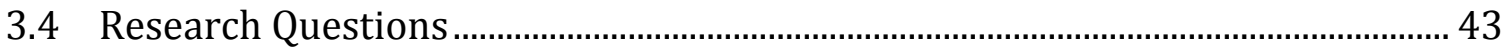

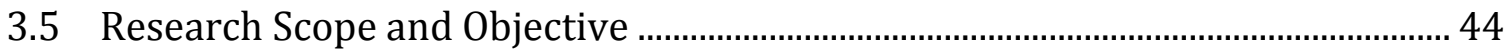

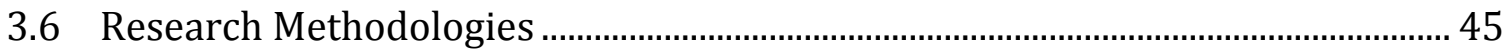


3.7 Research Process Flow ………………………………................................................. 48

3.7.1 Literature Review.......................................................................................... 48

3.7.2 Configure the Initial Model ............................................................................. 49

3.7.3 Identify and Define Potential NPPs Alternative Sitings................................. 50

3.7.4 Identify and Define Potential Model's Criteria and Sub-criteria................ 51

3.7.5 Identify and Invite Experts and Form Expert Panels ................................... 51

3.7.6 Validate Model's Elements................................................................................... 52

3.7.7 Evaluate Model's Elements .............................................................................. 52

3.7.8 Build a Base Model...................................................................................... 52

3.7.9 Run \& Test the Base Model ............................................................................. 53

3.7.10 Develop Desirability Metrics, Values, and Curves..................................... 53

3.7.11 Generalize the Base Model ............................................................................. 54

3.7.12 Test and Discuss Siting Technology Improvements.................................... 54

CHAPTER 4: RESEARCH METHODOLOGY .........................................................55

4.1 The Hierarchical Decision Model ........................................................................... 55

4.1.1 Judgment Quantification ................................................................................. 56

4.1.2 Pairwise Comparisons .................................................................................. 57

4.1.3 Inconsistency …………………………………………………………... 57

4.1.4 Disagreement .............................................................................................. 58

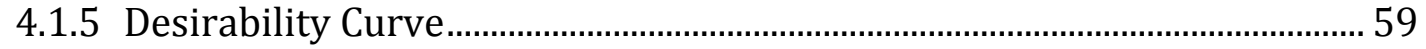

4.1.6 Sensitivity Analysis........................................................................................ 61

4.1.7 HDM Validations ............................................................................................. 62

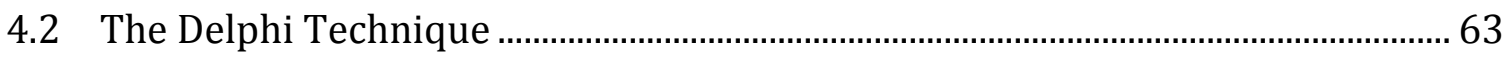

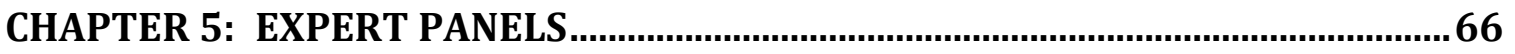

5.1 Preface

5.2 Nuclear Power Plant Experts .................................................................................... 67

5.3 Expert Types and Specialties................................................................................ 68

$5.4 \quad$ Expert Selection Criteria ........................................................................................ 70

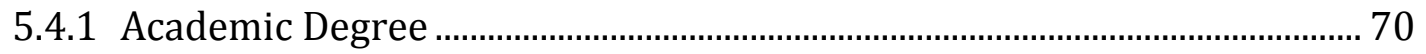




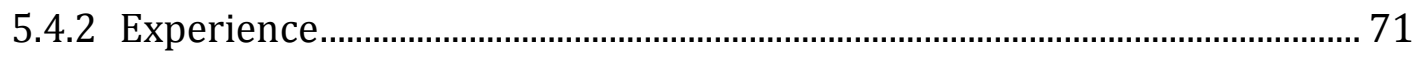

5.4.3 Participation .............................................................................................. 71

5.4.4 Research and Teaching................................................................................ 71

5.4.5 Willingness and Availability .............................................................................. 72

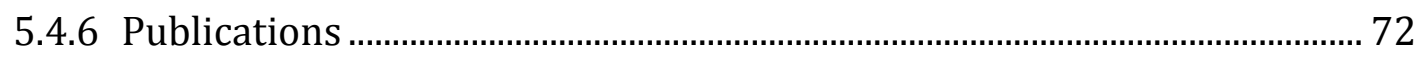

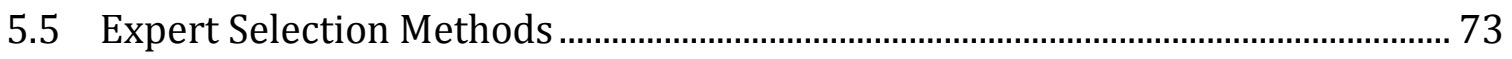

5.5.1 Citation Analysis .......................................................................................... 73

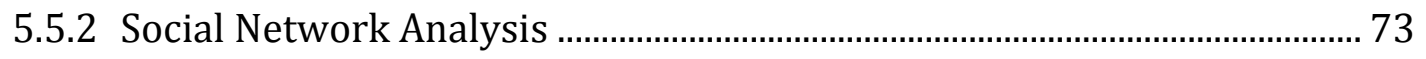

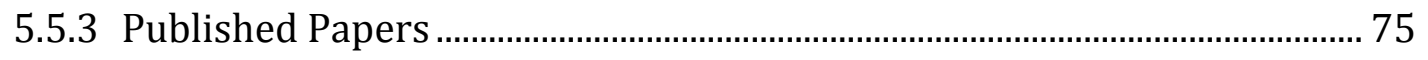

5.6 Experts Invitation and Replies................................................................................ 75

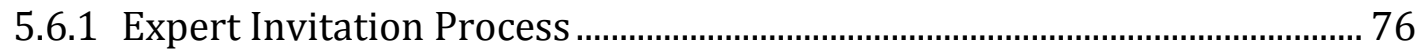

5.6.2 Expert Invitation Replies ................................................................................ 76

5.7 The Required Expert Panels and Their Tasks ……………………………………..... 77

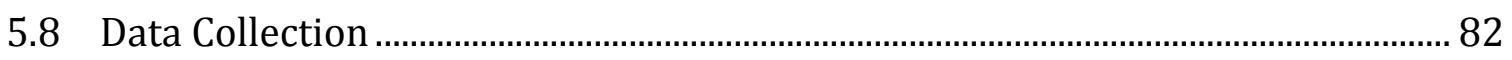

5.9 Samples of Experts' Positive Responses ................................................................... 84

CHAPTER 6: IDENTIFICATION OF MODEL ELEMENTS ..........................................85

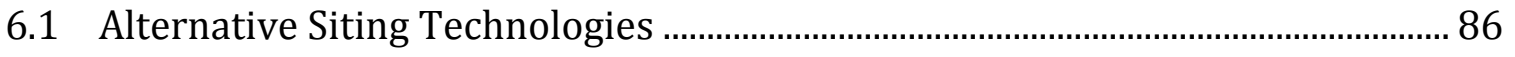

6.1.1 Underground Siting Technologies ............................................................... 86

6.1.2 Offshore Siting Technologies .................................................................... 91

6.2 Criteria and Sub-Criteria Identification and Definitions ....................................... 98

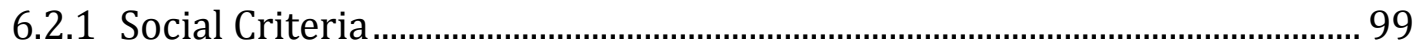

6.2.2 Technical Criteria ........................................................................................ 102

6.2.3 Economic Criteria......................................................................................107

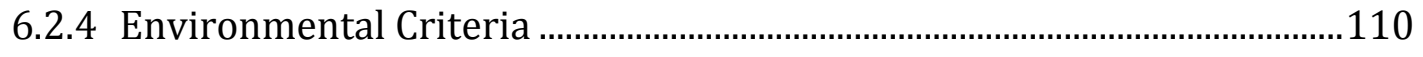

6.2.5 Political Criteria ……………………………………………………………...113

CHAPTER 7: VALIDATION AND EVALUATION OF MODEL ELEMENTS AND

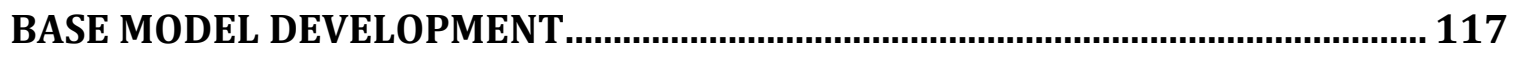

7.1 Elements Validation Process ………………………………………………......117

7.1.1 Validating Alternative Siting Technologies ...................................................118

7.1.2 Validating the Criteria and Sub-Criteria ......................................................120 
7.2 Elements Evaluation Process ……………………………………………………...124

7.2.1 Evaluating the Criteria and Sub-Criteria ……………....................................127

7.2.2 Evaluating the Siting Technologies..............................................................130

7.3 Base Model Development .....................................................................................137

7.3.1 Base Model Implementation ………………………......................................139

7.3.2 Base Model Testing by Changing the Priorities of the Perspectives.......146

CHAPTER 8: GENERALIZATION OF THE DECISION MODEL................................ 150

8.1 Development of Performance Measures...............................................................150

8.1.1 Defining Metrics for the Criteria and Sub-Criteria .....................................150

8.1.2 Developing Desirability Curves for the Criteria and Sub-Criteria............162

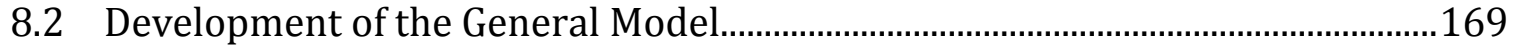

8.2.1 Modifying the Base Model by Using the Desirability Curves/Values .....169

8.2.2 General Model Assessment and Technology Improvements ....................176

CHAPTER 9: RESEARCH DISCUSSIONS AND CONCLUSIONS ................................. 185

9.1 Research Discussions .............................................................................................185

9.1.1 Land-Based vs. the Alternatives ..............................................................185

9.1.2 Influence of the Current Decision Model...………………………………......188

9.1.3 The Experts and Their Influence on Selecting the Natural Island ...........191

9.1.4 Model's Applicability for other Energy Technologies ..................................193

9.2 Research Conclusions...............................................................................................194

9.2.1 Research Contributions.................................................................................195

9.2.2 Research Limitations: ...................................................................................196

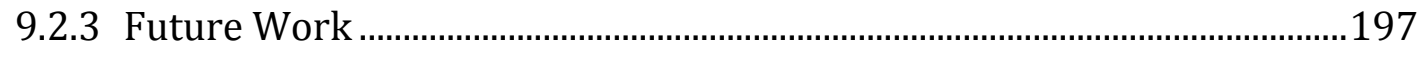

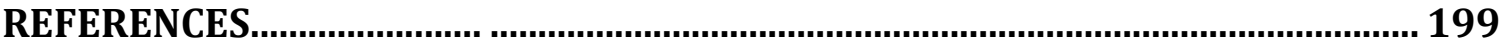

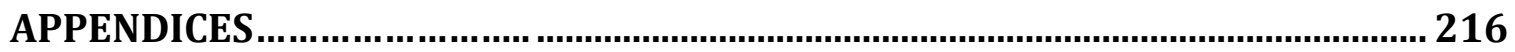

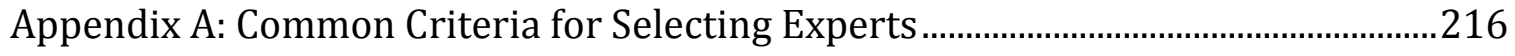

Appendix B: Common Methods for Selecting Experts.................................................219

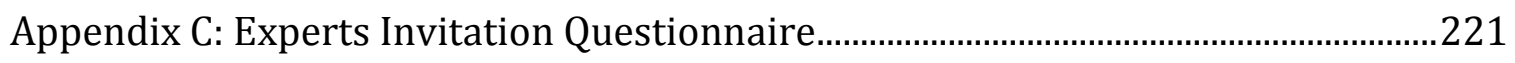

Appendix D: Siting Technologies Validation Questionnaire ...........................................222 
Appendix E: Model's Criteria and Sub-Criteria Validation Questionnaire

Appendix F: Tables of Pairwise Comparison Results for All Perspectives, Criteria,

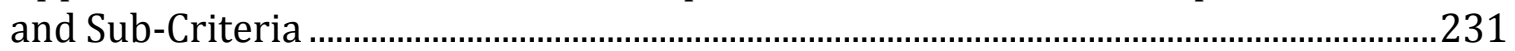

Appendix G: Desirability Tables and Curves of All 42 Decision Model's Criteria and

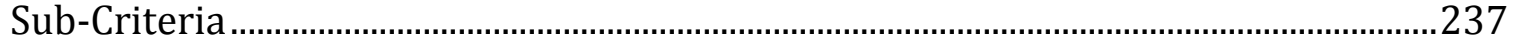




\section{LIST OF TABLES}

Table 2.1 Summary of Findings, Gaps, and Recommendations from the Literature Review on Nuclear Power Plants Siting Alternatives. 34

Table 5.1 Expert Types and Their Backgrounds/Specialties Required for Developing the Decision Model. 69

Table 5.2 Number of Experts Invited and the Responses ............................................... 77

Table 5.3 The Six Expert Panels and Their Tasks …………………………………….... 78

Table 5.4 Number of Experts Accepted to Participate in Each Panel ............................ 80

Table 5.5 List of Participated Experts, their Affiliations, and Countries ...................... 80

Table 7.1 Siting Technologies Applicability Rate ………………………………….....119

Table 7.2 Model's Criteria and Sub-Criteria Validity Percentage ................................121

Table 7.3 The Results of 10 Pairwise Comparisons for the 5-STEEP Perspectives 126

Table 7.4 Pairwise Comparisons Results of the Criteria and Sub-Criteria ................129

Table 7.5 The Relative Values of the Five Siting Technologies with Respect to All 42 Criteria and Sub-Criteria ................................................................................135

Table 7.6 The Base Model Relative Values ......................................................................141

Table 7.7 The Results of Evaluating the Five Siting Technologies under the Social Perspective ......................................................................................................144

Table 7.8 The Results of Evaluating the Five Siting Technologies under the 5-STEEP Perspectives' Criteria and Sub-Criteria ..........................................................145

Table 7.9 Impacts of Social Perspective Domination on Selection of Best Siting Technology .....................................................................................................147

Table 7.10 Impacts of Technical Perspective Domination on Selection of Best Siting Technology. 147

Table 7.11 Impacts of Economic Perspective Domination on Selection of Best Siting Technology.

Table 7.12 Impacts of Environmental Perspective Domination on Selection of Best Siting Technology. 148

Table 7.13 Impacts of Political Perspective Domination on Selection of Best Siting Technology 148

Table 8.1 Description of Criteria, Sub-Criteria, and Metrics 152 
Table 8.2 Desirability Values of Social Criterion (S1: Public Acceptance) 163

Table 8.3 Desirability Values of Social Sub-Criterion (S2.1: Health and Safety/ Public).

Table 8.4 Desirability Values of Social Sub-Criterion (S2.2: Health and Safety/

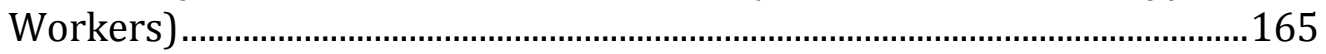

Table 8.6 Desirability Values of Social Criterion (S4: Visual Impact).........................167

Table 8.7 Desirability Values of Social Criterion (S5: Experts Availability) .............168

Table 8.8 Metrics Corresponding to the Decision Model's Criteria and Sub-Criteria for each Siting technology ................................................................................170

Table 8.9 Desirability Values Corresponding to the Decision Model's Criteria and Sub-Criteria for each Siting technology .........................................................173

Table 8.10 Evaluation of Siting Technologies by Using Desirability Values ...............175

Table 8.11 Comparison of Siting Technology Ranks in the Generalized Model vs. the Base Model.

Table 8.12 The Differences Between the Natural Island and Land-Based Siting Technologies

Table 8.13 Land-Based Improvements for the First Place as Best Siting Technology.... 181

Table 8.14 Floating Plant Improvements for the First Place as Best Siting Technology

Table 8.15 Semi-Embedded Plant Improvements for the First Place as Best Siting Technology.....

Table 8.16 Artificial Island Improvements for the First Place as Best Siting Technology.

Table 9.1 Results of Excluding the Social and Political Perspectives from the Base Decision Model 


\section{LIST OF FIGURES}

Figure 3.1 Elements of the NPPs Siting Technologies Decision Model .......................... 43

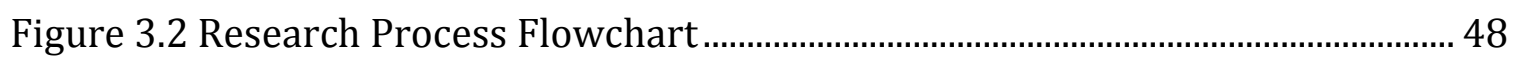

Figure 3.3 The Initial Hierarchical Decision Model (HDM) for Evaluating NPP Siting

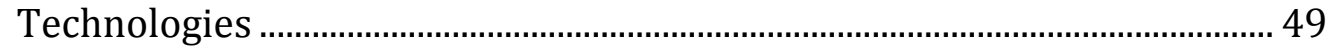

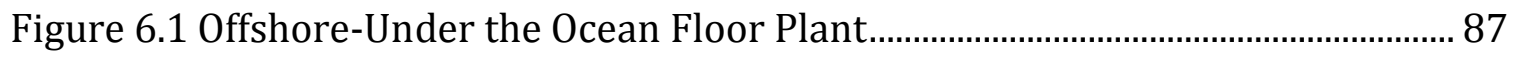

Figure 6.2 Primary and Secondary Underground Siting Technologies ......................... 89

Figure 6.3 Layout of Underground NPP Pit Siting Technology ....................................... 90

Figure 6.4 Primary and Secondary Offshore Siting Technologies .................................. 94

Figure 6.5 Offshore Floating Plant with Breakwater ....................................................... 95

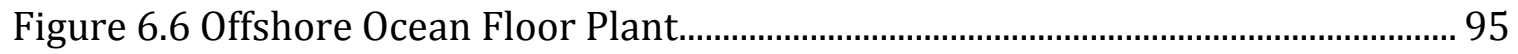

Figure 6.7 Pre-Stressed Concrete Barge Plant..................................................................... 96

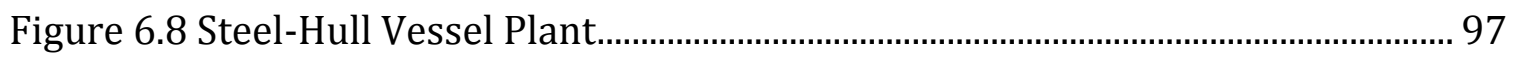

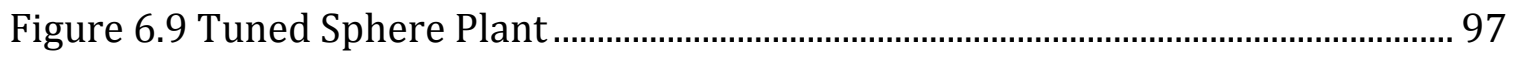

Figure 7.1 Judgment Quantification Instrument (10 Pairwise Comparisons) for Comparing the 5-STEEP Perspectives with Respect to the objective......125

Figure 7.2 The Relative Values of 5-STEEP Perspectives...............................................127

Figure 7.3 Social Criteria Relative Values...........................................................................128

Figure 7.4 Social Sub-Criteria (S2: People Health and Safety) Relative Values .........128

Figure 7.5 The Five Siting Technologies Relative Values with Respect to the Social Criteria S1.

Figure 7.6 The Five Siting Technologies Relative Values with Respect to the Social Sub-Criteria S2.1 …....................................................................................132

Figure 7.7 The Five Siting Technologies Relative Values with Respect to the Social Sub-Criteria S2.2

Figure 7.8 The Five Siting Technologies Relative Values with Respect to the Social Criteria S3.

Figure 7.9 The Five Siting Technologies Relative Values with Respect to the Social Criteria S4...

Figure 7.10 The Five Siting Technologies Relative Values with Respect to the Social Criteria S5. 
Figure 7.11The Hierarchical Decision Model (HDM) for Evaluating Nuclear Power

Plant Alternative Siting Technologies.

Figure 7.12 Judgment Quantification Instrument (10 Pairwise Comparisons) for Comparing the Five Siting Technologies with Respect to S1: Public Acceptance.

Figure 7.13 Siting Technologies' Relative Values under each Dominant Perspective....

Figure 8.1 Desirability Curve of Social Criterion (S1: Public Acceptance) ..................163

Figure 8.2 Desirability Curve of Social Sub-Criterion (S2.1: Health and Safety/Public) 164

Figure 8.3 Desirability Curve of Social Sub-Criterion (S2.2: Health and Safety/ Workers ) 165

Figure 8.4 Desirability Curve of Social Criterion (S3: Social Life and Activities)......166

Figure 8.5 Desirability Curve of Social Criterion (S4: Visual Impact) .........................167

Figure 8.6 Desirability Curve of Social Criterion (S5: Experts Availabiliy)................168

Figure 8.7 Differences Between the Desirability Values of Natural Island and Land-

Based Siting Technologies 178

Figure 8.8 Differences Between the Desirability Values of Natural Island and Floating Plant Siting Technologies 182

Figure 8.9 Differences Between the Desirability Values of Natural Island and SemiEmbedded Plant Siting Technologies 183

Figure 8.10 Differences Between the Desirability Values of Natural Island and Artificial Island Siting Technologies 


\section{CHAPTER 1: BACKGROUND}

Energy is an essential ingredient of life. Many natural and human-induced sources of energy are available today in both basic and complex forms. However, each energy source has some sort of drawback, limitation, or immaturity.

Currently accessible energy sources of fossil fuels such as petroleum, natural gas, and coal are associated with vital environmental issues, while potential renewable energy sources such as solar, wind, biofuel, geothermal, and waves are in need of significant efficiency improvements and cost-effectiveness. Ironically, with all these limitations and drawbacks, the need for energy is growing continuously due to increases in the human population and lifestyle improvements. The continuous need for energy has pushed the consumption of all available energy sources without considering their limits or drawbacks. The call for ideal source(s) of energy to mitigate the negative impacts becomes understandable and urgent.

An ideal or adequate energy source should satisfy the needs and expectations of society in terms of safe, clean, economical, controllable, abundant, and reliable energy. None of the known sources of energy (e.g., solar, wind, hydro, geothermal, biomass, fossil fuels, nuclear), by itself, fully satisfies these ideal characteristics. However, if the characteristic of "clean" energy were possible to ignore, fossil fuels would be the perfect source of energy. 


\subsection{Fossil Fuels}

Fossil fuels (i.e., natural gas, coal, and petroleum), which have been the most accessible and exploitable sources of energy, are currently used to satisfy a large portion of the energy demand and contribute to more than $85 \%$ of primary energy and $75 \%$ of electricity production [01].

Fossil fuels with this large contribution to the energy supply and long-term use have also contributed to major environmental problems due to the production of carbon dioxide $\left(\mathrm{CO}_{2}\right)$. The increased use of fossil fuels has intensified the pollution in the global environment, resulted in the increase of greenhouse gasses (GHGs) in the atmosphere, and distorted the balance of energy flow in the Earth's system [02]. The accumulation of GHGs is said to be responsible for the global warming that has caused an unexpected and undesirable climate change and had various impacts on the ecosystem, including threatening the sustainability of human life. In addition, the availability of fossil fuels is expected to reach a peak in the near future, leading to an increase in the final cost [01].

It is clear that the current situation of having a limited and environmentunfriendly source of energy cannot be sustained much longer and cannot be a favorable solution for humans. Therefore, it is becoming crucial to adopt alternative safe, clean, and abundant energy source(s), with renewable energy playing a significant role. 


\subsection{Renewable Energy}

Renewable energy is defined as "any naturally occurring energy that is not derived from fossil or nuclear fuels and theoretically inexhaustible, such as solar, wind, geothermal, biomass, and waves" [03].

Renewable energy was the only source of energy for humans before the discovery of fossil fuels; it was the first source of energy and will be the last available source of energy after fossil and nuclear fuels vanish. Technically, renewable energy has the best and highest potential to substitute for fossil fuels with its abundant, safe, and wide availability. Virtually every region in the world has a renewable energy source of one type or another. The natural availability of renewable energy is huge compared to the use and actual need of humans for energy. Therefore, all human needs for energy, now and in the future, theoretically can be met by energy from renewable sources.

However, the maturity and reliability of renewable sources have not been completely proven for large-scale use, for different applications, in all regions, and for all time periods [04]. The fluctuation in their availability has hindered them from being the ultimate reliable source of sustainable energy. Lots of development and improvements are required to reach the desired level of dependability and costeffectiveness. Today, only $2.8 \%$ of global electricity is from renewable sources (excluding hydropower), which reflects the limitations and the need for further 
improvements and deployment [05]. Moreover, economic systems and industries to support the wide use of renewable energy are not yet well prepared. This is mainly because renewable energy is usually weather dependent, which means uncontrollable [06]. In addition, mitigation of $\mathrm{CO}_{2}$ emissions is a key factor for adopting any reliable energy source, but renewable energy has not yet reached the level where it can make a significant contribution to $\mathrm{CO}_{2}$ mitigation.

Jeong et al. [07] extrapolated human historical data for 30 years between 1970 and 2000 and proposed a 'must-go path' scenario for the sustainable development of human civilization. They concluded that, to realize the must-go path scenario, it is important to ensure the sustainability of energy without further pollution. To limit pollution and increase sustainability, the study also recommended three potential solutions:
A) An urgent clean use of fossil fuels
B) The development of cost-effective renewable energy
C) The expanded use of nuclear energy

Menyah and Wolde-Rufael [08] focused on balancing between producing more secure and cheaper energy and reducing GHG emissions in the US and found empirical evidence indicating that the US can reduce its $\mathrm{CO}_{2}$ emissions by increasing nuclear energy consumption. Until the emission from fossil fuels is mitigated and/or renewable energy becomes efficient as a significant energy source, it seems 
reasonable and advantageous for many regions/countries to establish/continue the use of nuclear energy [07].

Because it is a relatively clean energy source compared to fossil fuels, nuclear energy can play a key role in the mix of energy sources in the next few decades. It is an attractive option to ensure security and diversity in the energy supply and to lower climate change risks.

\subsection{Nuclear Energy}

Nuclear energy is fundamentally a large-scale centralized source of energy that requires high levels of technological competence. It has been around for more than half a century of successful implementations and production of primary energy and electricity.

Today, nuclear energy contributes about $14 \%$ of world electric energy [09]. The current status of nuclear technology shows a high degree of compliance with sustainability criteria and performs excellently with regard to other energy alternatives. It is likely the most promising and viable source of energy for supplying the required capacity and quality of energy. Its quality is comparable to that of renewables in terms of meeting the clear-air objectives of low or negligible level of $\mathrm{CO}_{2}$ emission and better than fossil fuels [10]. At the same time, nuclear energy has been proven to be highly economical compared to renewable energy or even fossil fuels (except for the initial cost) [11]. Technically, it has evolved during the past 
several decades through different stages of major developments and achievements. The industry is expecting to see the fourth-generation nuclear reactor in operation soon [12].

Despite the long-term practice and hundreds of functioning reactors all over the world, nuclear energy has been wrapped in many political, social, environmental, and safety-related controversial issues. No other energy technology has had a global dichotomy about its future greater than nuclear energy. This dichotomy has existed not only among political parties of the same country, energy specialists, and the public but also among countries in general. For example, while many Western European countries such as Germany, Belgium, and Sweden have implemented policies for nuclear decommissioning, many industrial and developing nations such as China, India, Brazil, and others have turned to nuclear power. The latter want to address their escalating demands for energy and reduce reliance on fossil fuels while controlling GHG emission levels [13].

\subsubsection{Nuclear Energy Safety Issue}

The future of nuclear energy depends on many factors, including its technological advancement, financial investment and subsidizing, political legalization and support, public education and acceptance, fuel availability and efficiency, and ultimately its safety. 
Safety is at the top of the list of factors that, if considered and implemented effectively, would foster nuclear energy growth in the future. Safety is a major issue that has confronted nuclear technology from day one of its use as a bomb. The list of nuclear safety concerns is long, including proliferation, radiation, waste, terrorism attacks, and unpredictable accidents. The nuclear accidents that happened in the past were from technical malfunction, human error (e.g., Three Mile Island, Chernobyl) [14] and [15], or by nature and technical malfunction (e.g., Fukushima Daiichi) [16]. As a consequence of each of these major nuclear accidents, the industry learned significant lessons that led to more enhancements in safety aspects and measures, which in turn led to the limited number of nuclear accidents.

In light of the Fukushima Daiichi accident, where nature (earthquake/tsunami) played a major role in creating and magnifying the crisis, such an incident could happen again at the same site or anywhere else because of global warming. Even with all the safety improvements, the impact will be undesirable as long as nuclear power plants (NPPs) are not ready to adapt to the unexpected extremes of nature.

\subsubsection{Nuclear Power Plants}

Nuclear power plants are designed to maintain the integrity and performance of safety functions for a bounded set of normal operational events as well as abnormal events that are expected to occur or might occur at least once 
during the lifetime of the plant. In addition, they are designed to maintain the performance of safety functions for a set of design-basis accidents (DBAs) that involve failures that are possible but unlikely to occur during the plant's lifetime [17].

The plant design incorporates redundant safety systems that meet the requirements for inspection and testing to assure their performance when required [18]. Despite all these advanced safety design functions, accidents do happen.

The above-stated accidents have major implications for the industry. The first one, Three Mile Island (1979), showed that human error was behind the exacerbation of the accident after a minor technical malfunction. The second accident, Chernobyl (1986), created the notion of "a nuclear accident anywhere is a nuclear accident everywhere." [19]. In other words, local nuclear accidents have high global impacts. The most recent accident, Fukushima Daiichi (2011), compelled many countries to reevaluate their current and future nuclear plans and reassess the safety of power plants in light of the accident's causes and implications [20]. The Fukushima nuclear accident showed that serious accidents beyond (DBAs) happen; thus, external threats such as earthquakes, tsunamis, fires, flooding, tornadoes, and terrorist attacks remain among the greatest risk factors for a serious nuclear accident. This revelation is a challenge to the traditional nuclear safety design concept and has had a major impact on developing nuclear power around the world. 


\subsection{The Research}

The power plant lifespan has five major stages: siting, design, construction, operation, and decommissioning. Siting, the first stage, is defined as the process of selecting a suitable site for a plant, which involves two basic stages: site survey and site evaluation [21]. Careful consideration of siting-stage requirements helps in successfully performing the next stages (i.e., design, construction, etc.).

In general, the terms siting and site selection can be used interchangeably to describe the first stage. However, siting is a more comprehensive term while site selection is more specific and comes after deciding the siting style.

Site selection for power plants has been widely discussed in the literature, showing the significance of this stage in establishing a power plant [22 to 29]. In the site selection process, many criteria should be considered. For example, one study [30] identified and discussed more than 45 common criteria for power plant siting. The study categorized these criteria into six major groups: site requirements, community impacts, public health and safety concerns, environmental impacts, land use impacts, and economic impacts. These categories reveal the different potential key dimensions for use in evaluating any site for a power plant in general and an NPP in particular.

It is essential to consider that siting an NPP differs from siting a conventional plant (e.g., fossil plant) because of the high level of awareness that must be shown in 
terms of safety and protection of the public and environment. NPP site selection depends on site characteristics that are important to plant design and operation [30]. This means that great effort, careful investigation, and consideration of several significant factors should be involved in selecting a site for an NPP. For example, one major criterion for selecting a site for an NPP is "land" or plant space and its surroundings. A standard nuclear power plant site includes the area surrounding the plant, enclosed by a boundary that is under effective control of the plant management. An exclusion zone of at least $1 \mathrm{~km}$ radius around the plant is required in which public habitation is prohibited and the zone should be under the exclusive control of the plant. Additionally, a sterilized zone around the exclusion zone covering an area up to $5 \mathrm{~km}$ radius around the plant should be considered. In this sterilized zone, the natural growth of population is permitted [21] and [31].

According to this restriction in land use and other significant safety requirements, finding sites for NPPs has become a major problem [32]. However, the majority of all existing and operating NPPs (more than 430 plants) has used the conventional land-based siting as the only or best applicable siting.

In addition to the need for large land areas (the plant area and the exclusion zone), many other major barriers confront the deployment of land-based NPPs, including the need for a huge amount of water for cooling or steam generation, 
proximity to load centers, reductions in the environmental impact, and improvement of construction productivity to control costs [33].

In addition, considering Fukushima Daiichi and Hurricane Sandy in New Jersey (2012), it is obvious that the land-based siting, especially in coastal areas or areas with high potential for seismic events, is not safe or secure against unexpected natural disasters such as high-magnitude earthquakes and high tsunami waves. Indeed, Fukushima accident drew attention to safer sitings for NPPs [20].

The need for innovative siting solutions has become necessary to overcome safety barriers or mitigate their influence. Therefore, alternative new sitings should be considered especially with the need to deploy new NPPs in the next few years in different countries, circumstances, and geological environments.

This research is focused on NPP alternative sitings that would enhance the safety factor and support the endeavor to build more and new NPPs. It is dedicated to studying and evaluating potential NPP alternative siting technologies to select the best one. This research has three parts; part A is the research introduction, part B is the research process, and part $\mathrm{C}$ is the research outcomes. Part $\mathrm{A}$ is composed of five chapters where this chapter (Chapter 1) is the research background. Chapter 2 discusses the exploration of the literature of NPPs siting alternatives and other related topics. Chapter 3 is focused on the research fundamentals (i.e., research motivation, problem statement, research questions, scope, objective, methodology.) 
Chapter 4 explains the research methodologies, and Chapter 5 discusses the topic of experts' role and involvement in the research.

Part B is composed of three chapters. Chapter 6 describes the identification of model elements (i.e., siting technologies, criteria, and sub-criteria). Chapter 7 explains the validation and evaluation of model elements and the development of the base model, and chapter 8 discusses the model generalization and technology improvement. Part C is one chapter; Chapter 9 discusses important points and summarizes the research outcomes . 


\section{CHAPTER 2: LITERATURE REVIEW}

\subsection{Preface}

Nuclear energy is a source of energy that has been used for more than half a century to support the growing demand for energy. Thus, nuclear energy will continue to be important for decades to come unless significant improvements are achieved in fossil fuel and renewable energies. Hundreds of nuclear power plants (NPPs) have been built and operated around the world and supplied thousands of megawatts of electricity.

Although very few critical nuclear power plant accidents have occurred, they have raised concerns about and fears of a nuclear disaster. After each accident, the safety issue has become the focal point of the nuclear energy industries, officials, investors, researchers, and the public at large. Nuclear power plant safety issues mostly concern nuclear radiation, nuclear waste, and plant location.

Situating an NPP in a suitable site is a complex issue and requires stringent regulation. To increase the safety of a nuclear power plant and mitigate its potential environmental hazards, a novel solution was proposed a long time ago in the literature: Consider alternative siting technologies for NPPs. Offshore and underground are the two recognized siting options other than land-based siting, and they have been studied broadly in the literature. Today, the call to build new nuclear power plants to satisfy the increasing need for energy in many growing regions in 
the world while considering the NPP calamity of Japan in 2011 has made the need for safer siting more crucial.

Most previous studies on NPP siting options have concluded that the two alternative sitings (i.e., offshore and underground) have a high potential to improve nuclear power plants' safety. In addition, these two sitings would provide solutions for major issues related to NPPs, such as large land area for installation and exclusion zone, huge amounts of cooling water, waste disposal and management, environmental impact, and public safety concerns.

This chapter presents a review of the literature and summarizes the main findings of nearly 100 published papers on the subject of nuclear power plant alternative siting technologies and other related topics such as criteria for site selection and methodologies used to manage and evaluate the site selection process.

\subsection{The Literature}

The literature on nuclear power plant alternative siting technologies has introduced terms such as siting, land-based, offshore, and underground. The key term here is "siting". A broad definition of siting is given in [34] as "all activities, which are involved in supplying power, from identifying the need for new capacity through bringing that capacity online." Another definition of siting is given in [35] as "the process of selecting a suitable site for a facility, including appropriate assessment and definition of the related design bases." However, siting has been 
used in the literature to define the concept of positioning nuclear power plants (NPPs) or any industrial plant in a specific environment. Thus, siting should be understood as the process of selecting the proper environment for a plant either on the ground (land-based), off the ground (offshore), or underground.

Site selection is a stage within the whole process that is used to choose a proper location within a specific type of environment that satisfies all conditions and requirements.

The second term to mention here is "land-based", which is used in the literature to identify the conventional land siting. The term has been used interchangeably with "inland," "onshore," and similar terms but more frequently than the others. Land-based siting has been the option used most frequently since the first commercial nuclear power plant installation. With more than 430 nuclear reactors installed throughout the world, only a few have been installed underground for experimental purposes, with a small yield of power, and one expected installation of an offshore plant is imminent.

Offshore and underground sitings are alternatives to the conventional "landbased" siting. One study [36] calls the potential offshore and underground siting options and their sub-options novel siting solutions for NPPs. Each one of these sitings has sub-options, as mentioned in [37]. For example, offshore could be subdivided into shallow-water and deep-water concepts. Offshore shallow-water 
options include floating plants, seabed plants, natural islands, and artificial islands. Further, seabed option includes the option of ocean floor and under the ocean floor. Options for offshore deep-water are pre-stressed concrete barge, steel-hull vessels, and tuned spheres [38]. Underground main options are surface mounded, rock cavity, and pit siting. Rock cavity has two sub-options as hillside and deep below the surface while the two sub-options of pit siting are semi-embedded and totally embedded plants. More description of the offshore and underground siting options and their advantages and disadvantages were given in chapter 6 .

Most of the papers in the literature have discussed each of these main siting options (land-based, offshore, and underground) separately or independently of any other option. Very rarely, the three NPP alternative sitings have been considered simultaneously in one paper. For example, one paper [39] discussed the three types of siting technology in terms of their competency and distinctive features in Japan.

For purposes of the literature review, it is helpful to categorize the NPP siting papers into four groups: offshore, underground, common topics, and methods.

\subsubsection{Offshore Sitings}

Nearly $50 \%$ of the papers on alternative siting technologies have focused on offshore NPPs where the main concept of the offshore plant is explained in detail with well-done illustrations. This type of paper helps anyone clearly understand the concept and major characteristics of offshore siting. Technical, environmental, and 
safety aspects are the essence of most of these papers while a few discuss the economic, social, or regulatory aspects in detail. This siting option has been considered in the literature mostly as the first alternative to the land-based installation because it satisfies three major site requirements at once: land, water, and safety.

Detailed technological descriptions of the first planned floating power plant in the US were provided in [40]. The descriptions included a brief history of the concept, the design of the plant, site selection, manufacturing processes, the assembly line, and major safety concerns. A similar explanation of the first planned floating NPP was given briefly in [41]. In studying the potential and the need for constructing offshore NPPs, economic, environmental, and ergonomic considerations as well the benefits and problems associated with building offshore NPPs should be discussed as in [42].

Major offshore nuclear power plants' siting considerations were listed and discussed in [43 \& 44]. Offshore technical aspects, including detailed descriptions of plant design, layouts, components, auxiliary systems, construction, manufacturing processes, installation, and site technical investigation, were explained in [45 to 54]. Common environmental and safety considerations of offshore were discussed in [55 to 59]. Special safety considerations for offshore plants such as storms, tsunamis, 
earthquakes, and windstorms and human-induced accidents such as fire, collision, and sinking problems were explained in [60 \& 61].

Regulations for constructing and operating floating nuclear power plants (FNPPs) were discussed in [43, 62, and 63]. Detailed social impacts of offshore NPPs have been forecast by surveying visitors to nearby beaches [64]. Factors that would preclude large-scale commercial deployment of offshore NPPs such as lower energy growth and public acceptability or opposition were analyzed in [65]. Different offshore power plants (gas, coal, and nuclear) were explained, their advantages and disadvantages were highlighted, and economic considerations were pointed out in [66].

The dynamic behavior of floating power plants in the deep sea was discussed in [67 \& 68]. The dynamic analysis of floating nuclear plant sub-systems (basin, platform, and mooring systems) from the perspective of fluid-structure interaction effects was presented in [69]. Another study [70] discussed four alternative sitings to FNPPs (offshore, near-shore, riverine, and on-shore) and highlighted their advantages and disadvantages.

One study [71] stated that to situate an offshore NPP in a specific site, all necessary site selection studies in terms of geological, biological, ecological, political, economic, and engineering must be done in advance. In addition, other site-related 
characteristics such as meteorology, tides, current wave train, temperature, and salinity of the water should also be studied.

Using FNPPs to perform complex electrification operations for deep test bores for oil and gas was discussed in [72]. Usher [73] focused on the option of siting NPPs on an artificial island in terms of safety, technical requirements, engineering concepts, and the problems of island design and construction. One paper [74] discussed the characteristics, structural features, and related engineering problems of four types of offshore islands (fill, caisson, composite caisson/fill, and floating) as the ultimate possible siting options in Japan.

Moving nuclear power plants from the conventional established land-based locations to offshore marine environments greatly increased concerns about the nuclear energy industry. These concerns regarding offshore NPPs were discussed in [75] for a specific region of OSPAR (the Oslo and Paris Conventions for the protection of the marine environment of the Northeast Atlantic).

One potential offshore siting is the underwater siting. This option is a combination of the offshore and underground sitings. The market potential for this siting option, technical specifications, and safety considerations were highlighted in [76 and 77].

In addition to these papers, many others have also investigated offshore NPPs, discussing special topics such as floating nuclear desalination plant design, 
characteristics, and safety factors [78 and 79]. A Russian FNPP for remote regions was described in [80]. A low-capacity FNPP and detailed description of its main characteristics and technical specifications were discussed in [81]. Design and safety optimization of a ship-based small nuclear power reactor were explained in [82]. An assessment of radiological and radioecological consequences of FNPP was given in [83 and 84]. A description of a small barge-mounted NPP (10 MW) being built by the US army was provided in [85]. The idea of leasing new or replacing existing NPPs by using floating technologies for construction, mounting, and transportation was proposed in [86]. Finally, the coastal effects of offshore/floating nuclear power plants and other energy systems (oil and gas) were assessed in [87].

\subsubsection{Underground Sitings}

The literature has considered the underground siting option the second best alternative siting for nuclear power plants because it satisfies two major requirements at once: space and safety. Commonly, the space that is required to build and operate an NPP is huge (5 km in radius as a minimum and up to $25 \mathrm{~km}$ as a maximum) compared to other industrial or power plants. Underground installation does not require the huge amount of surface land as the plant is buried underneath the land.

With this siting option, the public and environment are at the lowest risk of thermal or radioactive exposure. Storing and cooling waste materials will be more 
affordable at the site until the materials are moved to a permanent location. In addition, in the worst possible scenario of nuclear meltdown, the risk of major damage to the surroundings will be at a minimum.

Studies on the underground option have confirmed its technical feasibility and revealed its potential for safety, security, and other promising advantages of underground nuclear power plants (UNPPs) [88]. A complete report on all aspects of a UNPP in terms of technical, structural, and operational aspects, in addition to detailed discussion of safety, the environment, and cost considerations was given in [89]. Advantages, disadvantages, and the economics of small UNPPs were discussed in [90]. Different alternatives for siting UNPPs such as rock cavity or pit sitings were explained in [91]. This paper also discussed the technical feasibility, safety considerations, time required, and associated costs of these two underground alternatives.

The underground nuclear park (UNP) is one of the daring notions that has been studied in the literature on NPP siting, mainly to exploit the potential of naturally available or created space and utilize effectively the site preparation cost. The concept of a UNP, technical aspects, environmental considerations, safety enhancement, and cost optimization as well the pros and cons of UNPs were described in [92]. The concept of the underground nuclear park in massive salt deposits was discussed in [93 and 94]. Its advantages, cost, challenges, 
environmental considerations, energy storage, and general issues (e.g., licensing, engineering, safety) were also explained in [93 and 94].

Two special studies on UNPPs by Watson et al. and Kammer [95\& 96] have been reported, one on a fully buried plant and the second on a partially buried plant with portions of the plant at the surface. These two studies provided technical details in terms of plant components, layouts, and configurations and described the construction techniques and requirements. Both studies also considered the economic aspects and associated costs. They both concluded that the underground siting in these two forms is technically and economically feasible.

Burckhardt [97] focused on three potential types of underground construction concepts: cut-and-cover burial, mined-rock caverns, and a combination of the two. The focus was on the evaluation of these concepts in terms of safety and the effect of different external impacts (e.g., aircraft impacts, seismic vulnerability, pressure waves) and internal impacts (e.g., internal accidents, radioactive release) as well as supplemental events such as fire, flood, and sabotage. The author also discussed the economic aspects of these different types of underground construction concepts, such as construction, operation, maintenance, and decommissioning costs. This paper recommended an equivalence comparison to a land-based plant to judge the pros and cons of the underground plant. 
In a similar study, the structural characteristics of four different underground concepts (cut-and-cover, unlined cavity, lined cavity, and lined cavity with an annular filling of soft material) were explained in [98]. The study also compared the advantages of each option to those of the others.

Takahashi [99] discussed the advantages of deep (more than a few hundred meters) underground nuclear plants over plants built on the Earth's surface.

Underground option for Singapore's nuclear power plant was explained in [100 and 101]. These two papers discussed why a state such as Singapore, with land restrictions and limited energy resources, might move to the option of nuclear energy and build the plant underground.

\subsubsection{Common Topics in Siting}

Siting any power plant must be done according to specific criteria. These criteria represent the concerns of a broad range of interested parties, including utility companies, power producers, regional planners, government agencies, and the public. As stated earlier, [29] listed most common power plant siting criteria used in determining the location of a new power plant or comparing possible power plant sites. Another paper [102] discussed NPP site evaluation in terms of site suitability characteristics, general evaluation criteria, and the potential of external (natural, human-induced) events. 
As an example of siting a power plant, either nuclear or fossil-based, [103] evaluated all major siting technologies (land-based, offshore, and underground) and some sub-technologies, which are illustrated in Chapter 6 (Figure 6.2 and Figure 6.4), for a specific region (i.e., California, US). The study considered common evaluation criteria such as cost, environmental impact, feasibility, and risk to evaluate all the technologies with respect to California. It concluded that land-based siting has the highest acceptability of the technologies.

Warnick [104] identified a methodology and criteria for siting power plants in Idaho, US. In this study, guidelines for future energy development that will meet the needs of the public, protect the environment, and ensure adequate safety were provided. Siting nuclear power plants differs from siting conventional plants in that a high level of safety and protection for the public and the environment must be taken into account in selecting the site. In most countries, the public and the environment are the key factors that make siting and selection of proper sites a serious issue. A study conducted in Australia by Macintosh [105] showed that these two factors play the key roles in siting NPPs. The author provided four primary and seven secondary criteria for siting and identifying NPP sites while considering the public and environmental requirements.

Jackson Consulting Limited summarized the major business, economic, safety, environmental, and technical factors that influence site selection for 
construction of one or more new nuclear power stations in the UK [106]. This paper also identified the basic scenarios for siting new nuclear power stations in the UK and examined the major factors that affect site evaluation.

In the US, applicants seeking to deploy new nuclear power facilities must obtain site permits and approval for construction and operation from the Nuclear Regulatory Commission (NRC) [107]. The NRC published its Siting Guide to provide a systematic and comprehensive site selection process. The process uses three basic types of criteria (exclusionary, avoidance, and suitability). The Siting Guide's objectives are to provide a road map for conducting the site selection process and a tool to identify sites that conform to the requirements for a site permit.

Two papers [35 and 108] introduced guidelines for site selection for NPPs. The common purpose of these guidelines was to assist applicants in the initial stage of selecting potential sites and to set forth general site selection considerations. Two other papers [109 and 110] summarized the most significant aspects of NPP site selection, the stages of the site selection process, site parameters affecting design safety, natural factors of site selection, and site selection human-related factors. For NPP site selection, Salman [111] focused on the treatment of the main geologic and tectonic features and the nature of the site.

The Atomic Energy Regulatory Board (AERB) in India has published procedures to follow in evaluating a site for a nuclear power plant [112]. This study 
identified three assessment criteria in siting NPPs: (1) rejection criteria: criteria must be satisfied or the site is deemed rejected, (2) mandatory requirements: need to be considered in the design of an NPP and evaluated during the siting process, and (3) desirable requirements: non-fulfillment of these requirements does not affect plant attributes.

One study [113] recommended formulating general guidance for site selection. Based on this recommendation, 120 scientists from different countries and organizations met at an International Atomic Energy Agency (IAEA) symposium to share their experiences and develop a site selection guide.

Safety of siting and design of nuclear power plants has been widely discussed in the literature. One paper [114] summarized the pattern of NPP siting and safety into three headings: (1) the choice of suitable sites on a practical basis, (2) the problems of identification and the effect of radioactive release from reactor containment, and (3) the problems associated with the provision for reactor containment. Based on expert opinion, the paper stated, that current containment technology is still not sufficient to build nuclear power reactors near towns. A study of urban siting of nuclear power plants focused on the assessment of reactor safety and relative health effects. This study relied on 30 other reports and studies to conclude that close-in urban sites should be avoided [115]. 
Farmer [116] proposed a new approach to developing NPP siting criteria. This new approach uses several means by which an appropriate safety standard can be defined as well as a means of assessing a reactor's ability to meet the standard. Draft documents have been prepared by the Canadian Nuclear Safety Commission (CNSC) to provide guidance on the design and siting of new nuclear power plants. Similar documents have been issued by the International Atomic Energy Agency (IAEA). Thompson [117] reviewed these documents and proposed safety criteria alternatives to the guidance set forth in the CNSC and IAEA documents.

Essential characteristics of the environment that highly affect the siting of NPPs were discussed in [118]. Another study [119] focused on the effect of NPP sitings on the environment revealed encouraging protection points for the public and the environment: (1) operating NPPs is safe for both the operating staff and the population in the areas surrounding the power plant, (2) radioactive monitoring in these areas has not revealed any major fluctuation and the level of radiation is hundreds of times lower than the maximum releases permitted in light of international recommendations, (3) discharged contaminated water with radioactive substances does not exceed the maximum levels permitted for drinking water.

Safety criteria that affect site selection were explained in [120]. The methodology that provides guidelines for the preliminary evaluation of the safety of 
NPPs, which are subject to strong seismic motions, was outlined in [121]. Howard, Ibáñez, and Smith [122] focused on reviewing and assessing the standards and the methods (analytical and experimental) used in the seismic design of NPPs that assure their safety.

\subsubsection{Siting Methodologies}

As mentioned earlier, siting a nuclear power plant in a suitable location is complex. This complexity stems from the stringent and long-term siting process as well as from dealing with multi-objective requirements, multi-group interests, and uncertainties. The range of siting considerations, such as safety, public, environmental, technical, and economic concerns and the choice of alternatives are wide. This makes it impractical to conduct the process through an informal or intuitive analysis. To proceed from selection of possible sites to selection of an optimum site, an efficient approach and systematic evaluation are required.

In the literature on NPP siting, only a few papers have discussed the methodologies used to evaluate the site selection process and validate the site selection criteria. For example, Fischer, Maniago, and Watson [123] explained the use of the Delphi method in defining and developing technical criteria to identify optimum sites for offshore nuclear power plants. The process starts by forming a multidisciplinary team to develop and validate a set of criteria for site judging. These criteria are weighted by team members according to their relative 
importance to establish a rating system. The established rating system is then used by the decision makers to identify the most suitable site. The role of the Delphi method is to reconcile the subjective differences among team members in developing the criteria, in assigning relative importance to these criteria, and in rating the selected sites. The iterative process that characterizes the Delphi method is the key factor that makes the method feasible in such application. The method has been used successfully to improve team output and efficiency.

Kirkwood [124] described the use of multi-objective decision analysis methods in evaluating and ranking candidate sites of a nuclear power plant and explained screening process to identify candidate sites for the plant. A risk analysis was conducted to determine the effects of major uncertainties.

Use of the judgmental method in recommending the most suitable sites for NPPs was explained in [125]. The study was carried out in two major steps: (1) a screening process to identify the candidate sites and (2) a decision analysis to evaluate and rank the candidate sites. The ranking process was based on the judgments and preferences of the project team.

The pairwise comparison technique was used as the base of three statistical methods employed to select a site for an NPP [126]. The Hinloopen-Nijkamp regime method, the Israels-Keller regime method, and the numerical interpretation method are three qualitative multicriteria statistical methods which are used to analyze 
problems marked by a choice between several discrete alternatives; they were used to select the optimal NPP site location among nine potential locations using 15 relevant criteria.

In a similar study by Lugasi, Mehrez, and Sinuany-Stern [127], two mathematical methods, Keeney's multi-attribute utility function and Saaty's Eigenvalues prioritization technique were used to select the preferred site for an NPP in Israel. This study focused on choosing one site from five nominated sites identified in previous studies. Although the two methods ranked four sites differently, they agreed on one site as the most desirable one.

\subsection{Literature Review Findings and Gaps}

The following are the major findings and gaps identified in the literature on NPP alternative siting technologies. A summary of findings, gaps, and recommendations is in Table 2.1.

* One study on urban siting of nuclear power plants [115] focused on the assessment of reactor safety and relative health effects. This study relied on 30 other reports and studies to conclude that siting close to urban areas should be avoided.

$\Rightarrow$ The recommendation to avoid building NPPs close to urban areas shows the necessity and importance of moving NPPs away from public areas; offshore and underground sitings are the best potential options 
* Most papers in the literature have discussed each of the main siting options separately or independently of any other siting.

$\Rightarrow$ There is a need to study and evaluate all three major siting options and/or their sub-options to determine the ideal siting for a specific project.

* Technical, environmental, and safety aspects are the essence of most papers on NPP siting, while a few have discussed the economic, social, or regulatory aspects in some detail.

$\Rightarrow$ Since NPP siting is so crucial, it is important to consider multiple key perspectives (i.e., social, technical, economic, environmental, and political) in evaluating the siting options.

* Most previous studies have been based on the technologies available from the 1960s to 1980 s.

$\Rightarrow$ Current development and improvement in NPP technologies (e.g., construction, containment, fuel, auxiliary systems) and new experiences should be considered when comparing and evaluating potential siting options.

* One special study of four different alternative sitings of FNPPs (offshore, nearshore, riverine, and on-shore) was conducted [70]. Another paper [97] focused on studying three potential types of underground construction concepts (cut-and-cover burial, mined-rock caverns, or a combination of 
both). The paper recommended an equivalent comparison with land-based siting to judge the pros and cons of those sitings.

$\Rightarrow$ An equivalent comparison of all aspects of all potential sitings is recommended.

* Design and safety optimization of a ship-based small nuclear power reactor was performed and a description of a small barge-mounted NPP (10 MW) being built by the US army was given in [85].

$\Rightarrow$ Another possible sub-option of offshore siting is to build an NPP as ship-based or barge-mounted to provide flexibility and support for the need for power in remote coastal areas.

* One paper [29] defined and listed the most common power plant siting criteria that can be used in determining the location of a new power plant or comparing possible power plant sites.

$\Rightarrow$ There is a need to identify and define evaluation criteria to be used in designing and developing a decision system and comparing potential sitings.

* One study [103] evaluated all major siting options (land-based, offshore, and underground) and their sub-options, regardless of the technology, for a specific region (California, US).

$\Rightarrow$ The same evaluation is needed for all siting options for nuclear power technology to develop a comprehensive generic evaluation system. 
* One study [113] revealed the need to formulate general guidance for site selection. Based on this recommendation, 120 scientists from different countries and organizations met at an (IAEA) symposium to share their experiences and develop the required site selection guide.

$\Rightarrow$ There is a need to invite and utilize experts' experiences to develop and validate the evaluation criteria for a siting selection guide.

* The range of siting considerations (safety, public, environmental, technical, and economic concerns) and the choice of alternatives are wide that this issue becomes impractical to process through an informal and intuitive analysis.

$\Rightarrow$ The wide range of considerations, alternatives, and objectives requires developing a systematic decision model to address the critical NPP siting issues.

* Many methods have been used in NPP siting evaluation. For example, the Delphi method has been used to develop and validate a set of criteria for site judging. Multi-objective decision analysis methods have been used to evaluate and rank the candidate sites and risk analysis has been used to determine the effects of major uncertainties. A pairwise comparison of alternatives has been used as a base for qualitative multicriteria statistical methods to select the best NPP location from many locations. 
$\Rightarrow$ Multiple methods, not necessarily only one, might be required to build the NPP siting evaluation system, where one method supports or enhances the results of others.

Table 2.1 Summary of Findings, Gaps, and Recommendations from the Literature Review on Nuclear Power Plants Siting Alternatives

\begin{tabular}{|c|c|c|c|}
\hline $\begin{array}{l}\text { Key Research } \\
\text { Areas in NPP } \\
\text { Sitings }\end{array}$ & Findings & References & $\begin{array}{c}\text { Gaps \& } \\
\text { Recommendations }\end{array}$ \\
\hline $\begin{array}{c}\text { Nuclear Power } \\
\text { Plants (NPPs) } \\
\text { Siting } \\
\text { Technologies }\end{array}$ & $\begin{array}{l}\text { Most papers in the } \\
\text { literature have discussed } \\
\text { each of the main siting } \\
\text { options separately or } \\
\text { independently of any } \\
\text { other siting }\end{array}$ & $\begin{array}{l}36,37,38,40, \\
41,45-54,70, \\
74,76,77,78, \\
81,82,88,86, \\
91,94,95,96, \\
97 .\end{array}$ & $\begin{array}{l}\text { There is a need to study } \\
\text { and evaluate major siting } \\
\text { options and/or their } \\
\text { sub-options to determine } \\
\text { decide the ideal siting for } \\
\text { a specific project. }\end{array}$ \\
\hline $\begin{array}{l}\text { Evaluation } \\
\text { Perspectives }\end{array}$ & $\begin{array}{l}\text { Technical, safety, and } \\
\text { environmental aspects } \\
\text { are the essence of most } \\
\text { papers on NPP, while few } \\
\text { have discussed the social, } \\
\text { economic, or the } \\
\text { regulatory aspects in } \\
\text { some details. }\end{array}$ & $\begin{array}{c}34,39,42,55 \\
-59,43,62, \\
63,64,71,73, \\
81,89,91,92 \\
106,107 \\
109,110 \\
115,119 \\
120,121\end{array}$ & $\begin{array}{l}\text { There is a need to } \\
\text { consider multiple key } \\
\text { perspectives in evaluating } \\
\text { the siting options. }\end{array}$ \\
\hline $\begin{array}{l}\text { Old \& Updated } \\
\text { Technologies }\end{array}$ & $\begin{array}{l}\text { Most previous studies } \\
\text { have been based on the } \\
\text { technologies available } \\
\text { from 1960s to } 1980 \mathrm{~s}\end{array}$ & $\begin{array}{c}36,37,38,40, \\
41,45-54,70, \\
74,76,77,80, \\
81,82,86,87, \\
91,93,94,95, \\
69,97 .\end{array}$ & $\begin{array}{l}\text { There is a need to update } \\
\text { the studies based on } \\
\text { updated technologies and } \\
\text { fresh experiences when } \\
\text { comparing and evaluating } \\
\text { potential siting options }\end{array}$ \\
\hline
\end{tabular}




\begin{tabular}{|c|c|c|c|}
\hline $\begin{array}{l}\text { Key Research } \\
\text { Areas in NPP } \\
\text { Sitings }\end{array}$ & Findings & References & $\begin{array}{c}\text { Gaps \& } \\
\text { Recommendations }\end{array}$ \\
\hline $\begin{array}{l}\text { Siting and Site } \\
\text { Evaluation } \\
\text { criteria }\end{array}$ & $\begin{array}{l}\text { Many papers have } \\
\text { defined and listed the } \\
\text { most common power } \\
\text { plant siting criteria that } \\
\text { can be used in } \\
\text { determining the location } \\
\text { of a power plant or in } \\
\text { comparing possible } \\
\text { power plant sites. }\end{array}$ & $\begin{array}{c}34,44,60,61 \\
102,103 \\
105,113 \\
117,121\end{array}$ & $\begin{array}{l}\text { There is a need to } \\
\text { identify and define } \\
\text { evaluation criteria to be } \\
\text { used in designing and } \\
\text { developing a decision } \\
\text { system and in comparing } \\
\text { potential sitings. }\end{array}$ \\
\hline $\begin{array}{l}\text { Evaluation and } \\
\text { Decision } \\
\text { Making System }\end{array}$ & $\begin{array}{l}\text { The range of siting } \\
\text { considerations and the } \\
\text { choice of alternatives are } \\
\text { wide that this issue } \\
\text { becomes impractical to } \\
\text { process through an } \\
\text { informal and intuitive } \\
\text { analysis. }\end{array}$ & $\begin{array}{c}35,108,109,1 \\
14,115,122,1 \\
23 .\end{array}$ & $\begin{array}{c}\text { There is a need to } \\
\text { develop a systematic } \\
\text { decision model to } \\
\text { address the critical NPP } \\
\text { siting issues. }\end{array}$ \\
\hline $\begin{array}{l}\text { Evaluation and } \\
\text { Analysis } \\
\text { Methods Used } \\
\text { in the Topic of } \\
\text { NPPs. }\end{array}$ & $\begin{array}{c}\text { Delphi, } \\
\text { Multi-Objective } \\
\text { Decision Analysis, } \\
\text { Judgmental Method, } \\
\text { Pairwise Comparison } \\
\text { Mathematical Method }\end{array}$ & $\begin{array}{c}124,125 \\
126,127 \\
128\end{array}$ & $\begin{array}{l}\text { There is a need to use } \\
\text { robust and reliable } \\
\text { methods to build the } \\
\text { NPP siting evaluation } \\
\text { system, where one } \\
\text { method would support } \\
\text { or enhance the results of } \\
\text { other. }\end{array}$ \\
\hline
\end{tabular}

In summary, the literature review has revealed the need to:

* Locate NPPs away or in isolation from urban areas, especially new installations.

Design and develop a comprehensive model for evaluating NPP siting options 
* Consider all potential siting technologies at once and decide the best among them.

* Consider multiple perspectives (social, technical, economic, environmental, political)

* Identify and define evaluation criteria for NPP siting technologies.

* Use multi-objective, quantitative, and qualitative methodology(ies) in the evaluation process 


\section{CHAPTER 3: RESEARCH FUNDAMENTALS}

\subsection{Preface}

Nuclear power plants that generate electricity and heat are the typical commercial application of nuclear technology. Many nuclear power plants were built from the 1960s through the 1980s, while very few were built afterward, mainly because of crucial safety issues. During the entire history of nuclear power plants, only a few critical accidents have occurred. Since the first commercial NPP accident in 1979 , the main concern of all the technology-involved parties has been how to improve NPP safety measures and prevent future accidents. However, even with all these efforts to develop a high level of safety actions, the accident at Fukushima Daiichi, Japan, in 2011 proved that safety still needs further consideration and improvement. The accident also revealed that the standard land-based siting of NPPs is not totally protected from extreme natural events such as earthquakes and tsunamis that can occur at any time or place.

Considering additional site safety measures to deal with all possible causes of accidents and reaching that level of safety perfection is becoming mandatory. One innovative solution to enhance NPP safety is to build nuclear power plants in isolated environments. Offshore and underground are the two potential sitings cited in the literature to substitute and compete with land-based siting in terms of safety and other factors. These alternative sitings are required, particularly at this time 
with the current trend to install more nuclear power plants worldwide and the limitation of available and suitable lands.

\subsection{Research Motivation}

In the technological era, the need for energy is growing tremendously. This growing demand is based on increases in the human population and improvements to the human lifestyle. Fossil fuels, hydro, geothermal, bio-fuels, renewables, and nuclear energy are the current functional sources of energy on which humanity can rely. However, concerns about energy air pollution, availability, efficiency, reliability, and safety limit the use of many of these sources. Fossil fuels are the major source of air pollution due to the large production of GHGs. Hydro and geothermal, natural cost-effective sources of energy, are limited to their availability and location. Renewables and bio-fuels, naturally abundant sources of energy, are in need of satisfactory levels of efficiency, reliability, and cost. Nuclear power, the most controversial source of energy, has crucial safety issues. However, nuclear power is the only existing energy source that can generate electricity with $24 / 7$ reliably, efficiency, and no GHG emission and at a competitive low cost for electricity of about two cents per kilowatt-hour [128].

Generally, role and advantage of nuclear power in societies are understood; however, the main concern is safety. The nuclear power safety issue can be defined in terms of radiation, malfunction, waste, proliferation, terrorism attack, external 
threats, and unpredictable accidents. The long history of nuclear energy has shown that some of these threats to safety have already happened and some are likely to happen. Indeed, nuclear power plant malfunctions and accidents such as Three Mile Island (US, 1979), Chernobyl (Ukraine, 1986), and Fukushima (Japan, 2011) have already occurred, and the first two resulted in decisions not to build more NPPs for decades. However, the undeniable contribution of this source of energy (more than $14 \%$ worldwide) and the demand for reliable sources of energy strengthen the call to build additional nuclear power plants.

My interest in conducting this research started with the Fukushima Daiichi nuclear plant crisis in Japan in May 2011. In studying the first two NPP accidents (i.e., Three Mile Island and Chernobyl), one can see that the main causes of these accidents were technical malfunctions and human error. In response, nuclear organizations developed and implemented regulations to prevent further accidents. Ironically, the Fukushima accident was caused by external forces, with the earthquake and strong tsunami destroying most of the Fukushima plant's facilities and turning the incident from an earthquake into a nuclear disaster. A similar incident that is worth mentioning here is Hurricane Sandy of October 2012, which hit the east coast of the US where 34 NPPs were operating, but no nuclear accident occurred. The worst impact of this event was the full shutdown of all NPPs at the New Jersey shore for a few days, where the strong winds and high waves left no other choice to prevent a nuclear crisis in the region. These incidents drew attention 
to the reality of the external causes of accidents and the criticality of onshore NPP siting. These two events have raised the bar for NPP installations in safer and more secure places than onshore.

The second motivation for conducting this research was many countries' announcement of an intention to implement nuclear power in their power grids. According to the World Nuclear Association, 45 countries are planning to build their first NPPs by the end of 2030 [129]. In addition to the 430 existing and operating nuclear power plants, 66 new NPP installations are underway almost everywhere in the world. These new and planned installations of NPPs should be considered carefully to avoid the previous faults in plant design, plant site selection, plant security systems, land requirements, water availability, and public and surroundings safety. Most of these faults are related to NPP location. Thus, a proper location will mitigate these faults and enhance plant effectiveness.

In considering the location issue, the best potential solution is to limit construction of NPPs in inhabited lands and prevent it in earthquake and hurricane pathways. This would require either building NPPs in remote areas where the cost is too high or building them in different settings such as underground or offshore.

\subsection{Research Problem Statement}

The process of selecting a land-based site for a conventional or nuclear power plant is long, complicated, and stringent. So, what is the case for selecting a 
siting type in different environments and having multiple alternatives for each environment?

The literature reveals three potential environments for siting nuclear power plants: land-based, underground, and offshore. Each of these options has one or more potential sub-options (alternatives). The literature has indicated eight suboptions for offshore siting and five sub-options for underground siting [38]. Landbased siting currently is one option but the future might reveal more options.

The nuclear power plant siting issue has multi-dimensional impacts for the environment and socioeconomic life, while it is affected by technical, economic, and political issues. However, considering only one or some of these aspects in discussing or evaluating the NPP siting issue is not adequate, particularly after the long-term experience of environmental, safety, technical, and economic issues and the crises associated with nuclear energy. Studies in the literature have focused on one or two of these aspects but not all of them at once. It would be more realistic to consider all possible aspects of social, technical, economic, environmental, and political (STEEP) perspectives. Thus, to deal with a problem of this magnitude, it is crucial to consider all these perspectives. General

Each one of the five STEEP perspectives can be characterized by criteria that define its objective or function. For example, the economic perspective on the NPP siting issue can be represented by the costs of site development, plant construction, 
plant operation and maintenance, labor, fuel, insurance, and similar costs. Thus, it is necessary to consider all criteria that characterize and play certain roles within each of the five perspectives. In some cases, a criterion can have sub-criteria that also must be identified and considered. The perspective's criteria and sub-criteria need to be identified and understood to define the perspective.

In addition, in most complex cases such as nuclear power plant siting, a number of decision makers or knowledgeable people (experts) is required. Experts are helpful because they have knowledge and experience, both of which are unavailable or limited in the literature and needed to study such an issue. Experts are required mainly to provide supportive information, feedback, and recommendations and to validate and evaluate the identified elements. This research required several groups of experts to deal with the large number of elements.

The criticality of the energy source and the involvement of several elements (i.e., alternatives, perspectives, criteria, sub-criteria, experts) have exposed the need to study the nuclear power plant siting issue comprehensively. Figure 3.1 represents the NPP siting technologies issue and its associated elements. 


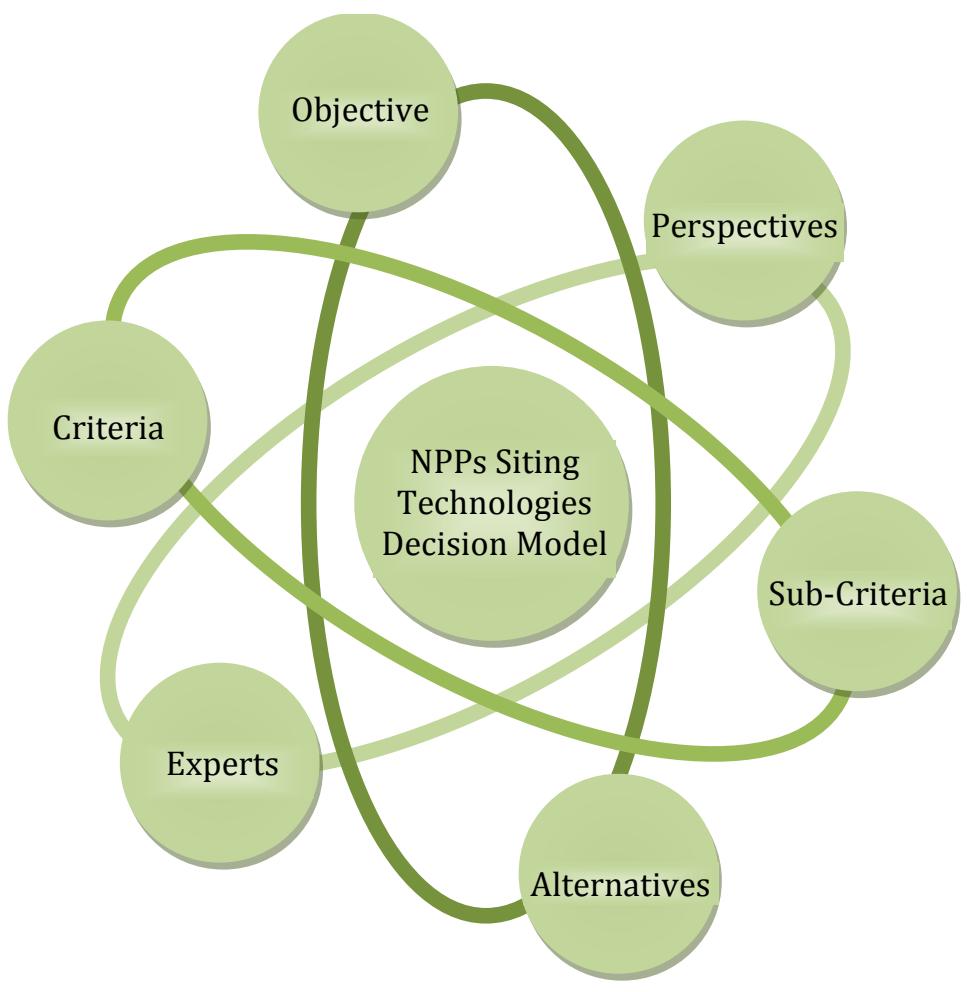

Figure $3.1 \quad$ Elements of the NPPs Siting Technologies Decision Model

\subsection{Research Questions}

Land-based siting has been used for almost all existing NPPs. Underground and offshore sitings have not yet been employed for commercial use. However, based on many studies in the literature, both are technically and economically feasible. Thus, it is advisable to consider the three possible sitings (land-based, offshore, and underground) and their sub-sitings for future installations and not to limit the decisions to land-based siting, especially after the recent events in Fukushima and New Jersey. 
The literature has identified several NPP siting technologies that have the potential to compete with land-based siting and improve safety. However, the current literature does not evaluate these alternative siting technologies in a way that distinguishes the best among them in specific circumstances. To do so, five questions can be asked:

1. What siting technologies for NPPs have the most potential?

2. What is the best way to evaluate all siting technologies and choose the best among them while considering all elements involved in the evaluation?

3. What are the appropriate criteria to perform the evaluation process?

4. What is the appropriate methodology to control and facilitate the evaluation process?

5. Is it possible to develop a systematic evaluation model for future potential siting technologies?

\subsection{Research Scope and Objective}

The intent of this research is to identify, study, and evaluate all potential and applicable alternative siting technologies for nuclear power plants to choose the best one. The primary research objective is to answer the five research questions. Answering the research questions requires the development of a holistic and practical evaluation process framework or decision model. The function of the decision model is to evaluate and determine which siting technology best fits the 
needs of a specific project or circumstance. The decision model must deal with multiple conflicting elements, control the evaluation process, and be comprehensive and flexible for further improvement or upgrading.

The outcome of the decision model, in addition to selection of the best siting technology, will help decision/policy makers:

- Understand the role and impact of each element within the decision model.

- $\quad$ Perform further analysis to improve the decision.

- Identify the actual requirements of a new nuclear power plant.

- Design the new nuclear power plant and its related systems.

\subsection{Research Methodologies}

The discipline of decision-making offers a host of methodologies and tools developed to facilitate the process of making a decision; however, not all methods are the same. They differ in how they are designed, the objectives for which they are used, the cases they are tackling, and the restrictions they can accommodate or by which they are limited. With different structures and requirements, the methodologies and tools can be categorized as single-criterion methods and multicriteria methods.

Multi-criteria decision making (MCDM) is a common term for all methods that exist to help in making decisions in the presence of multiple objectives or 
multiple attributes. The objectives and attributes usually conflict and, therefore, the solution depends highly on the preferences of the decision maker [130]. MCDM methods can also be used to filter alternative solutions and point out the best possible matrix of solutions. MCDM methods offer a wider understanding of the problem when decision makers who are unfamiliar with the problem are involved, coherent decisions are easier to achieve, and the problem is analyzed in a realistic framework [131].

Multi-criteria decisions are more complex than single-criterion decisions because of the difficulty of finding an alternative that outweighs all others with respect to all criteria [130]. Therefore, there is a need to break down the problem and represent it in a simpler form. Thus, after weighing considerations and making judgments about smaller components, the pieces are reassembled to present an overall picture to the decision makers [130].

Social, environmental, political, and other issues (qualitative data) that do not have numerical values (quantitative data) can be taken into account as well; thus, MCDM methods can be used to determine compromise solutions in complex mixed data problems [131]. MCDM methods also help to improve the quality of decisions by making them more explicit, rational, and efficient.

MCDM methods are applied in a wide spectrum of areas such as water and land management, technological investments, and energy planning [131]. Despite 
the large number of available MCDM methods and their applications, none of them is considered the best for all kinds of decision-making situations. There are no better or worse methods, but only methods that fit better in a certain situation. However, different methods, when applied to the same problem using similar data, often produce different results.

One well-known MCDM method that fits our problem (i.e., evaluating NPP alternative siting technologies) is the Hierarchical Decision Modeling (HDM).

Developing a decision model requires data and a data collection approach. Data that are required for the model will essentially be gathered from experts. To deal with a good number of experts who are not available at one time or place, it is necessary to use a suitable data collection approach. Several approaches to data collection are available, but one has the functionality to satisfy the current research needs, which is the Delphi technique.

The Delphi technique is a well-known structured approach that is very helpful in gathering experts' opinion independently and efficiently. Details of the HDM and the Delphi methods are provided in Chapter 4. 


\subsection{Research Process Flow}

This research is a long-term task and multi-phases project. Thus, to perform and control the research process, a sequence of twelve phases is adopted, illustrated in figure 3.2, and described below.

(1)

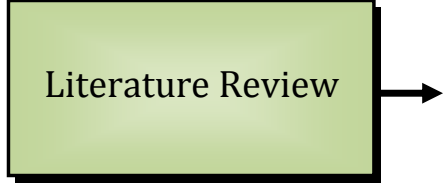

(6)
(2)

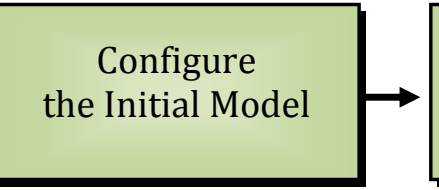

$(5)$

(3)

Identify and Define Potential NPPs Alternative Sitings

(4)

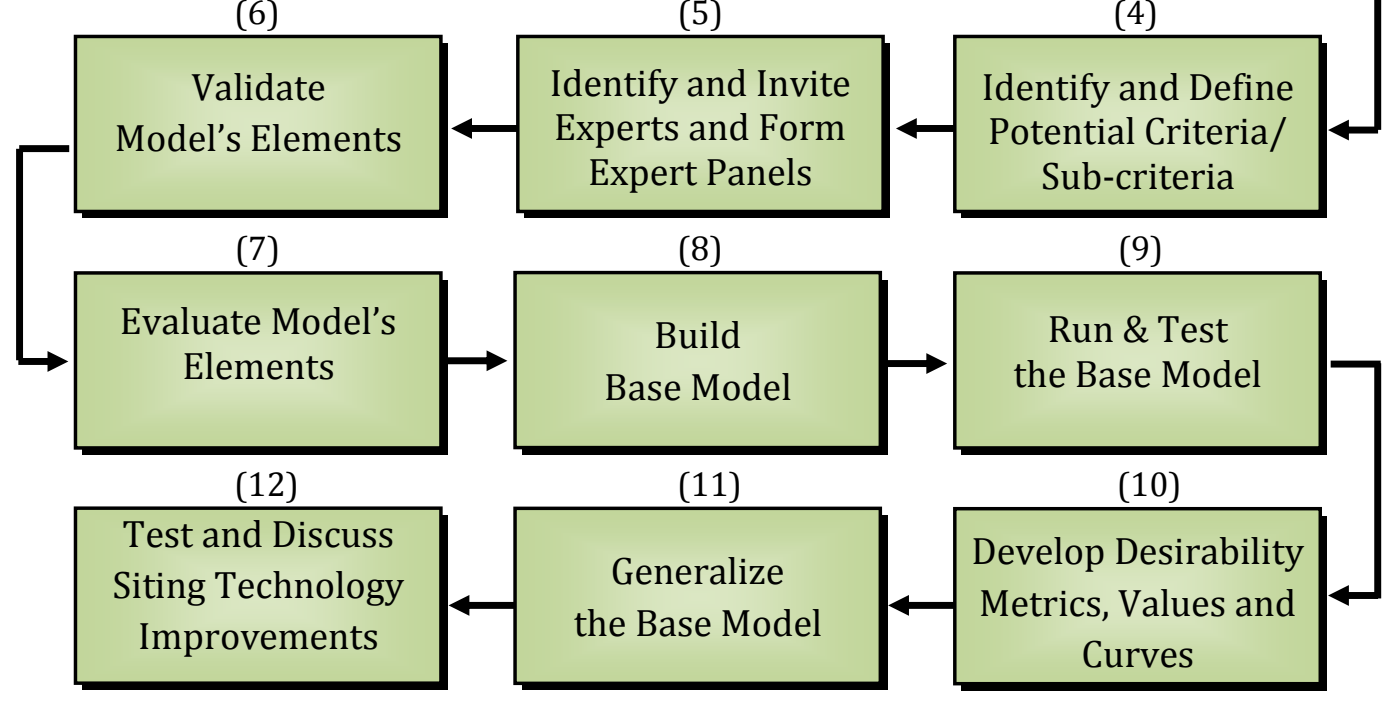

Figure 3.2 Research Process Flowchart

\subsubsection{Literature Review}

This first phase is an essential phase of a research to explore and understand research's topic and identify the gaps. An extensive review of more than one hundred papers on the topic of nuclear power plants alternative siting technologies was done. In addition, major literature findings and gaps were identified (Chapter 2) 


\subsubsection{Configure the Initial Model}

One of the fundamentals of building a decision model is to develop a general configuration of the required model. This step helps to identify key elements, number of hierarchical levels, and relationships among elements. Model's initial configuration was developed and illustrated in figure 3.3; and model's mathematical representation is explained below.

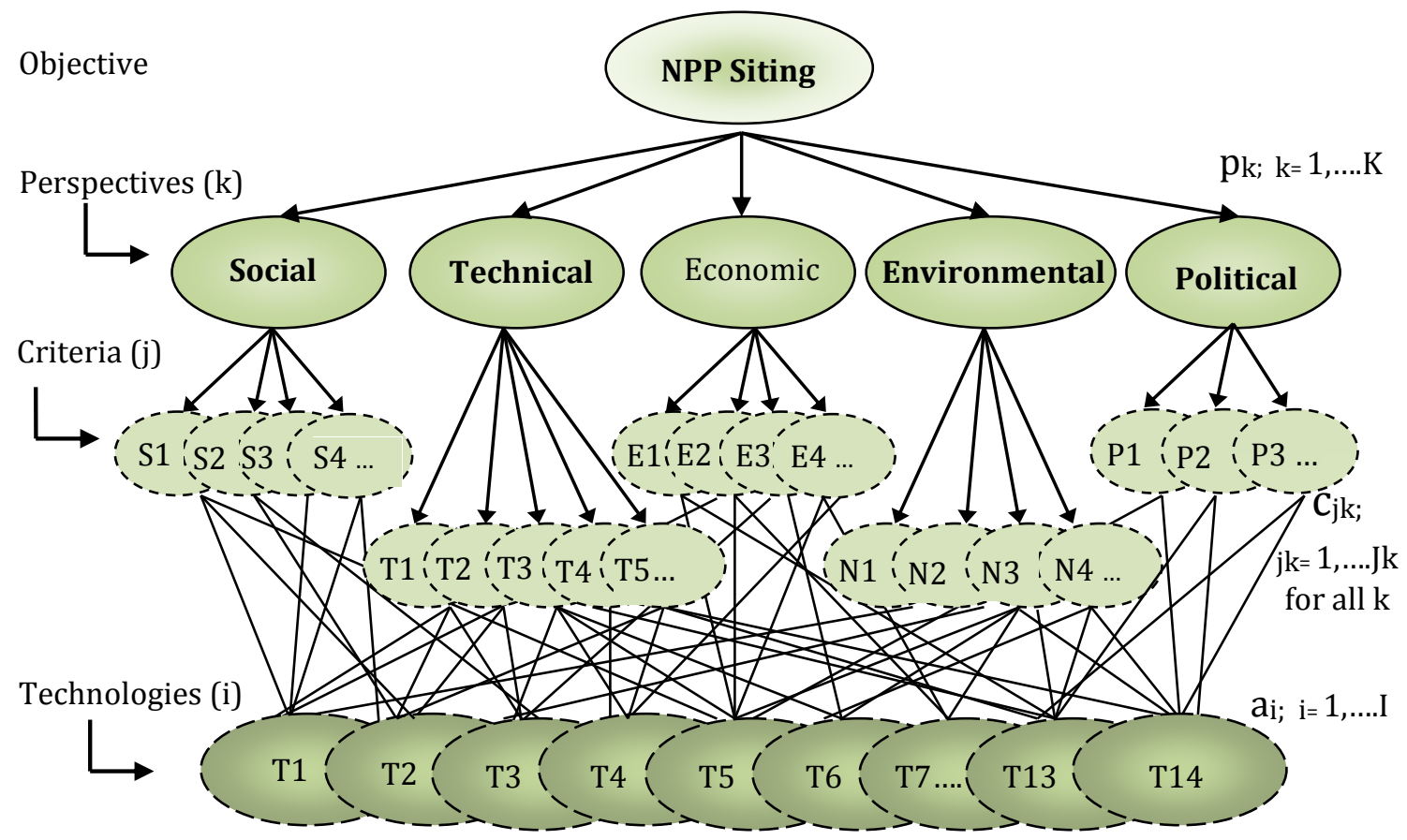

Figure 3.3 The Initial Hierarchical Decision Model (HDM) for Evaluating NPP Siting Technologies 
The model above is represented by the following mathematical equation:

The Value of an alternative (i) is defined as: $\mathrm{V}\left(\mathrm{a}_{\mathrm{i}}\right)=\sum_{k=1}^{K} \sum_{j k=1}^{J k} p_{k}^{o} \cdot c_{j k}^{k} \cdot d\left(m_{i}, j k\right)$ for $\mathrm{i}=1, \ldots ., \mathrm{I}$

Where:

$d\left(m_{i}, j k\right)=$ Desirability of performance metric of alternative (i) for jth criterion under perspective $(\mathrm{k})$,

$\boldsymbol{C}_{j k}^{k}=$ Relative importance of criterion (jk) under perspective (k) with respect to perspective $(\mathrm{k})$,

$p_{k}^{o}=$ Relative importance of perspective (k) with respect to objective (o)

Notice that each perspective can have a different number of criteria and subcriteria associated with it. The number of criteria for perspective (k) is denoted by (Jk).

\subsubsection{Identify and Define Potential NPPs Alternative Sitings}

The objective of the decision model is to evaluate NPPs siting technologies. Therefore, it is necessary to identify all potential siting technologies and define their characteristics. In addition to the land-based siting, 13 different offshore and underground potential siting technologies were identified as cited in the literature and listed below: 
a) Land-Based

b) Offshore: (1) Floating Plants (2) Ocean Floor (3) Under the Ocean Floor (4) Natural Islands (5) Artificial Islands (6) Pre-Stressed Concrete Barge (7) Steel-Hull Vessel (8) Tuned Spheres.

c) Underground: (1) Surface Mounded (2) Hillside Plant (3) Deep below the Surface (4) Semi-Embedded Plant (5) Totally Embedded Plant.

Potential siting technologies' definition and illustration were provided in Chapter 6.

\subsubsection{Identify and Define Potential Model's Criteria and Sub-criteria}

Siting Technologies are several and their characteristics under the 5-STEEP perspectives are different. To evaluate NPPs siting technologies, their criteria and sub-criteria that distinguish among them must be identified. Model's criteria and sub-criteria were identified and selected carefully from the literature to make feasible and efficient evaluation. The criteria and sub-criteria definitions were provided and explained in Chapter 6.

\subsubsection{Identify and Invite Experts and Form Expert Panels}

Evaluating NPPs siting technologies requires sort of data. Since most of the identified siting technologies have never been used in real commercial applications, the need of experts' knowledge and experiences are imperative. In addition, experts 
are required to participate in many aspects of developing, validating, and testing the decision model. Expert selection criteria, methods, qualifications, and their roles were explained in the Chapter 5.

\subsubsection{Validate Model's Elements}

The identified elements (i.e., siting technologies, criteria, and sub-criteria) should be valid in order to develop a reliable decision model. Validation processes were performed by developing and distributing particular questionnaires as explained in Chapter 7.

\subsubsection{Evaluate Model's Elements}

Elements evaluation is the process of assigning relative value for each element to express its importance or contribution within the model with respect to an associated element in the upper level. Pairwise technique was used to evaluate the elements and Judgment Quantification Instruments (JQI) were developed to facilitate experts' task of the pairwise comparisons. The results (i.e., elements' relative values) were presented in Chapter 7 .

\subsubsection{Build a Base Model}

A base model is a complete representation of all decision elements. Based on the above completed phases, the initial decision model was modified and a base model was built. The base model is the required hierarchical decision model (HDM) 
for evaluating NPPs alternative siting technologies. However, it is limited to the selected/validated siting technologies under evaluation.

\subsubsection{Run \& Test the Base Model}

To verify the functionality of the base model, it is necessary to execute it. Model execution is the process of calculating the vector value of each siting technology in the model using the mathematical equation in phase 2 . The outputs of model execution were presented and explained in Chapter 7. Testing the base model is to study its behavior under some sort of priority changes. The base model was tested by changing the priority values of the five STEEP perspectives. Testing results were observed and explained in Chapter 7.

\subsubsection{Develop Desirability Metrics, Values, and Curves}

To generalize the base model, a technique known as desirability curve was used. In order to use the desirability curve, model's criteria and sub-criteria performances were measured by metrics. Appropriate metrics were considered to represent the highest and lowest possible values of each criterion/sub-criterion. The experts then assigned a value for each performance and desirability curves were drawn as explained in Chapter 8. 


\subsubsection{Generalize the Base Model}

The base model was built based on the relative values of the model's elements, which had been calculated based on the experts' judgment quantifications. Relative values of model's elements were then matched with their performances and then converted to desirability values using the desirability curves. The generalized model was then built based on the derisible values.

\subsubsection{Test and Discuss Siting Technology Improvements}

The generalized model was tested by doing the same process of calculating the technology value for each siting technology using the equivalent desirable value correspond to each criterion's performance. The generalized model selected the Land-Based siting as the best one and ranked the other siting technologies accordingly. To study the potential of each siting technology for the first place (the best), adjustments of the more weighted criteria or sub-criteria were made per each siting to improve its total technology value. The required improvements for each siting technology were explained in Chapter 8. 


\section{CHAPTER 4: RESEARCH METHODOLOGY}

\subsection{The Hierarchical Decision Model}

The hierarchical decision model (HDM) is a multi-criteria method for analyzing complex decisions. HDM has been developed by Prof. Dundar F. Kocaoglu in 1979 with the same concept as the Analytical Hierarchy Process (AHP) methodology, but using a different pairwise comparison scale and judgmental quantification technique [132]. The general form of the HDM, which was developed by Dr. Cleland and Dr. Kocaoglu in 1981, consists of five hierarchical levels as Mission, Objectives, Goals, Strategies, and Actions (MOGSA) [133]. These levels are not fixed or limited, but flexible to match the actual requirements of any case under study. Determining the number of hierarchical levels depends on how simple or complex the decision problem is.

HDM is a method by which the problem is first decomposed into a hierarchy of more easily comprehended sub-problems to be analyzed independently. The hierarchy is organized into different levels with a number of decision elements residing on each level. At each level, the decision elements are connected to other decision elements on the level above and below them. The decision objective is placed at the top of the hierarchy, perspectives and their associated criteria/subcriteria are at levels and sublevels underneath the objective level, and the potential alternatives at the bottom of the hierarchy. The elements of the hierarchy can relate 
to any aspect of the decision problem that applies to the decision at hand. The hierarchical structure of HDM provides a simple and effective way for decision makers to compare tangibles and intangibles side by side, synthesizes a large amount of information at different scales, and converts judgments into data for quantitative decision makings.

Since its introduction, an overwhelming amount of publications using HDM as the research method has been generated. Hundreds of applications have been reported in different fields such as technology forecasting and assessment, $R \& D$ portfolio development, problem solving planning, energy choices, investment analysis, medical and health care decisions, risk assessment, resources allocation, priority setting, selection among alternatives, etc. [134] \& [135].

In addition to its flexible hierarchical structure that could accommodate any decision problem, the HDM uses several techniques to analyze the inputs and outputs during the evaluation process. These techniques are explained below:

\subsubsection{Judgment Quantification}

Judgment quantification is a technique usually used to obtain subjective data when objective data are not available for making a decision. It is used to derive local contribution of each element within the decision model. HDM uses the constant-sum method of allocating a total of 100 points between two elements of a decision model at a given time. Distributing the points is done to compare relative importance of the 
two elements with respect to the upper level element to which the two lower elements are linked. The subjective values of the two elements are then calculated and normalized to obtain the relative importance value of each element in a ratio scale. The calculated percentage value of each element describes its relative importance. For example, an element (A) of $75 \%$ relative important value is three times as important, to the upper level, as an element (B) of $25 \%$. The levels are recomposed after all decision elements are evaluated. The process results in the overall relative contribution of each element with respect to the objective of the decision model.

\subsubsection{Pairwise Comparisons}

Pairwise technique is used for the quantification process for all decision

elements. The number of pairwise comparisons (N) for (n) is $\left[N=\frac{n(n-1)}{2}\right]$. For example, if a group has 5 elements, the number of pairwise comparisons that should be done is $(5.4) / 2=10$. If the number of elements of a group is increased, the number of comparisons increases significantly. For example, 10 elements require $(10.9 / 2) 45$ comparisons

\subsubsection{Inconsistency}

Consistency can be explained as: if A is twice important as B, and B is twice as important as $\mathrm{C}$, then $\mathrm{A}$ is 4 times as important as $\mathrm{C}$. When the pairwise comparisons give different results, it is called "inconsistency". Inconsistency in HDM is a measure 
that shows how an expert is responding to the judgment quantification process and how valid his/her judgments can be considered.

Since the HDM has developed, the inconsistency measure was a value of 0.10 or less to consider as acceptable inconsistency. However a recent research titled “Consistency Analysis for Judgment Quantification in Hierarchical Decision Model" [136], introduced a new inconsistency measure. The research defined the inconsistency for HDM as the Root of the Sum of Variances (RSV) of the n decision variables. Thus, the inconsistency value can be determined by calculating the square root of the sum of variances of the means of $n$ variables.

The research considered a number of decision variables from 3 to 12 and calculated their corresponding fitted distributions at different levels of $(\alpha)$. According to the research outputs, inconsistency value ranges from 0.0001 , for 3 variables at $0.01(\alpha)$, to 0.7859 , for 12 variables at $0.50(\alpha)$ level. The range of inconsistency value is large and satisfies our decision model requirements. For this research we opted $(\alpha)$ level at 0.05 where the inconsistency values for 5 and 7 variables are 0.2651 and 0.5143 respectively.

\subsubsection{Disagreement}

Disagreement is a term used with the HDM to describe the harmony among experts' inputs. Large number of experts with diversity of knowledge and experiences would probably give different opinions or judgments. To consider 
experts' inputs (relative values) for a group of decision elements, disagreement among experts should be calculated and selected within an acceptable range. Disagreement can be determined from the Intraclass Correlation Coefficient (ICC). ICC describes the degree to which a number of experts are in agreement with one another on the relative importance on a number of subjects. Detailed description of the ICC equation is given in [137] and a comprehensible example of calculating the ICC is given in [138]. Since the ICC only gives a guideline to interpret the degree of agreement/disagreement among experts, additional test can be performed by using the F-test. F-test determines whether the disagreement among expert is statistically significant or not. Understanding and resolving the disagreement is an important aspect of the research and for building the decision model.

\subsubsection{Desirability Curve}

Strategic decisions are often made based on the level of goodness or usefulness of the decision elements not on their numerical values [137]. Decision making with a large number of decision elements of different types (i.e., quantitative and qualitative) or conflict of interests (i.e., social, technical, economic, etc.,) is difficult to be made because not all elements are quantitative or not all quantitative

elements have real values. To tackle the issue of dealing with different types of elements or the availability of real quantitative values, a desirability curve concept were used in this research. Desirability curve is a new concept, developed by Dr. Kocaoglu, and used with the HDM by many researchers. Desirability curve is a 
method developed to convert a decision element of any type to a numerical value that would be used to do the numerical calculations of the HDM decision model.

Each element of the decision model is supposed to be measured by using a range of metrics, either qualitative or quantitative, to express its importance or performance. For example, the social element of Public Acceptance and Attitude towards a nuclear power plant could be expressed at different levels as "no acceptance", "neutral acceptance", "low acceptance", "average acceptance", or "high acceptance". Each one of these public acceptance levels could be interpreted differently where no such actual meaning to any one of them. The concept of desirability curve allows an expert to assign desirable values for each element's metrics to express their importance or performance numerically. Desirability value ranges from 0 to 100 , where 0 is the lowest level, but not necessary to be the least desirable value; and 100 is the highest level, but not necessary to be the most desirable value. For example, 0 could be the most desirable value in terms of cost or time, while it could be the least desirable value in terms of acceptance or resources availability and vice versa. The other levels, in between, can be any value as long as they are in the range of 0 to 100 . Then, a curve should be drawn to represent the different metrics and their associate numerical values.

Desirability curve's axes are the metrics on the horizontal axis and the assigned desirability values are on the vertical axis. A desirability curve could be of 
any shape (e.g., straight line/linear, concave, convex, parabolic, etc.) The same thing could be done with a quantitative element when its numerical value is not accurate or not available. Thus, the desirability curve concept is a reliable approach to quantify any decision element for the current or future project.

\subsubsection{Sensitivity Analysis}

Generally, decisions are timely and conditionally manners. Thus, whenever a condition or time is changed the decision is mostly changed. A decision that could be made by one or few decision elements is likely more reliable or stable for minor changes than a decision made by several or large numbers of elements. To assess the decision's quality or validity, decision's elements should be examined under different conditions or by performing elements sensitivity analysis. Sensitivity analysis of the HDM is a method that is developed by Dr. Chen and Dr. Kocaoglu [133] and [134]. It uses a mathematical deduction method to ensure the robustness of the results under any changing conditions. Sensitivity analysis could be done at any level or for any element of the HDM decision model to understand how sensitive or responsive the decision to any possible changes in the relative values of the 5 perspectives or the criteria/sub-criteria. The analysis will allow policy/decision maker(s) to:

- Understand the decision model's behavior

- Assess the flexibility of the decision model for any potential changes 
- Distinguish the most critical elements within the decision model

- Find an allowable range of perturbation or tolerance of any decision element

- $\quad$ Focus on his/her priorities, and

- $\quad$ Build more reliable decision.

\subsubsection{HDM Validations}

Developing a decision model is a long term process of different stages. To develop and construct the whole model from a single objective node at the upper level to more than one node at different hierarchical levels, the process requires continuous quality assurance or process validation. It is important to ensure that at any stage of decision building, certain type of validation should be performed. Three different validation approaches were used: content, construct, and criterion-related validation.

\section{- Content Validation}

Decision model elements are supposed to be identified from the literature, selected based on the case under study, and then evaluated by experts. Experts were utilized to ensure that each selected decision element is of a significant role within the model and should be accepted at an agreeable level (e.g., more than $60 \%$ or so by all experts) 


\section{- Construct Validation}

Approved elements were used to construct the model. Allocating elements at different hierarchical levels were done according to the functionality of each element. The generic model structure were developed and then checked by experts to validate its logical and functionality order.

\section{- Criterion-Related Validation}

This validation approach was used at the end of the research to examine model's results. Experts were asked to confirm that model's results are acceptable and within their expectations. It was helpful at this stage to verify that the model is generalizable and would be used in future similar cases.

\subsection{The Delphi Technique}

As explained in Chapter 3, the proposed HDM consists of five levels that illustrate the major elements of the model. Each of these levels consists of several elements that represent the function of that level. For example, the second level is the 5-STEEP perspectives level while the third level is their associated criteria. The elements of these two levels are either quantitative or qualitative. Judging quantitative elements is manageable, while judging qualitative elements is a burden without experience and expertise. Accordingly, to judge the qualitative elements or determine their relative importance within the model, experts' unbiased opinions 
are required. Gathering experts' opinion requires a well-structured technique that combines all opinions and comes up with a common consensus for each issue or situation. Dealing with experts is not a simple task because they are not available in one place at the same time. Therefore, it is necessary to consider a technique that works efficiently to utilize experts' knowledge and time. The Delphi technique is a well-known practice in such cases.

The Delphi technique is a tool for judging, forecasting, and decision making in a variety of disciplines. It was developed in the 1950s at the RAND Corporation. The technique is "a procedure to obtain the most reliable consensus of opinion of a group of experts by a series of intensive questionnaires interspersed with controlled opinion feedback."

In particular, the structure of the technique is intended to allow access to the positive attributes (e.g., knowledge from a variety of sources, creative synthesis), while pre-empting their negative aspects (e.g., attributable to social, personal, and political conflicts). From a practical perspective, the method allows input from a larger number of participants than could feasibly be included in a group or committee meeting and from members who are geographically dispersed.

The Delphi technique is intended for use in judgment situations in which pure model-based statistical methods are not practical or possible because of the lack of appropriate historical, economic, or technical data and, thus, where some 
form of human judgmental input is necessary [139]. The technique allows experts to deal systematically with complex problems or tasks.

Four key features may be regarded as necessary for defining a procedure as a Delphi procedure: anonymity, iteration, controlled feedback, and the statistical aggregation of group response [140]. Anonymity is achieved by questionnaire. By allowing the individual group members the opportunity to express their opinions and judgments privately, undue social pressures - as from dominant or dogmatic individuals or from a majority - can be avoided. Ideally, this should allow the individual group members to consider each idea based on merit alone, rather than on the basis of potentially invalid criteria. 


\section{CHAPTER 5: EXPERT PANELS}

\subsection{Preface}

People seek knowledge, experience, and wisdom from others to help in solving problems, finding answers, or making successful decisions. In some cases, problems or required solutions are so complex that they need additional input from others who are recognized as knowledgeable people (experts). The business dictionary website defines the term "expert" as a "professional who has acquired knowledge and skills through study and practice over years, in a particular field or subject, to the extent that his/her opinion may be helpful in fact-finding, problemsolving, understanding of a situation, or making decision(s)." A group of experts working on the same task is called an expert council, board, cabinet, committee, or panel.

An expert panel is particularly appropriate for issues that are highly complex and/or require highly technical knowledge or the synthesis of experts from many different disciplines [141]. An expert panel typically consists of independent specialists in one field or more than one of the fields addressed by the case/system under evaluation. The literature has provided considerable evidence indicating that many industries and organizations have successfully utilized groups of individuals (expert panels) to participate in decision-making or problem-solving activities by soliciting informed recommendations or opinions from them [142]. The literature 
has also shown that the use of expert panels has become a well-documented tool specifically for use in decision making [143].

\subsection{Nuclear Power Plant Experts}

The complexity and criticality of managing or evaluating some projects, such as selecting a feasible NPP siting technology from among many options, requires multiple people with different knowledge, skills, and attitudes (i.e., experts) to judge various criteria or measures and help in identifying solution(s). In such complex situations, an individual usually provides a single perspective, personal judgment, or limited input, while a group of experts (i.e., panel) provides collective, more comprehensive, and accurate judgments.

As mentioned, the NPP siting evaluation issue involves five perspectives, a number of criteria and sub-criteria associated with each perspective, and several alternative siting technologies. To facilitate the evaluation process and come up with an acceptable and reliable decision model, experts are required to expose their knowledge and share their experiences through contributions and comments.

The initial decision model was designed tentatively by the author. Experts were utilized to judge, validate, evaluate, and finalize the decision model design, components, and outputs.

This chapter focuses on how the experts were identified, selected, and invited to participate in the research. Expert types and specialties, expert selection 
criteria and methods, and the required expert panels and their tasks are explained in this chapter. A list of the experts who agreed to participate, their affiliations, and their countries is also provided.

\subsection{Expert Types and Specialties}

It is important to emphasize that the experts selected to develop and validate the essential decision model work in professions that are highly related to the model's objective and elements. In addition, experts are supposed to work within groups/panels to assure consistent feedback and decision opinions.

Expert panels can be formed on different bases or specialties and categorized into different clusters. For the purpose of this research, expert panels were formed based on the diversity of the 5-STEEP perspectives. The group of experts included a variety of perspectives, diverse knowledge of nuclear energy technologies, knowledge of engineering and technology, economics and financing, the environment and climate change, economic and social development, market development, and governance and institutional issues including policy and regulatory frameworks, as shown in Table 5.1. 
Table 5.1 Expert Types and Their Backgrounds/Specialties Required for Developing the Decision Model

\begin{tabular}{|c|c|}
\hline Expert Panels & Backgrounds/Specialties \\
\hline Social & $\begin{array}{l}\text { Public opinion and position, workforce issues, public health } \\
\text { requirements and issues, occupational safety, job } \\
\text { creation/emplovment, direct and indirect social impact. }\end{array}$ \\
\hline Technical & $\begin{array}{l}\text { Nuclear power generation technologies (e.g., reactor types, coolant } \\
\text { technologies). Nuclear power plant's site exploration, selection, and } \\
\text { preparation. Plant construction, operation, and maintenance. Plant } \\
\text { safety and security measures. Nuclear power generation system } \\
\text { planning and scheduling. Used fuel and waste management. Nuclear } \\
\text { plant auxiliary systems (e.g., grid connection, water supply, plant } \\
\text { transportation, air-conditioning and ventilation). Nuclear plant } \\
\text { generation capacity and applications. Plant decommissioning } \\
\text { requirements. }\end{array}$ \\
\hline Economic & $\begin{array}{l}\text { Energy economic development, energy systems financing, budgeting, } \\
\text { contracting, loans and interest, subsidies, return on investments, } \\
\text { nuclear energy types and all associated costs. }\end{array}$ \\
\hline Environmental & $\begin{array}{l}\text { Common energy generation environmental benefits and issues, } \\
\text { Climate Change, Waste management, Used fuel management, Fuel } \\
\text { mining and transportation, Fire and hazards protection, Energy } \\
\text { impacts on the ecosystem, Power plant siting issues, Site } \\
\text { requirements and limitations. }\end{array}$ \\
\hline Political & $\begin{array}{l}\text { Nuclear power plants regulations, nuclear energy projects' approval } \\
\text { and licensing process and requirements, national/international } \\
\text { nuclear energy policies, nonproliferation, nuclear energy history and } \\
\text { future, different party overviews, foreign collaboration, energy rules } \\
\text { and legalities. }\end{array}$ \\
\hline
\end{tabular}




\subsection{Expert Selection Criteria}

Selecting experts to deal with the elements of the decision model is a crucial task that needs to be considered carefully. In general, numerous experts are available in any field with different levels of knowledge, experience, and interest. However, not all types of experts are required for the current case. The literature has identified several common criteria for selecting experts where some are highly required for the research and others might help in improving the selection process [143-149]. The common criteria is listed and and described in Appendix A. Since there is no previous experience with experts of those types and specialties, and for the purpose of this research and the required decision model, expert selection criteria have been considered carefully.

The six essential criteria used to select the research experts are explained below.

\subsubsection{Academic Degree}

Expert education is a key element of an expert's curriculum vitae and expert knowledge is highly regarded as a source of power. A university/college degree provides an expert with some measure of credibility. A university/college degree in one of the disciplines directly related to the research area or decision model's elements was required to select and invite an expert to participate. 


\subsubsection{Experience}

Experience generally complements education. In some situations, certain knowledge can only be gained through experience. It is commonly accepted that where an expert has been employed says as much about the expert as where he or she went to school. A significant history of work experience at a university, government research lab, or a top or well-known organization lends credibility to the expert's curriculum vitae. Therefore, long-term experience (10 years or more) was a key criterion for selecting experts for the research.

\subsubsection{Participation}

Active involvement in technical societies or committees is an excellent means for an expert to stay current with the state of the art in a particular industry or technology. Many experts, especially in technical or highly critical area of study, participate in conferences, seminars, and debates to share their experience, update their knowledge, or influence the discipline. Such participation helped in identifying experts for the research.

\subsubsection{Research and Teaching}

Research and teaching are indicators of an active and updated expert. Research and teaching tend to enhance an expert's credibility and help the expert comment on the research, method, criteria, and alternatives or recommend something different for the benefit of the study. To an extent, a helpful expert knows 
the requirements of academic research, how to deal with graduate students, and how to support research with current information and data.

\subsubsection{Willingness and Availability}

An expert should have the interest and the time to play an active part in the case for which he/she has been selected, as well as the passion for involvement in developing the decision model and sharing knowledge and experience. The expert should be eager to participate more than once and repeat his/her role, discuss the results, and make changes. Reluctant experts who are pushed into assisting may not ultimately give the best or right opinion. Thus, an expert who has little available time may not be the best choice. The willingness and availability criterion influenced the selection of experts in cases where the majority is either willing to participate but unavailable or available but not willing to participate.

\subsubsection{Publications}

Published papers in well-known journals or scientific magazines was an important criterion that distinguished and helped in identifying suitable experts for the research. A number of publications, related topics, detailed information, and updated data reflect the level of interest, experience, and knowledge that one can expect or ask for from the expert. 


\subsection{Expert Selection Methods}

Finding experts in any particular area is frequently difficult. In addition, determining who knows what is challenging. The literature describes several wellknown, efficient, and recommended techniques for identifying and locating experts, including citation analysis, social network analysis, snowball sampling, and published papers. More description of each method is given in Appendix B. Each method employed is explained below.

\subsubsection{Citation Analysis}

Citation analysis was not an effective technique in this research since most of the published papers found and used for preparing the literature review on NPP alternative siting technologies were very old (1970-1990). Most were not in an accessible electronic format but rather available as images. To perform the citation analysis, it was necessary to have the articles in portable document format (PDF). In addition, many were available as hard copies only. Thus, the author did not use the citation analysis method to select experts.

\subsubsection{Social Network Analysis}

Social network analysis (SNA) was a good tool to search for experts, not in famous public formats such as LinkedIn or Facebook, but in similar professional networks. Several professional nuclear organizations have an online presence, including the IAEA, American Nuclear Society (ANS), US Department of Energy 
(DOE), and Nuclear Security Governance Experts Group (NSGEG). These organizations are reliable and generous sources of information, facts, data, and professionals. Some of these organizations limit access to their member profiles while others provide a long list of members. To access these lists and look for experts within the mentioned organizations, emails with a short description of the research topic and the role of the required experts were sent to these organizations. The response from the organization was good in terms of promising to distribute the invitation, but few members responded.

Fortunately, two organizations, the Nuclear Energy Institute (NEI) and International Nuclear Energy Academy (INEA), are available online and allow access to their member lists. The NEI website (www.nei.org) provides a list of more than 60 experts with their names, organizations, positions, academic degrees, specialties, backgrounds, areas of interest, and contact information. The INEA website also provides a list of 144 experts with their names, countries, positions, and email addresses. Invitation emails with a short description of the research topic and the role of the required expert were sent directly to the experts listed on both organizations' websites.

Other types of professional networks are academic institutions such as engineering schools and nuclear departments. Academic organizations were more accessible than nuclear organizations. The research offered a good opportunity to 
access engineering/nuclear departments within US universities and check the list of academic staff members and browse their information. Around 200 faculty members' bios, contacts, research areas, topics of interest, and years and field of experience within engineering schools and other departments are available.

\subsubsection{Published Papers}

Looking for published papers was a valuable and efficient method of searching for experts. Most papers on nuclear power plant siting technologies were old and their authors were not easy to identify or contact. However, some recent papers on the topic were very helpful. These papers list their authors' names, institutes, and email addresses.

\subsection{Experts Invitation and Replies}

Contacting, inviting, and convincing experts to participate in the research was a remarkable but time-consuming task. An expert who matches the selection criteria was somewhat easy to find; however, securing his/her approval to participate was a repetitive and prolonged process. It was by itself a new and rich experience for the author to practice how to search, read bios, and select and invite experts and then to practice how to reply to their emails, concerns, and questions.

The support of the research committee's chair and adviser, Dr. Kocaoglu, was very helpful in dealing with experts, providing them with professional answers, and obtaining their approval to participate. 


\subsubsection{Expert Invitation Process}

- A three-page summary of the research topic, objective, methodology, and expected outcomes was prepared.

- A questionnaire with a simple question and a single request was prepared. The question asked the expert to choose either Yes or No as a reply to the invitation to participate in the research. The request asked the expert to nominate, if possible, other experts for the research. The questionnaire is available in Appendix C.

- A list of selected expert names, email addresses, and a formal invitation message were prepared.

- Emails with the three-page summary and questionnaire were sent to the available names.

\subsubsection{Expert Invitation Replies}

Several different replies were received, ranging from a single word such as decline, regret, and good luck to several words declaring interest but no time to participate, interest and the need for more information, or an immediate acceptance with some supportive words (examples are provided at the end of this chapter).

The plan was to contact and invite a reasonable number of experts (e.g., 50 to 100) to achieve the diversity in required specialties for the decision model. However, and based on many negative responses, the plan was changed to invite experts to satisfy the actual requirements (i.e., 10 to 15 experts per 
perspective/panel) and to deal with unexpected cases that might appear during the research, such as lack of interest or time.

The invitation task lasted for three consecutive months, the total number of sent emails and invited experts was almost (500), and the response rate was satisfactory (11\%). Table 5.2 shows the number of invited experts per source/method and their responses.

Table 5.2 Number of Experts Invited and the Responses

\begin{tabular}{|l|l|c|c|c|c|}
\hline No & \multicolumn{1}{|c|}{ Source/Method } & $\begin{array}{c}\text { Invited } \\
\text { Experts }\end{array}$ & $\begin{array}{c}\text { Accepted } \\
\text { to } \\
\text { Participate }\end{array}$ & $\begin{array}{c}\text { Declined } \\
\text { to } \\
\text { Participate }\end{array}$ & $\begin{array}{c}\text { No } \\
\text { Response }\end{array}$ \\
\hline 1 & Nuclear Energy Institute & 66 & 6 & 10 & 50 \\
\hline 2 & International Nuclear Energy Academy & 111 & 17 & 11 & 83 \\
\hline 3 & U.S. Nuclear Engineering Schools & 196 & 14 & 20 & 162 \\
\hline 4 & Published Papers & 37 & 10 & 4 & 73 \\
\hline 5 & Snowballing & 492 & $\mathbf{5 3}$ & 47 & 392 \\
\hline
\end{tabular}

\subsection{The Required Expert Panels and Their Tasks}

The objective of inviting experts was to have them participate in the process of validating and evaluating the decision model elements. The initial decision model consisted of five perspectives and many criteria and sub-criteria. The plan for this research was to form six expert panels, five representing the 5-STEEP perspectives 
and the sixth as the principal panel. The principal panel was the strategic panel (EP-1), which was dedicated to performing several major tasks and to fulfilling the shortages on other panels. The other five expert panels (EP-2 through EP-6) were assigned two tasks; one was to validate the criteria and sub-criteria under the 5-STEEP perspectives and the second was to perform pairwise comparisons based on each perspective.

Table 5.3 The Six Expert Panels and Their Tasks

\section{Expert Panel}

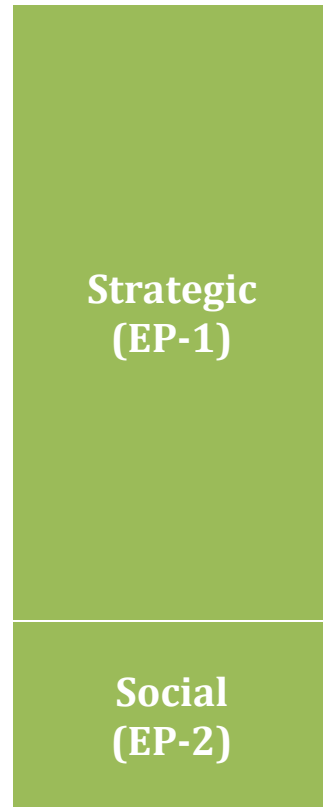

Technical

(EP-3)

Economic

(EP-4)

\section{Task}

- To help in validating and evaluating all model elements (perspectives, criteria \& sub-criteria, and potential siting technologies under study)

- To rank the five perspectives and their contributions with respect to the model's objective (do pairwise comparisons for the perspectives)

- To assign desirability values for developing desirability curves.

- To validate model's outcomes.

- Validate and perform the pairwise comparisons of Social perspective's criteria and sub-criteria

- Validate and perform the pairwise comparisons of Technical perspective's criteria and sub-criteria

- Validate and perform the pairwise comparisons of Economic perspective's criteria and sub-criteria 
Environmental

(EP-5)

Political

(EP-6)
- Validate and perform the pairwise comparisons of Environmental perspective's criteria and sub-criteria

- Validate and perform the pairwise comparisons of Political perspective's criteria and sub-criteria

The number of experts on each panel should be considered carefully because fewer or more experts than required might affect the inputs or outputs. Based on the study [154], fewer than six experts will limit the effectiveness of a panel, and more than 15 experts will be unnecessary because the benefit of having them will not increase. Thus, the number of experts required for each panel ranged from 6 to 15. However, it is not necessary to limit experts to a single panel; they can participate on any number of panels or be on the strategic panel.

When invited to devise the model's criteria and sub-criteria validation tasks, the experts were given a description of the tasks of each panel and the option and flexibility to choose the panel(s) in which they were interested. This flexibility encouraged many experts to choose the strategic panel. Having a large number of experts for the strategic panel was helpful because a large number of tasks was required and expert input was significant for the whole model. The number of experts who agreed to participate was 53 and 25 of them (47\%) selected the strategic panel. Table 5.4 shows the number of experts who participated in each panel, with overlaps in some panels. 
Table 5.4 Number of Experts Accepted to Participate in Each Panel

\begin{tabular}{|c|c|c|c|c|c|c|}
\hline Panel & Strategic & Social & Technical & Economic & Environmental & Political \\
\hline No. of Experts & 25 & 4 & 23 & 8 & 10 & 0 \\
\hline Total per Panel & & 29 & 48 & 33 & 35 & 25 \\
\hline
\end{tabular}

The experts' entity and privacy were highly respected and secured. As a part of this research policy and approval, experts' names have been concealed and substituted with a symbol ("EXP") and two digits (e.g., EXP01) to represent each expert throughout the research and as a reference for further needs. Table 5.5 lists chronologically the participated experts, their affiliations, and countries.

Table 5.5 List of Participated Experts, their Affiliations, and Countries

\begin{tabular}{|l|l|c|}
\hline EXpert & \multicolumn{1}{|c|}{ Affiliation } & Country \\
\hline EXP01 & Massachusetts Institute of Technology (MIT) & USA \\
\hline EXP02 & North Carolina State University & USA \\
\hline EXP03 & Nuclear Science and Engineering Institute, WA & USA \\
\hline EXP04 & Massachusetts Institute of Technology (MIT) & USA \\
\hline EXP05 & North Carolina State University & USA \\
\hline EXP06 & University of New Mexico & USA \\
\hline EXP07 & North Carolina State University & USA \\
\hline EXP08 & Massachusetts Institute of Technology (MIT) & USA \\
\hline EXP09 & Texas A \& M University & USA \\
\hline EXP10 & University of California, Berkeley & USA \\
\hline EXP11 & Missouri University of Science and Technology & USA \\
\hline
\end{tabular}




\begin{tabular}{|c|c|c|}
\hline Expert & Affiliation & Country \\
\hline EXP12 & Idaho National Laboratory & USA \\
\hline EXP13 & Neutrek, Inc. & USA \\
\hline EXP14 & Pennsylvania State University & USA \\
\hline EXP15 & University of Wisconsin & USA \\
\hline EXP16 & Royal Institute of Technology (KTH) & Sweden \\
\hline EXP17 & Massachusetts Institute of Technology (MIT) & USA \\
\hline EXP18 & AREVA, Nuclear Power \& Renewable Energy Company & France \\
\hline EXP19 & The University of New Mexico & USA \\
\hline EXP20 & Lithuania Energy Institute & Lithuania \\
\hline EXP21 & Nuclear Engineering Institute & Brazil \\
\hline EXP22 & The National Commission for Nuclear safety and Safeguards & Mexico \\
\hline EXP23 & $\begin{array}{l}\text { National Institute of Advanced Industrial Science and } \\
\text { Technology }\end{array}$ & Japan \\
\hline EXP24 & Atilim University & Turkey \\
\hline EXP25 & Nuclear Engineering Institute & Brazil \\
\hline EXP26 & International Nuclear Energy Academy, Executive Member & USA \\
\hline EXP27 & Colorado School of Mines & USA \\
\hline EXP28 & TerraPower/Nuclear Energy Technology Company & USA \\
\hline EXP29 & Federal Electricity Commission Company, Nuclear Dept. & Mexico \\
\hline EXP30 & AREVA, Nuclear Power \& Renewable Energy Company & France \\
\hline EXP31 & Texas A \& M University, Retired & USA \\
\hline EXP32 & Nuclear Technology Programs, Oak Ridge National Laboratory & USA \\
\hline EXP33 & Universidad Politecnica De Madrid, Dept. of Nuclear Engineering & Spain \\
\hline EXP34 & Rossin Associates, Enregy Consultation & USA \\
\hline EXP35 & University of Rhode Island & USA \\
\hline
\end{tabular}




\begin{tabular}{|r|l|r|}
\hline Expert & \multicolumn{1}{|c|}{ Affilliation } & Country \\
\hline EXP36 & Advisory Council of Nuclear Spain, Commissioner & Spain \\
\hline EXP37 & The European Organization for Nuclear Research (CERN) & Switzerland \\
\hline EXP38 & National Research Nuclear University (MEPHI) & Russia \\
\hline EXP39 & Canadian Nuclear Safety Commission (CNEC), Consultant & Ukraine \\
\hline EXP40 & Laboratory of Nuclear Installation Safety, & Lithuania \\
\hline EXP41 & University of California-Berkeley & USA \\
\hline EXP42 & McMaster University & Canada \\
\hline EXP43 & Diablo Valley College & USA \\
\hline EXP44 & University of California-Berkeley & USA \\
\hline EXP45 & University of Florida & USA \\
\hline EXP46 & University of Illinois & USA \\
\hline EXP47 & University of Illinois & USA \\
\hline EXP48 & McMaster University & Canada \\
\hline EXP49 & Georgia Institute of Technology & USA \\
\hline EXP50 & University of California-Berkeley & USA \\
\hline EXP51 & University of Michigan & USA \\
\hline EXP52 & Jonathan Mirrlees-Black Consultation & USA \\
\hline EXP53 & University of Michigan & UK \\
\hline
\end{tabular}

\subsection{Data Collection}

The core of this research was the development of the decision model and the core of the decision model was data collection (i.e., expert input). The data collection process focused on the model's element validation, relative values, and desired 
values. Data collection was performed after identifying and securing the required number of experts. The total number of experts who agreed to participate in this research was 53, with a range of 24-47 experts per panel.

The model's element validation was conducted by utilizing the Delphi technique while the model's elements' relative values were assigned using pairwise comparisons by experts and calculated using the Judgmental Quantification Instrument (JQI). JQI is a web-based tool developed by the engineering and technology management department's researchers utilizing the constant-sum method.

After obtaining the data, any disagreements among the experts were calculated at each level. If the level of disagreement was above the acceptable level, a semi-structured interview was conducted with the experts to obtain explanations for the disagreement. If a consensus could not be reached, further analysis was conducted to explain the effects of disagreement. The arithmetic mean of the values was used to determine the group values. All data collected and validated by experts were used in the model to calculate the numerical values (weights or priorities) at each hierarchical level, and then all weights were summed to obtain the score at the higher level.

This procedure was repeated upward for each hierarchy, until the top of the hierarchy model was reached. The overall calculated weights with respect to the 
goal of each decision alternative were then obtained. The alternative with the highest score was deemed the best alternative.

\subsection{Samples of Experts' Positive Responses}

- "I'll be happy to participate in your Ph.D. research."

- "My response is affirmative. In fact, siting issues are of concern to me after the Fukushima tragic accident. The siting issues did not matter for Chernobyl since it was a high-energy accident and the consequences were intercontinental. So I would be glad to look at alternative siting technologies".

- $\quad$ "I am very interested indeed. Count me in."

- $\quad$ "I would be happy to help out and offer my knowledge of nuclear power if you think it would be helpful. I look forward to learning more about your research."

- $\quad$ "I shall be happy to participate on this panel."

- $\quad$ "I would be happy to participate in this study. Please let me know how to proceed."

- $\quad$ "Thanks for the invitation, which would be an honor for me to participate." 


\section{CHAPTER 6: IDENTIFICATION OF MODEL ELEMENTS}

The initial hierarchical decision model for evaluating several alternatives NPP siting technologies consists of five hierarchical levels; each level has one element or a number of elements.

The top level has one element and is known as the decision model's objective. The model's objective is to select the best siting technology among the others for a specific project. The second level has the essential five worldviews or perspectives.

The model's five perspectives are social, technical, economic, environmental, and political (5-STEEP perspectives). The third level has groups of elements known as criteria that characterize the 5-STEEP perspectives. A single criterion can be a standalone element or be composed of two or more elements called sub-criteria. The fourth level is where the sub-criteria are placed. The last or fifth level is where alternatives or potential siting technologies under consideration should be located.

The literature on nuclear power plants is full of criteria for evaluting NPP sites and describing siting technologies. However; criteria for evaluating alternative siting technologies undert the 5-STEEP perspectives are not available as required for the decision model. Thus, to develop the required decision model, elements of the third, fourth, and fifth levels (i.e., criteria, sub-criteria, and alternative siting technologies) had to be identified and defined. 
The objective of identifying model elements is to reveal all potential siting technologies that might compete with the Land-Based technology and to consider the most influential criteria that may significantly differentiate the potential siting technologies.

\subsection{Alternative Siting Technologies}

As explained in Chapter 02, several potential nuclear power plant siting technologies have been described in the literature as alternatives to the conventional Land-Based technology. These alternatives generally compete with the Land-Based technology in some aspects. In addition to the Land-Based siting technology, the literature has identified 13 other siting technologies. These 14 technologies are categorized into three different groups based on the natural environment in which a plant could be placed: aboveground, underground, and offshore. Some of these technologies can be considered a combination of two technologies. For example, Under the Ocean Floor plant is a combination of offshore and underground technologies (Figure 6.1).

\subsubsection{Underground Siting Technologies}

The idea of underground siting of nuclear reactors for power generation is not new. In Europe, four experimental scale (20 to $275 \mathrm{MWe}$ ) nuclear power reactors were located underground between 1957 and 1977. In the U.S., as early as the mid-1950s, studies and independent preliminary assessments of the potential 
for NPP underground siting were undertaken by several agencies. Virtually all of these studies concluded that the underground siting was viable and within the capabilities of that time's technology. They also stated that underground sitings offer an increased level of containment and safety over that achievable by a surface plant.

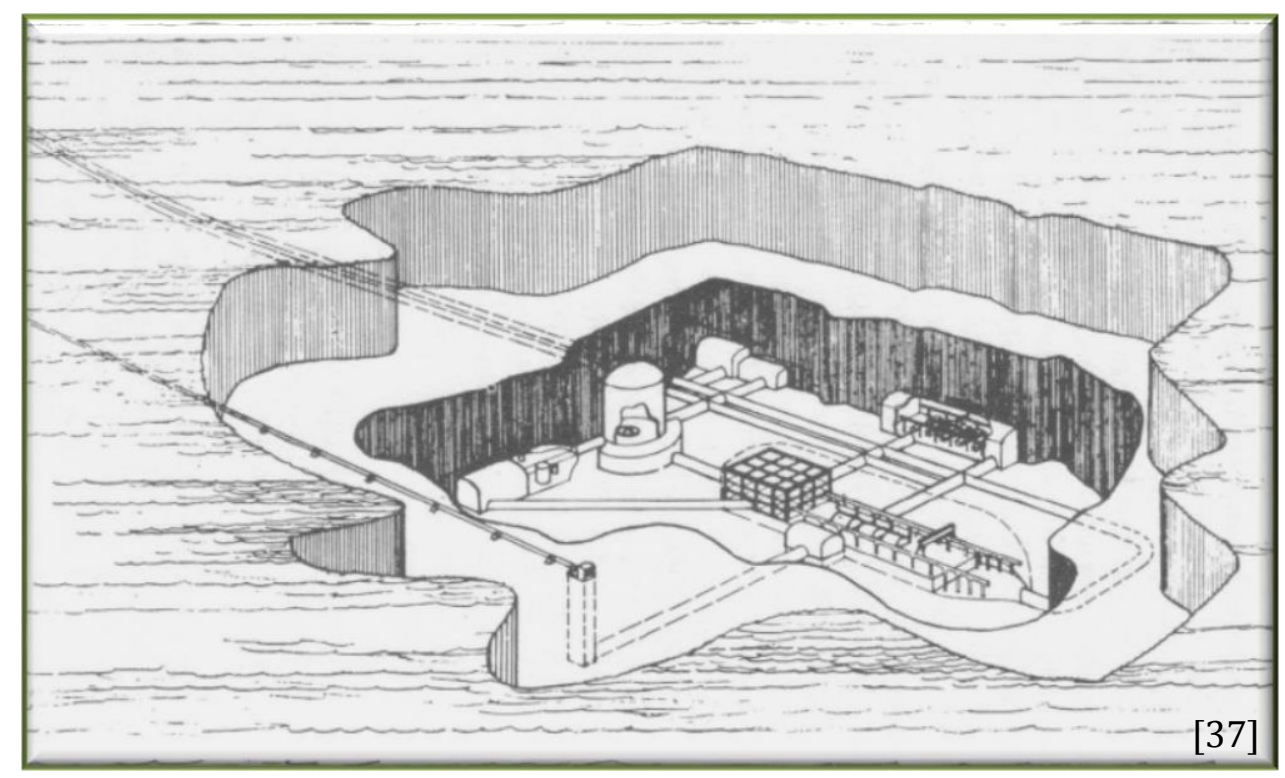

Figure 6.1 Offshore-Under the Ocean Floor Plant

\section{Major Advantages of Underground Siting Technology are:}

- It has greater containment capability relative to Land-Based plant, which provides considerably protection to the population and to the environment in case of extreme hypothetical accidents.

- $\quad$ Land acquisition costs will be lower than Land-Based siting due to smaller land commitment where the exclusion and sterilized zones could be reduced significantly. 
- It is much better protected against such natural surface phenomena as storms and tornadoes and higher resistance human threats of terrorist attack, aircraft impacts, proliferation, sabotage and vandalism, or conventional warfare effects.

- It provides less seismic motion that would lessen destruction effects and increase plant safety in case of earthquake events. In addition, using underground siting would decrease overall costs, particularly in high seismic areas, due to the less severe seismic design conditions associated with structures and equipment located underground in rock cavities.

- It also would decreases overall cost due to the possibility of close-in urban siting and hence, reduce length of transmission line.

- It provides a potential solution for spent fuel pool where it can be ideally situated at the same location, underground, close to the reactor core.

- It provides aesthetical benefits in terms of the absence of large industrial structures in rural siting, which usually increases public rejection of nuclear plant constructions.

\section{Potential Disadvantages of Underground Siting Technology are:}

- Higher costs due to longer schedule, excavation costs, and special equipments design.

- Problems related to the sealing of penetrations and hence reduced safety.

- $\quad$ Reduced accessibility would lead to reduced safety and difficulty of in-service inspections.

- Shortage of adequate sites due to constraints imposed by geotechnical requirements 
Undergrounding concepts range from a surface-located "mounded" type through cut-and-cover locations in rock or in overburden, to totally underground sites in hillsides or below grade locations. The underground sitings that have been identified in most studies are five primary and secondary technologies: (1) Surface Mounded, (2) Rock Cavity Hillside, (3) Rock Cavity Deep Below the Surface, (4) In Rock/Soil Semi Embedded and (5) In Rock/Soil Totally Embedded as illustrated in Figure 6.2. Short descriptions of the primary alternatives are given below.

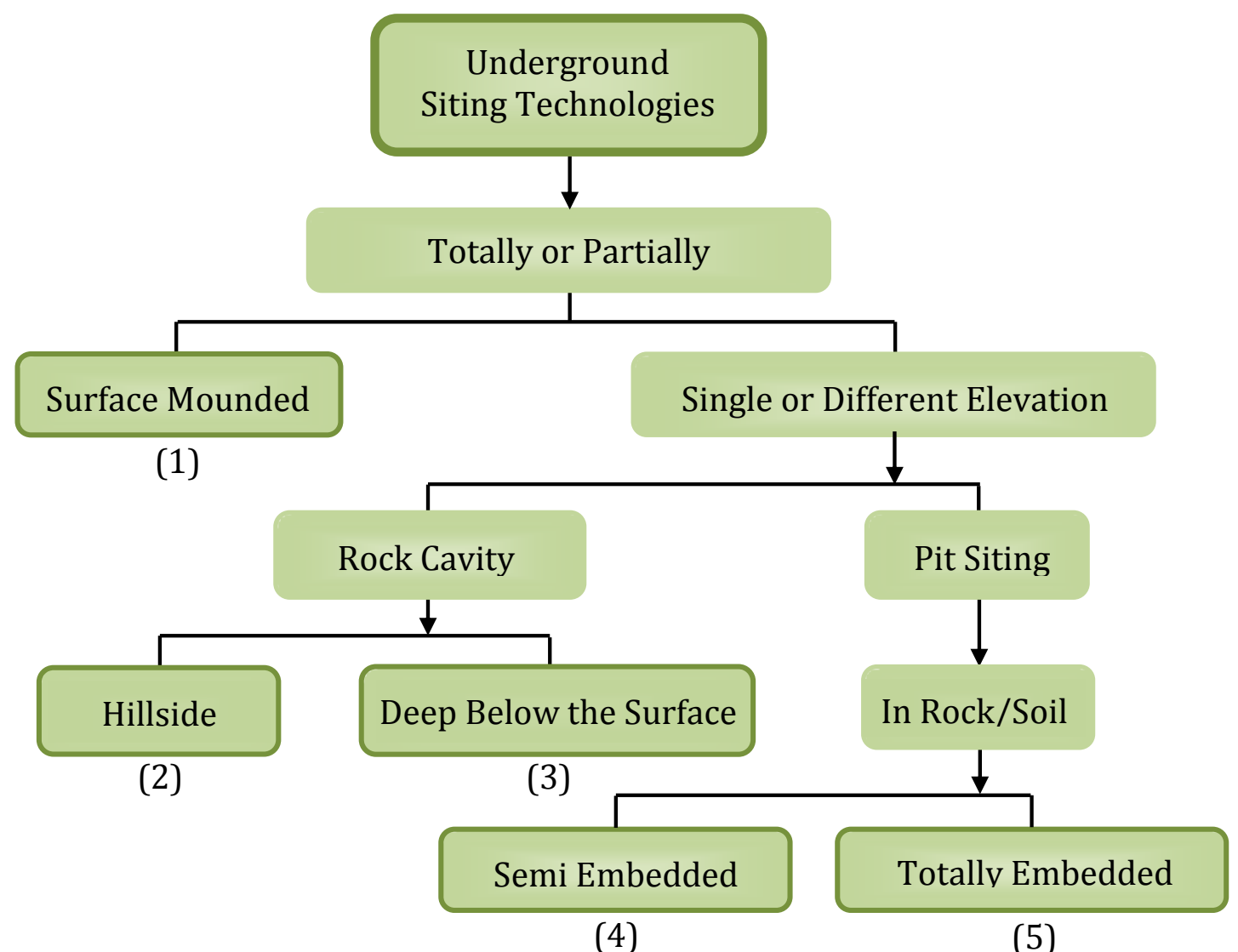

Figure 6.2 Primary and Secondary Underground Siting Technologies 
- $\quad$ Surface Mounded:

The plant is essentially constructed at the ground level and the outside surfaces of vital structures are backfilled with soil and/or special material

\section{- $\quad$ Pit Siting:}

The plant is constructed below the ground level in an open cut excavation and then covered with soil and/or special material. The cut-and-fill concept can be achieved either in soil or in rock. It is also known as cut-and-cover or cut-and-fill. The two sub-siting technologies of Pit siting technology are SemiEmbedded and Totally-Embedded.

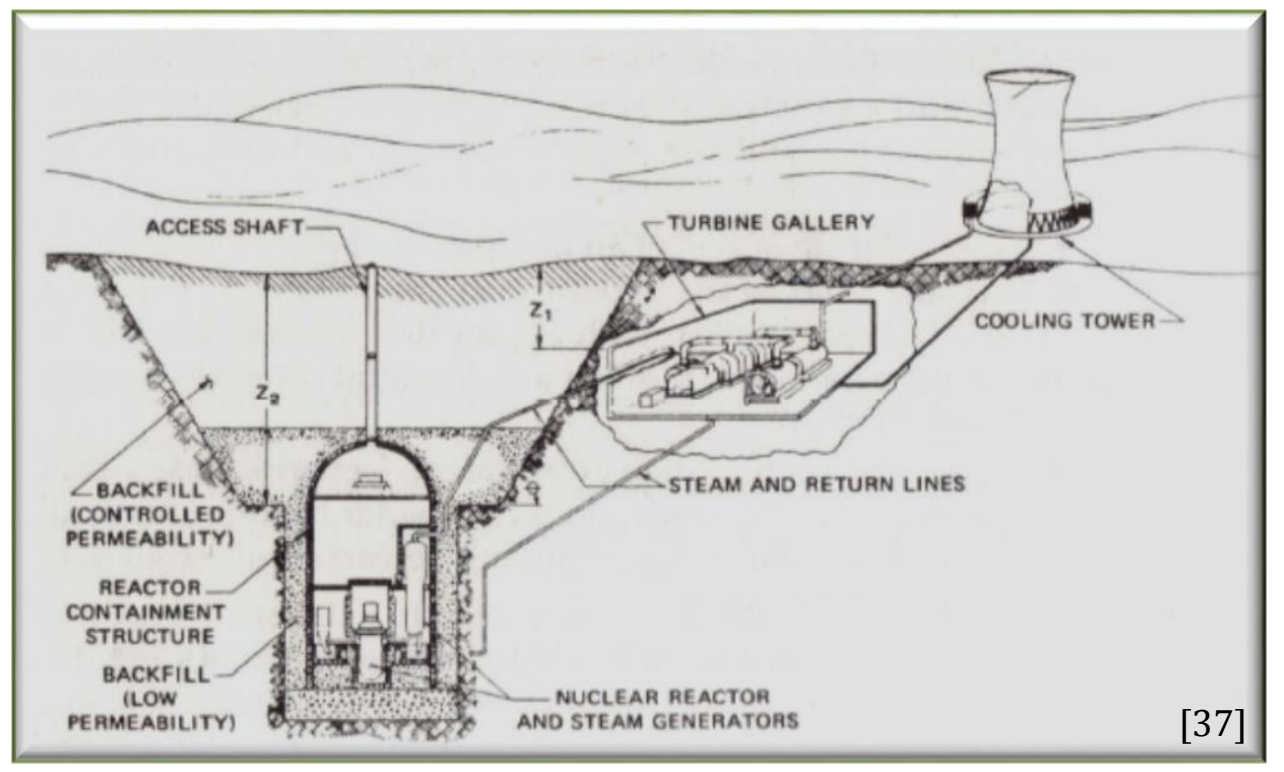

Figure 6.3 Layout of Underground NPP Pit Siting Technology 


\section{- $\quad$ Rock Cavity:}

The plant is constructed in cavern excavated at depth in a rock mass. In this concept, variation often referred to as "rock cavity alternative". The excavation can be achieved either horizontally into a mountain/hill or vertically deep below the earth's surface. The two sub-siting technologies of Rock Cavity siting technology are Hillside and Deep Below the Surface

\subsubsection{Offshore Siting Technologies}

Offshore power plants are also not a completely new idea to most people. Visionaries have often proposed the use of oceans for floating cities. On a more realistic scale, the placing of a nuclear power plant on a moored floating vessel has been proposed as a simple extension of the nuclear submarine, the first of which, the Nautilis, was launched in 1954. In 1959, detailed studies of the operational safety and public hazards of a ship-borne reactor were carried out in preparation for the nuclear ship Savannah. In 1965, the Oak Ridge National Laboratory completed a comparative study of three types of offshore dual plant possibilities for Southern California. The study considered floating barges, underwater caissons, and artificial island sites.

To date, not one single real installation of an offshore NPP reflects technical or economic feasibility. However, many compelling advantages are behind consideration of siting nuclear power plants offshore. 


\section{Potential Advantages of Offshore Siting Technology are:}

- An offshore plant provides new highly available potential sites where suitable land sites are less in availability.

- Potential offshore locations provide a solution to many of objections to LandBased siting in heavily urbanized areas (e.g., the US west coast)

- $\quad$ One of the essential requirements for operating nuclear power plant is plenty of water supply, offshore plant will have unlimited supply of cooling water from the ocean/sea.

- There are strong objections to possible concentrated thermal effects of nuclear plant operation on the environment from warm water discharges but a discharge design and action of offshore plant in the sea/ocean will rapidly dissolve the heat discharged from the plant so that any environmental effect will be minimal.

- $\quad$ Site preparation can proceed while the manufacturing of the plant is carried out at another location, resulting in a considerable saving of time.

- There will be a potential financial saving since the manufacturing lead-time for these plants will be less than that for conventional land construction of a nuclear plant.

- The utility may realize potential financial savings on its transmission costs because the plants can be located closer to areas where the demand for electric power is greatest.

- Because of standardized design, the effort required for review of the design by regulatory agencies could be reduced on a per plant basis when compared to current Land-Based plants 


\section{Potential Disadvantages of Offshore Siting Technology are:}

- Limited control over exclusion zone. The exclusion zone is that area immediately surrounding the site water and extends over a large portion of, under which an effective control must be exercised to ensure the safety of those who reside in or traverse this zone

- Distribution of negative impacts. Offshore plant differs from the Land-Based plant is terms of the impacted area. For an offshore plant, there are four separate impact areas that could be considered as an extension of any negative impacts during the construction and operation phases of offshore plant. These four impact areas are plant site, construction yard, switchyard, and personnel dock.

- There is no control over the esthetics of an offshore plant, mainly for marine activities, because of its ocean open location. Land-Based plant can be sited in such a manner to reduce visibility or it can be screened, while an offshore plant can neither be hidden nor screened.

- Environmentally sensitive land/water interface. The transmission line from the plant to the switchyard must cross the shoreline. This is an environmentally sensitive area, because of shoreline disruption during construction and operation.

The offshore sitings are of eight primary and secondary technologies: (1) Floating Plant, (2) Natural Island, (3) Artificial Island, (4) Ocean Floor, (5) Under the Ocean Floor, (6) Pre-Stressed Concrete Barge, (7) Steel-Hull Vessel, and (8) Tuned Sphere Plant as illustrated in Figure 6.4. 


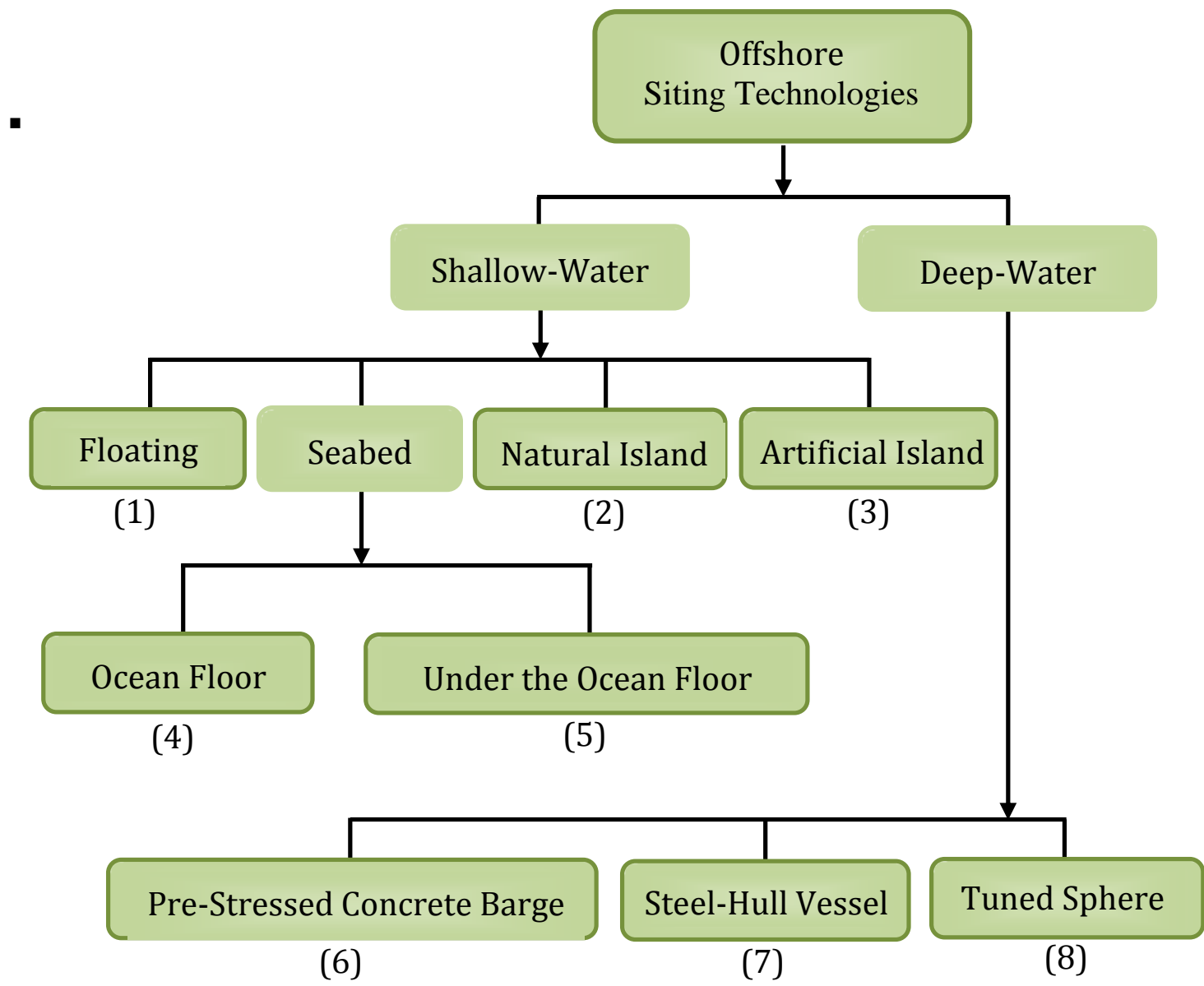

Figure 6.4 Primary and Secondary Offshore Siting Technologies

The descriptions of the offshore primary siting technologies are given below:

- Shallow-Water:

The plant is mounted on a floating platform within a breakwater for water depth of 40-60 feet. This siting is represented by four different technologies:

Floating plants (Figure 6.5), Seabed plants (Ocean Floor and Under Ocean Floor, Figures 6.6 and 6.1 respectively), Natural Islands, and Artificial Islands. 


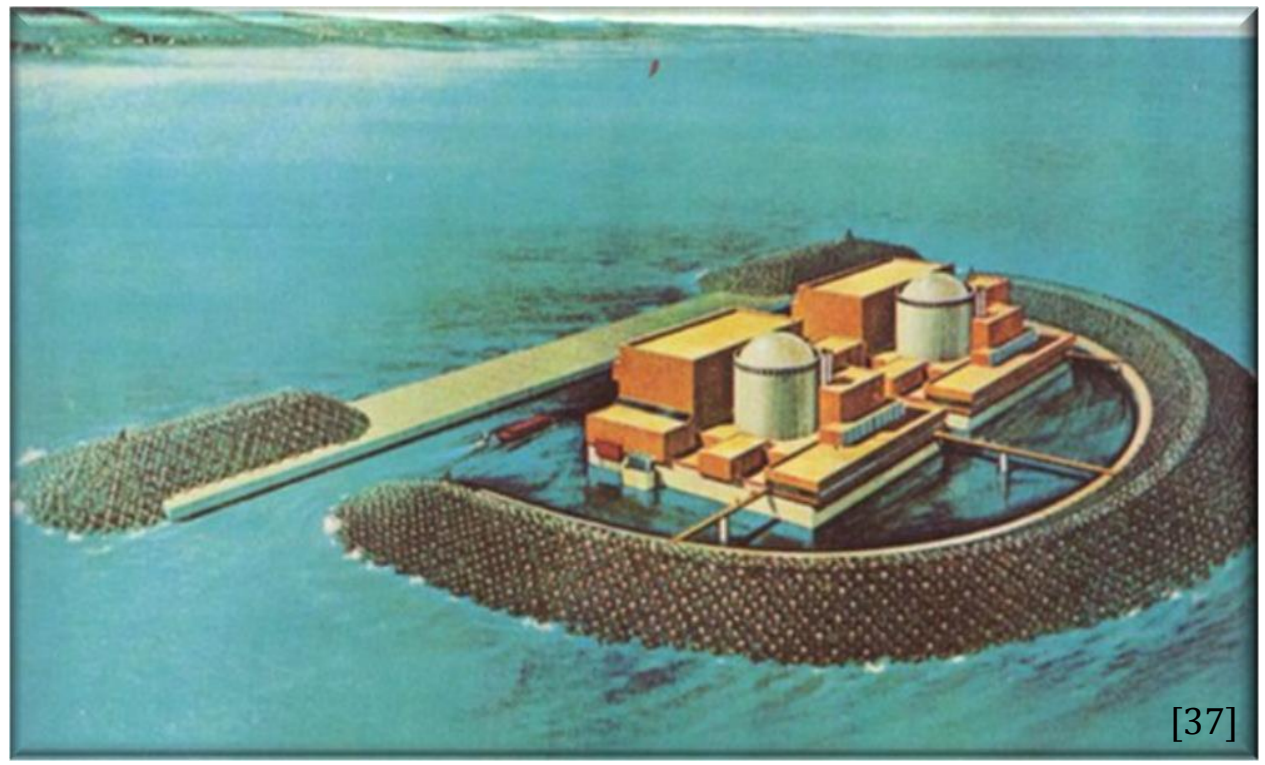

Figure 6.5 Offshore Floating Plant with Breakwater

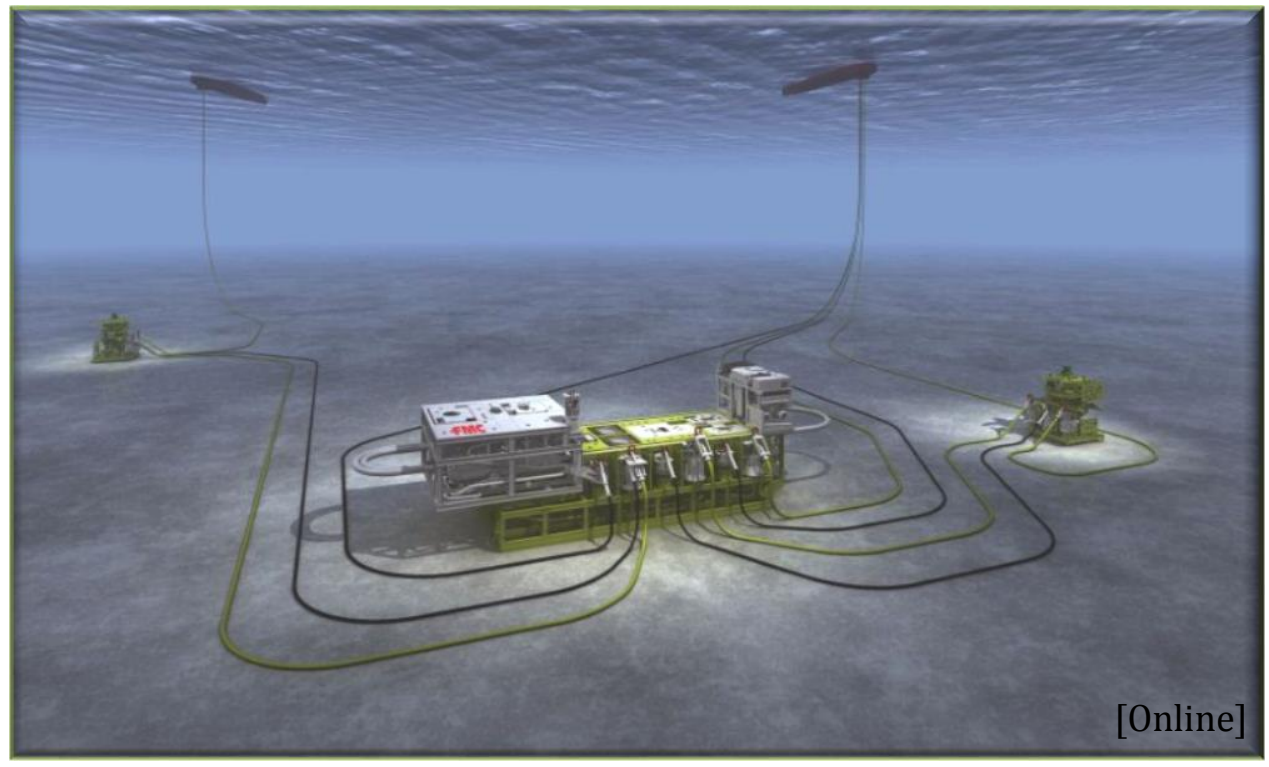

Figure 6.6 Offshore Ocean Floor Plant 


\section{- Deep-Water:}

The plant is mounted on a floating platform located in deep waters of about 150-200 ft with a floating ring type breakwater of about half a mile radius around the platform and strong enough to stop ocean vessels. This siting is represented by three different technologies: Pre-stressed concrete barge (Figure 6.7), Steel-hull vessels (Figure 6.8), and Tuned sphere (Figure 6.9).

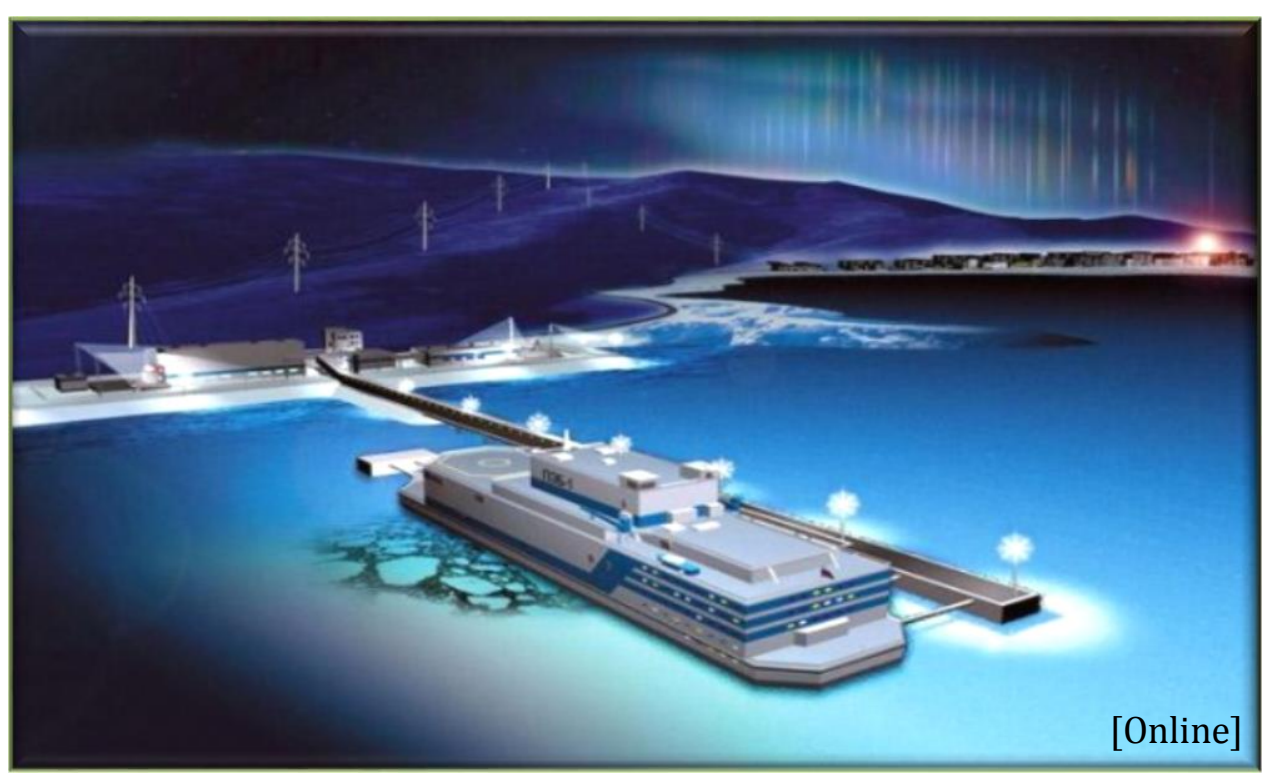

Figure 6.7 Pre-Stressed Concrete Barge Plant 


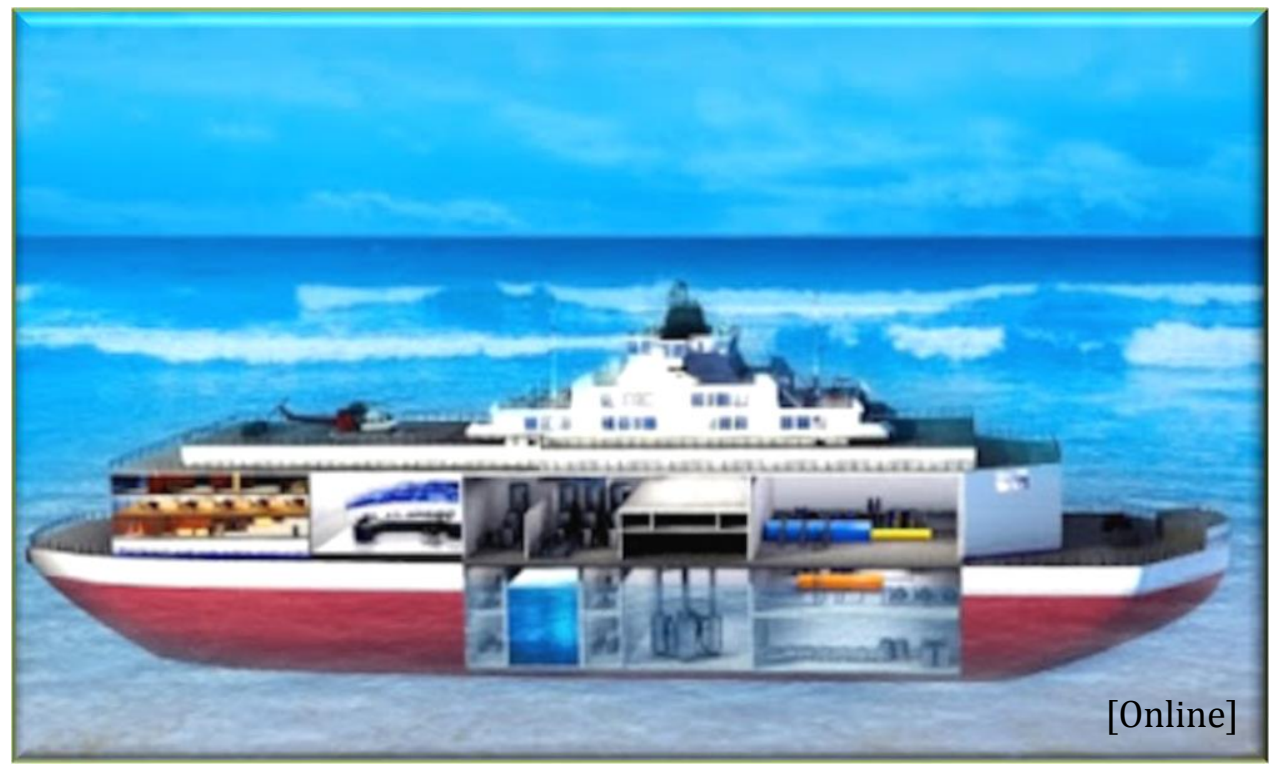

Figure 6.8 Steel-Hull Vessel Plant

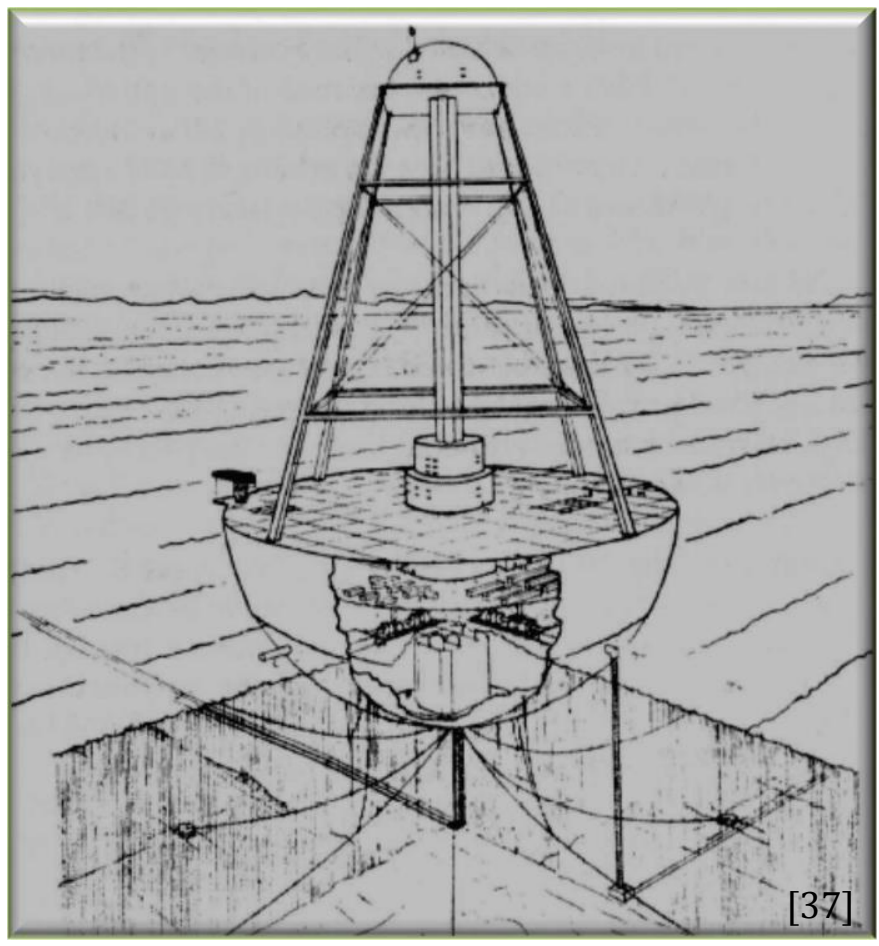

Figure 6.9 Tuned Sphere Plant 


\subsection{Criteria and Sub-Criteria Identification and Definitions}

The literature on nuclear power plant alternative siting technologies has focused mostly on the technical, economic, and environmental characteristics of the identified technologies to promote their potential, while very few of those published papers have focused on the social or political aspects. The focus has also been on criteria for site selection and site evaluation but not on criteria required for evaluating siting technologies.

A major part of the decision model developed in this research involved the identification of criteria and sub-criteria required to differentiate between the potential siting technologies. Thus, it was necessary not only to identify as many of these criteria as possible but also to choose the ones that best fit the model's objective. To select the appropriate criteria for the proposed model, it is helpful to understand that each criterion has a certain role within the model and should quantify something important. According to Baker, et al. [155] criteria should be:

- $\quad$ Able to discriminate among the alternatives and support the comparison of the relative performance of the alternatives,

- Complete to include and describe all goals,

- $\quad$ Operational and meaningful,

- Non-redundant to prevent conflicts,

- $\quad$ Few in number to keep the problem dimensions manageable 
Based on the above characteristics and the lists of advantages and disadvantages of underground and offshore siting technologies, the criteria and subcriteria identification process was done in two steps:

- First, all common and potential criteria and sub-criteria for nuclear power plant site selection and site evaluation topics were gathered from the literature and listed for review and classification.

- Second, the author conducted a comprehensive study to identify and choose the criteria and their sub-criteria that fulfill the above characteristics, and then each criterion and sub-criterion was given a clear and concise definition to state its role in the decision model.

The selected criteria and sub-criteria that match the above characteristics are grouped under the 5-STEEP perspectives; they are listed and their definitions are given below.

\subsubsection{Social Criteria}

Setting up a nuclear power plant in any society or region does not come without concerns and criticism from a large number of people, which normally generates major impacts. The impacts on the social structure of a society are substantial. They involve public concerns about health and safety issues, changes in social life and activity, increased migration from or to the society, and general services in the area. The list of social criteria that can be identified in the topic of 
siting nuclear power plants is long; however, the most functional criteria that provide differentiation among alternative siting technologies for the decision model are explained.

\section{S1. Public Acceptance and Attitude}

Nuclear power generation is a very safe, efficient, and green industry. However, public confidence in nuclear power is still limited. The history of nuclear power has shown that many nuclear power plant projects have been rejected or postponed because of the lack of public acceptance or the existence of local resistance. The public is a key player in implementing new technology and only as much as the public is aware of the new technology can the new technology be applied. In its 2010 Public Attitudes to Nuclear Energy report, the Nuclear Energy Agency reviewed a variety of public opinion data in an attempt to understand public attitudes toward nuclear power. The report noted a correlation between the level of experience and knowledge about nuclear energy and public support [156]. Therefore, to select a siting technology for a new nuclear power plant project, considering the public position and the level of public acceptance is highly recommended.

\section{S2. People's Health and Safety}

A nuclear power plant of any type involves some risk to surroundings and the public from either a plant's malfunction/accident or its by-products (e.g., radiation). Providing a safe environment to the people living within the permissible 
boundary or exiting in the larger boundary of the nuclear power plant is a "must" criterion to consider in site selection and approval. People's safety refers to the level of protection that a siting technology provides during the construction and operation phases. People associated with NPPs are of two types: (S2.1) the public (inhabitants living within or outside permissible boundaries) and (S2.2) Workers (people involved in constructing and operating the plant). A technology with a high level of protection for the public and the workers is preferable.

\section{S3. Social Life and Activities}

The impact of the NPP siting technology during site preparation, plant construction, and operation mostly affect the way the locals are used to living and enjoying their daily or occasional activities. Boating, fishing, and swimming are occupations or hobbies people practice on beaches and coastal areas. Thus, offshore power plants and their inland facilities would negatively affect these activities, the locals, and possibly visitors. Underground plants would have similar negative impacts during the preparation and construction phases but less impact during the operation phase. This criterion has a significant impact that should be considered while evaluating NPP siting technologies.

\section{S4. Visual Impact}

The visual effect of a plant refers to the physical appearance of the facility relative to the landscape. Changes in the landscape in terms of huge buildings, restricted areas, or the absence of natural scenes usually limit the acceptability of a 
technology. Buildings and cooling towers of Land-Based plants are obvious examples of unattractive scenarios for undesirable power (i.e., nuclear). Underground and, in some cases, offshore plants would help in mitigating the negative visual impact. The visual impact can be reduced by utilizing the existing topography or by integrating plant structures with the environment (e.g., Steel-Hull Vessels and Hillside).

\section{S5. Experts Availability}

Building and operating a nuclear power plant requires skilled workers and competent personnel. Several reports and reviews have stated that one of the biggest challenges in building new nuclear power plants is finding qualified people to support construction and operation. Designing, implementing, constructing, and operating a new siting technology is more critical and would rely heavily on the availability of skilled people. The availability of experts in a technology will be a key factor in preferring one technology over others.

\subsubsection{Technical Criteria}

Technical characteristics of any technology are the key factors that make a technology more or less favorable than other technologies, especially if the other aspects (e.g., economic, social) are not considered or are almost the same for all technologies. The alternative NPP siting technologies have a long list of technical 
characteristics. Most of these characteristics are common while others make a real difference in the technologies. These most desirable characteristics are listed below.

\section{T1. Maturity}

Maturity defines the degree of readiness of a technology for implementation. It also refers to the level of improvements that a technology has gone through from concept to final product. The length of implementation indicates how mature the technology is. For example, Land-Based siting is a mature technology since the majority of existing nuclear power plants is based on Land-Based technology that has been implemented for more than 50 years. Underground and offshore sitings are at different maturity levels because some of them have been used for experimental plants and others have not yet been used. The maturity level of a nuclear power plant siting technology is addressed by three key attributes: (T1.1) Applicability (the number of times a siting technology has been implemented commercially or experimentally), (T1.2) reliability (the level of trustworthiness and dependability a siting technology has or at which it can be rated), and (T1.3) competency (explains how a siting technology is efficient or fit for use in a certain project).

\section{T2. Flexibility}

Flexibility refers to a technology's ability to respond to potential internal or external changes or needs that affect its current function in a timely and cost- 
effective manner. Flexibility of a siting technology, accordingly, is defined in three dimensions: (T2.1) Scalability (a plant's ability to be expanded in size, number of units, or space to accommodate more reactors or auxiliary systems for future plans), (T2.2) mobility (allows a plant to be relocated at different sites to supply power for remote areas or in case of emergencies or to be sited at a totally different location), and (T2.3) modularity (the possibility of a plant being built on smaller standard units (modules) to facilitate or standardize the construction and installation processes).

\section{T3. Siting Technology Safety and Security}

Safety and security of a siting technology is a generic term that can be expressed in three different dimensions: technical (the plant), environmental (the surroundings), and social (the people). Technically, a siting technology should have the potential to limit any external attacks, avoid any internal accidents, resist severe seismic activities, prevent any leakage of radioactive materials, and provide high levels of protection to people during construction, operation, and evacuation. In addition, it should provide a secure system for the attached systems (e.g., cabling systems, storage system, water-circulation system). Safety and security of a siting technology is explained by three aspects: (T3.1) Resistance (the ability to resist any external phenomenon (e.g., storm, flood, earthquake, attack), (T3.2) containment (the level of containment or decrease in impacts of an internal malfunction or external radioactive leakage), and (T3.3) evacuation (the capability of providing a 
safe, secure, and fast process to transfer workers or people to a safe and secure

place). The identified siting technologies have different levels of safety and security and should be evaluated accordingly.

\section{T4. Power Generation Capacity}

The identified NPP siting technologies have different structural concepts and designs that affect the plant's capability to accommodate small/large reactors or one/several reactors. NPP power generation capacities range from several kilowatts to a few thousand megawatts. More or less capacity is preferred depending on the actual and future needs. The required power capacity directly affects the selection of a siting technology. For example, a few hundred kilowatts of electricity can be generated at any siting, while the need for few thousand megawatts of electricity would eliminate many of the identified siting technologies.

\section{T5. Plant Life Span}

Nuclear power plants are built to serve for a certain minimum life span to be economical. In a few cases, plants may be decommissioned before their actual retirement date, but for most of them, the operating license is renewed for several additional years. Some of the identified siting technologies have the potential to exceed the plant's lifetime, while others might have a limited lifetime based on the design, location, or application. A plant's life span influences the selection of a 
proper siting technology. For example, a plant can serve for as little as 10-20 years or for more than 50 years.

\section{T6. Used Fuel Storage Capacity}

One NPP issue is the generation of radioactive materials (the outcome of nuclear fuel consumption). Currently, used fuel is stored at reactor sites for 3 to 5 years of cooling in water pools. Then, and if possible, used fuel is transferred to a permanent secure location to rest forever. The amount of used fuel generated by nuclear power plants is very small compared to the waste generated by electricity generation systems as a whole. For example, a 1000 MWe nuclear power plant produces annually some 30 tones of discharged high-level radioactive used-fuel along with 800 tones of low and intermediate level radioactive materials. The significance of the small volumes of radioactive waste is that it is possible to isolate them safely and economically from the human environment. The site's capacity to store radioactive materials for a very long time is a positive characteristic. Thus, a siting technology capable of safely storing larger amounts of used fuel is a major consideration in the selection process.

\section{T7. Decommissioning and Site Cleanup}

Decommissioning is a technical process that includes cleanup of radioactive materials and progressive demolition of the plant. Total decommission of a LandBased plant is considered a burden and mostly leaves the site with lots of restrictions for a very long time. Other siting technologies are considered more 
acceptable in terms of plant decommissioning and plant site immediate utilization. For example, decommissioning underground or offshore siting technologies is safer and would not hinder other activities in the site for a long time. Decommissioning is measured in terms of the required time (a unit of years, months, weeks) to get rid of any waste residue that limits site utilization.

\subsubsection{Economic Criteria}

Evaluating technologies could not be done without considering the economic aspects. Technical aspects are the main criteria that distinguish among different technologies, while economic aspects are the main criteria that influence the decision. Many economic criteria are available in the literature, but the most feasible economic criteria for evaluating alternative siting technologies are listed below.

\section{E1. Site Development Cost}

Site development is an initial stage for setting up a nuclear power plant. To select a plant location that is Land-Based, underground, or offshore, three consecutive actions are needed at an early stage. First is (E1.1) site exploration (to investigate site characterization and the suitability of subsurface materials; this is a site data collection stage). Next is (E1.2) site acquisition/hosting (to obtain and control the site for a long period of time), and then comes (E1.3) site preparation (to make the site suitable for plant construction and operation). Site development cost is the accumulated costs of these three actions, which are different for different 
siting technologies. For example, the site exploration and preparation costs of LandBased siting may be less expensive than the underground option and the site acquisition cost for offshore siting may be cheaper than for Land-Based siting.

\section{E2. Plant Development Cost}

Developing a nuclear power plant starts with (E2.1) the plant's engineering, construction, and installation (a comprehensive technical picture of the plant's main components and the process of building and setting up the plant), then (E2.2) involves operation and maintenance (plant's frequent and continuous activities), and (E2.3) decommissioning (the process to withdraw the plant from service and

utilize the site). At each stage, a significant amount of costs (i.e., work, time, and money) needs to be considered. Considerable differences exist in plant development costs among the different technologies of the three siting environments.

\section{E3. Plant Supplementary Systems Cost}

A nuclear power plant requires several additional systems to support its operation and continuation. These systems differ in their functionalities but work together to enhance the plant's overall operations. Supplementary systems include (E3.1) a water delivery system (provides the required usable water resources for steam generation or/and plant cooling), (E3.2) grid connection system (electrical transmission and distribution channels to connect the plant to the grid), (E3.3) ventilation system (provides fresh air circulation for a highly sealed environment 
and high-quality filtration system), (E3.4) protection system (provides the required level of protection for the plant and from the plant), and (E3.5) transportation system (provides appropriate means to transfer people and materials from and to the plant). The costs of these additional systems should be considered since they differ significantly from one siting technology to another.

\section{E4. Technology Outsourcing Cost}

Most of the identified siting technologies are new in terms of concept and implementation. A major factor in selecting a technology is the level of knowledge about or experience available with the technology. Exchanging knowledge (i.e., know-how) or acquiring experience (i.e., hiring experts) from others (locally or internationally) involves some cost, which can be defined as a technology outsourcing cost

\section{E5. Return on Investment}

Return on investment (ROI) is the ratio of net output to total investment. Each of the costs mentioned above affects the selection of a siting technology differently. The total of all costs indicates the expense involved with a siting technology. However, the total cost should not be the sole factor considered because some of these sitings may cost more at the beginning but justify the high cost by the output in the long run of the plant's operation. Return on investment is a major criterion that can differentiate the siting technologies. 


\subsubsection{Environmental Criteria}

The processes involved in constructing and operating a power plant normally disturb the surroundings and environment. New roads, increasing traffic flow in the existing roads, excavations, cutting trees and other plants, frightened animals, and pollution are some of negative environmental impacts expected from any power plant project. A nuclear power plant disturbs the environment before, during, and after the plant life span. The following criteria are those with significant impacts.

\section{N1. Site Preparation-Related Impacts (Disruption)}

Site development, which includes site exploration, acquisition, and preparation, is an essential phase of building a nuclear power plant. Some changes in the site take place in accordance with site preparation work, which in turn alters the site's ecological system. The situation in Land-Based siting is more noticeable where some of the natural scenery, green areas, or wildlife may be removed to prepare the site and obtain the required area. Environmental impacts of offshore and underground sitings also exist but they have not been clearly observed. The environmental impact of offshore sitings, mainly on the ocean's aquatic life, is disruptive. Underground sitings typically affect the nature of soil or the existence of groundwater. Thus, the level of negative impacts of site development on the ecosystem should be considered, which in turn differentiates among potential sitings. 


\section{N2. Construction-Related Impacts}

Constructing a nuclear power plant is a long process that requires a large number of workers and building materials to move and be available at the site. All activities during this phase directly affect the nature of the site in terms of daily site reformation and waste generation. If site preparation disrupts the site's ecosystem, the construction phase makes permanent changes in the ecosystem. Land-Based siting consumes a large area of pure land and prevents any ecological activities in its restricted area. Offshore sitings affect vital aquatic species/inhabitants' lifestyle in terms of migration and reproduction. Underground sitings play a major role in affecting negatively groundwater's pathways, quality, and quantity as well as soil's quality.

\section{N3. Operation-Related Impacts}

The majority of nuclear power plant technologies uses water for steam generation, cooling, or as a moderator. Massive quantities of usable water are required and need to be extracted from lakes, rivers, seas, oceans, or underground. This practice can negatively affect water sources by discharging highly heated water (thermal contamination) from the plant or small amounts of radionuclide (radioactive contamination) back into the water source. Both contaminations, which accumulate during the life span of a nuclear plant of $50 \pm$ years, have a certain level of negative impact on drinking water and aquatic life at the site. The impact of siting technologies on the water varies from one type to another based on the volume of 
available water that would dilute the contamination. In a relatively small-volume aquatic environment such as lakes, rivers, ponds, or underground water resources, contamination increases the environmental risk. However, in an open aquatic environment such as seas or oceans, contamination can be mitigated by the large amount of available water. Offshore sitings have a higher dilution factor and in turn less negative impact, while Land-Based and underground sitings have a lower dilution factor and higher negative impact. The siting technology that has a smallest factor of water pollution is preferable.

\section{N4. Land Availability and Utilization}

An environmental feature that supports siting technology selection is the wise use of available land/space. In most countries, land is a scarce commodity and there are usually many options for its utilization. Freeing up land for residential, commercial, or industrial projects can be a great motivation to move nuclear power plants to underground or offshore locations. Land-Based siting uses very large land areas for the exclusion and sterilized zones. Offshore sitings do not use any vital land space and have more space for potential expansion. Underground sitings use large human-made or natural caverns/cavities but at the same time provide the potential of using the plant's surface area for socioeconomic activities. The siting technology that allows for better utilization of the available space is the preferred technology. 


\section{N5. Site Recovery}

Almost all nuclear power plants are decommissioned at the end of their functional lives. The ability to return the site to its natural state at retirement is a key factor for choosing an environment-friendly siting technology. The risk of not decommissioning the site adequately or abandoning it for any reason is an environmental issue. Any residue of solid or radioactive waste will negatively affect the site's usability for a long time. Siting technologies differ in terms of site recovery and reuse. For example, Land-Based site recovery requires major effort, time, and cost to remove all the plant's belongings and leave the site free of any waste. Offshore and underground sitings are somewhat different. Offshore and underground sitings might not require cleaning up the sites completely and may allow for burial of the wastes and critical residues with less effort, time, and money. In addition, offshore and underground sites mitigate decommissioning and site recovery environmental issues.

\subsubsection{Political Criteria}

The development of nuclear power began in 1945 as a government program. The criticality of nuclear power in terms of waste and nuclear weapons proliferation has required strong commitments from governments. Thus, governments are key players in the nuclear industry. The U.S. government is involved in commercial nuclear power more than in any other industry. Since 1945, the design and location of nuclear power plants has been subject to federal control and approval. General 
assessment of site compatibility for a nuclear power plant involves analysis of site relationships with the whole geographic area. This analysis includes considerations, which flow not only from suitability criteria, but also from legal and political constraints, which vary widely among potential sites. Therefore, considering political criteria in selecting a proper siting technology is crucial. The following criteria are selected to develop the proposed model for evaluating siting technologies

\section{P1. Government Perception}

Government is a key player in adopting and diffusing a technology. In most cases, government intervention can have a significant impact on choosing or proving a new technology. Land-Based technology is well known by most local and federal governments. Governments also need to be aware of the advantages and disadvantages of new siting technologies. The level of government perceptions regarding these new siting technologies can support or hinder selecting the proper one.

\section{P2. Government Support}

Governments typically have the best mechanisms to promote a new technology. These mechanisms include raising public awareness, implementing stringent or flexible regulations and standards, licensing, tax exemption, subsidies, and loans. Each of these governmental tools can be used as a standalone criterion in 
the evaluation process from the viewpoint of the evaluator. However, these tools are defined in this research as one criterion because all identified siting technologies have the same type of energy technology (i.e., nuclear).

\section{P.3 Political Side of Technology Transfer}

Technology know-how sharing or exchanging has several dimensions (i.e., social, technical, economic, and political). The potential of having an option to exchange information and experience of a new siting technology with any local or international government(s) is an important factor that affects the decision to select one siting technology over others. The political side of technology transfer is critical when technical or economic obstacles can be reduced or amplified if such collaboration exists or not.

\section{P.4 National/International Laws and Agreements}

A potential accident in a nuclear power plant can lead to consequences (radioactive releases) that extend many miles. A site near an international (either sea or land) border raises the problem of appropriate treaties with the neighboring state/country. Since inter-country relations can change, even with an agreement, it seems prudent to avoid siting a nuclear power plant close to an international border. This type of agreement should be considered carefully while choosing the type of siting technology. This criterion can be measured in terms of how flexible or strict the agreement is between states or governments since siting technology 
location can be in a common place between two authorities and thus affect the decision.

\section{P5. Rules and Regulations Availability}

Land-Based siting has a long list of rules and regulations for managing and approving site selection and licensing. However, selecting a siting technology differs from the site selection process. It is important to refer to any existing rules and regulations to evaluate or consider a siting technology. Preparing rules and issuing legislation are time-consuming. Thus, the availability of rules and regulations for use in selecting a siting technology is important. 


\section{CHAPTER 7: VALIDATION AND EVALUATION OF MODEL ELEMENTS AND BASE MODEL DEVELOPMENT}

To validate is to prove that something is based on truth or fact, or is acceptable [157]. Validation of model elements is the process of confirming the suitability of an element for use in the decision model. Evaluating is an appraisal of something to determine its worth or fitness [158]. Evaluation of model elements is the process of allocating a numerical value to each element within the model to define or determine its weight or relative importance. Validation and evaluation processes, in this research, have been done in succession via different means utilizing experts' knowledge and judgments. The validation was completed by developing two web-based questionnaires using Qualtrics Survey Software and by customizing judgment quantification instruments.

\subsection{Elements Validation Process}

Elements needing validation included (a) the identified 13 siting technologies and (b) the identified list of 28 criteria and 23 sub-criteria. A valid element is an element that achieved a high level of consensus from the group of experts who defined its suitability for use in developing the decision model. The process of validating the identified elements (the siting technologies and the criteria/subcriteria) involved developing two separate questionnaires with Yes/No-style questions. In addition, a three-page research summary was prepared and given to the experts. The summary explained the research topic, objective, scope, and 
methodology and listed the potential siting technologies to help the experts understand the research idea and answer the questionnaires' questions.

\subsubsection{Validating Alternative Siting Technologies}

The literature on NPP siting technologies has identified 13 potential alternatives in addition to Land-Based siting. These siting technologies can be considered for any future nuclear power plant projects. However, some of these technologies are well described and discussed in the literature, while others are merely mentioned as concepts or a sub-set of major sitings, as illustrated in Figures 6.2 and 6.4 of Chapter 6.

The literature has also categorized these alternatives into five categories, two offshore and three underground options, respectively: floating shallow siting, floating deep siting, surface mounded siting, pit siting, and rock cavity siting. This categorization means that some similarities and/or some differences exist among these major groups. Thus, to develop a holistic and efficient decision model that considers the current most important siting technologies and accommodates any future technologies, the focus of this research was to consider siting technologies that have the highest applicability and implementation rates. The validation process

involved the experts answering a questionnaire that verified the applicability of each technology. The siting technologies with the most potential are those that have 
a high applicability rate. For the purpose of this research, the rate was set to $75 \%$ or more.

The questionnaire for validating the identified siting technologies is available in Appendix D. Table 7.1 shows the results of the questionnaire and the applicability rate of each technology. Based on the 53 experts' consensus, the selected sitings are Artificial Island (86\%), Semi-Embedded Plant (77\%), Floating Plant (77\%), and Natural Island (75\%).

Table 7.1 Siting Technologies Applicability Rate

\begin{tabular}{|l|l|c|}
\hline No & \multicolumn{1}{|c|}{ Siting Technology Option } & $\begin{array}{c}\text { Applicability } \\
(\%)\end{array}$ \\
\hline 01 & Floating Plant & $\mathbf{7 7 \%}$ \\
\hline 02 & Ocean Floor Plant & $29 \%$ \\
\hline 03 & Under the Ocean Floor & $17 \%$ \\
\hline 04 & Natural Island & $\mathbf{7 5 \%}$ \\
\hline 05 & Artificial Island & $\mathbf{8 6 \%}$ \\
\hline 06 & Pre-Stressed Concrete Barge & $63 \%$ \\
\hline 07 & Steel-Hall Vessel Plant & $63 \%$ \\
\hline 08 & Tuned Sphere Plant & $26 \%$ \\
\hline 09 & Surface Mounded Plant & $60 \%$ \\
\hline 10 & Hillside Plant & $34 \%$ \\
\hline 11 & Deep Below the Surface & $29 \%$ \\
\hline 12 & Semi-Embedded Plant & $\mathbf{7 7 \%}$ \\
\hline 13 & Totally Embedded Plant & $60 \%$ \\
\hline
\end{tabular}




\subsubsection{Validating the Criteria and Sub-Criteria}

The questionnaire to validate the criteria and sub-criteria is explained below (the complete questionnaire is available in Appendix E):

- $\quad$ The questionnaire started by listing the six expert panels (i.e., the strategic and the 5-STEEP perspectives) with a selection button next to each panel. This first step allowed the questionnaire taker (the expert) to select his/her area(s) of expertise or the panel(s) he/she was interested in joining. Selection of the strategic panel button allowed the experts to be involved in all 5-STEEP panels.

- $\quad$ According to the experts' selection, a list of all elements (criteria and subcriteria) of the selected panel(s) was displayed with a short definition of each criterion to explain its role within the model.

- $\quad$ Each criterion had an option button of either Yes or No. The expert had to answer a single and common question for all elements "Please click 'Yes' or 'No' for each criterion to indicate whether the criterion is appropriate and should be used in the model."

- Validating all listed questions by either Yes or No was mandatory for the expert; this input was collected with other experts' input and automatically averaged. 
- At the end of each section of the questionnaire, there was a text-entering space, which allowed the expert to add or share important comments, suggestions, or justifications. The text-entering space was a useful feature of the questionnaire because the author could gather useful information that helped in understanding the experts' input and improving the elements' definitions or names.

Table (7.2) shows a list of the identified 51 criteria \& sub-criteria under the five perspectives and their validity percentages as per the average inputs of all 53 experts who are involved in the validation task.

Table 7.2 Model's Criteria and Sub-Criteria Validity Percentage

\begin{tabular}{|c|c|c|c|c|c|}
\hline Perspective & Criteria & $\begin{array}{l}\text { Sub- } \\
\text { Criteria }\end{array}$ & Title & $\begin{array}{c}\text { Sub- } \\
\text { Criteri } \\
\text { a } \\
\text { Validity } \\
(\%)\end{array}$ & $\begin{array}{c}\text { Criteria } \\
\text { Validity } \\
(\%)\end{array}$ \\
\hline \multirow{7}{*}{ Social } & $\mathrm{S} 1$ & & Public Acceptance and Attitude & & 100 \\
\hline & $\mathrm{S} 2$ & & People Health and Safety & & 86 \\
\hline & & $\mathrm{S} 2.1$ & - Public & 83 & \\
\hline & & $\mathrm{S} 2.2$ & - Workers & 79 & \\
\hline & S3 & & Social Life and Activities & & 83 \\
\hline & S4 & & Visual Impact & & 76 \\
\hline & S5 & & Experts Availability & & 79 \\
\hline \multirow{4}{*}{ Technical } & $\mathrm{T} 1$ & & Maturity & & 98 \\
\hline & & $\mathrm{T} 1.1$ & - Applicability & 83 & \\
\hline & & $\mathrm{T} 1.2$ & - Reliability & 93 & \\
\hline & & $\mathrm{T} 1.3$ & - Competency & 76 & \\
\hline
\end{tabular}




\begin{tabular}{|c|c|c|c|c|c|}
\hline Perspective & Criteria & $\begin{array}{c}\text { Sub- } \\
\text { Criteria }\end{array}$ & Title & $\begin{array}{c}\text { Sub- } \\
\text { Criteri } \\
\text { a } \\
\text { Validity } \\
(\%)\end{array}$ & $\begin{array}{c}\text { Criteria } \\
\text { Validity } \\
(\%)\end{array}$ \\
\hline & $\mathrm{T} 2$ & & Flexibility & & 77 \\
\hline & & $\mathrm{T} 2.1$ & - Scalability & 89 & \\
\hline & & $\mathrm{T} 2.2$ & - Mobility & 75 & \\
\hline & & $\mathrm{T} 2.3$ & - Modularity & 83 & \\
\hline & T3 & & Safety and Security & & 91 \\
\hline & & $\mathrm{T} 3.1$ & - Resistance & 95 & \\
\hline & & T3.2 & - Containment & 95 & \\
\hline & & T3.3 & - Evacuation & 86 & \\
\hline & $\mathrm{T} 4$ & & Power Generation Capacity & & 91 \\
\hline & $\mathrm{T} 5$ & & Plant Life Span & & 79 \\
\hline & T6 & & Used Fuel Storage Capacity & & 83 \\
\hline & $\mathrm{T} 7$ & & Decommissioning and Site Cleanup & & 85 \\
\hline \multirow{17}{*}{ Economic } & E1 & & Site Development Cost & & 94 \\
\hline & & E1.1 & - Exploration Cost & 93 & \\
\hline & & E1.2 & - Acquisition Cost & 97 & \\
\hline & & E1.3 & - Preparation Cost & 100 & \\
\hline & E2 & & Plant Development Cost & & 91 \\
\hline & & E2.1 & - Design Cost & 65 & \\
\hline & & $\mathrm{E} 2.2$ & $\begin{array}{l}\text { - Engineering, Construction, and } \\
\text { Installation }\end{array}$ & 100 & \\
\hline & & $\mathrm{E} 2.3$ & - Operation and Maintenance Cost & 100 & \\
\hline & & E2.3 & - Decommission Cost & 97 & \\
\hline & E3 & & Plant Supplementary Systems Cost & & 84 \\
\hline & & E3.1 & - Water Delivery System Cost & 96 & \\
\hline & & E3.2 & - Grid Connection System Cost & 100 & \\
\hline & & E3.3 & - Ventilation System Cost & 93 & \\
\hline & & E3.4 & $\begin{array}{l}\text { - Protection \& Isolation Systems } \\
\text { Cost }\end{array}$ & 93 & \\
\hline & & E3.5 & - Transportation System Cost & 96 & \\
\hline & $\mathrm{E} 4$ & & Technology Outsourcing Cost & & 84 \\
\hline & E5 & & Return On Investment & & 100 \\
\hline
\end{tabular}




\begin{tabular}{|c|c|c|c|c|c|}
\hline Perspective & Criteria & $\begin{array}{l}\text { Sub- } \\
\text { Criteria }\end{array}$ & Title & $\begin{array}{c}\text { Sub- } \\
\text { Criteri } \\
\text { a } \\
\text { Validity } \\
(\%)\end{array}$ & $\begin{array}{c}\text { Criteria } \\
\text { Validity } \\
(\%)\end{array}$ \\
\hline & E6 & & Site Sharing Benefits & & 66 \\
\hline \multirow{5}{*}{ Environmental } & N1 & & Site Preparation-Related Impacts & & 100 \\
\hline & N2 & & Construction-Related Impacts & & 97 \\
\hline & N3 & & Operation-Related Impacts & & 91 \\
\hline & N4 & & Land Consumption and Utilization & & 88 \\
\hline & N5 & & Site Recovery & & 82 \\
\hline \multirow{5}{*}{ Political } & $\mathrm{P} 1$ & & Government Perception & & 92 \\
\hline & $\mathrm{P} 2$ & & Government Support & & 100 \\
\hline & P3 & & Political Side of Technology Transfer & & 100 \\
\hline & $\mathrm{P} 4$ & & $\begin{array}{l}\text { National/International Laws and } \\
\text { Agreements }\end{array}$ & & 100 \\
\hline & P5 & & Rules and Regulations Availability & & 96 \\
\hline
\end{tabular}

As shown in Table 7.2 , the validity values range from $65 \%$ to $100 \%$. These values indicate that the identified criteria and sub-criteria were accepted by the majority of experts and valid for use in developing the decision model. As per some experts' comments, design cost E2.1 should be part of the sub-criterion E2.2 (engineering, construction, and installation cost).

By setting the validity rate to $75 \%$, the same as for the siting technologies' applicability rate, one criterion (i.e., site sharing benefits, 66\%) and one subcriterion (design cost, 65\%) were excluded. Therefore, the total valid criteria and sub-criteria totaled 27 and 22, respectively. 


\subsection{Elements Evaluation Process}

Three categories of elements had to be evaluated: (1) the 5-STEEP perspectives, (2) The valid list of criteria and sub-criteria, and (3) The five siting technologies (the selected four sitings and Land-Based siting)

The processes for evaluating these three types of elements involved using the judgment quantification method (JQM). As explained in Chapter 04, JQM is an effective method for evaluating or determining the relative importance (weight) of an element with respect to its superior element. For each category, specific judgment quantification instruments were formed. The category of the 5-STEEP perspectives has one JQI to evaluate them with respect to the model's objective. Each group of criteria that belong to one perspective has one JQI for evaluating them with respect to perspective. In addition, each group of sub-criteria has one JQI for evaluating the sub-criteria with respect to their superior criterion.

The category of the 5-Siting technologies had 42 judgment quantification instruments for evaluating them with respect to their superior 42 criteria and subcriteria. A total of 55 judgment quantification instruments (i.e., 1 for prespectives, 2 for social, 4 for each technical, economic, 1 for each environmental and polticial criteria and sub-criteria) were formed to help the experts evaluate the elements (pairwise comparisons). Figure 7.1 shows an example of one JQI for evaluating the 5-STEEP perspectives with respect to the model's objective and Table 7.3 shows the 10 different pairwise comparisons required to evaluate the 5-STEEP perspectives. 


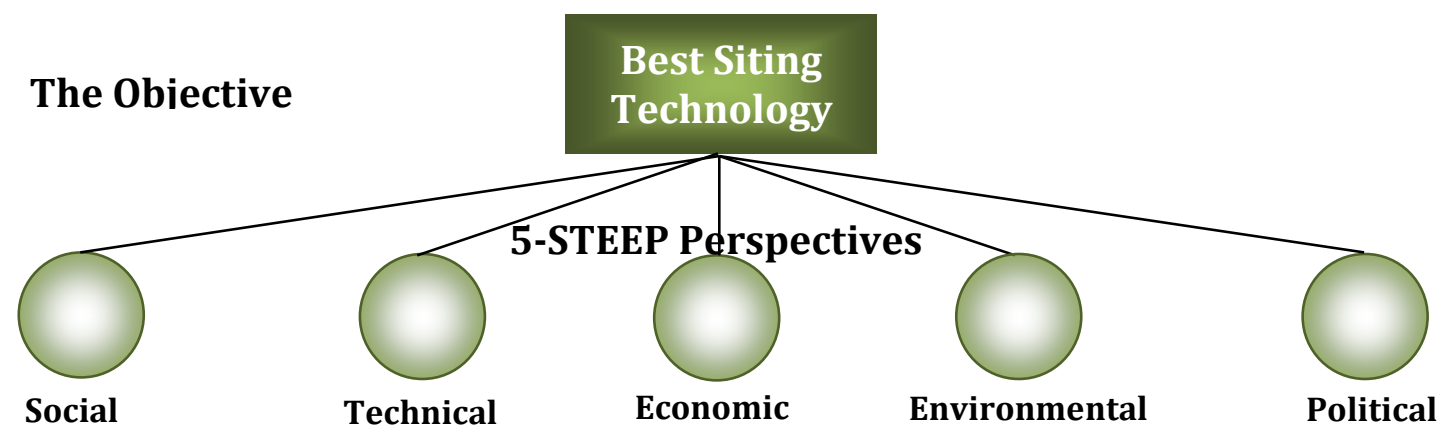

Please give your judgment for each pair of nodes below
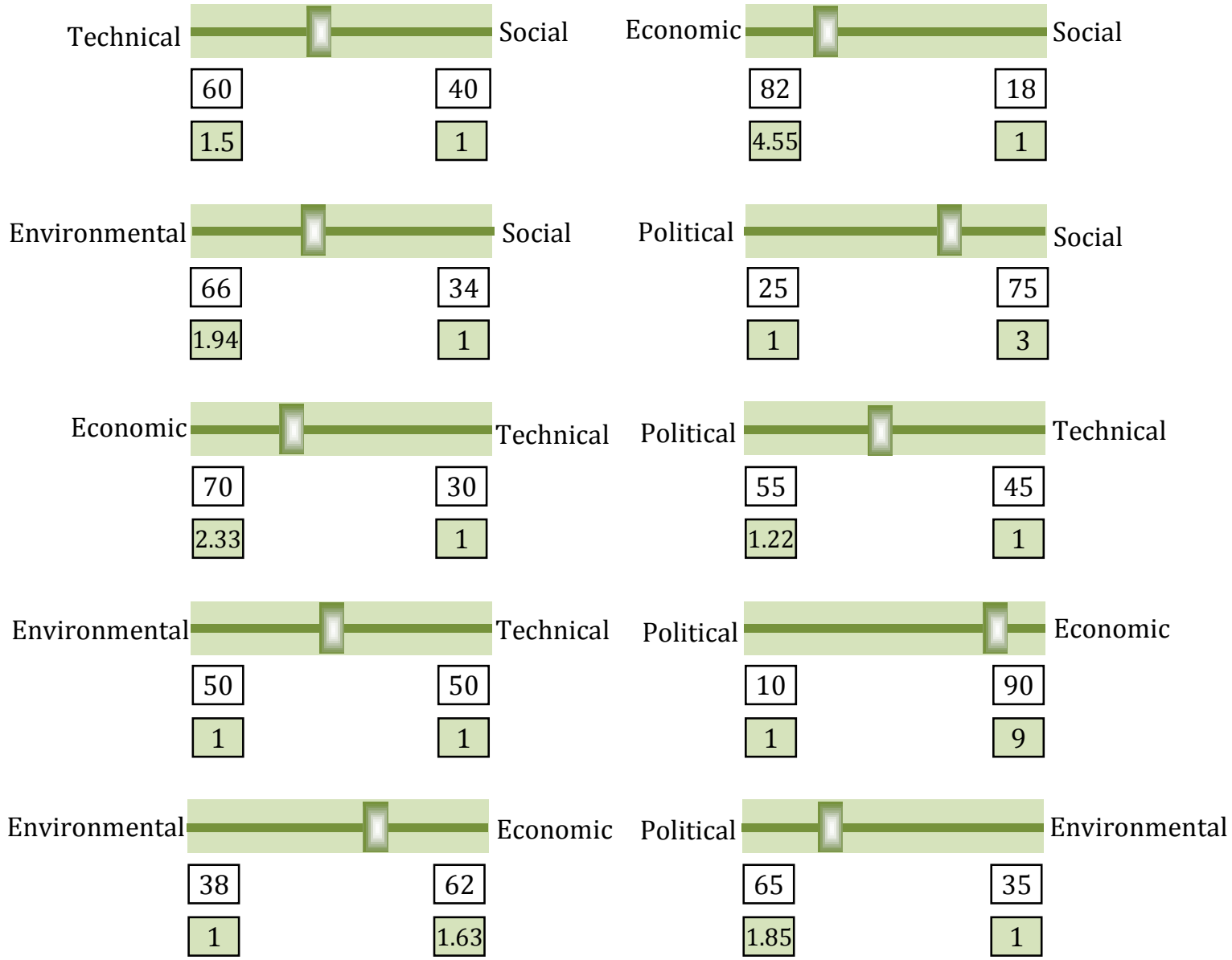

Figure 7.1 Judgment Quantification Instrument (10 Pairwise Comparisons) for Comparing the 5-STEEP Perspectives with Respect to the objective 
Table 7.3 The Results of 10 Pairwise Comparisons for the 5-STEEP Perspectives

\begin{tabular}{|c|c|c|c|c|c|c|}
\hline & \multicolumn{7}{|c|}{ Perspectives } \\
\hline & EXperts & & \\
\hline & Social & Technical & Economic & Environmental & Political & \\
\hline EXP01 & 0.13 & 0.24 & 0.31 & 0.14 & 0.18 & 0.01 \\
\hline EXP03 & 0.03 & 0.16 & 0.26 & 0.25 & 0.30 & 0.09 \\
\hline EXP04 & 0.18 & 0.23 & 0.17 & 0.37 & 0.05 & 0.08 \\
\hline EXP05 & 0.11 & 0.24 & 0.35 & 0.17 & 0.13 & 0.02 \\
\hline EXP06 & 0.15 & 0.25 & 0.09 & 0.08 & 0.43 & 0.09 \\
\hline EXP07 & 0.04 & 0.13 & 0.33 & 0.12 & 0.38 & 0.06 \\
\hline EXP08 & 0.12 & 0.34 & 0.30 & 0.14 & 0.10 & 0.03 \\
\hline EXP09 & 0.41 & 0.09 & 0.14 & 0.26 & 0.10 & 0.04 \\
\hline EXP10 & 0.16 & 0.23 & 0.23 & 0.23 & 0.15 & 0.00 \\
\hline EXP11 & 0.20 & 0.30 & 0.27 & 0.13 & 0.10 & 0.01 \\
\hline EXP12 & 0.11 & 0.33 & 0.26 & 0.19 & 0.11 & 0.02 \\
\hline EXP13 & 0.12 & 0.26 & 0.38 & 0.13 & 0.11 & 0.04 \\
\hline EXP14 & 0.16 & 0.25 & 0.25 & 0.18 & 0.16 & 0.01 \\
\hline EXP15 & 0.12 & 0.20 & 0.32 & 0.14 & 0.22 & 0.00 \\
\hline \hline Mean & 0.19 & 0.18 & 0.20 & 0.24 & 0.19 & 0.04 \\
\hline Minimum & $\mathbf{0 . 1 5}$ & $\mathbf{0 . 2 3}$ & $\mathbf{0 . 2 6}$ & $\mathbf{0 . 1 8}$ & $\mathbf{0 . 1 8}$ & \\
\hline Maximum & 0.03 & 0.09 & 0.09 & 0.08 & 0.05 & \\
\hline Std. Deviation & 0.41 & 0.34 & 0.38 & 0.37 & 0.43 & \\
\hline Disagreement & 0.09 & 0.07 & 0.08 & 0.08 & 0.12 & \\
\hline & & & & & & 0.08 \\
\hline
\end{tabular}

The Statistical F-test for evaluating all null hypothesis (Ho: ric $=0$ ) is obtained by dividing between-subjects variability with residual variability

\begin{tabular}{|l|c|c|c|c|}
\hline Sources of Variation & $\begin{array}{c}\text { Sum } \\
\text { of Squares }\end{array}$ & $\begin{array}{c}\text { Degree of } \\
\text { Freedom }\end{array}$ & $\begin{array}{c}\text { Mean } \\
\text { of squares }\end{array}$ & $\begin{array}{c}\text { F-test } \\
\text { Value }\end{array}$ \\
\hline Between Subjects & 0.10 & 4 & 0.024 & $\mathbf{2 . 2 1}$ \\
\hline Between Conditions & 0.00 & 11 & 0.000 & \\
\hline Residual & 0.49 & 44 & 0.011 & \\
\hline Total & 0.58 & 59 & & 3.78 \\
\hline Critical F-value with degree of freedom 4 \& 44 at 0.01 level: \\
\hline Critical F-value with degree of freedom 4 \& 44 at 0.025 level: \\
\hline Critical F-value with degree of freedom 4 \& 44 at 0.050 level: \\
\hline Critical F-value with degree of freedom 4 \& 44 at 0.1 level: \\
\hline
\end{tabular}


The figure below (Figure 7.2) shows the relative values of the 5-STEEP perspectives as the mean value of the 15 experts' inputs as shown in Table 7.3.

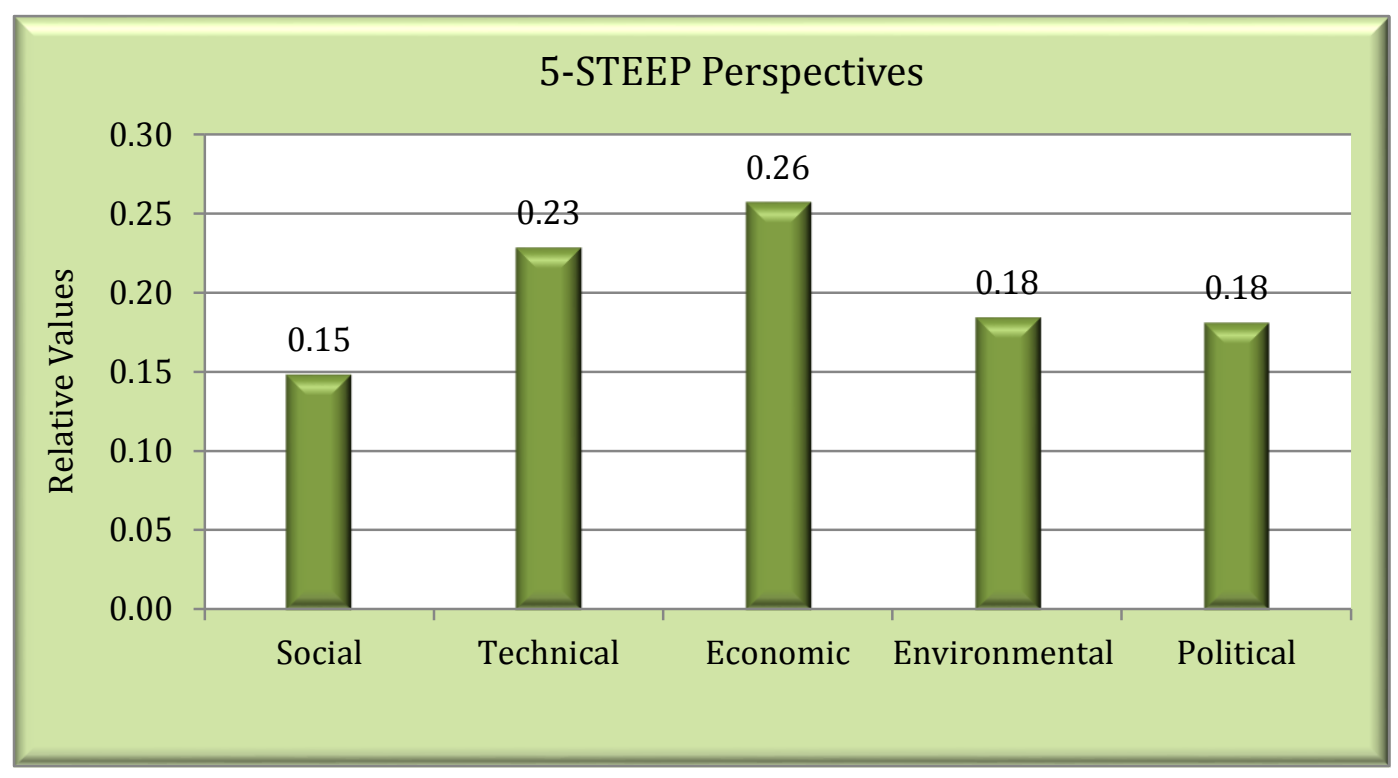

Figure 7.2 The Relative Values of 5-STEEP Perspectives

\subsubsection{Evaluating the Criteria and Sub-Criteria}

The validated criteria and sub-criteria as listed in Table 7.2 were also evaluated by the experts using the web-based JQI. The results are summarized in Table 7.4

The relative values of the social criteria and sub-criteria are depicted in Figures 7.3 and 7.4 respectively. The relative values of the other perspectives (technical, economic, environmental, and political) are listed in Appendix F. 


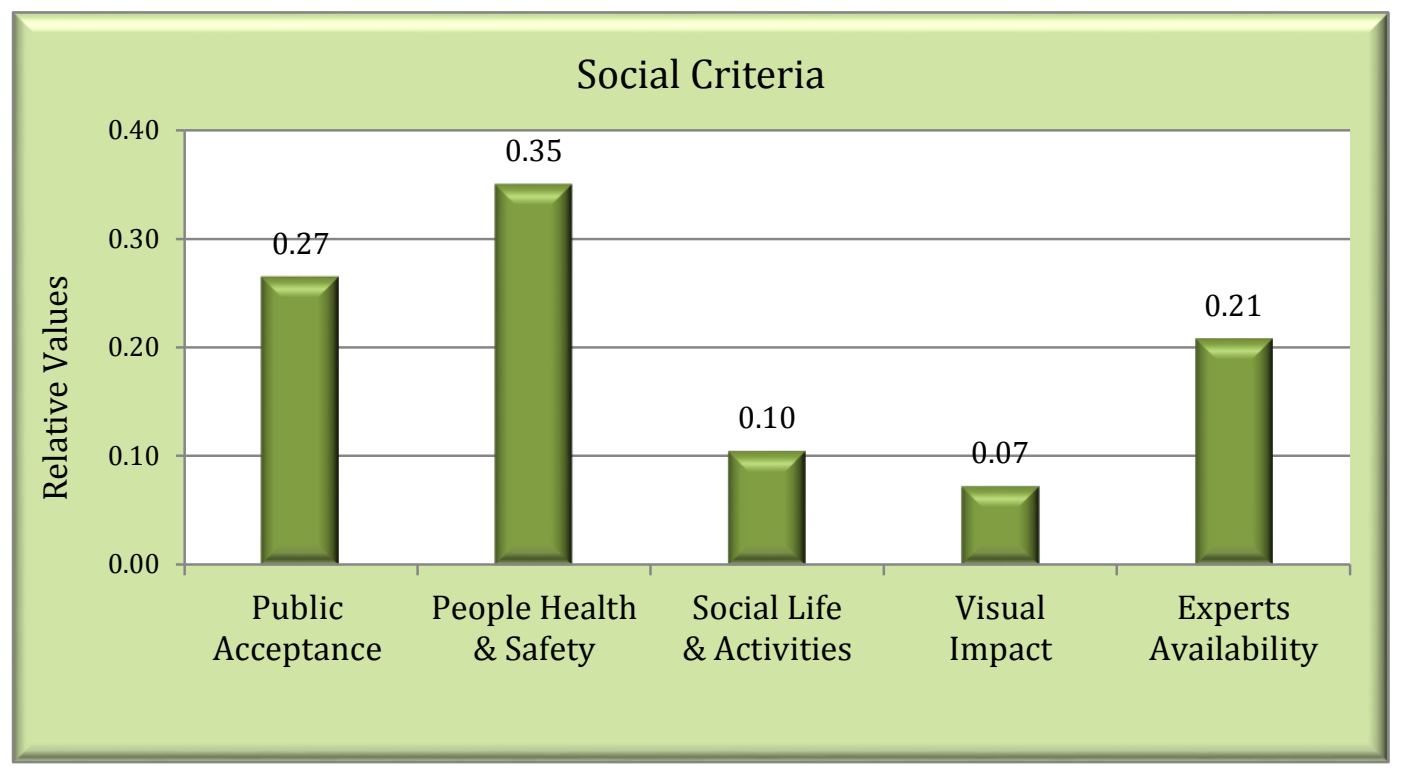

Figure 7.3 Social Criteria Relative Values

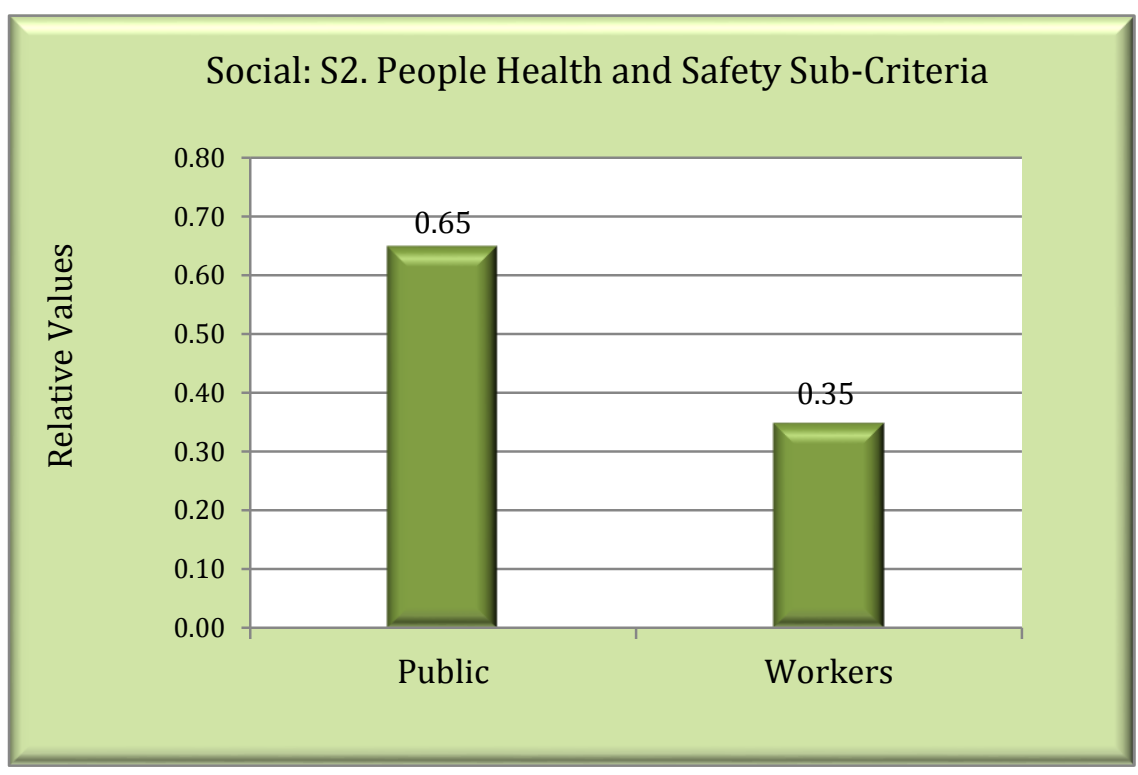

Figure 7.4 Social Sub-Criteria (S2: People Health and Safety) Relative Values 
Table 7.4 Pairwise Comparisons Results of the Criteria and Sub-Criteria

\begin{tabular}{|c|c|c|c|c|c|}
\hline Perspective & 苞 & 官 & Title & $\begin{array}{c}\text { Sub- } \\
\text { Criteria } \\
\text { Relative } \\
\text { Values }\end{array}$ & $\begin{array}{c}\text { Criteria } \\
\text { Relative } \\
\text { Values }\end{array}$ \\
\hline \multirow{7}{*}{ Social } & S1 & & Public Acceptance and Attitude & & 0.27 \\
\hline & S2 & & People Health and Safety & & 0.35 \\
\hline & & S2.1 & - Public & 0.66 & \\
\hline & & S2.2 & - Workers & 0.34 & \\
\hline & S3 & & Social Life and Activities & & 0.10 \\
\hline & S4 & & Visual Impact & & 0.07 \\
\hline & S5 & & Experts Availability & & 0.21 \\
\hline \multirow{16}{*}{ Technical } & $\mathrm{T} 1$ & & Maturity & & 0.14 \\
\hline & & $\mathrm{T} 1.1$ & - Applicability & 0.32 & \\
\hline & & $\mathrm{T} 1.2$ & - Reliability & 0.49 & \\
\hline & & $\mathrm{T} 1.3$ & - Competency & 0.19 & \\
\hline & $\mathrm{T} 2$ & & Flexibility & & 0.13 \\
\hline & & $\mathrm{T} 2.1$ & - Scalability & 0.40 & \\
\hline & & $\mathrm{T} 2.2$ & - Mobility & 0.13 & \\
\hline & & $\mathrm{T} 2.3$ & - Modularity & 0.47 & \\
\hline & T3 & & Safety and Security & & 0.25 \\
\hline & & T3.1 & - Resistance & 0.33 & \\
\hline & & T3.2 & - Containment & 0.50 & \\
\hline & & T3.3 & - Evacuation & 0.17 & \\
\hline & $\mathrm{T} 4$ & & Power Generation Capacity & & 0.13 \\
\hline & T5 & & Plant Life Span & & 0.11 \\
\hline & T6 & & Used Fuel Storage Capacity & & 0.12 \\
\hline & $\mathrm{T} 7$ & & Decommissioning and Site Cleanup & & 0.12 \\
\hline \multirow{11}{*}{ Economic } & E1 & & Site Development Cost & & 0.16 \\
\hline & & E1.1 & - Exploration Cost & 0.25 & \\
\hline & & E1.2 & - Acquisition Cost & 0.34 & \\
\hline & & E1.3 & - Preparation Cost & 0.41 & \\
\hline & E2 & & Plant Development Cost & & 0.23 \\
\hline & & E2.1 & - Engineering, Construction, and & 0.47 & \\
\hline & & E2.2 & - Operation and Maintenance Cost & 0.32 & \\
\hline & & E2.3 & - Decommission Cost & 0.21 & \\
\hline & E3 & & Plant Supplementary Systems Cost & & 0.16 \\
\hline & & E3.1 & - Water Delivery System Cost & 0.22 & \\
\hline & & E3.2 & - Grid Connection System Cost & 0.18 & \\
\hline
\end{tabular}




\begin{tabular}{|c|c|c|c|c|c|}
\hline Perspective & 苞 & 흘 & Title & $\begin{array}{c}\text { Sub- } \\
\text { Criteria } \\
\text { Relative } \\
\text { Values }\end{array}$ & $\begin{array}{c}\text { Criteria } \\
\text { Relative } \\
\text { Values }\end{array}$ \\
\hline & & E3.3 & - Ventilation System Cost & 0.16 & \\
\hline & & E3.4 & - Protection and Isolation Systems Cost & 0.27 & \\
\hline & & E3.5 & - Transportation System Cost & 0.17 & \\
\hline & E4 & & Technology Outsourcing Cost & & 0.14 \\
\hline & E5 & & Return On Investment & & 0.31 \\
\hline \multirow{5}{*}{ Environmental } & $\mathrm{N} 1$ & & Site Preparation-Related Impacts & & 0.16 \\
\hline & $\mathrm{N} 2$ & & Construction-Related Impacts & & 0.20 \\
\hline & N3 & & Operation-Related Impacts & & 0.27 \\
\hline & N4 & & Land Consumption and Utilization & & 0.17 \\
\hline & N5 & & Site Recovery & & 0.20 \\
\hline \multirow{5}{*}{ Political } & P1 & & Government Perception & & 0.15 \\
\hline & P2 & & Government Support & & 0.25 \\
\hline & P3 & & Political Side of Technology Transfer & & 0.12 \\
\hline & P4 & & $\begin{array}{l}\text { National/International Laws and } \\
\text { Agreements }\end{array}$ & & 0.20 \\
\hline & P5 & & Rules and Regulations Availability & & 0.28 \\
\hline
\end{tabular}

\subsubsection{Evaluating the Siting Technologies}

Developing the initial decision model required the availability of all relative importance values (weights) of all elements. In the previous sections, relative values of the 5-STEEP perspectives and the criteria and sub-criteria were obtained by using judgment quantification instruments. The validated siting technologies are characterized by the list of valid criteria and sub-criteria. In reality, Land-Based is the only siting technology that has real values for these criteria and sub-criteria because it has been implemented commercially hundreds of times. The other siting technologies are still under development. To evaluate the selected/validated siting 
technologies for the decision model, weights or relative values of these sitings had to be obtained.

The same method (i.e., JQM) was used to evaluate the five siting technologies with respect to their superior elements. For this particular evaluation, we had to consider that pairwise comparisons between two siting technologies should be done with respect to the element in direct connection to the technologies, whether a criterion or sub-criterion. For example, to evaluate any two siting technologies with respect to the social criteria, evaluation should first be perform with the S1 (public acceptance and attitude); the second evaluation should be done with respect to S2.1 (public) and then with respect to S2.2 (workers), but not with S2 (people's health and safety), which is never used in such evaluation. The third evaluation should be done with respect to S3 as long as it has no sub-criteria and so on.

The validated siting technologies, as listed in Table 7.1, were evaluated by the experts using the web-based JQI. The results of evaluating the five siting technologies with respect to the social criteria and sub-criteria are shown in Figures 7.5 to 7.10. The results of evaluating the five siting technologies with respect to all 42 criteria and sub-criteria are summarized in Table 5.7. 


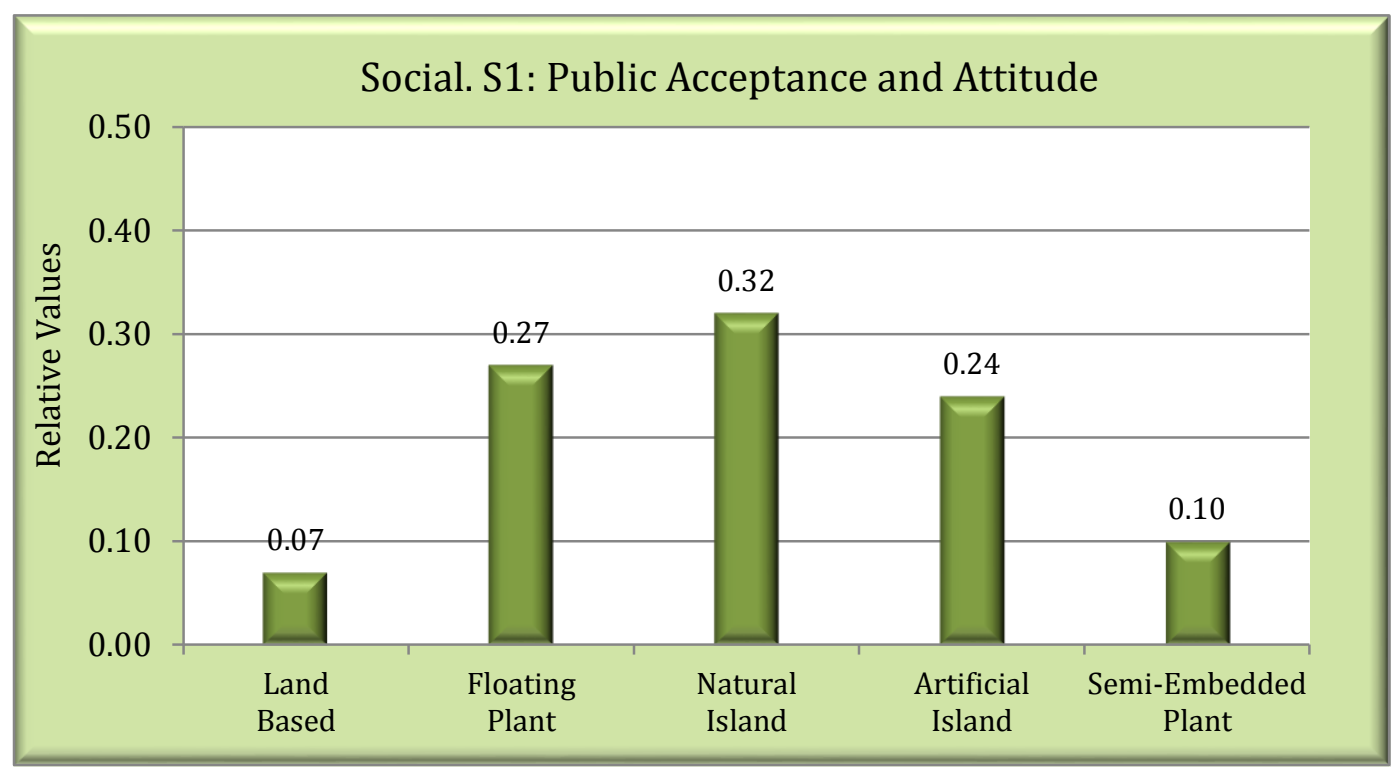

Figure 7.5 The Five Siting Technologies Relative Values with Respect to the Social Criteria S1

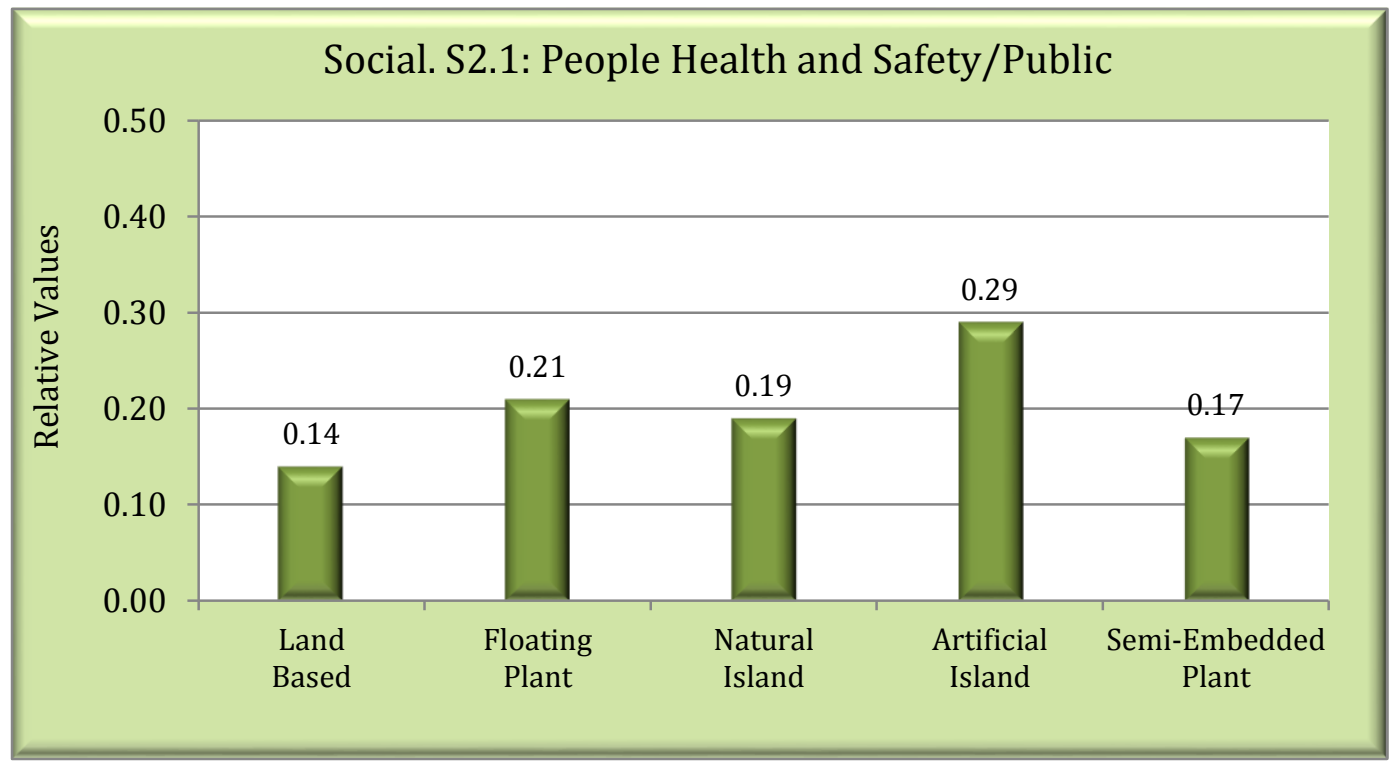

Figure 7.6 The Five Siting Technologies Relative Values with Respect to the Social Sub-Criteria S2.1 


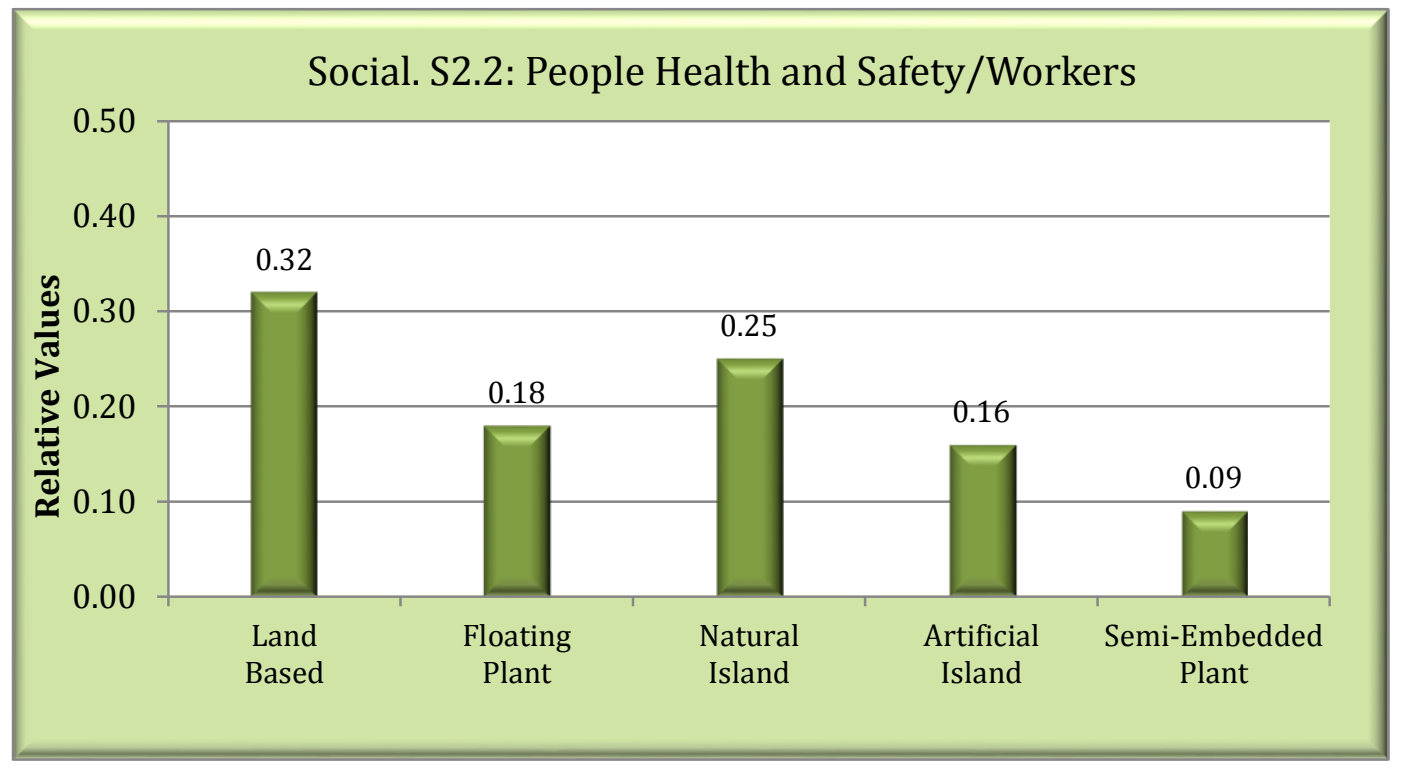

Figure 7.7 The Five Siting Technologies Relative Values with Respect to the Social Sub-Criteria S2.2

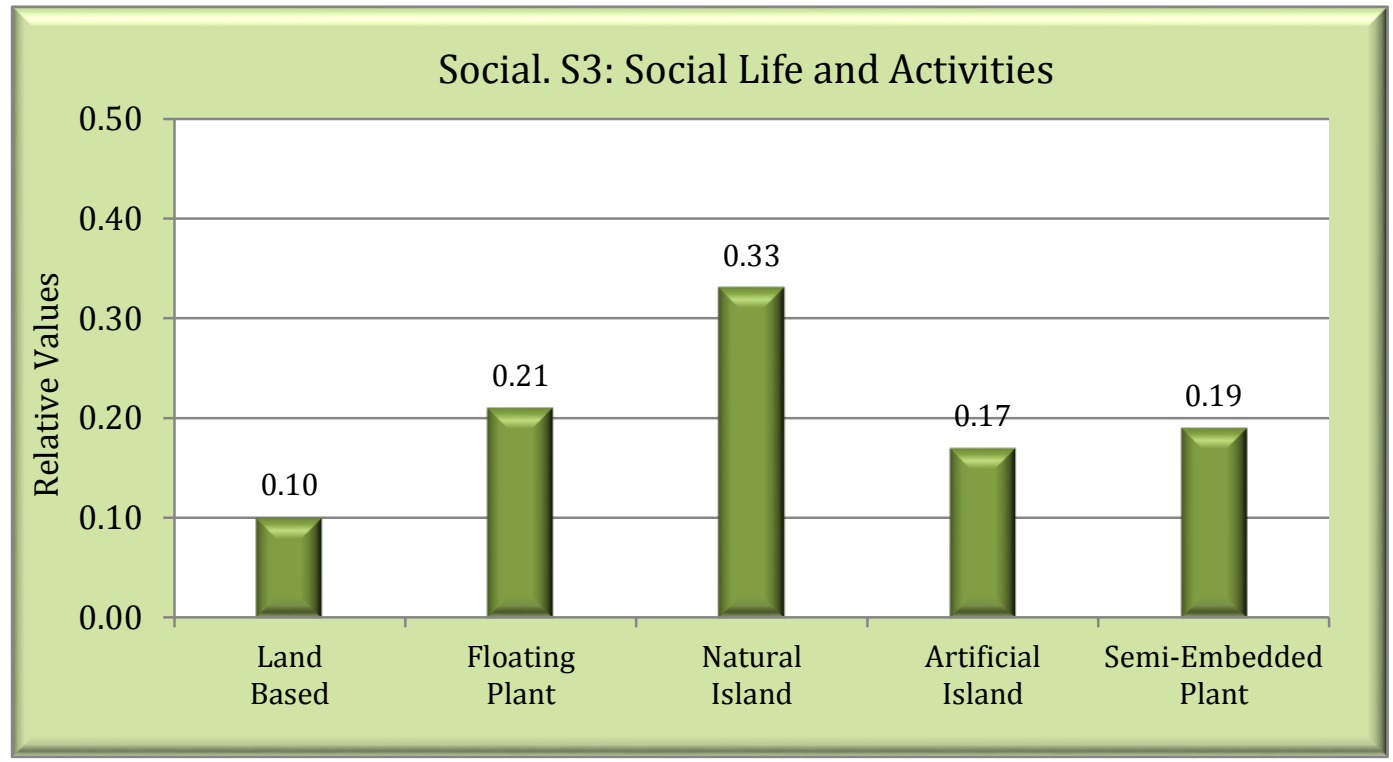

Figure 7.8 The Five Siting Technologies Relative Values with Respect to the Social Criteria S3 


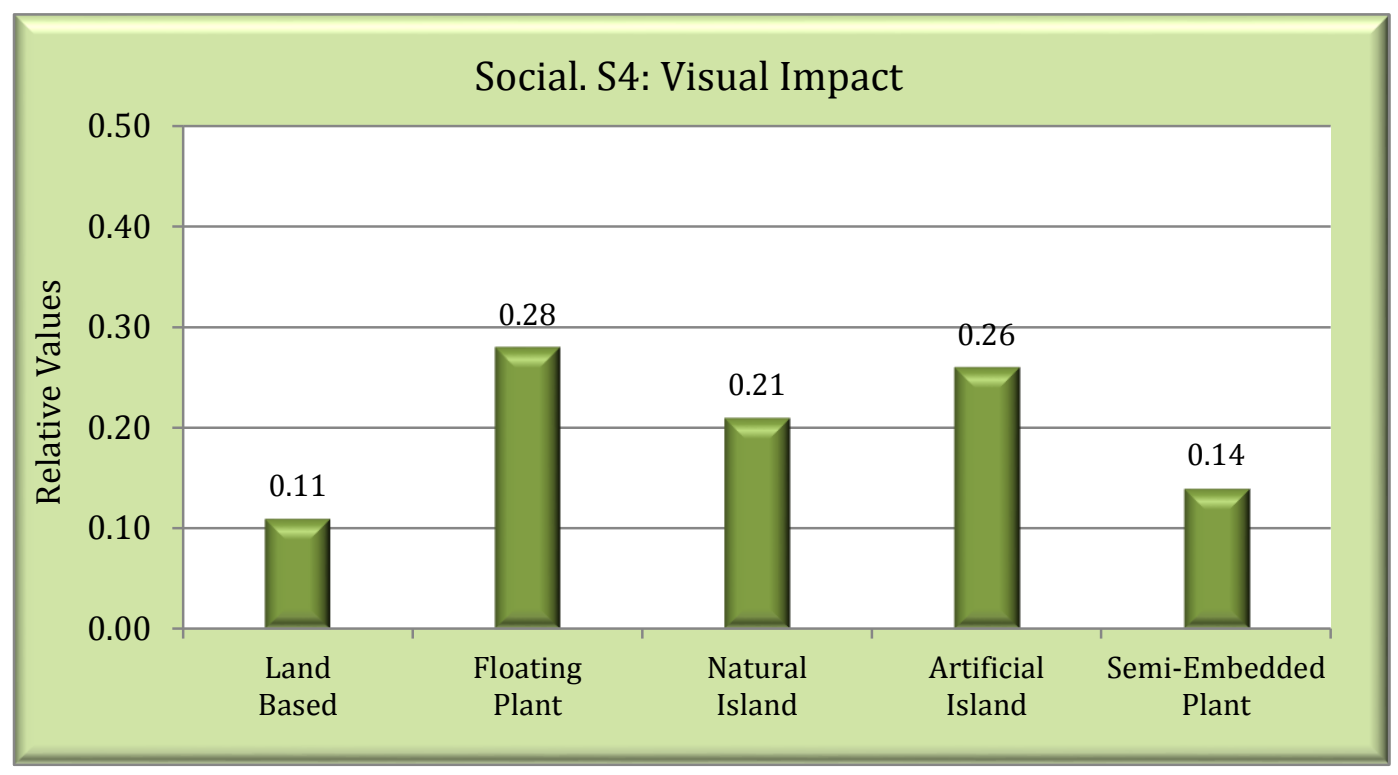

Figure 7.9 The Five Siting Technologies Relative Values with Respect to the Social Criteria S4

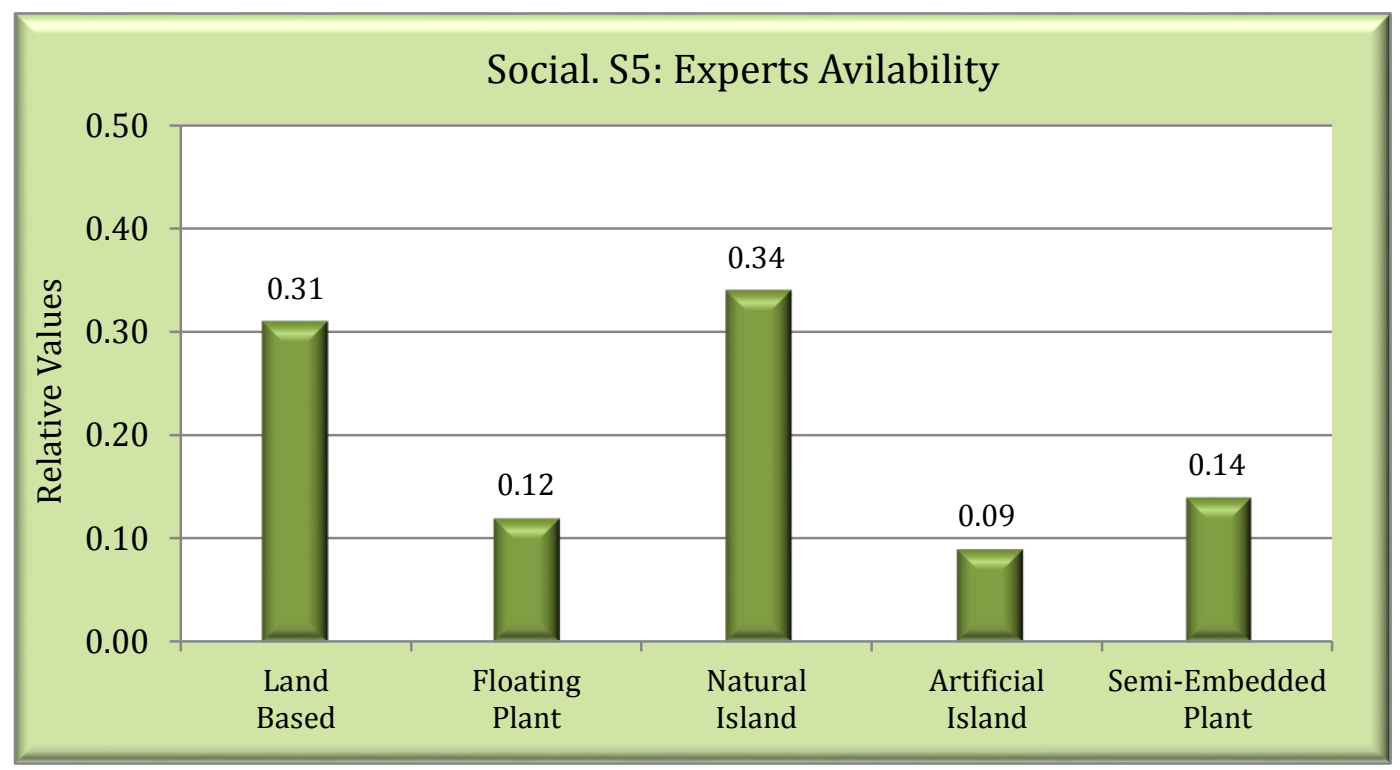

Figure 7.10 The Five Siting Technologies Relative Values with Respect to the Social Criteria S5 
Table 7.5 The Relative Values of the Five Siting Technologies with Respect to All 42 Criteria and Sub-Criteria

\begin{tabular}{|c|c|c|c|c|c|c|c|c|}
\hline \multirow{2}{*}{$\begin{array}{l}0 \\
\stackrel{0}{0} \\
0 \\
0 \\
\frac{0}{0} \\
0 \\
0\end{array}$} & \multirow{2}{*}{$\frac{\sqrt[0]{0}}{0}$} & \multirow{2}{*}{ 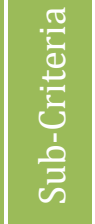 } & \multirow[b]{2}{*}{ Title } & \multicolumn{5}{|c|}{ Siting Technologies } \\
\hline & & & & $\begin{array}{l}\text { Land } \\
\text { Based }\end{array}$ & $\begin{array}{l}\text { Floating } \\
\text { Plant }\end{array}$ & $\begin{array}{l}\text { Natural } \\
\text { Island }\end{array}$ & $\begin{array}{l}\text { Artificial } \\
\text { Island }\end{array}$ & $\begin{array}{c}\text { Semi- } \\
\text { Embedded } \\
\text { Plant }\end{array}$ \\
\hline \multirow[t]{8}{*}{$\mathbf{S}$} & & & Social & & & & & \\
\hline & S1 & & Public Acceptance \& Attitude & 0.07 & 0.27 & 0.32 & 0.24 & 0.10 \\
\hline & S2 & & People Health and Safety & & & & & \\
\hline & & S2.1 & - Public & 0.14 & 0.21 & 0.19 & 0.29 & 0.17 \\
\hline & & $\mathrm{S} 2.2$ & - Workers & 0.32 & 0.18 & 0.25 & 0.16 & 0.09 \\
\hline & S3 & & Social Life and Activities & 0.10 & 0.21 & 0.33 & 0.17 & 0.19 \\
\hline & S4 & & Visual Impact & 0.11 & 0.28 & 0.21 & 0.26 & 0.14 \\
\hline & S5 & & Experts Availability & 0.31 & 0.12 & 0.34 & 0.09 & 0.14 \\
\hline \multirow[t]{17}{*}{$\mathbf{T}$} & & & Technical & & & & & \\
\hline & $\mathrm{T} 1$ & & Maturity & & & & & \\
\hline & & $\mathrm{T} 1.1$ & - Applicability & 0.41 & 0.11 & 0.21 & 0.02 & 0.25 \\
\hline & & $\mathrm{T} 1.2$ & - Reliability & 0.23 & 0.20 & 0.27 & 0.19 & 0.11 \\
\hline & & $\mathrm{T} 1.3$ & - Competency & 0.30 & 0.14 & 0.27 & 0.14 & 0.15 \\
\hline & $\mathrm{T} 2$ & & Flexibility & & & & & \\
\hline & & $\mathrm{T} 2.1$ & - Scalability & 0.13 & 0.34 & 0.15 & 0.31 & 0.07 \\
\hline & & $\mathrm{T} 2.2$ & - Mobility & 0.15 & 0.43 & 0.13 & 0.17 & 0.12 \\
\hline & & $\mathrm{T} 2.3$ & - Modularity & 0.14 & 0.31 & 0.10 & 0.32 & 0.13 \\
\hline & T3 & & Safety and Security & & & & & \\
\hline & & T3.1 & - Resistance & 0.07 & 0.21 & 0.13 & 0.17 & 0.42 \\
\hline & & T3.2 & - Containment & 0.08 & 0.23 & 0.16 & 0.14 & 0.39 \\
\hline & & T3.3 & - Evacuation & 0.38 & 0.16 & 0.18 & 0.19 & 0.09 \\
\hline & $\mathrm{T} 4$ & & Power Generation Capacity & 0.32 & 0.14 & 0.19 & 0.20 & 0.15 \\
\hline & T5 & & Plant Life Span & 0.30 & 0.07 & 0.28 & 0.19 & 0.16 \\
\hline & T6 & & Used Fuel Storage Capacity & 0.16 & 0.09 & 0.21 & 0.24 & 0.30 \\
\hline & T7 & & $\begin{array}{l}\text { Decommission \& Site } \\
\text { Cleanup }\end{array}$ & 0.11 & 0.28 & 0.12 & 0.19 & 0.30 \\
\hline \multirow[t]{4}{*}{$\mathbf{E}$} & & & Economic & & & & & \\
\hline & E1 & & Site Development Costs & & & & & \\
\hline & & E1.1 & - Exploration Cost & 0.20 & 0.38 & 0.12 & 0.22 & 0.08 \\
\hline & & E1.2 & - Acquisition Cost & 0.07 & 0.41 & 0.19 & 0.21 & 0.12 \\
\hline
\end{tabular}




\begin{tabular}{|c|c|c|c|c|c|c|c|c|}
\hline \multirow{2}{*}{$\begin{array}{l}0 \\
\geq \\
\geq \\
0 \\
0 \\
0 \\
0 \\
0 \\
0 \\
0\end{array}$} & \multirow{2}{*}{ 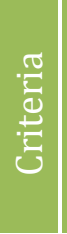 } & \multirow{2}{*}{ 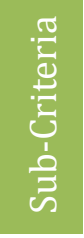 } & \multirow[b]{2}{*}{ Title } & \multicolumn{5}{|c|}{ Siting Technologies } \\
\hline & & & & $\begin{array}{l}\text { Land } \\
\text { Based }\end{array}$ & $\begin{array}{l}\text { Floating } \\
\text { Plant }\end{array}$ & $\begin{array}{c}\text { Natural } \\
\text { Island }\end{array}$ & $\begin{array}{l}\text { Artificial } \\
\text { Island }\end{array}$ & $\begin{array}{l}\text { Semi- } \\
\text { Embedded } \\
\text { Plant }\end{array}$ \\
\hline & & E1.3 & - Preparation Cost & 0.16 & 0.59 & 0.07 & 0.16 & 0.02 \\
\hline & \multirow[t]{4}{*}{ E2 } & & Plant Development Costs & & & & & \\
\hline & & E2.2 & $\begin{array}{l}\text { - Construction \& } \\
\text { Installation }\end{array}$ & 0.35 & 0.19 & 0.28 & 0.10 & 0.08 \\
\hline & & E2.3 & $\begin{array}{l}\text { - Operation \& } \\
\text { Maintenance }\end{array}$ & 0.30 & 0.21 & 0.19 & 0.22 & 0.08 \\
\hline & & E2.4 & - Decommissioning Cost & 0.16 & 0.11 & 0.27 & 0.08 & 0.38 \\
\hline & \multirow[t]{6}{*}{ E3 } & & $\begin{array}{l}\text { Plant Supplementary Sys. } \\
\text { Cost }\end{array}$ & & & & & \\
\hline & & E3.1 & - Water Delivery System & 0.10 & 0.32 & 0.18 & 0.34 & 0.06 \\
\hline & & E3.2 & - Grid Connection System & 0.37 & 0.10 & 0.14 & 0.11 & 0.28 \\
\hline & & E3.3 & - Ventilation System & 0.15 & 0.24 & 0.25 & 0.26 & 0.10 \\
\hline & & E3.4 & $\begin{array}{l}\text { - Protection \& Isolation } \\
\text { System }\end{array}$ & 0.18 & 0.09 & 0.29 & 0.11 & 0.33 \\
\hline & & E3.5 & - Transportation System & 0.43 & 0.08 & 0.11 & 0.13 & 0.25 \\
\hline & E4 & & Technology Outsourcing Cost & 0.35 & 0.07 & 0.31 & 0.09 & 0.18 \\
\hline & E5 & & Return on Investment & 0.31 & 0.09 & 0.29 & 0.10 & 0.21 \\
\hline \multirow[t]{6}{*}{$\mathbf{N}$} & & & Environmental & & & & & \\
\hline & N1 & & $\begin{array}{l}\text { Site Preparation-Related } \\
\text { Impact }\end{array}$ & 0.08 & 0.32 & 0.29 & 0.20 & 0.11 \\
\hline & N2 & & $\begin{array}{l}\text { Construction-Related } \\
\text { Impacts }\end{array}$ & 0.25 & 0.27 & 0.24 & 0.16 & 0.08 \\
\hline & N3 & & Operation-Related Impacts & 0.13 & 0.29 & 0.23 & 0.26 & 0.09 \\
\hline & N4 & & $\begin{array}{l}\text { Land Consumption \& } \\
\text { Utilization }\end{array}$ & 0.07 & 0.31 & 0.12 & 0.20 & 0.30 \\
\hline & N5 & & Site Recovery & 0.10 & 0.30 & 0.15 & 0.16 & 0.29 \\
\hline \multirow[t]{6}{*}{$\mathbf{P}$} & & & Political & & & & & \\
\hline & P1 & & Government Perception & 0.16 & 0.12 & 0.30 & 0.14 & 0.28 \\
\hline & P2 & & Government Support & 0.06 & 0.18 & 0.29 & 0.17 & 0.30 \\
\hline & P3 & & $\begin{array}{l}\text { Political Side of Technology } \\
\text { Transfer }\end{array}$ & 0.26 & 0.19 & 0.21 & 0.17 & 0.17 \\
\hline & P4 & & $\begin{array}{l}\text { National/International Laws } \\
\text { \& Agreements }\end{array}$ & 0.28 & 0.16 & 0.14 & 0.17 & 0.25 \\
\hline & P5 & & $\begin{array}{l}\text { Rules \& Regulations } \\
\text { Availability }\end{array}$ & 0.34 & 0.07 & 0.32 & 0.15 & 0.12 \\
\hline
\end{tabular}




\subsection{Base Model Development}

The processes of developing the decision model for evaluating nuclear power plant alternative siting technologies were completed in terms of identifying, validating, and evaluating the decision model's objective, perspectives, criteria, subcriteria, and alternatives. These elements were then used to construct the essential decision model, as shown in Figure 7.11.

However, the decision model would not be considered complete without testing its functionality. Testing the model was important to demonstrate its validity and applicability. The model was tested using two approaches. The model was first implemented to find out which siting technology was the best among the others based on the available information and relative importance values and then by changing the 5-STEEP perspectives' priority values to study the sensitivity of the model. 


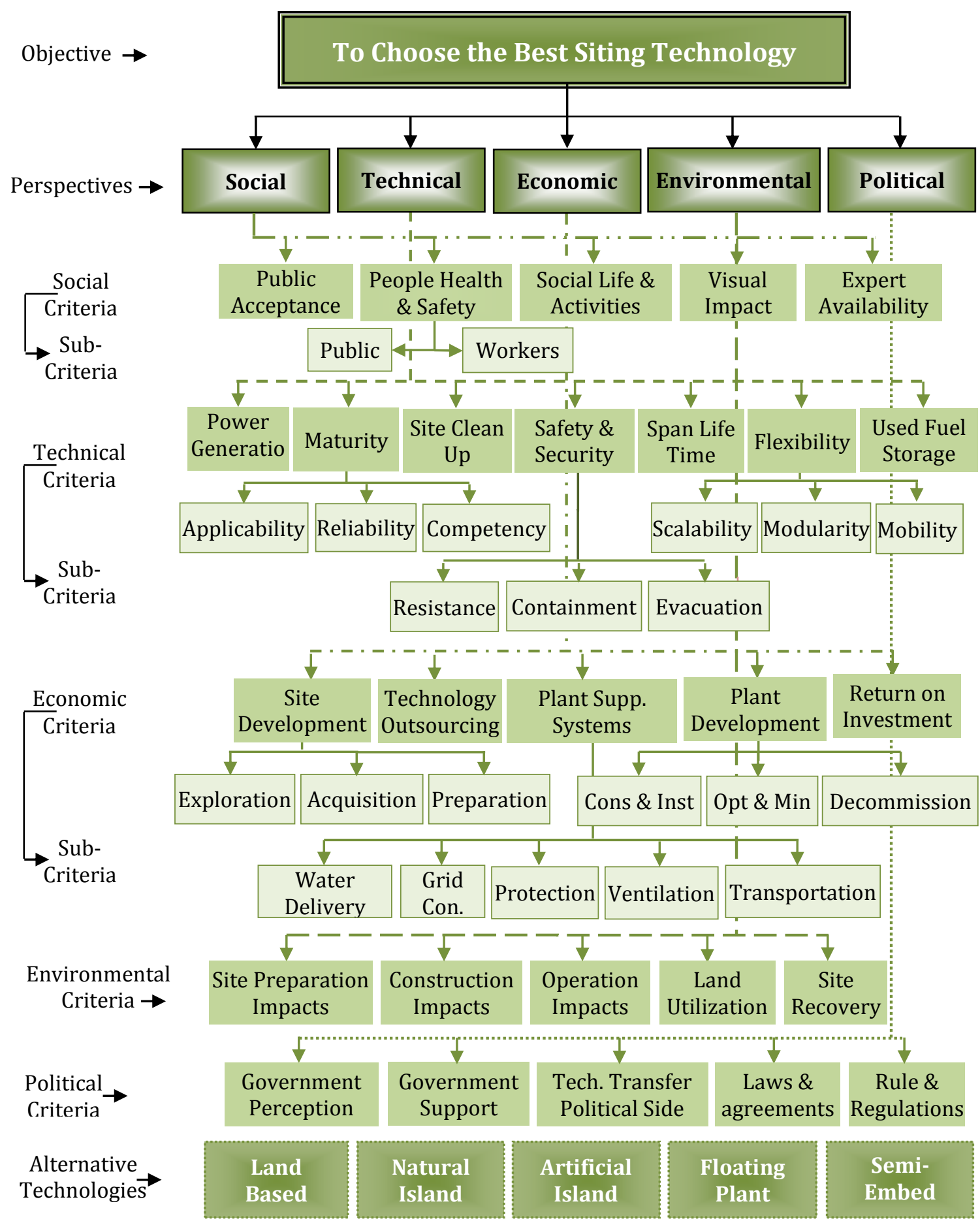

Figure 7.11 The Hierarchical Decision Model (HDM) for Evaluating Nuclear Power Plant Alternative Siting Technologies 


\subsubsection{Base Model Implementation}

The base model is the essential decision model as shown in Figure 7.11. It is a complete decision model in terms of structure and the necessary elements for making a decision. However, it is called a base model because:

(1) The model considers only the five siting technologies validated by the experts,

(2) The relative values of the five siting technologies were obtained by performing pairwise comparisons among these technologies only. Figure 7.12 shows a sample of the pairwise comparisons among the five siting technologies with respect to a scocial criterion (i.e., Public Acceptance and Attitude)

This means that these relative values would become obsolete if any additional siting technology is considered by the model. Implementing the base model means using the model elements' current relative values to determine the technology value (TV) for each one of the five siting technologies. The siting technology with the highest TV is considered the best technology according to the decision model.

Table 7.6 shows the relative values of the 5-STEEP perspectives, criteria, subcriteria, and five siting technologies that were used to calculate the TVs. 


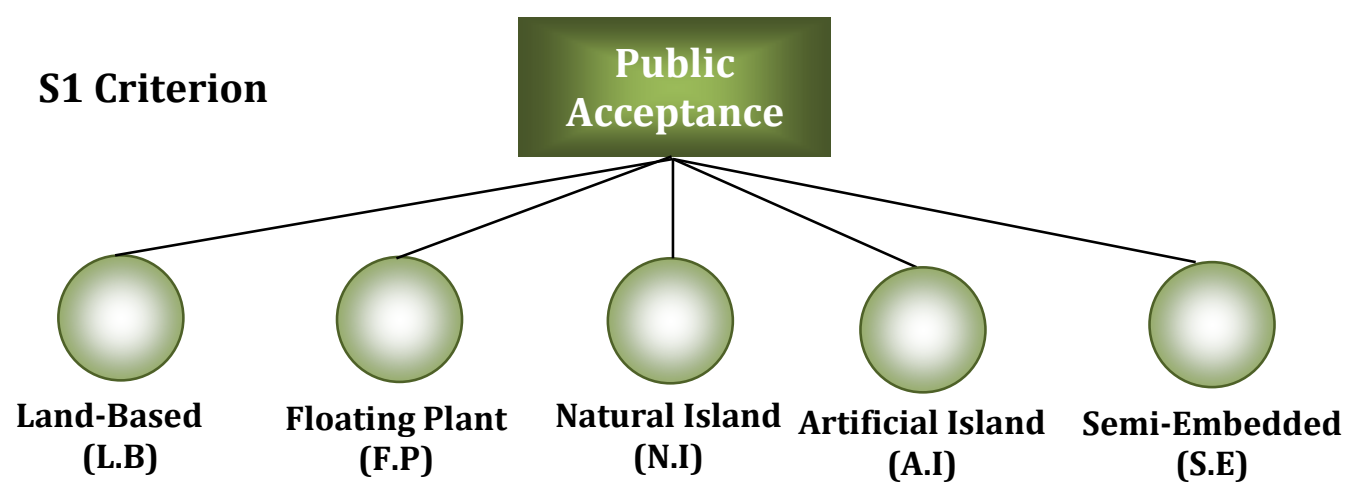

Please give your judgment for each pair of nodes below
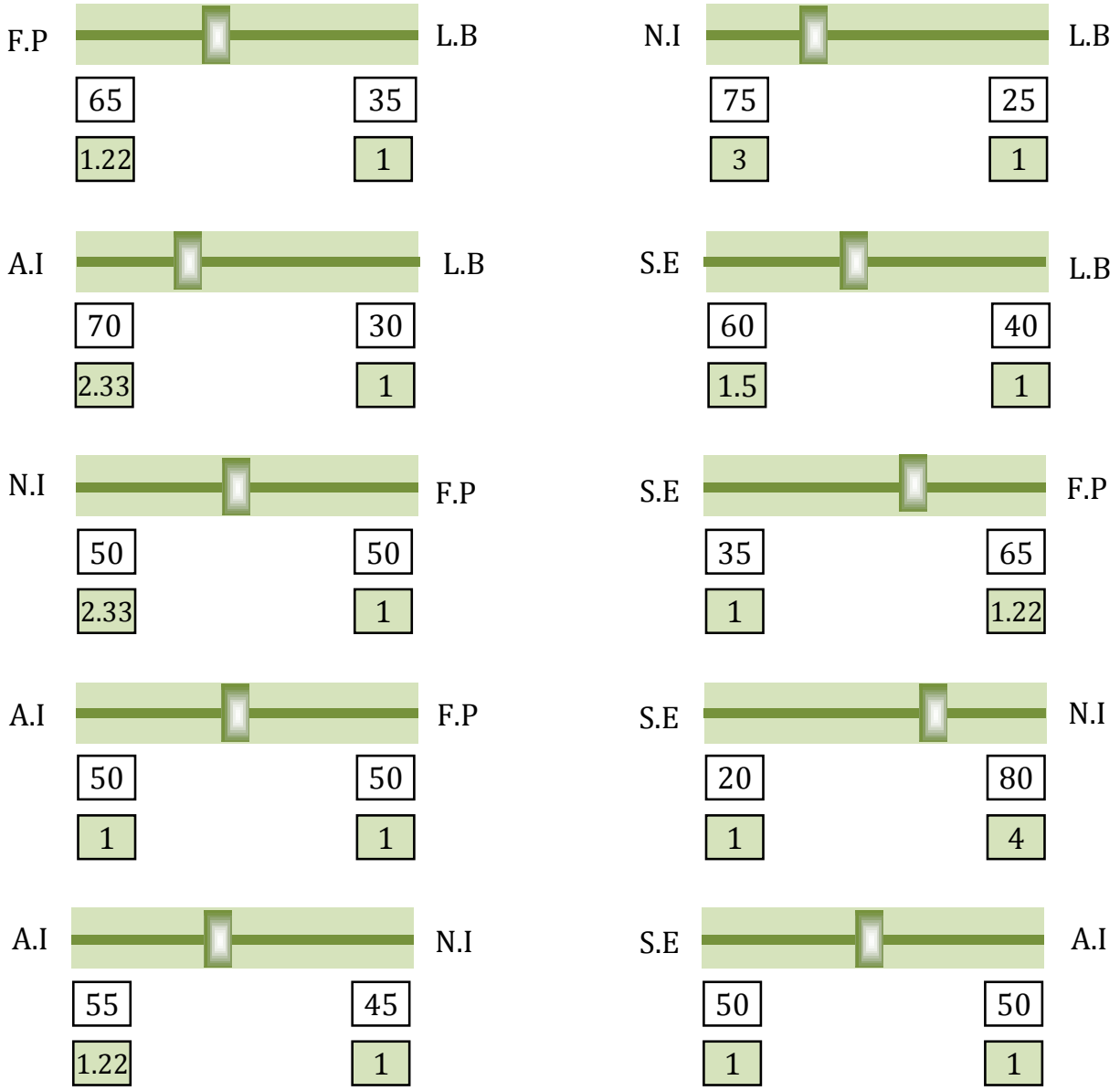

Figure 7.12 Judgment Quantification Instrument (10 Pairwise Comparisons) for Comparing the Five Siting Technologies with Respect to S1: Public Acceptance 
Table 7.6 The Base Model Relative Values

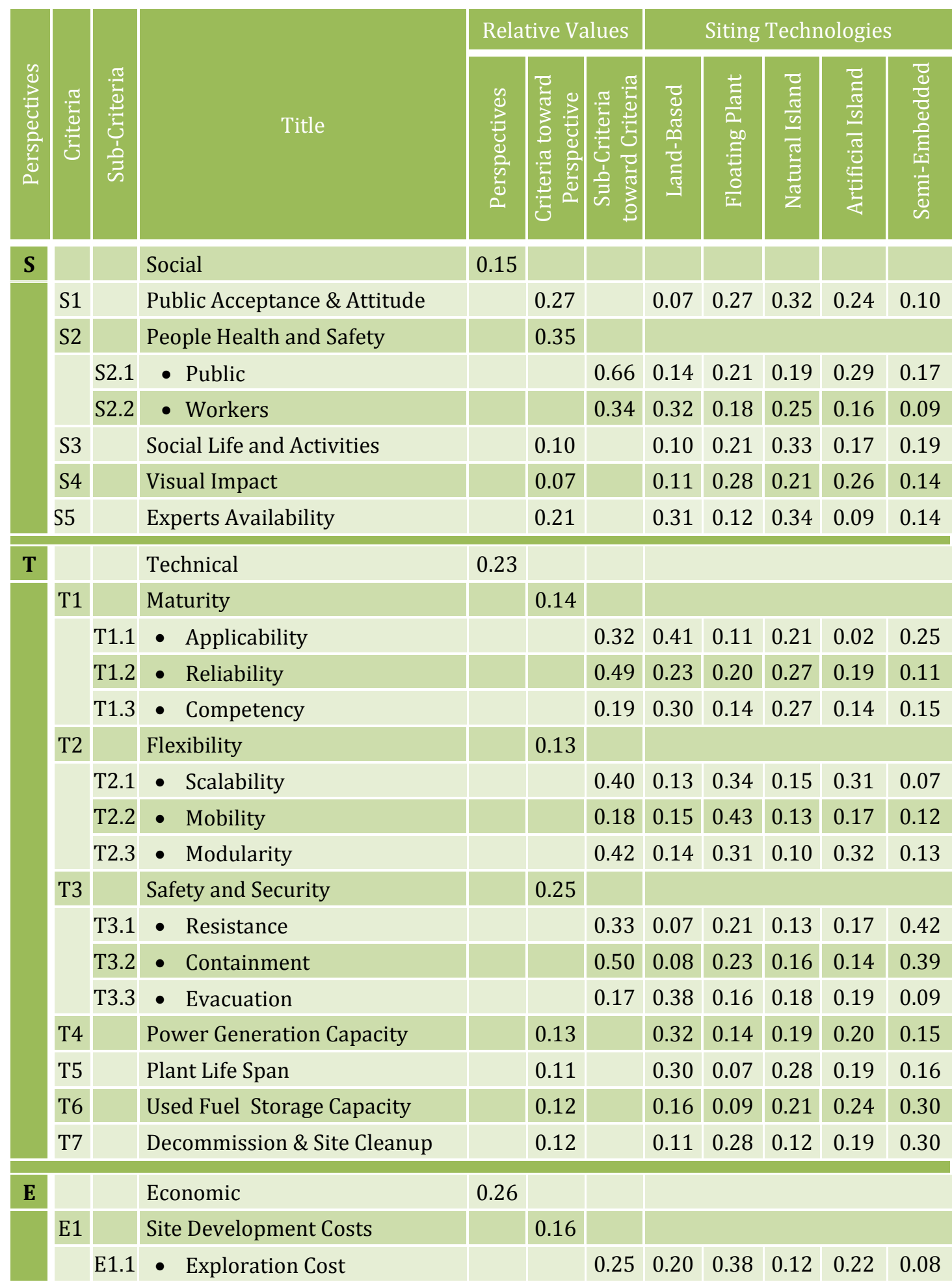




\begin{tabular}{|c|c|c|c|c|c|c|c|c|c|c|c|}
\hline \multirow[b]{2}{*}{ 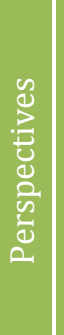 } & \multirow[b]{2}{*}{ } & \multirow[b]{2}{*}{ 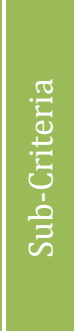 } & \multirow[b]{2}{*}{ Title } & \multicolumn{3}{|c|}{ Relative Values } & \multicolumn{5}{|c|}{ Siting Technologies } \\
\hline & & & & 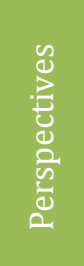 & 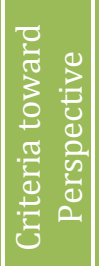 & 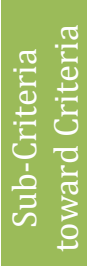 & 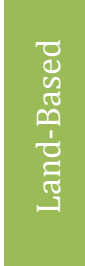 & 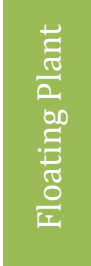 & 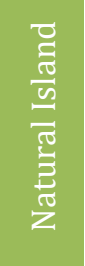 & 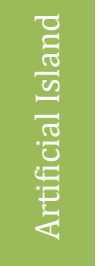 & 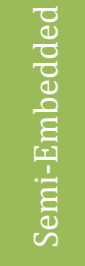 \\
\hline & & E1.2 & - Acquisition Cost & & & 0.34 & 0.07 & 0.41 & 0.19 & 0.21 & 0.12 \\
\hline & & E1.3 & - Preparation Cost & & & 0.41 & 0.16 & 0.59 & 0.07 & 0.16 & 0.02 \\
\hline & E2 & & Plant Development Costs & & 0.23 & & & & & & \\
\hline & & E2.2 & - Construction \& Inst. & & & 0.47 & 0.35 & 0.19 & 0.28 & 0.10 & 0.08 \\
\hline & & E2.3 & - Operation \& Maintenance & & & 0.32 & 0.30 & 0.21 & 0.19 & 0.22 & 0.08 \\
\hline & & E2.4 & - Decommissioning Cost & & & 0.21 & 0.16 & 0.11 & 0.27 & 0.08 & 0.38 \\
\hline & E3 & & Plant Supplementary Sys. Cost & & 0.16 & & & & & & \\
\hline & & E3.1 & - Water Delivery System & & & 0.22 & 0.10 & 0.32 & 0.18 & 0.34 & 0.06 \\
\hline & & E3.2 & - Grid Connection System & & & 0.18 & 0.37 & 0.10 & 0.14 & 0.11 & 0.28 \\
\hline & & E3.3 & - Ventilation System & & & 0.16 & 0.15 & 0.24 & 0.25 & 0.26 & 0.10 \\
\hline & & E3.4 & - Protection \& Isolation Sys. & & & 0.27 & 0.18 & 0.09 & 0.29 & 0.11 & 0.33 \\
\hline & & E3.5 & - Transportation System & & & 0.17 & 0.43 & 0.08 & 0.11 & 0.13 & 0.25 \\
\hline & E4 & & Technology Outsourcing Cost & & 0.14 & & 0.35 & 0.07 & 0.31 & 0.09 & 0.18 \\
\hline & E5 & & Return on Investment & & 0.31 & & 0.31 & 0.09 & 0.29 & 0.10 & 0.21 \\
\hline $\mathbf{N}$ & & & Environmental & 0.18 & & & & & & & \\
\hline & N1 & & Site Preparation Impact & & 0.16 & & 0.08 & 0.32 & 0.29 & 0.20 & 0.11 \\
\hline & N2 & & Construction-Related Impacts & & 0.20 & & 0.25 & 0.27 & 0.24 & 0.16 & 0.08 \\
\hline & N3 & & Operation-Related Impacts & & 0.27 & & 0.13 & 0.29 & 0.23 & 0.26 & 0.09 \\
\hline & N4 & & Land Availability \& Utilization & & 0.17 & & 0.07 & 0.31 & 0.12 & 0.20 & 0.30 \\
\hline & N5 & & Site Recovery & & 0.20 & & 0.10 & 0.30 & 0.15 & 0.16 & 0.29 \\
\hline $\mathbf{P}$ & & & Political & 0.18 & & & & & & & \\
\hline & P1 & & Government Perception & & 0.15 & & 0.16 & 0.12 & 0.30 & 0.14 & 0.28 \\
\hline & P2 & & Government Support & & 0.25 & & 0.06 & 0.18 & 0.29 & 0.17 & 0.30 \\
\hline & P3 & & Political Side of Tech. Transfer & & 0.12 & & 0.26 & 0.19 & 0.21 & 0.17 & 0.17 \\
\hline & P4 & & Laws \& Agreements & & 0.20 & & 0.28 & 0.16 & 0.14 & 0.17 & 0.25 \\
\hline & P5 & & Rules/Regulations Availability & & 0.28 & & 0.34 & 0.07 & 0.32 & 0.15 & 0.12 \\
\hline
\end{tabular}


The following examples demonstrate the calculations of the Technology Value (TV) of Land-Based siting technology under the 6 social criteria and subcriteria:

(S1) L.B's relative value with respect to S1 Criterion (0.07) x S1 Criterion's realtive value with respect to the Social perspective (0.27) $x$ Social perspective's realtive value with respect to the Objective $(0.15)=>(0.07) \mathrm{x}$ $(0.27) \times(0.15)=0.002835$

(S2.1) L.B's relative value with respect to the S2.1 Sub-Criterion (0.14) x S2.1 SubCriterion's relative value with respect to crietrion S2 (0.66) x S2 Criterion's realtive value with respect to the Social perspective $(0.35) \times$ Social perspective's realtive value with respect to the Objective (0.15) $=>(0.14) \times(0.66) \times(0.35) \times(0.15)=0.004851$

(S2.2) L.B's relative value with respect to the S2.2 Sub-Criterion (0.32) x S2.2 SubCriterion's relative value with respect to crietrion S2 (0.34) x S2 Criterion's realtive vaue with respect to the Social perspective (0.35) x Social perspective's realtive value with respect to the Objective (0.15) $=>(0.32) \times(0.34) \times(0.35) \times(0.15)=0.005712$

(S3) L.B's relative value with respect to S3 Criterion (0.10) x S3 Criterion's realtive vaue with respect to the Social perspective $(0.10) \times$ Social perspective's realtive value with respect to the Objective $(0.15)=>$ $(0.10) \times(0.10) \times(0.15)=0.00150$

(S4) L.B's relative value with respect to S4 Criterion (0.11) x S4 Criterion's realtive value with respect to the Social perspective (0.07) $\mathrm{x}$ Social perspective's realtive value with respect to the Objective $(0.15) \Rightarrow$ $(0.11) \times(0.07) \times(0.15)=0.001155$ 
(S5) L.B's relative value with respect to S5 Criterion (0.31) x S5 Criterion's realtive value with respect to the Social perspective (0.21) x Social perspective's realtive value with respect to the Objective $(0.15)=>(0.31) \mathrm{x}$ $(0.21) \times(0.15)=0.009765$

L.Bs' TV(Social) $=\mathrm{S} 1+\mathrm{S} 2 \cdot 1+\mathrm{S} 2 \cdot 2+\mathrm{S} 3+\mathrm{S} 4+\mathrm{S} 5=$ $=0.00284+0.00485+0.00571+0.00150+0.00116+0.00977=0.02583$

Table 7.7 shows the results of calcualting the TVs of the 5 sitign technologies under the social criteria and sub-criteria. Table 7.8 shows the results of calcualting the TVs of the 5 siting technologies under the 5-STEEP prespectives' criteira and sub-criteira.

Table 7.7 The Results of Evaluating the Five Siting Technologies under the Social Perspective

\begin{tabular}{|c|c|c|c|c|c|c|c|c|c|c|c|}
\hline \multirow[b]{2}{*}{ 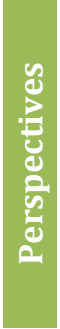 } & \multirow[b]{2}{*}{ 窇 } & \multirow[b]{2}{*}{ 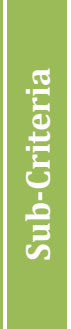 } & \multirow[b]{2}{*}{ Title } & \multicolumn{3}{|c|}{ Relative Values } & \multicolumn{5}{|c|}{ Siting Technologies } \\
\hline & & & & 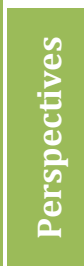 & 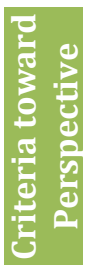 & 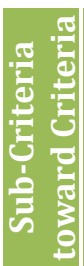 & 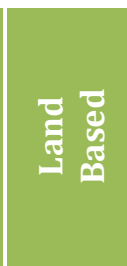 & 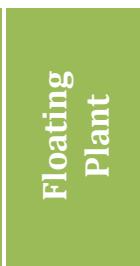 & 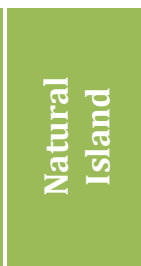 & 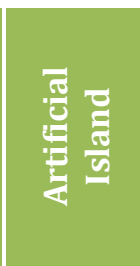 & 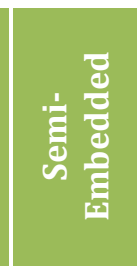 \\
\hline $\mathrm{S}$ & & & Social & 0.15 & & & & & & & \\
\hline & S1 & & Public Acceptance & & 0.27 & & 0.00284 & 0.01094 & 0.01296 & 0.00972 & 0.00405 \\
\hline & S2 & & People Health \& Safety & & 0.35 & & & & & & \\
\hline & & S2.1 & - Public & & & 0.66 & 0.00485 & 0.00728 & 0.00658 & 0.01005 & 0.00589 \\
\hline & & S2.2 & - Workers & & & 0.34 & 0.00571 & 0.00321 & 0.00453 & 0.00285 & 0.00162 \\
\hline & S3 & & Social Life \& Activities & & 0.10 & & 0.00150 & 0.00315 & 0.00495 & 0.00255 & 0.00286 \\
\hline & S4 & & Visual Impact & & 0.07 & & 0.00116 & 0.00294 & 0.00221 & 0.00273 & 0.00147 \\
\hline & S5 & & Experts Availability & & 0.21 & & 0.00977 & 0.00378 & 0.01071 & 0.00284 & 0.00438 \\
\hline & & & Total & & 1.00 & 1.00 & 0.02583 & 0.03129 & 0.04194 & 0.03074 & 0.02026 \\
\hline
\end{tabular}


Table 7.8 The Results of Evaluating the Five Siting Technologies under the 5-STEEP Perspectives' Criteria and Sub-Criteria

\begin{tabular}{|c|c|c|c|c|c|c|c|}
\hline \multirow[b]{2}{*}{ हे } & \multirow[b]{2}{*}{ Perspective } & \multirow[b]{2}{*}{$\begin{array}{l}\text { Relative } \\
\text { Value }\end{array}$} & \multicolumn{5}{|c|}{ Siting Technologies } \\
\hline & & & 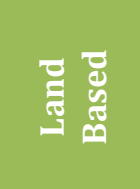 & 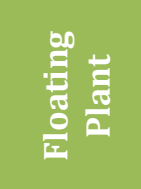 & స్ & 武 & 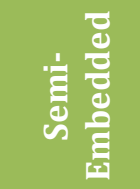 \\
\hline$S$ & Social & 0.15 & 0.02583 & 0.03129 & 0.04194 & 0.03074 & 0.02026 \\
\hline $\mathrm{T}$ & Technical & 0.23 & 0.04578 & 0.04247 & 0.04248 & 0.04468 & 0.05151 \\
\hline E & Economic & 0.26 & 0.07178 & 0.04511 & 0.06202 & 0.03413 & 0.04253 \\
\hline E & Environmental & 0.18 & 0.02357 & 0.04424 & 0.03719 & 0.03591 & 0.03001 \\
\hline $\mathrm{P}$ & Political & 0.18 & 0.04002 & 0.03464 & 0.04684 & 0.02876 & 0.03973 \\
\hline & Total & 1.00 & 0.20698 & 0.19775 & 0.23047 & 0.17422 & 0.18404 \\
\hline & Technology Value & & 0.21 & 0.20 & 0.23 & 0.17 & 0.18 \\
\hline & Technology Rank & & 2 & 3 & 1 & 5 & 4 \\
\hline
\end{tabular}

According to the results of implementing the base model, the best siting technology is the Natural Island with a technology value of 0.23 . Next to best is Land-Based (0.21) and then Floating Plant (0.20). The Semi-Embedded plant (0.18) and Artificial Island (0.17) are in the fourth and fifth places, respectively.

Although the Natural Island (NI) siting technology is similar to the wellknown Land-Based technology in most aspects, the natural island was preferred to the Land-Based because of its better characteristics in the social (0.042), environmental (0.037), and political (0.047) dimensions, as shown in Table 7.8. Land-Based came in second place over the other three siting technologies because of its high contributions to the economic and technical perspectives, both of which 
were given high relative values by the experts ( 0.26 and 0.23 , respectively), as shown in Table 7.3 and Figure 7.2.

\subsubsection{Base Model Testing by Changing the Priorities of the Perspectives}

Based on the experts' pairwise comparisons, the relative priority value of each of the 5-TEEP perspectives was calculated. The sum of the perspectives' priority values equals $100 \%$. A perspective's priority value, obtained from the experts' quantified judgments, represents that perspective's impact on the selection. For example, the economic perspective's value of 0.26 means that the impact of the economic perspective on the final decision is $26 \%$. Technical, environmental, political, and social perspectives have $23 \%, 18 \%, 18 \%$, and $15 \%$ impacts on the decision, respectively. Based on these priority values, the Natural Island ranked as the best siting technology among the five technologies.

The model was tested to see whether the best siting technology would be different in case of changes in the perspective priorities. This was accomplished by assigning a value of 0.96 to one of the perspectives to define it as the "dominant

perspective" and 0.01 to each of the other four perspectives. The dominant perspective was then alternated. The results for each dominant perspective are shown in Tables 7.9 through 7.13 and summarized in Figure 7.13. 
Table 7.9 Impacts of Social Perspective Domination on Selection of Best Siting Technology

\begin{tabular}{|c|c|c|c|c|}
\hline Social & Technical & Economic & Environmental & Political \\
\hline $\mathbf{0 . 9 6}$ & 0.01 & 0.01 & 0.01 & 0.01 \\
\hline
\end{tabular}

\begin{tabular}{|l|l|l} 
Siting Technology & Technology Value & Technology Rank \\
\hline
\end{tabular}

\begin{tabular}{|c|c|c|}
\hline Land Based & 0.17 & 4 \\
\hline Floating Plant & 0.21 & 2 \\
\hline Natural Island & $\mathbf{0 . 2 8}$ & $\mathbf{1}$ \\
\hline Artificial Island & 0.20 & 3 \\
\hline Semi-Embedded & 0.14 & 5 \\
\hline
\end{tabular}

Table 7.10 Impacts of Technical Perspective Domination on Selection of Best Siting Technology

\begin{tabular}{|c|c|c|c|c|}
\hline Social & Technical & Economic & Environmental & Political \\
\hline 0.01 & $\mathbf{0 . 9 6}$ & 0.01 & 0.01 & 0.01 \\
\hline
\end{tabular}

\begin{tabular}{|l|l|l|}
\hline Siting Technology & Technology Value & Technology Rank
\end{tabular}

\begin{tabular}{|c|c|c|}
\hline Land Based & 0.20 & 2 \\
\hline Floating Plant & 0.19 & 3 \\
\hline Natural Island & 0.19 & 3 \\
\hline Artificial Island & 0.19 & 3 \\
\hline Semi-Embedded & $\mathbf{0 . 2 3}$ & $\mathbf{1}$ \\
\hline
\end{tabular}

Table 7.11 Impacts of Economic Perspective Domination on Selection of Best Siting Technology

\begin{tabular}{|c|c|c|c|c|}
\hline Social & Technical & Economic & Environmental & Political \\
\hline 0.01 & 0.01 & $\mathbf{0 . 9 6}$ & 0.01 & 0.01 \\
\hline
\end{tabular}

\begin{tabular}{|c|c|c|}
\hline Siting Technology & Technology Value & Technology Rank \\
\hline Land Based & $\mathbf{0 . 2 7}$ & $\mathbf{1}$ \\
\hline Floating Plant & 0.18 & 3 \\
\hline Natural Island & 0.24 & 2 \\
\hline Artificial Island & 0.14 & 5 \\
\hline Semi-Embedded & 0.17 & 4 \\
\hline
\end{tabular}


Table 7.12 Impacts of Environmental Perspective Domination on Selection of Best Siting Technology

\begin{tabular}{|c|c|c|c|c|}
\hline Social & Technical & Economic & Environmental & Political \\
\hline 0.01 & 0.01 & 0.01 & $\mathbf{0 . 9 6}$ & 0.01 \\
\hline
\end{tabular}

\begin{tabular}{|l|l|l} 
Siting Technology & Technology Value & Technology Rank
\end{tabular}

\begin{tabular}{|c|c|c|}
\hline Land Based & 0.13 & 5 \\
\hline Floating Plant & $\mathbf{0 . 2 9}$ & $\mathbf{1}$ \\
\hline Natural Island & 0.21 & 2 \\
\hline Artificial Island & 0.20 & 3 \\
\hline Semi-Embedded & 0.17 & 4 \\
\hline
\end{tabular}

Table 7.13 Impacts of Political Perspective Domination on Selection of Best Siting Technology

\begin{tabular}{|c|c|c|c|c|}
\hline Social & Technical & Economic & Environmental & Political \\
\hline 0.01 & 0.01 & 0.01 & 0.01 & $\mathbf{0 . 9 6}$ \\
\hline
\end{tabular}

\begin{tabular}{|l|l|l}
\hline Siting Technology & Technology Value & Technology Rank \\
\hline
\end{tabular}

\begin{tabular}{|c|c|c|}
\hline Land Based & 0.23 & 2 \\
\hline Floating Plant & 0.14 & 5 \\
\hline Natural Island & $\mathbf{0 . 2 6}$ & $\mathbf{1}$ \\
\hline Artificial Island & 0.16 & 4 \\
\hline Semi-Embedded & 0.23 & 2 \\
\hline
\end{tabular}

Natural Island was in the first place in the base model, and it remained in first place under the dominant social and political perspectives and was the second best siting technology under the dominant economic and environmental perspectives. The domination of the technical perspective affected the decision by moving the fourth place technology of the base model, the semi-embedded plant, to first place. The domination of the economic and environmental perspectives moved the Land-Based technology and Floating Plant technology to first place, respectively. 
Artificial Island was always in third, fourth, or fifth place, indicating that it is the least preferred siting technology.

The above test shows that decisions about the best siting technology are influenced by significant changes in the priorities of the perspectives. The domination of one perspective over the others can change the decision completely, as shown in Table 7.10 where the fourth-ranked technology (Semi-Embedded) in the base model became the highest-ranked technology when the decision was made solely on a technical basis.

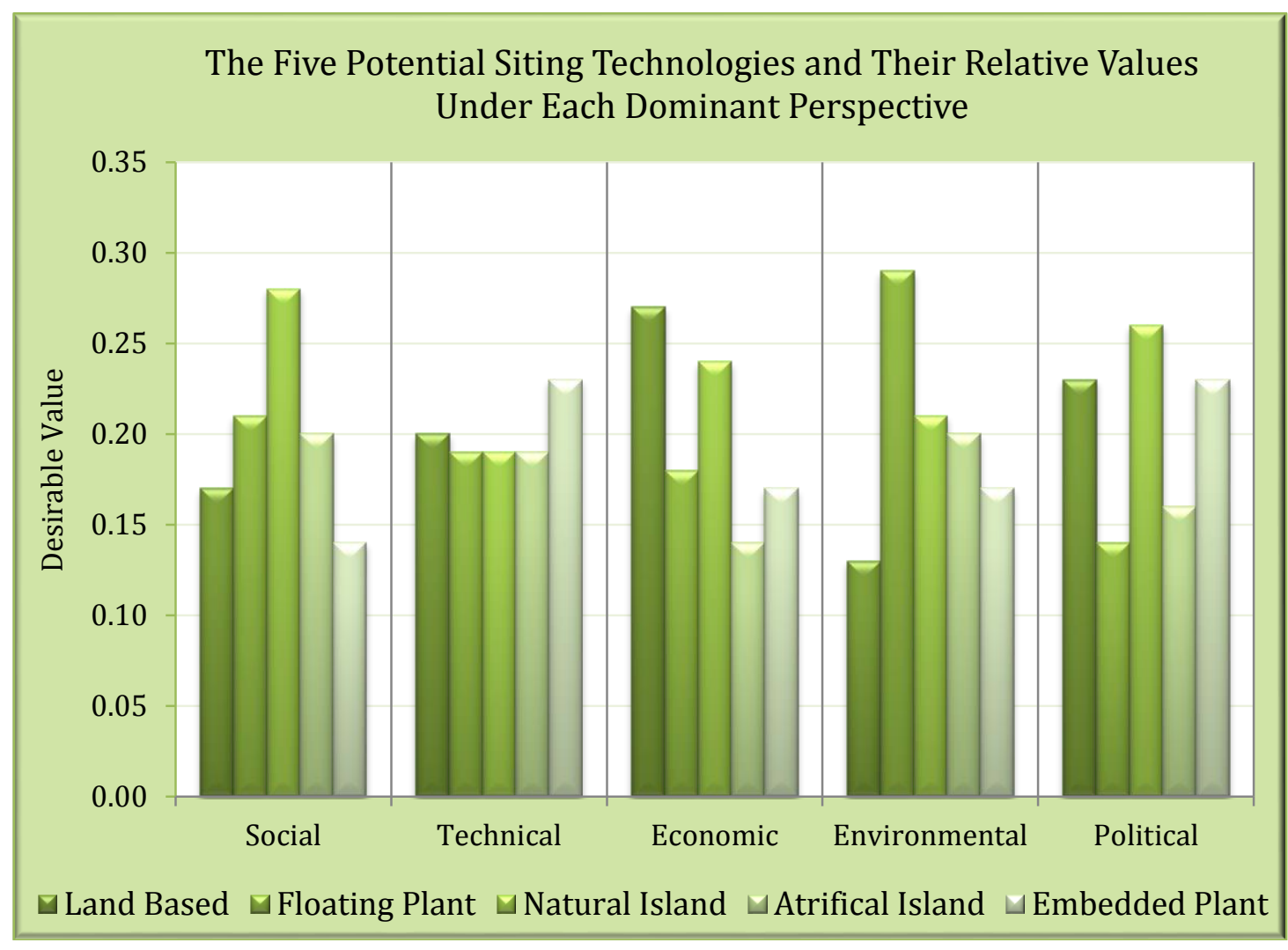

Figure 7.13 Siting Technologies' Relative Values under each Dominant Perspective 


\section{CHAPTER 8: GENERALIZATION OF THE DECISION MODEL}

Model generalization is an important step performed to accomplish the goal of this research: building a comprehensive decision model for evaluating nuclear power plant alternative siting technologies. Model generalization is advanced development of the base model that was built, implemented, and tested to select the best siting technology out of five potential technologies. The general model is a decision model used to evaluate any other, either current or future, siting technologies to choose the best among them.

\subsection{Development of Performance Measures}

To generalize the decision model for evaluating NPP siting technologies, the model's criteria and sub-criteria must be quantified in common or standard scales. A standard scale should be designed to accommodate the highest, lowest, and all possible values in between that measure a criterion's different performance levels. Performance levels are metrics and their graphical representations are desirability curves. The desirability curve concept is explained in Chapter 4.

\subsubsection{Defining Metrics for the Criteria and Sub-Criteria}

Metrics are parameters or factors of quantitative or qualitative assessment used to measure, compare, or differentiate between two things or among several things in terms of performance, quality, importance, or any other scale of 
measurement. Metrics are useful for evaluating elements with many variations but that use the same reference..

A model's criteria and sub-criteria involve two types: quantitative and qualitative. A qualitative model's criteria or sub-criteria are difficult to evaluate numerically, so a measure of the non-numerical scale was used. An ordinal scale such as very low, low, medium, high, and very high was used to describe the level of performance, acceptance, importance, or any other scale of measurement for each of these qualitative elements. The quantitative model's criteria and sub-criteria were measured by using numerical values and appropriate units. The numerical values used were the most updated values available in the literature.

To evaluate the potential siting technologies with respect to the identified criteria and sub-criteria by using the desirability values, it was necessary to define common performance measures (metrics) for each criterion (or sub-criterion) immediately above the technologies in the model, as shown in Table 8.1. 
Table 8.1 Description of Criteria, Sub-Criteria, and Metrics

\begin{tabular}{|c|c|c|c|}
\hline Perspective & Criterion & Description & Metrics \\
\hline \multicolumn{4}{|l|}{ Social } \\
\hline S1 & Public Acceptance & $\begin{array}{l}\text { Level of public readiness to } \\
\text { accept a nuclear power plant } \\
\text { based on its siting } \\
\text { technology. }\end{array}$ & $\begin{array}{l}\text { Public acceptance (PA) will } \\
\text { be measured as: } \\
\text { - no acceptance } \\
\text { - neutral acceptance } \\
\text { - low acceptance } \\
\text { - average acceptance } \\
\text { - high acceptance }\end{array}$ \\
\hline S2 & $\begin{array}{l}\text { Impact on People's } \\
\text { Health and Safety }\end{array}$ & \multicolumn{2}{|c|}{$\begin{array}{l}\text { Negative impacts of NPP on people's health and safety } \\
\text { during the construction and operation phases }\end{array}$} \\
\hline S2.1 & Public & $\begin{array}{c}\text { Inhabitants living outside/ } \\
\text { within permissible } \\
\text { boundaries }\end{array}$ & $\begin{array}{l}\text { Negative impact on the } \\
\text { public health and safety } \\
\text { (PH) will be measured as: } \\
\text { - high negative impact } \\
\text { - average negative impact } \\
\text { - low negative impact } \\
\text { - trivial negative impact } \\
\text { - no negative impact }\end{array}$ \\
\hline S2.2 & Workers & $\begin{array}{l}\text { People involve in } \\
\text { constructing and operating } \\
\text { the plant }\end{array}$ & $\begin{array}{l}\text { Negative impact on the } \\
\text { workers health and safety } \\
(\mathrm{WH}) \text { will be measured as: } \\
\text { - high negative impact } \\
\text { - average negative impact } \\
\text { - low negative impact } \\
\text { - trivial negative impact } \\
\text { - no negative impact }\end{array}$ \\
\hline S3 & $\begin{array}{l}\text { Social Life } \\
\text { \& Activities }\end{array}$ & $\begin{array}{l}\text { Impacts of a siting technology } \\
\text { during site preparation, plant } \\
\text { construction, or operation on } \\
\text { public social life and daily } \\
\text { activities. }\end{array}$ & $\begin{array}{l}\text { Negative impact on social } \\
\text { life and activities (SL) will } \\
\text { be measured as : } \\
\text { - high negative impact } \\
\text { - average negative impact } \\
\text { - low negative impact } \\
\text { - very low negative impact } \\
\text { - no negative impact }\end{array}$ \\
\hline
\end{tabular}




\begin{tabular}{|c|c|c|c|}
\hline Perspective & Criterion & Description & Metrics \\
\hline S4 & $\begin{array}{l}\text { Visual } \\
\text { Impact }\end{array}$ & $\begin{array}{l}\text { Physical appearance of a } \\
\text { plant is a source of fear or } \\
\text { rejection. }\end{array}$ & $\begin{array}{l}\text { Visual impact (VI) of a siting } \\
\text { technology will be } \\
\text { measured as: } \\
\text { - highly disturbing } \\
\text { - moderately disturbing } \\
\text { - slightly disturbing } \\
\text { - barely disturbing } \\
\text { - not disturbing }\end{array}$ \\
\hline S5 & $\begin{array}{c}\text { Experts } \\
\text { Availability }\end{array}$ & $\begin{array}{l}\text { Skillful people required to } \\
\text { work for designing, } \\
\text { implementing, and } \\
\text { constructing a specific siting } \\
\text { technology }\end{array}$ & $\begin{array}{l}\text { Experts availability (EA) } \\
\text { will be measured as: } \\
\text { - no availability } \\
\text { - very low availability } \\
\text { - limited availability } \\
\text { - average availability } \\
\text { - high availability }\end{array}$ \\
\hline \multicolumn{4}{|l|}{ Technical } \\
\hline $\mathrm{T} 1$ & Maturity & \multicolumn{2}{|c|}{$\begin{array}{l}\text { Maturity defines the degree of readiness of a technology } \\
\text { for implementation. Maturity level of a nuclear power } \\
\text { plant siting technology would be addressed by three key } \\
\text { attributes: (1) Applicability, (2) Reliability, and (3) } \\
\text { Competency }\end{array}$} \\
\hline $\mathrm{T} 1.1$ & Applicability & $\begin{array}{l}\text { Number of times a siting } \\
\text { technology had been } \\
\text { implemented commercially } \\
\text { or experimentally }\end{array}$ & $\begin{array}{l}\text { Applicability }(\mathrm{AP}) \text { will be } \\
\text { measured as: } \\
\text { - none }(\mathrm{AP}=0) \\
\text { - once }(\mathrm{AP}=1) \\
\text { - twice }(\mathrm{AP}=2) \\
\text { - few }(2<\mathrm{AP} \leq 5) \\
\text { - several }(5<\mathrm{AP} \leq 10) \\
\text { - many }(\mathrm{AP}>10)\end{array}$ \\
\hline $\mathrm{T} 1.2$ & Reliability & $\begin{array}{l}\text { Level of trustworthiness or } \\
\text { dependability a siting } \\
\text { technology has or it could be } \\
\text { rated at }\end{array}$ & $\begin{array}{l}\text { Reliability(RE)will be } \\
\text { measured as: } \\
\text { - } \mathrm{RE}=0 \% \\
\text { - } 0<\mathrm{RE} \leq 20 \% \\
\text { - } 20<\mathrm{RE} \leq 40 \% \\
\text { - } 40<\mathrm{RE} \leq 60 \% \\
\text { - } 60<\mathrm{RE} \leq 80 \% \\
\text { - } 80<\mathrm{RE} \leq 100 \%\end{array}$ \\
\hline
\end{tabular}




\begin{tabular}{|c|c|c|c|}
\hline Perspective & Criterion & Description & Metrics \\
\hline $\mathrm{T} 1.3$ & Competency & $\begin{array}{l}\text { Explains how a siting } \\
\text { technology is efficient or fit to } \\
\text { be used for a certain project. }\end{array}$ & $\begin{array}{l}\text { Competency(CO)will be } \\
\text { measured as: } \\
\text { - } \mathrm{CO}=0 \% \\
\text { - } 0<\mathrm{CO} \leq 20 \% \\
\text { - } 20<\mathrm{CO} \leq 40 \% \\
\text { - } 40<\mathrm{CO} \leq 60 \% \\
\text { - } 60<\mathrm{CO} \leq 80 \% \\
\text { - } 80<\mathrm{CO} \leq 100 \%\end{array}$ \\
\hline $\mathrm{T} 2$ & Flexibility & $\begin{array}{l}\text { The ability of a siting techno } \\
\text { internal or external changes o } \\
\text { function, in timely and cost-e } \\
\text { a siting technology, according } \\
\text { dimensions: (1) Scalability, } \\
\text { Modularity }\end{array}$ & $\begin{array}{l}\text { logy to respond to potential } \\
\text { r needs that affect its current } \\
\text { ffective manner.Flexibility of } \\
\text { ly, could be defined in three } \\
\text { (2) Mobility, and }\end{array}$ \\
\hline $\mathrm{T} 2.1$ & Scalability & $\begin{array}{l}\text { The ability of a siting } \\
\text { technology to expand in size } \\
\text { or space in order to } \\
\text { accommodate more } \\
\text { plants/reactors or auxiliary } \\
\text { systems for future plans }\end{array}$ & $\begin{array}{l}\text { Scalability (SC) will be } \\
\text { measured as: } \\
\text { - unscalable } \\
\text { - possible } \\
\text { - totally scalable }\end{array}$ \\
\hline $\mathrm{T} 2.2$ & Mobility & $\begin{array}{l}\text { The ability of a siting } \\
\text { technology to be relocated at } \\
\text { different sites in order to } \\
\text { supply the power for remote } \\
\text { areas or in case of } \\
\text { emergencies; or to be sited at } \\
\text { totally different location }\end{array}$ & $\begin{array}{l}\text { Mobility (MB) will be } \\
\text { measured as: } \\
\text { - fixed } \\
\text { - possible } \\
\text { - totally mobile }\end{array}$ \\
\hline $\mathrm{T} 2.3$ & Modularity & $\begin{array}{l}\text { The possibility of a plant to } \\
\text { be built on smaller standard } \\
\text { units (modules) to ease or } \\
\text { standardize the construction } \\
\text { and installation processes }\end{array}$ & $\begin{array}{l}\text { Modularity(MD)will be } \\
\text { measured as: } \\
\text { - nonstandard } \\
\text { - possible } \\
\text { - standard }\end{array}$ \\
\hline T3 & $\begin{array}{l}\text { Siting Technology } \\
\text { Safety \& Security }\end{array}$ & \multicolumn{2}{|c|}{$\begin{array}{l}\text { The potential of a siting technology to limit any external } \\
\text { attacks, avoid any internal accidents, resist severe seismic } \\
\text { activities, prevent any leakage of radioactive materials, } \\
\text { and provide high level of protection to people. Safety and } \\
\text { security of a siting technology could be explained in three } \\
\text { aspects: (1) Resistance } \\
\begin{array}{llll}\text { Evacuation } & \text { (2) Containment, and }\end{array}\end{array}$} \\
\hline
\end{tabular}




\begin{tabular}{|c|c|c|c|}
\hline Perspective & Criterion & Description & Metrics \\
\hline T3.1 & Resistance & $\begin{array}{l}\text { The ability of a siting } \\
\text { technology to resist any } \\
\text { external phenomenon (e.g., } \\
\text { storms, earthquake, floods, } \\
\text { attacks, etc. }\end{array}$ & $\begin{array}{l}\text { Siting resistance (SR) will } \\
\text { be measured as: } \\
\text { - no resistance } \\
\text { - very low resistance } \\
\text { - low resistance } \\
\text { - medium resistance } \\
\text { - high resistance } \\
\text { - very high resistance }\end{array}$ \\
\hline T3.2 & Containment & $\begin{array}{l}\text { Level of containing or } \\
\text { decreasing the impacts of an } \\
\text { internal malfunction or } \\
\text { external radioactive leakage }\end{array}$ & $\begin{array}{l}\text { Containment level (CL) will } \\
\text { be measured as: } \\
\text { - no containment } \\
\text { - very low containment } \\
\text { - low containment } \\
\text { - medium containment } \\
\text { - high containment } \\
\text { - very high containment }\end{array}$ \\
\hline T3.3 & Evacuation & $\begin{array}{l}\text { The capability of a siting } \\
\text { technology to transfer } \\
\text { workers or people to a safe } \\
\text { and secure place }\end{array}$ & $\begin{array}{l}\text { Evacuation level (EL) will } \\
\text { be measured as: } \\
\text { - zero evacuation level } \\
\text { - very low evacuation level } \\
\text { - low evacuation level } \\
\text { - medium evacuation level } \\
\text { - high evacuation level } \\
\text { - very high evacuation level }\end{array}$ \\
\hline T4 & $\begin{array}{l}\text { Power Generation } \\
\text { Capacity }\end{array}$ & $\begin{array}{l}\text { Nuclear reactor power } \\
\text { generation capacity ranging } \\
\text { from several megawatts to } \\
\text { few thousand megawatts. }\end{array}$ & $\begin{array}{l}\text { Plant power generation } \\
\text { (PG) capacity will be } \\
\text { measured as [159]: } \\
\text { - } \mathrm{PG}<1 \mathrm{MWe} \\
\text { - } 1<\mathrm{PG} \leq 500 \mathrm{MWe} \\
\text { - } 500<\mathrm{PG} \leq 1000 \mathrm{MWe} \\
\text { - } 1000<\mathrm{PG} \leq 1500 \mathrm{MWe} \\
\text { - } 1500<\mathrm{PG} \leq 2000 \mathrm{MWe} \\
\text { - } 2000<\mathrm{PG} \leq 2500 \mathrm{MWe} \\
\text { - } \mathrm{PG}>2500 \mathrm{MWe}\end{array}$ \\
\hline
\end{tabular}




\begin{tabular}{|c|c|c|c|}
\hline Perspective & Criterion & Description & Metrics \\
\hline T5 & Plant Life Span & $\begin{array}{l}\text { Some of the identified } \\
\text { technologies have the } \\
\text { potential to exceed their life } \\
\text { span while others might have } \\
\text { limited span life based on the } \\
\text { design, location, or } \\
\text { application }\end{array}$ & $\begin{array}{l}\text { The plant life span (LS) will } \\
\text { be measured as [160]: } \\
\text { - } \mathrm{LS}=0 \text { year } \\
\text { - } 0<\mathrm{LS} \leq 20 \text { years } \\
\text { - } 20<\mathrm{LS} \leq 40 \text { years } \\
\text { - } 40<\mathrm{LS} \leq 60 \text { years } \\
\text { - } 60<\mathrm{LS} \leq 80 \text { years } \\
\text { - } 80<\mathrm{LS} \leq 100 \text { years } \\
\text { - } \mathrm{LS}>100 \text { years }\end{array}$ \\
\hline T6 & $\begin{array}{l}\text { Used Fuel Storage } \\
\text { Capacity }\end{array}$ & $\begin{array}{l}\text { Plant's capacity to store large } \\
\text { quantities of radioactive } \\
\text { materials for a very long time }\end{array}$ & $\begin{array}{l}\text { Used fuel storage }(\mathrm{FS}) \\
\text { capacity will be measured } \\
\text { as [161]: } \\
\text { - } \mathrm{FS}=0 \text { metric tons } \\
\text { - } 1<\mathrm{FS} \leq 500 \mathrm{MT} \\
\text { - } 500<\mathrm{FS} \leq 1000 \mathrm{MT} \\
\text { - } 1000<\mathrm{FS} \leq 1500 \mathrm{MT} \\
\text { - } 1500<\mathrm{FS} \leq 2000 \mathrm{MT} \\
\text { - } 2000<\mathrm{FS} \leq 2500 \mathrm{MT} \\
\text { - FS }>2500 \text { metric tons }\end{array}$ \\
\hline $\mathrm{T7}$ & $\begin{array}{l}\text { Decommissioning \& } \\
\text { Site Cleanup }\end{array}$ & $\begin{array}{l}\text { Time required to cleanup } \\
\text { plant's site of residues after } \\
\text { plant's shutdown and } \\
\text { demolition. }\end{array}$ & $\begin{array}{l}\text { Decommissioning Time } \\
\text { (DT) can be measured as } \\
\text { [162]: } \\
\text { - } \text { DT }>50 \text { years } \\
\text { - } 40<\text { DT } \leq 50 \text { years } \\
\text { - } 30<\text { DT } \leq 40 \text { years } \\
\text { - } 20<\text { DT } \leq 30 \text { years } \\
\text { - } 10<\text { DT } \leq 20 \text { years } \\
-0<\text { DT } \leq 10 \text { years } \\
\text { - DT }=0 \text { year }\end{array}$ \\
\hline
\end{tabular}

\section{Economic}

Site Development Cost
Site development is an initial stage of setting up a nuclear power plant. In order to select a plant location as LandBased, underground, or offshore; three consecutive actions are needed at an early stage: (1) Exploration (2) Acquisition, and (3) Preparation. Site development cost is the costs of these actions. 


\begin{tabular}{|c|c|c|c|}
\hline Perspective & Criterion & Description & Metrics \\
\hline E1.1 & Exploration Cost & $\begin{array}{l}\text { To investigate site } \\
\text { characterization and pre- } \\
\text { operational data collection }\end{array}$ & $\begin{array}{l}\text { Site exploration cost (SE) } \\
\text { will measured as [163]: } \\
\text { - } \mathrm{SE}>\$ 10 \mathrm{M} \\
\text { - } \$ 8<\mathrm{SE} \leq \$ 10 \mathrm{M} \\
\text { - } \$ 6<\mathrm{SE} \leq \$ 8 \mathrm{M} \\
\text { - } \$ 4<\mathrm{SE} \leq \$ 6 \mathrm{M} \\
\text { - } \$ 2<\mathrm{SE} \leq \$ 4 \mathrm{M} \\
\text { - } \$ 0<\mathrm{SE} \leq \$ 2 \mathrm{M} \\
\text { - } \mathrm{SE}=\$ 0 \mathrm{M}\end{array}$ \\
\hline E1.2 & $\begin{array}{l}\text { Acquisition } \\
\text { (Hosting) Cost }\end{array}$ & $\begin{array}{l}\text { To obtain and control the site } \\
\text { for a certain period of time }\end{array}$ & $\begin{array}{l}\text { Site acquisition cost }(\mathrm{SA}) \\
\text { will be measured as }[164] \\
\text { - } \mathrm{SA}>\$ 25 \mathrm{M} \\
\text { - } \$ 20<\mathrm{SA} \leq \$ 25 \mathrm{M} \\
\text { - } \$ 15<\mathrm{SA} \leq \$ 20 \mathrm{M} \\
\text { - } \$ 10<\mathrm{SA} \leq \$ 15 \mathrm{M} \\
\text { - } \$ 5<\mathrm{SA} \leq \$ 10 \mathrm{M} \\
\text { - } \$ 0<\mathrm{SA} \leq \$ 5 \mathrm{M} \\
\text { - } \mathrm{SA}=\$ 0 \mathrm{M}\end{array}$ \\
\hline E1.3 & Preparation Cost & $\begin{array}{l}\text { To make the site suitable for } \\
\text { plant construction and } \\
\text { operation }\end{array}$ & $\begin{array}{l}\text { Site preparation (SP) cost } \\
\text { will be measured as [163]: } \\
\text { - } \mathrm{SP}>\$ 50 \mathrm{M} \\
\text { - } \$ 40<\mathrm{SP} \leq \$ 50 \mathrm{M} \\
\text { - } \$ 30<\mathrm{SP} \leq \$ 40 \mathrm{M} \\
\text { - } \$ 20<\mathrm{SP} \leq \$ 30 \mathrm{M} \\
\text { - } \$ 10<\mathrm{SP} \leq \$ 20 \mathrm{M} \\
\text { - } \$ 0<\mathrm{SP} \leq \$ 10 \mathrm{M} \\
\text { - } \mathrm{SP}=\$ 0 \mathrm{M}\end{array}$ \\
\hline E2 & $\begin{array}{l}\text { Plant Development } \\
\text { Cost }\end{array}$ & \multicolumn{2}{|c|}{$\begin{array}{l}\text { Costs of developing a nuclear power plant start with } \\
\text { engineering, procurement, construction cost follows with } \\
\text { operation and maintenance cost, and ends with } \\
\text { decommissioning and site cleanup cost. }\end{array}$} \\
\hline E2.1 & $\begin{array}{l}\text { Construction and } \\
\text { Installation Cost }\end{array}$ & $\begin{array}{l}\text { Cost of plant's engineering, } \\
\text { procurement, and } \\
\text { construction. }\end{array}$ & $\begin{array}{l}\text { (EPC) cost will be measured } \\
\text { as }[165 \& 166] \text { : } \\
\text { - } \mathrm{EPC}>\$ 10000 / \mathrm{KW} \\
\text { - } \$ 8000<\mathrm{EPC} \leq \$ 10000 / \mathrm{KW} \\
\text { - } \$ 6000<\mathrm{EPC} \leq \$ 8000 / \mathrm{KW} \\
\text { - } \$ 4000<\mathrm{EPC} \leq \$ 6000 / \mathrm{KW} \\
\text { - } \$ 2000<\mathrm{EPC} \leq \$ 4000 / \mathrm{KW} \\
\text { - } \$ 0<\mathrm{EPC} \leq \$ 2000 / \mathrm{KW} \\
\text { - } \mathrm{EPC}=\$ 0 / \mathrm{KW}\end{array}$ \\
\hline
\end{tabular}




\begin{tabular}{|c|c|c|c|}
\hline Perspective & Criterion & Description & Metrics \\
\hline E2.2 & $\begin{array}{c}\text { Operation \& } \\
\text { Maintenance Cost }\end{array}$ & $\begin{array}{l}\text { Cost of the plant's frequent } \\
\text { and continuous activities } \\
\text { such as operation, } \\
\text { maintenance, administration, } \\
\text { and support. }\end{array}$ & $\begin{array}{l}\text { The }(0 \& \mathrm{M}) \text { cost could be } \\
\text { measured as }[165 \& 166] \text { : } \\
\text { - } 0 \& \mathrm{M}>\$ 50 / \mathrm{MWh} \\
\text { - } \$ 40<0 \& \mathrm{M} \leq \$ 50 / \mathrm{MWh} \\
\text { - } \$ 30<0 \& \mathrm{M} \leq \$ 40 / \mathrm{MWh} \\
\text { - } \$ 20<0 \& \mathrm{M} \leq \$ 30 / \mathrm{MWh} \\
\text { - } \$ 10<0 \& \mathrm{M} \leq \$ 20 / \mathrm{MWh} \\
\text { - } \$ 0<0 \& \mathrm{M} \leq \$ 10 / \mathrm{MWh} \\
\text { - } 0 \& \mathrm{M}=\$ 0 / \mathrm{MWh}\end{array}$ \\
\hline E2.3 & $\begin{array}{l}\text { Decommissioning } \\
\text { Cost }\end{array}$ & $\begin{array}{l}\text { Cost of withdrawing the plant } \\
\text { from service and cleanup the } \\
\text { site. }\end{array}$ & $\begin{array}{l}\text { The decommissioning cost } \\
\text { (DE) could be measured as } \\
\text { [167]: } \\
\text { - } \mathrm{DC}>\$ 1000 \mathrm{M} \\
\text { - } \$ 800<\mathrm{DE} \leq \$ 1000 \mathrm{M} \\
\text { - } \$ 600<\mathrm{DE} \leq \$ 800 \mathrm{M} \\
\text { - } \$ 400<\mathrm{DE} \leq \$ 600 \mathrm{M} \\
\text { - } \$ 200<\mathrm{DE} \leq \$ 400 \mathrm{M} \\
\text { - } \$ 0<\mathrm{DE} \leq \$ 200 \mathrm{M} \\
\text { - } \mathrm{DC}=\$ 0 \mathrm{M}\end{array}$ \\
\hline E3 & $\begin{array}{l}\text { Plant Supplementary } \\
\text { Systems Cost }\end{array}$ & $\begin{array}{l}\text { A nuclear power plant require } \\
\text { to support its operation and } \\
\text { differ in their functionalities b } \\
\text { the plant's overall functionalit }\end{array}$ & $\begin{array}{l}\text { es several additional systems } \\
\text { continuation. These systems } \\
\text { but work together to enhance } \\
\text { ty }\end{array}$ \\
\hline E3.1 & $\begin{array}{l}\text { Water Delivery } \\
\text { System Cost }\end{array}$ & $\begin{array}{l}\text { Cost of providing the } \\
\text { required usable water } \\
\text { resources for steam } \\
\text { generation or/and plant } \\
\text { cooling. }\end{array}$ & $\begin{array}{l}\text { Water delivery (WD) cost } \\
\text { will be measured as [168]: } \\
\text { - } \mathrm{WD}>\$ 5 / \mathrm{MWh} \\
\text { - } \$ 4<\mathrm{WD} \leq \$ 5 / \mathrm{MWh} \\
\text { - } \$ 3<\mathrm{WD} \leq \$ 4 / \mathrm{MWh} \\
\text { - } \$ 2<\mathrm{WD} \leq \$ 3 / \mathrm{MWh} \\
\text { - } \$ 1<\mathrm{WD} \leq \$ 2 / \mathrm{MWh} \\
\text { - } \$ 0<\mathrm{WD} \leq \$ 1 / \mathrm{MWh} \\
\text { - } \mathrm{WD}=\$ 0 / \mathrm{MWh}\end{array}$ \\
\hline E3.2 & $\begin{array}{l}\text { Grid Connection } \\
\text { System Cost }\end{array}$ & $\begin{array}{l}\text { Cost of electrical } \\
\text { transmission and distribution } \\
\text { channels to connect the plant } \\
\text { to the grid. }\end{array}$ & $\begin{array}{l}\text { Grid connection }(\mathrm{GC}) \text { cost } \\
\text { measured as[ } 169] \text { : } \\
\text { - } \mathrm{GC}>\$ 100 / \mathrm{MWh} \\
\text { - } \$ 80<\mathrm{GC} \leq \$ 100 / \mathrm{MWh} \\
\text { - } \$ 60<\mathrm{GC} \leq \$ 80 / \mathrm{MWh} \\
\text { - } \$ 40<\mathrm{GC} \leq \$ 60 / \mathrm{MWh} \\
\text { - } \$ 20<\mathrm{GC} \leq \$ 40 / \mathrm{MWh} \\
\text { - } \$ 0<\mathrm{GC} \leq \$ 20 / \mathrm{MWh} \\
\text { - } \mathrm{GC}=0 / \mathrm{MWh}\end{array}$ \\
\hline
\end{tabular}




\begin{tabular}{|c|c|c|c|}
\hline Perspective & Criterion & Description & Metrics \\
\hline E3.3 & $\begin{array}{c}\text { Ventilation System } \\
\text { Cost }\end{array}$ & $\begin{array}{l}\text { Cost of providing fresh air } \\
\text { circulation and high quality } \\
\text { filtration system for a highly } \\
\text { sealed environment }\end{array}$ & $\begin{array}{l}\text { Ventilation system (VS)cost } \\
\text { will measured as [170]: } \\
\text { - VS }>\$ 25 \mathrm{M} \\
\text { - } \$ 20<\mathrm{VS} \leq \$ 25 \mathrm{M} \\
\text { - } \$ 15<\mathrm{VS} \leq \$ 20 \mathrm{M} \\
\text { - } \$ 10<\mathrm{VS} \leq \$ 15 \mathrm{M} \\
\text { - } \$ 5<\mathrm{VS} \leq \$ 10 \mathrm{M} \\
\text { - } \$ 0<\mathrm{VS} \leq \$ 5 \mathrm{M} \\
\text { - VS }=\$ 0 \mathrm{M}\end{array}$ \\
\hline E3.4 & $\begin{array}{l}\text { Protection \& } \\
\text { Isolation System } \\
\text { Cost }\end{array}$ & $\begin{array}{l}\text { Cost of providing the } \\
\text { required level of protection } \\
\text { for the plant and from the } \\
\text { plant. }\end{array}$ & $\begin{array}{l}\text { Protection and isolation } \\
\text { (PI) cost will be measured } \\
\text { as }[163] \text { : } \\
\text { - } \mathrm{PI}>\$ 25 \mathrm{M} \\
\text { - } \$ 20<\mathrm{PI} \leq \$ 25 \mathrm{M} \\
\text { - } \$ 15<\mathrm{PI} \leq \$ 20 \mathrm{M} \\
\text { - } \$ 10<\mathrm{PI} \leq \$ 15 \mathrm{M} \\
\text { - } \$ 5<\mathrm{PI} \leq \$ 10 \mathrm{M} \\
\text { - } \$ 0<\mathrm{PI} \leq \$ 5 \mathrm{M} \\
\text { - } \mathrm{PI}=\$ 0 \mathrm{M}\end{array}$ \\
\hline E3.5 & $\begin{array}{l}\text { Transportation } \\
\text { System Cost }\end{array}$ & $\begin{array}{l}\text { Cost of providing appropriate } \\
\text { means to transfer people and } \\
\text { materials from and to the } \\
\text { plant. }\end{array}$ & $\begin{array}{l}\text { Transportation system (TS) } \\
\text { cost will be measured as } \\
{[163] \text { : }} \\
\text { - } \mathrm{TS}>\$ 25 \mathrm{M} \\
\text { - } \$ 20<\mathrm{TS} \leq \$ 25 \mathrm{M} \\
\text { - } \$ 15<\mathrm{TS} \leq \$ 20 \mathrm{M} \\
\text { - } \$ 10<\mathrm{TS} \leq \$ 15 \mathrm{M} \\
\text { - } \$ 5<\mathrm{TS} \leq \$ 10 \mathrm{M} \\
\text { - } \$ 0<\mathrm{TS} \leq \$ 5 \mathrm{M} \\
\text { - } \mathrm{TS}=\$ 0 \mathrm{M}\end{array}$ \\
\hline E4 & $\begin{array}{c}\text { Technology } \\
\text { Outsourcing Cost }\end{array}$ & $\begin{array}{l}\text { Acquiring knowledge or } \\
\text { experiences from others } \\
\text { involves some costs }\end{array}$ & $\begin{array}{l}\text { Technology outsourcing } \\
\text { (TO) cost will be measured } \\
\text { as a percentage of overnight } \\
\text { capital cost: } \\
\text { - } \mathrm{TO}=100 \% \\
\text { - } \mathrm{TO}=80 \% \\
\text { - } \mathrm{TO}=60 \% \\
\text { - } \mathrm{TO}=40 \% \\
\text { - } \mathrm{TO}=20 \% \\
\text { - } \mathrm{TO}=0 \%\end{array}$ \\
\hline
\end{tabular}




\begin{tabular}{|c|c|c|c|}
\hline Perspective & Criterion & Description & Metrics \\
\hline E5 & $\begin{array}{l}\text { Return on } \\
\text { Investment }\end{array}$ & $\begin{array}{l}\text { Return on investment (ROI) } \\
\text { is the ratio of net output over } \\
\text { the total input. }\end{array}$ & $\begin{array}{l}\text { ROI will be measured as: } \\
\text { - } \mathrm{ROI}=0 \% \\
\text { - } \mathrm{ROI}=20 \% \\
\text { - } \mathrm{ROI}=40 \% \\
\text { - } \mathrm{ROI}=60 \% \\
\text { - } \mathrm{ROI}=80 \% \\
\text { - } \mathrm{ROI}=100 \%\end{array}$ \\
\hline \multicolumn{4}{|c|}{ Environmental } \\
\hline N1 & $\begin{array}{l}\text { Site Preparation- } \\
\text { Related Impacts } \\
\text { (Disruption) }\end{array}$ & $\begin{array}{l}\text { Some changes in the site will } \\
\text { take place in accordance with } \\
\text { site preparation works, which } \\
\text { in turn will alter the site's } \\
\text { ecological system }\end{array}$ & $\begin{array}{l}\text { Ecological impacts (EI) will } \\
\text { be measured as: } \\
\text { - very high disruption } \\
\text { - high disruption } \\
\text { - medium disruption } \\
\text { - low disruption } \\
\text { - very low disruption } \\
\text { - no disruption }\end{array}$ \\
\hline N2 & $\begin{array}{l}\text { Construction- } \\
\text { Related Impacts }\end{array}$ & $\begin{array}{l}\text { All activities during the } \\
\text { construction phase will } \\
\text { impact directly the nature of } \\
\text { the site in terms of daily site } \\
\text { reformation and waste } \\
\text { generation. }\end{array}$ & $\begin{array}{l}\text { Construction-related } \\
\text { impacts (CI) will be } \\
\text { measured as: } \\
\text { - very high negative impact } \\
\text { - high negative impact } \\
\text { - medium negative impact } \\
\text { - low negative impact } \\
\text { - very low negative impact } \\
\text { - no negative impact }\end{array}$ \\
\hline N3 & $\begin{array}{l}\text { Operation-Related } \\
\text { Impacts }\end{array}$ & $\begin{array}{l}\text { Massive quantities of usable } \\
\text { water are to be extracted } \\
\text { from lakes, rivers, seas, } \\
\text { ocean, or underground, which } \\
\text { can negatively affect water } \\
\text { sources. }\end{array}$ & $\begin{array}{l}\text { Water contamination (WC) } \\
\text { will be measured as: } \\
\text { - very high contamination } \\
\text { - high contamination } \\
\text { - medium contamination } \\
\text { - low contamination } \\
\text { - very low contamination } \\
\text { - no contamination }\end{array}$ \\
\hline
\end{tabular}




\begin{tabular}{|c|c|c|c|}
\hline Perspective & Criterion & Description & Metrics \\
\hline N4 & $\begin{array}{c}\text { Land Availability and } \\
\text { Utilization }\end{array}$ & $\begin{array}{l}\text { An environmental feature } \\
\text { that would support siting } \\
\text { technology selection is the } \\
\text { wise use of available } \\
\text { land/space }\end{array}$ & $\begin{array}{l}\text { Land utilization (LU) will be } \\
\text { measured as: } \\
\text { - very poor utilization } \\
\text { - poor utilization } \\
\text { - fair utilization } \\
\text { - good utilization } \\
\text { - very good utilization } \\
\text { - excellent land utilization }\end{array}$ \\
\hline N5 & Site Recovery & $\begin{array}{l}\text { The ability to return the site } \\
\text { to its natural state at } \\
\text { retirement is a siting } \\
\text { technology preferable factor. }\end{array}$ & $\begin{array}{l}\text { The level of site recovery } \\
\text { (RC) will be measured as: } \\
\text { - very difficult recovery } \\
\text { - difficult recovery } \\
\text { - somewhat difficult } \\
\text { - neutral recovery } \\
\text { - easy recovery } \\
\text { - very easy recovery }\end{array}$ \\
\hline \multicolumn{4}{|l|}{ Political } \\
\hline P1 & $\begin{array}{l}\text { Government } \\
\text { Perception }\end{array}$ & $\begin{array}{l}\text { The level of government } \\
\text { perception of siting } \\
\text { technologies could support or } \\
\text { hinder the decision of } \\
\text { selecting the proper siting }\end{array}$ & $\begin{array}{l}\text { Government perception } \\
\text { (GP) could be measured as: } \\
\text { - poor } \\
\text { - fair } \\
\text { - good } \\
\text { - very good } \\
\text { - excellent }\end{array}$ \\
\hline P2 & Government Support & $\begin{array}{l}\text { Governments have } \\
\text { supportive mechanisms to } \\
\text { promote a new technology } \\
\text { such as raising public } \\
\text { awareness, licensing, tax } \\
\text { exemption, subsidies, etc. }\end{array}$ & $\begin{array}{l}\text { Government support (GS) } \\
\text { level will be measured as: } \\
\text { - strong opposition } \\
\text { - average opposition } \\
\text { - no support/opposition } \\
\text { - average support } \\
\text { - strong support }\end{array}$ \\
\hline
\end{tabular}




\begin{tabular}{|c|c|c|c|}
\hline Perspective & Criterion & Description & Metrics \\
\hline P3 & $\begin{array}{l}\text { Political Side of } \\
\text { Technology Transfer }\end{array}$ & $\begin{array}{l}\text { Technical or economic } \\
\text { obstacles could be lessened } \\
\text { or amplified depending on } \\
\text { whether collaboration exists } \\
\text { among governments. }\end{array}$ & $\begin{array}{l}\text { The level of political side of } \\
\text { technology transfer (PTT) } \\
\text { will be measured as: } \\
\text { - critical } \\
\text { - unhelpful } \\
\text { - neutral } \\
\text { - collaborative } \\
\text { - supportive }\end{array}$ \\
\hline P4 & $\begin{array}{c}\text { National/ } \\
\text { International Laws } \\
\text { and Agreements }\end{array}$ & $\begin{array}{l}\text { A site near the national or } \\
\text { international border could } \\
\text { raise a problem with the } \\
\text { neighboring state or country. } \\
\text { The existence of stringent or } \\
\text { flexible laws or agreements } \\
\text { will impact siting technology } \\
\text { selection }\end{array}$ & $\begin{array}{l}\text { The impact of international } \\
\text { or national laws and } \\
\text { agreements (LA) will be } \\
\text { measured as: } \\
\text { - strongly prevent } \\
\text { - conditionally prevent } \\
\text { - indifferent } \\
\text { - mostly permit } \\
\text { - highly permit }\end{array}$ \\
\hline P5 & $\begin{array}{l}\text { Rules and } \\
\text { Regulations } \\
\text { Availability }\end{array}$ & $\begin{array}{l}\text { The availability of relevant } \\
\text { rules and regulations would } \\
\text { enhance the chance of } \\
\text { selecting a siting technology } \\
\text { over others }\end{array}$ & $\begin{array}{l}\text { Rules and regulations (RR) } \\
\text { availability will be } \\
\text { measured as: } \\
\text { - not available } \\
\text { - under development } \\
\text { - available }\end{array}$ \\
\hline
\end{tabular}

\subsubsection{Developing Desirability Curves for the Criteria and Sub-Criteria}

Based on the defined metrics, spreadsheets were developed to ease the process of data entry and draw the graphs (desirability curves) automatically. Each spreadsheet represented a single criterion/sub-criterion and contained a data entry table that listed the different levels of performance. The spreadsheets were then sent to the available experts and they were asked how desirable each level of 
performance was on a 0 to 100 scale. The desirability curve was then developed to match various levels of each metric to a desirability value. The final desirability curve for each criterion/sub-criterion was drawn as the average value of all experts' inputs per criterion. Tables 8.2 to 8.7 and Figures 8.1 to 8.6 show the social criteria and sub-criteria desirability values and curves respectively. Desirability tables and curves of the other perspectives are listed in Appendix G.

Table 8.2 Desirability Values of Social Criterion (S1: Public Acceptance)

\begin{tabular}{|l|c|c|c|c|c|c|c|}
\hline \multicolumn{10}{|c|}{ Social: (S1) Public Acceptance and Attitude } \\
\hline \multicolumn{1}{|c|}{ Metrics } & EXP01 & EXP02 & EXP03 & EXP04 & EXP05 & Avg. & $\%$ \\
\hline no acceptance & 0 & 10 & 10 & 0 & 0 & 4 & 0.04 \\
\hline neutral acceptance & 10 & 50 & 50 & 25 & 10 & 29 & 0.29 \\
\hline low acceptance & 10 & 60 & 60 & 40 & 25 & 39 & 0.39 \\
\hline average acceptance & 60 & 80 & 75 & 75 & 50 & 68 & 0.68 \\
\hline high acceptance & 100 & 100 & 100 & 90 & 100 & 98 & 0.98 \\
\hline
\end{tabular}

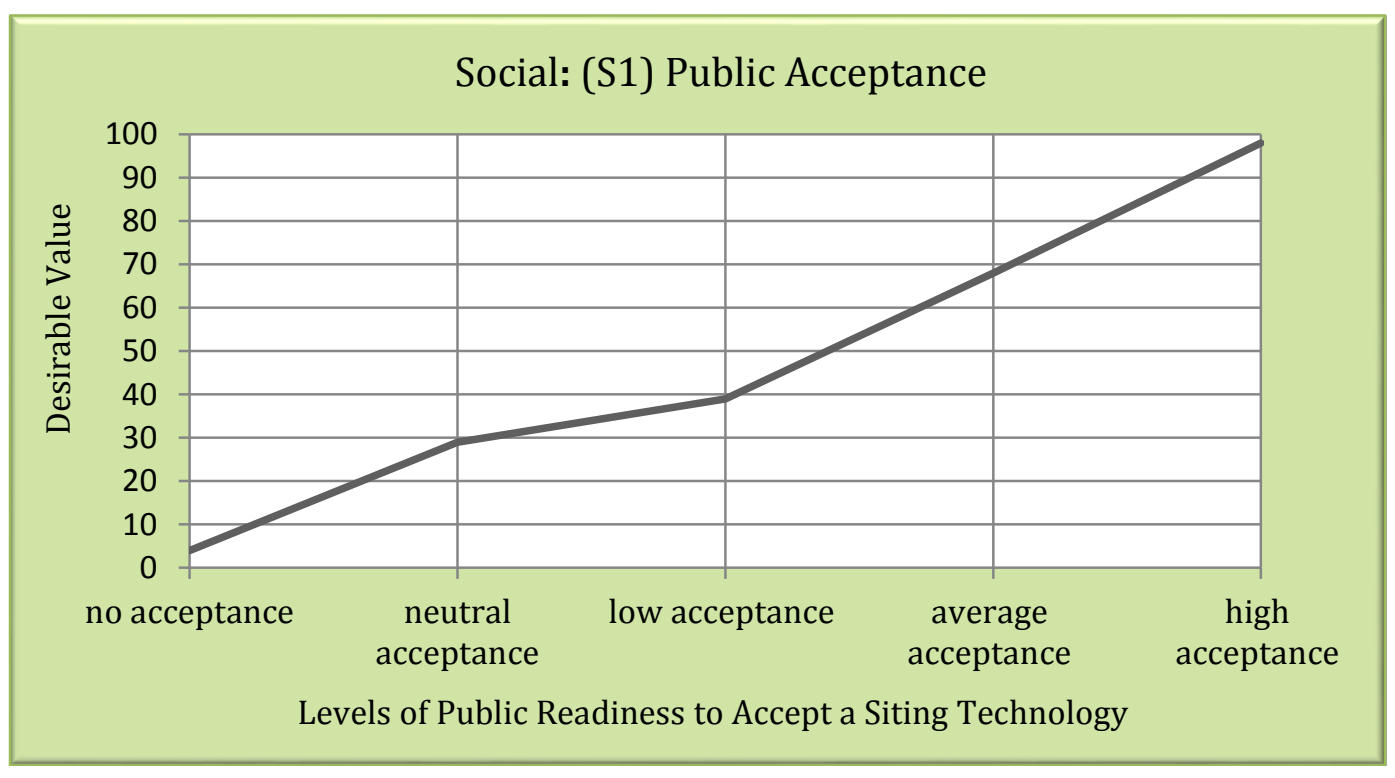

Figure 8.1 Desirability Curve of Social Criterion (S1: Public Acceptance) 
Table 8.3 Desirability Values of Social Sub-Criterion (S2.1: Health and Safety/Public)

\begin{tabular}{|c|c|c|c|c|c|c|c|}
\hline \multicolumn{1}{c|}{ Social: (S2.1) Health and Safety/Public } \\
\hline Metrics & EXP01 & EXP02 & EXP03 & EXP04 & EXP05 & Avg. & $\%$ \\
\hline high negative impact & 0 & 0 & 0 & 0 & 0 & 0 & 0.00 \\
\hline average negative impact & 50 & 75 & 60 & 70 & 40 & 59 & 0.59 \\
\hline low negative impact & 75 & 80 & 70 & 90 & 60 & 75 & 0.75 \\
\hline trivial negative impact & 80 & 95 & 80 & 90 & 80 & 85 & 0.85 \\
\hline no negative impact & 100 & 100 & 100 & 100 & 100 & 100 & 1.00 \\
\hline
\end{tabular}

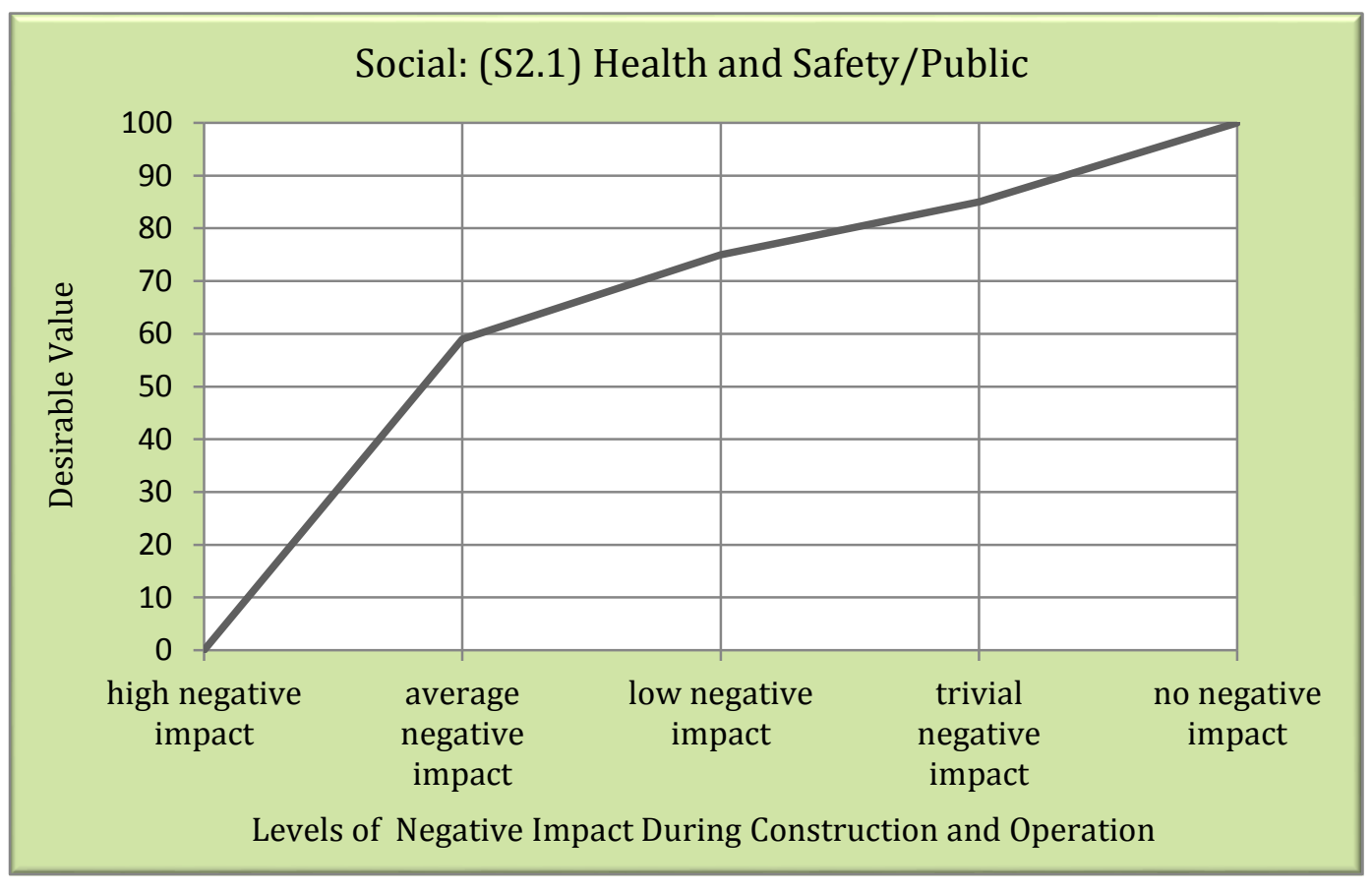

Figure 8.2 Desirability Curve of Social Sub-Criterion (S2.1: Health and Safety/Public) 
Table 8.4 Desirability Values of Social Sub-Criterion (S2.2: Health and Safety/Workers)

\begin{tabular}{|l|c|c|c|c|c|c|c|}
\hline \multicolumn{1}{c|}{ Social: (S2.2) Health and Safety/Workers } \\
\hline \multicolumn{1}{|c|}{ Metrics } & EXP01 & EXP02 & EXP03 & EXP04 & EXP05 & Avg. & $\%$ \\
\hline high negative impact & 0 & 0 & 0 & 0 & 0 & 0 & 0.00 \\
\hline average negative impact & 85 & 50 & 50 & 50 & 25 & 52 & 0.52 \\
\hline low negative impact & 90 & 75 & 70 & 60 & 50 & 69 & 0.69 \\
\hline trivial negative impact & 95 & 95 & 90 & 80 & 75 & 87 & 0.87 \\
\hline no negative impact & 100 & 100 & 100 & 100 & 100 & 100 & 1.00 \\
\hline
\end{tabular}

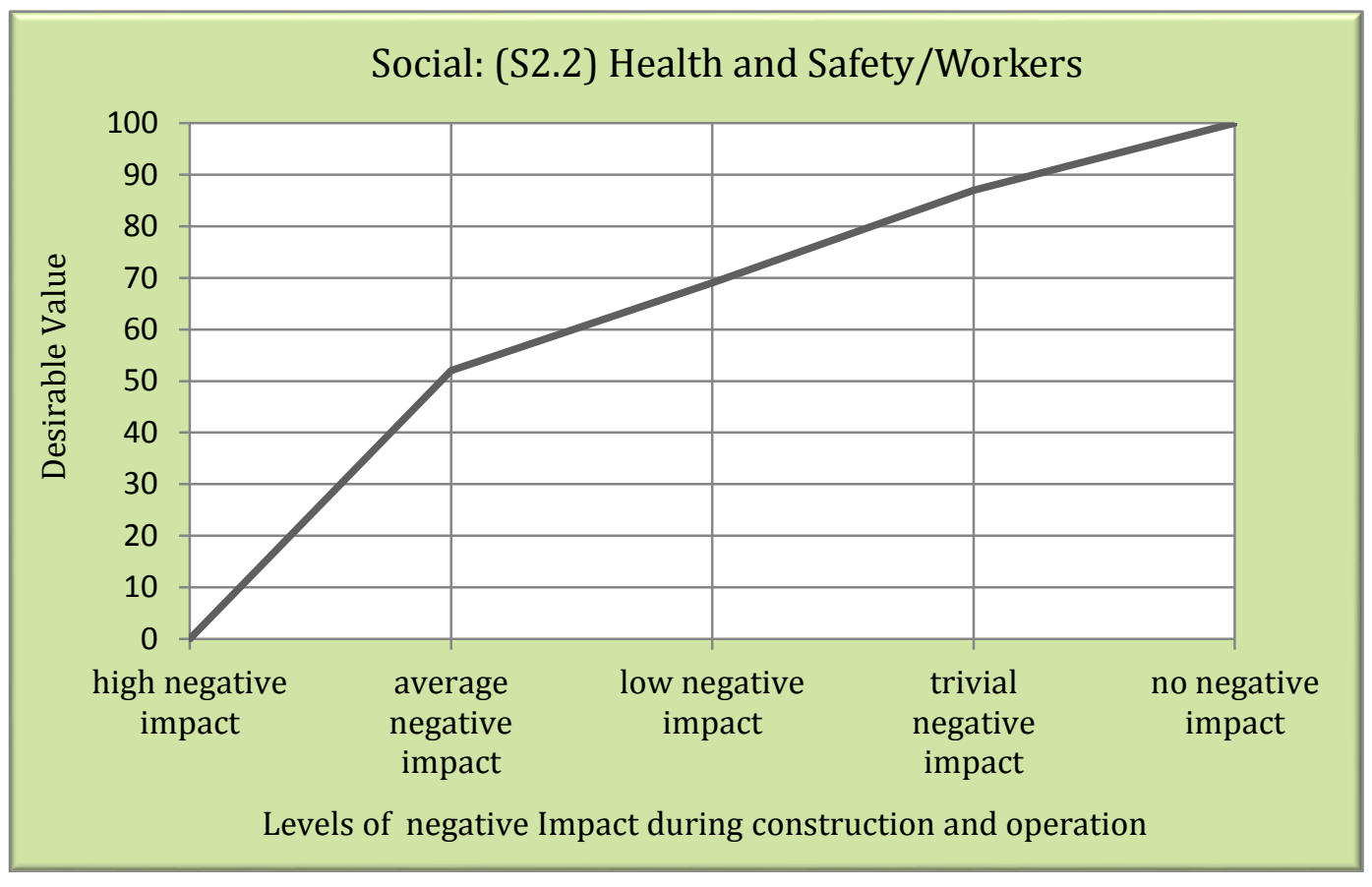

Figure 8.3 Desirability Curve of Social Sub-Criterion (S2.2: Health and Safety/Workers) 
Table 8.5 Desirability Values of Social Criterion (S3: Social Life and Activities)

\begin{tabular}{|l|c|c|c|c|c|c|c|}
\hline \multicolumn{7}{c|}{ Social: (S3) Social Life and Activities } \\
\hline \multicolumn{1}{|c|}{ Metrics } & EXP01 & EXP02 & EXP03 & EXP04 & EXP05 & Avg. & $\%$ \\
\hline high negative impact & 0 & 0 & 0 & 0 & 0 & 0 & 0.00 \\
\hline average negative impact & 25 & 20 & 45 & 35 & 50 & 35 & 0.35 \\
\hline low negative impact & 50 & 60 & 65 & 55 & 70 & 60 & 0.60 \\
\hline very low negative impact & 75 & 90 & 85 & 75 & 90 & 83 & 0.83 \\
\hline no negative impact & 100 & 100 & 100 & 100 & 100 & 100 & 1.00 \\
\hline
\end{tabular}

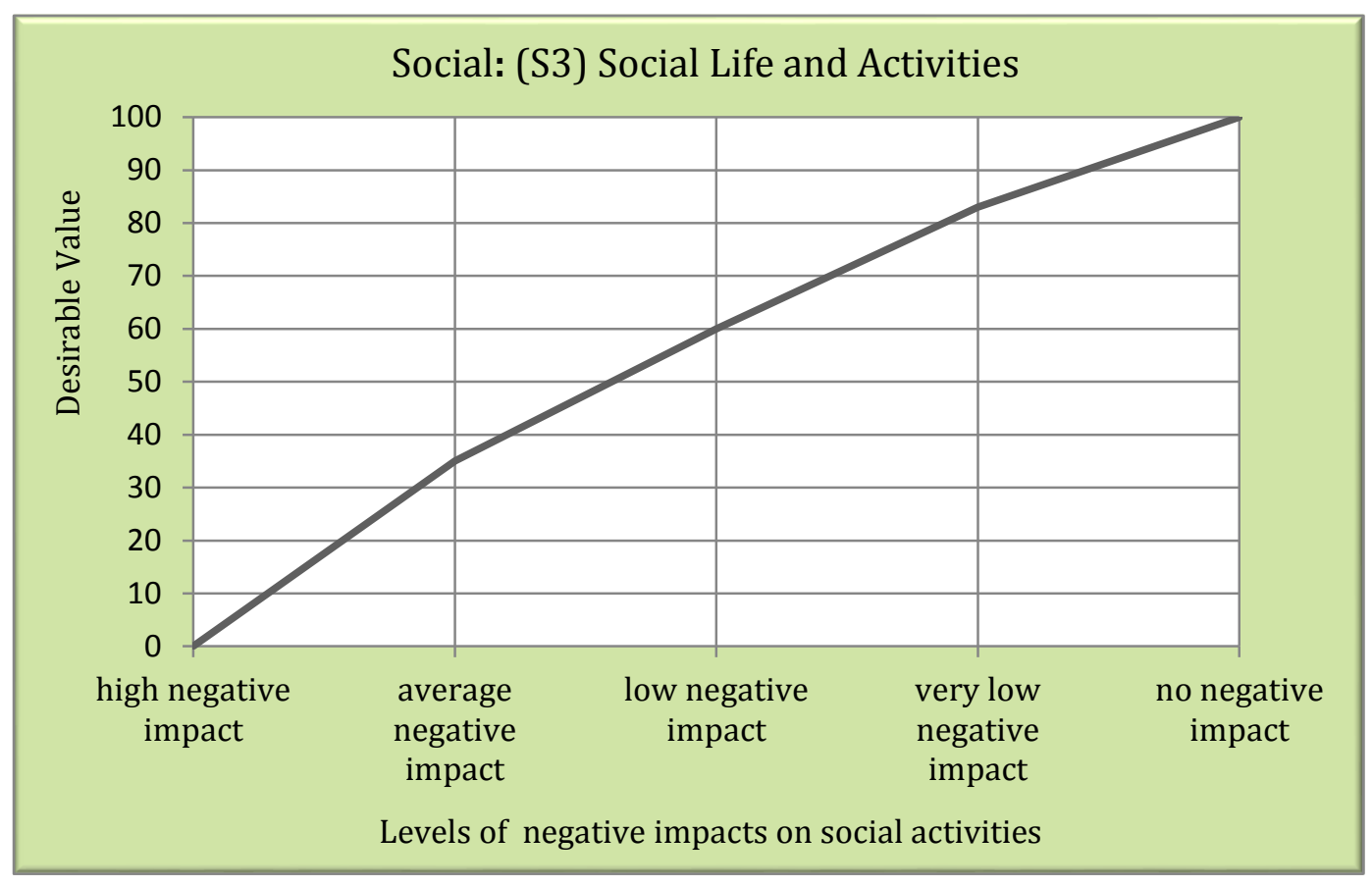

Figure 8.4 Desirability Curve of Social Criterion (S3: Social Life and Activities) 
Table 8.6 Desirability Values of Social Criterion (S4: Visual Impact)

\begin{tabular}{|c|c|c|c|c|c|c|c|}
\hline \multicolumn{10}{|c|}{ Social: (S4) Visual Impact } \\
\hline Metrics & EXP01 & EXP02 & EXP03 & EXP04 & EXP05 & Avg. & $\%$ \\
\hline highly disturbing & 0 & 0 & 0 & 0 & 0 & 0 & 0.00 \\
\hline moderately disturbing & 50 & 60 & 40 & 25 & 50 & 45 & 0.45 \\
\hline slightly disturbing & 90 & 80 & 60 & 50 & 80 & 72 & 0.72 \\
\hline barely disturbing & 95 & 90 & 80 & 75 & 80 & 84 & 0.84 \\
\hline not disturbing & 100 & 100 & 100 & 100 & 100 & 100 & 1.00 \\
\hline
\end{tabular}

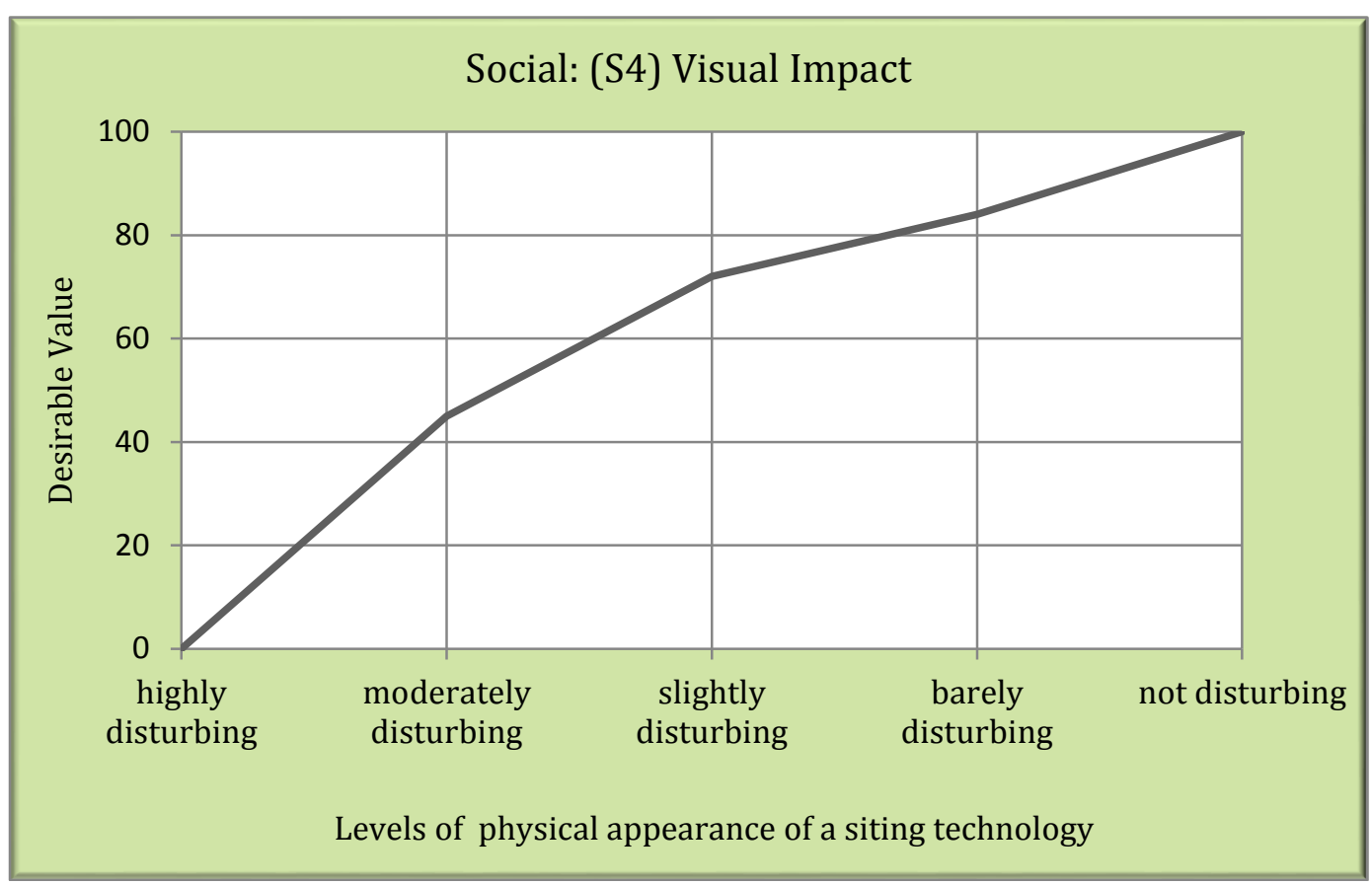

Figure 8.5 Desirability Curve of Social Criterion (S4: Visual Impact) 
Table 8.7 Desirability Values of Social Criterion (S5: Experts Availability)

\begin{tabular}{|l|c|c|c|c|c|c|c|}
\hline \multicolumn{10}{c|}{ Social: (S5) Experts Availability } \\
\hline \multicolumn{1}{|c|}{ Metrics } & EXP01 & EXP02 & EXP03 & EXP04 & EXP05 & Avg. & $\%$ \\
\hline highly disturbing & 0 & 0 & 0 & 0 & 0 & 0 & 0.00 \\
\hline moderately disturbing & 50 & 60 & 40 & 25 & 50 & 45 & 0.45 \\
\hline slightly disturbing & 90 & 80 & 60 & 50 & 80 & 72 & 0.72 \\
\hline barely disturbing & 95 & 90 & 80 & 75 & 80 & 84 & 0.84 \\
\hline not disturbing & 100 & 100 & 100 & 100 & 100 & 100 & 1.00 \\
\hline
\end{tabular}

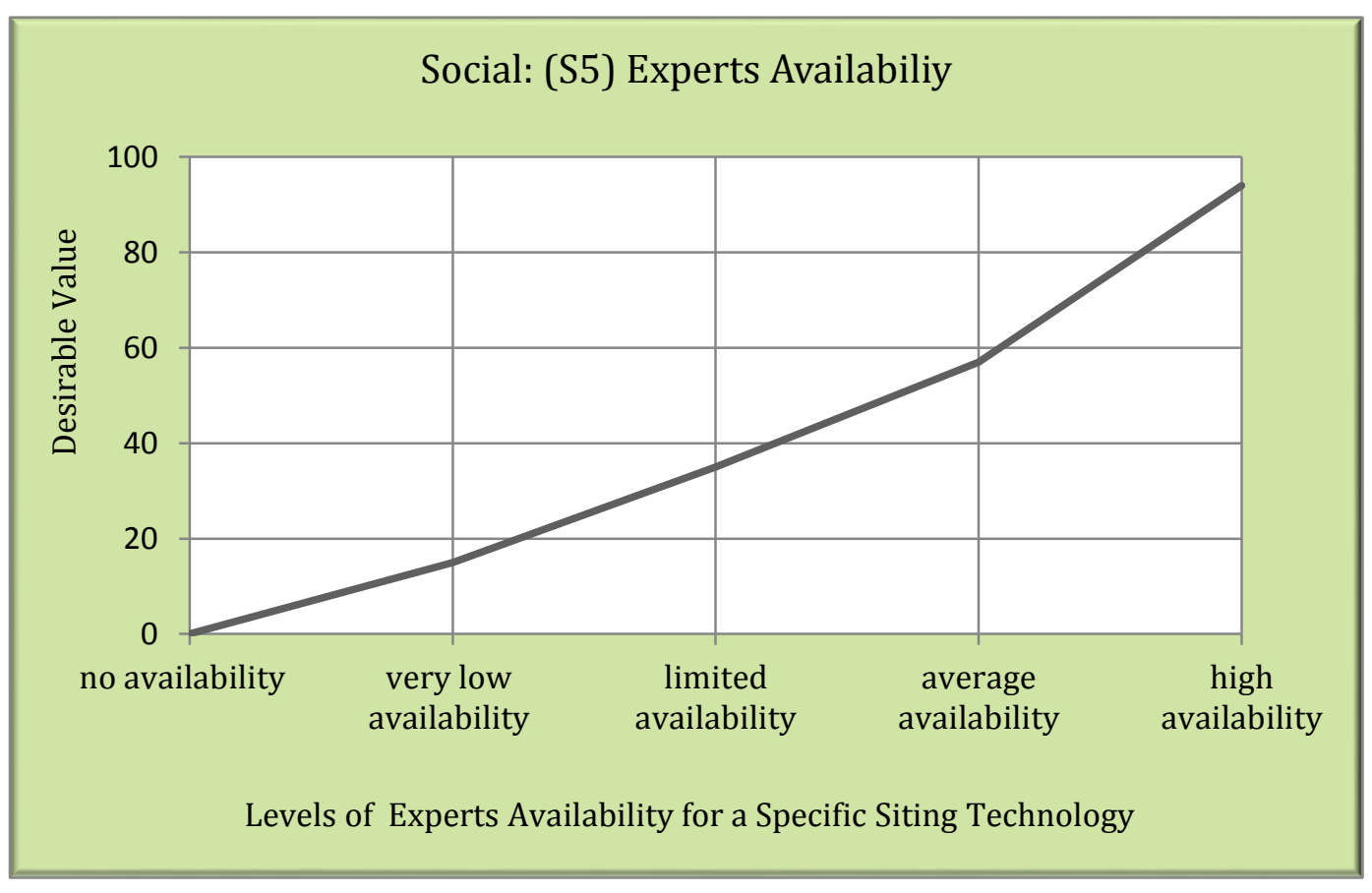

Figure 8.6 Desirability Curve of Social Criterion (S5: Experts Availabiliy) 


\subsection{Development of the General Model}

The base model was developed by using the relative importance values of the model's elements while the general model was developed by replicating the base model but using the desirability values

\subsubsection{Modifying the Base Model by Using the Desirability Curves/Values}

The approach of modifying the base model to be a general model was to match each relative value of each criterion/sub-criterion in the base model with a corresponding desirable performance level of the criterion/sub-criterion.

For example, a relative value of 0.07 that represents the criterion S1 (public acceptance and attitude) of the Land-Based siting technology was matched with the performance level of "low acceptance", and a relative value of 0.32 that represents the same criterion of the Natural Island siting technology was matched with the performance level of "high acceptance".

The same approach was used to match all criteria/sub-criteria's relative values to corresponding desirable performance levels, as shown in Table 8.8 
Table 8.8 Metrics Corresponding to the Decision Model's Criteria and Sub-Criteria for each Siting technology

\begin{tabular}{|c|c|c|c|c|c|c|c|c|}
\hline \multirow[b]{2}{*}{ 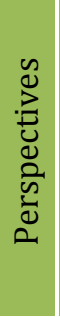 } & \multirow[b]{2}{*}{ 苞 } & \multirow[b]{2}{*}{ 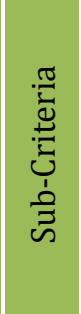 } & \multirow[b]{2}{*}{ Title } & \multicolumn{5}{|c|}{ Siting Technologies } \\
\hline & & & & 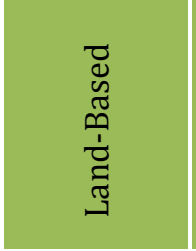 & 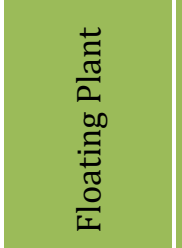 & 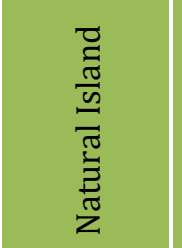 & 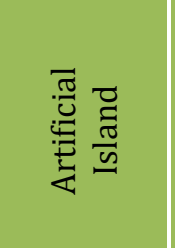 & 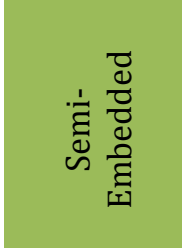 \\
\hline $\mathbf{S}$ & & & Social & & & & & \\
\hline & S1 & & $\begin{array}{l}\text { Public Acceptance and } \\
\text { Attitude }\end{array}$ & $\begin{array}{l}\text { Low } \\
\text { acceptance }\end{array}$ & $\begin{array}{l}\text { average } \\
\text { acceptance }\end{array}$ & $\begin{array}{l}\text { high } \\
\text { acceptance }\end{array}$ & $\begin{array}{l}\text { average } \\
\text { acceptance }\end{array}$ & $\begin{array}{c}\text { low } \\
\text { acceptance }\end{array}$ \\
\hline & S2 & & $\begin{array}{l}\text { People Health and } \\
\text { Safety }\end{array}$ & & & & & \\
\hline & & S2.1 & - Public & $\begin{array}{c}\text { low } \\
\text { negative } \\
\text { impact }\end{array}$ & $\begin{array}{c}\text { no } \\
\text { negative } \\
\text { impact }\end{array}$ & $\begin{array}{c}\text { trivial } \\
\text { negative } \\
\text { impact }\end{array}$ & $\begin{array}{c}\text { no } \\
\text { negative } \\
\text { impact }\end{array}$ & $\begin{array}{c}\text { trivial } \\
\text { negative } \\
\text { impact }\end{array}$ \\
\hline & & S2.2 & - Workers & $\begin{array}{c}\text { no } \\
\text { negative } \\
\text { impact }\end{array}$ & $\begin{array}{c}\text { low } \\
\text { negative } \\
\text { impact }\end{array}$ & $\begin{array}{c}\text { trivial } \\
\text { negative } \\
\text { impact }\end{array}$ & $\begin{array}{c}\text { low } \\
\text { negative } \\
\text { impact }\end{array}$ & $\begin{array}{c}\text { average } \\
\text { negative } \\
\text { impact }\end{array}$ \\
\hline & S3 & & $\begin{array}{l}\text { Social Life and } \\
\text { Activities }\end{array}$ & $\begin{array}{c}\text { average } \\
\text { negative } \\
\text { impact }\end{array}$ & $\begin{array}{c}\text { low } \\
\text { negative } \\
\text { impact }\end{array}$ & $\begin{array}{c}\text { very low } \\
\text { negative } \\
\text { impact }\end{array}$ & $\begin{array}{l}\text { Low } \\
\text { negative } \\
\text { impact }\end{array}$ & $\begin{array}{c}\text { Low } \\
\text { negative } \\
\text { impact }\end{array}$ \\
\hline & S4 & & Visual Impact & $\begin{array}{c}\text { moderately } \\
\text { disturbing }\end{array}$ & $\begin{array}{c}\text { barely } \\
\text { disturbing }\end{array}$ & $\begin{array}{l}\text { slightly } \\
\text { disturbing }\end{array}$ & $\begin{array}{c}\text { barely } \\
\text { disturbing }\end{array}$ & $\begin{array}{l}\text { moderately } \\
\text { disturbing }\end{array}$ \\
\hline & S5 & & Experts Availability & $\begin{array}{l}\text { high } \\
\text { availability }\end{array}$ & $\begin{array}{l}\text { limited } \\
\text { availability }\end{array}$ & $\begin{array}{l}\text { high } \\
\text { availability }\end{array}$ & $\begin{array}{l}\text { limited } \\
\text { availability }\end{array}$ & $\begin{array}{c}\text { average } \\
\text { availability }\end{array}$ \\
\hline $\mathbf{T}$ & & & Technical & & & & & \\
\hline & $\mathrm{T} 1$ & & Maturity & & & & & \\
\hline & & T1.1 & Applicability & $\begin{array}{c}\text { Many } \\
(\mathrm{AP}>10)\end{array}$ & $\begin{array}{c}\text { once } \\
(\mathrm{AP}=1)\end{array}$ & $\begin{array}{c}\text { few } \\
(2<\mathrm{AP} \leq 5)\end{array}$ & $\begin{array}{c}\text { None } \\
(\mathrm{AP}=0)\end{array}$ & $\begin{array}{c}\text { few } \\
(2<\mathrm{AP} \leq 5)\end{array}$ \\
\hline & & $\mathrm{T} 1.2$ & Reliability & $80<\mathrm{RE} \leq 100$ & $60<\mathrm{RE} \leq 80$ & $80<\mathrm{RE} \leq 100$ & $60<\mathrm{RE} \leq 80$ & $40<\mathrm{RE} \leq 60$ \\
\hline & & T1.3 & Competency & $80<\mathrm{CO} \leq 100$ & $40<\mathrm{CO} \leq 60$ & $80<\mathrm{CO} \leq 100$ & $60<\mathrm{CO} \leq 80$ & $60<\mathrm{CO} \leq 80$ \\
\hline & $\mathrm{T} 2$ & & Flexibility & & & & & \\
\hline & & $\mathrm{T} 2.1$ & Scalability & possible & $\begin{array}{l}\text { totally } \\
\text { scalable }\end{array}$ & Possible & $\begin{array}{l}\text { totally } \\
\text { scalable }\end{array}$ & unscalable \\
\hline & & $\mathrm{T} 2.2$ & Mobility & fixed & $\begin{array}{l}\text { totally } \\
\text { mobile }\end{array}$ & fixed & possible & fixed \\
\hline & & T2.3 & Modularity & possible & standard & possible & standard & possible \\
\hline & $\mathrm{T} 3$ & & Safety and Security & & & & & \\
\hline & & T3.1 & Resistance & low & high & medium & medium & very high \\
\hline & & T3.2 & Containment & low & high & medium & medium & very high \\
\hline
\end{tabular}




\begin{tabular}{|c|c|c|c|c|c|c|c|c|}
\hline \multirow[b]{2}{*}{ 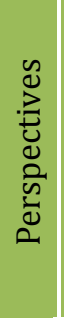 } & \multirow[b]{2}{*}{ 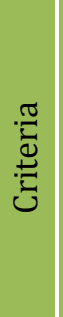 } & \multirow[b]{2}{*}{ 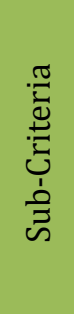 } & \multirow[b]{2}{*}{ Title } & \multicolumn{5}{|c|}{ Siting Technologies } \\
\hline & & & & 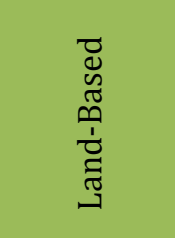 & 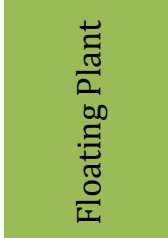 & 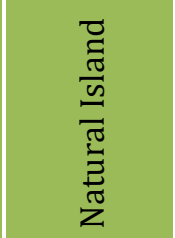 & 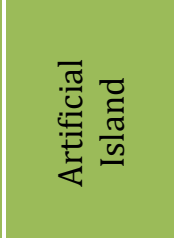 & 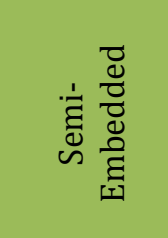 \\
\hline & & T3.3 & Evacuation & high level & medium & medium & medium & low \\
\hline & $\mathrm{T} 4$ & & $\begin{array}{l}\text { Power Generation } \\
\text { Capacity }\end{array}$ & $\begin{array}{c}1500<\mathrm{PG} \leq \\
2000\end{array}$ & $\begin{array}{c}500<\mathrm{PG} \leq \\
1000\end{array}$ & $\begin{array}{c}1000<\mathrm{PG} \leq \\
1500\end{array}$ & $\begin{array}{c}1000<\mathrm{PG} \leq \\
1500\end{array}$ & $\begin{array}{c}500<\mathrm{PG} \leq \\
1000\end{array}$ \\
\hline & T5 & & Plant Life Span & $60<\mathrm{LT} \leq 80$ & $20<\mathrm{LT} \leq 40$ & $60<\mathrm{LT} \leq 80$ & $40<\mathrm{LT} \leq 60$ & $40<\mathrm{LT} \leq 60$ \\
\hline & T6 & & $\begin{array}{l}\text { Used Fuel Storage } \\
\text { Capacity }\end{array}$ & $\begin{array}{c}1000<\mathrm{FS} \\
\leq 1500\end{array}$ & $\begin{array}{c}500<\mathrm{FS} \leq \\
1000\end{array}$ & $\begin{array}{c}1500<\mathrm{FS} \leq \\
2000\end{array}$ & $\begin{array}{c}1000<\mathrm{FS} \\
\leq 1500\end{array}$ & $\begin{array}{c}2000<\mathrm{FS} \leq \\
2500\end{array}$ \\
\hline & $\mathrm{T} 7$ & & $\begin{array}{l}\text { Decommission \& Site } \\
\text { Cleanup }\end{array}$ & $20<\mathrm{DT} \leq 30$ & $0<\mathrm{DT} \leq 10$ & $20<\mathrm{DT} \leq 30$ & $10<\mathrm{DT} \leq 20$ & $0<\mathrm{DT} \leq 10$ \\
\hline \multirow[t]{17}{*}{$\mathbf{E}$} & & & Economic & & & & & \\
\hline & \multirow{4}{*}{ E1 } & & Site Development Costs & & & & & \\
\hline & & E1.1 & Exploration Cost & $4<\mathrm{SE} \leq 6$ & $2<\mathrm{SE} \leq 4$ & $6<\mathrm{SE} \leq 8$ & $4<\mathrm{SE} \leq 6$ & $8<\mathrm{SE} \leq 10$ \\
\hline & & E1.2 & Acquisition Cost & $20<S A \leq 25$ & $0<\mathrm{SA} \leq 5$ & $10<\mathrm{SA} \leq 15$ & $10<\mathrm{SA} \leq 15$ & $15<\mathrm{SA} \leq 20$ \\
\hline & & E1.3 & Preparation Cost & $20<\mathrm{SP} \leq 30$ & $0<\mathrm{SP} \leq 10$ & $30<\mathrm{SP} \leq 40$ & $20<\mathrm{SP} \leq 30$ & $40<\mathrm{SP} \leq 50$ \\
\hline & \multirow[t]{4}{*}{ E2 } & & $\begin{array}{l}\text { Plant Development } \\
\text { Costs }\end{array}$ & & & & & \\
\hline & & E2.2 & Construction \& Inst. & $2<\mathrm{EPC} \leq 4$ & $6<\mathrm{EPC} \leq 8$ & $4<\mathrm{EPC} \leq 6$ & $8<$ EPC $\leq 10$ & $8<\mathrm{EPC} \leq 10$ \\
\hline & & E2.3 & $\begin{array}{l}\text { Operation and } \\
\text { Maintenance }\end{array}$ & $\begin{aligned} 10 & <0 \& M \\
& \leq 20\end{aligned}$ & $\begin{aligned} 20 & <0 \& M \\
& \leq 30\end{aligned}$ & $\begin{aligned} 20 & <0 \& M \\
& \leq 30\end{aligned}$ & $\begin{aligned} 20 & <0 \& M \\
& \leq 30\end{aligned}$ & $\begin{aligned} 30 & <0 \& M \\
& \leq 40\end{aligned}$ \\
\hline & & E2.4 & Decommissioning Cost & $\begin{array}{c}400<\mathrm{DC} \\
\leq 600\end{array}$ & $\begin{array}{c}600<\mathrm{DC} \\
\leq 800\end{array}$ & $\begin{array}{c}200<\mathrm{DC} \\
\leq 400\end{array}$ & $\begin{array}{l}800<\mathrm{DC} \\
\leq 1000\end{array}$ & $\begin{array}{l}0<\mathrm{DC} \\
\leq 200\end{array}$ \\
\hline & \multirow[t]{6}{*}{ E3 } & & $\begin{array}{l}\text { Plant Supplementary } \\
\text { Sys. Cost }\end{array}$ & & & & & \\
\hline & & E3.1 & Water Delivery System & $3<\mathrm{WD} \leq 4$ & $1<\mathrm{WD} \leq 2$ & $2<W D \leq 3$ & $1<\mathrm{WD} \leq 2$ & $4<W D \leq 5$ \\
\hline & & E3.2 & Grid Connection System & $0<\mathrm{GC} \leq 20$ & $60<\mathrm{GC} \leq 80$ & $40<\mathrm{GC} \leq 60$ & $60<\mathrm{GC} \leq 80$ & $20<\mathrm{GC} \leq 40$ \\
\hline & & E3.3 & Ventilation System & $10<\mathrm{VS} \leq 15$ & $5<\mathrm{VS} \leq 10$ & $5<\mathrm{VS} \leq 10$ & $5<\mathrm{VS} \leq 10$ & $15<\mathrm{VS} \leq 20$ \\
\hline & & E3.4 & $\begin{array}{l}\text { Protection and } \\
\text { Isolation System }\end{array}$ & $10<\mathrm{P} \leq 15$ & $15<\mathrm{PI} \leq 20$ & $5<\mathrm{PI} \leq 10$ & $20<\mathrm{PI} \leq 25$ & $0<\mathrm{PI} \leq 5$ \\
\hline & & E3.5 & Transportation System & $0<\mathrm{TS} \leq 5$ & $15<\mathrm{TS} \leq 20$ & $10<\mathrm{TS} \leq 15$ & $15<\mathrm{TS} \leq 20$ & $5<\mathrm{TS} \leq 10$ \\
\hline & E4 & & $\begin{array}{l}\text { Technology } \\
\text { Outsourcing Cost }\end{array}$ & $\mathrm{TO}=20 \%$ & $\mathrm{TO}=60 \%$ & $\mathrm{TO}=20 \%$ & $\mathrm{TO}=80 \%$ & $\mathrm{TO}=40 \%$ \\
\hline & E5 & & Return on Investment & $\mathrm{ROI}=60 \%$ & $\mathrm{ROI}=20 \%$ & $\mathrm{ROI}=60 \%$ & $\mathrm{ROI}=20 \%$ & $\mathrm{ROI}=40 \%$ \\
\hline $\mathbf{N}$ & & & Environmental & & & & & \\
\hline & N1 & & Site Preparation Impact & $\begin{array}{c}\text { high } \\
\text { disruption }\end{array}$ & $\begin{array}{l}\text { very low } \\
\text { disruption }\end{array}$ & $\begin{array}{c}\text { low } \\
\text { disruption }\end{array}$ & $\begin{array}{l}\text { average } \\
\text { disruption }\end{array}$ & $\begin{array}{c}\text { high } \\
\text { disruption }\end{array}$ \\
\hline & $\mathrm{N} 2$ & & $\begin{array}{l}\text { Construction-Related } \\
\text { Impacts }\end{array}$ & $\begin{array}{c}\text { low } \\
\text { negative }\end{array}$ & $\begin{array}{l}\text { very low } \\
\text { negative }\end{array}$ & $\begin{array}{c}\text { Low } \\
\text { negative }\end{array}$ & $\begin{array}{l}\text { average } \\
\text { negative }\end{array}$ & $\begin{array}{c}\text { high } \\
\text { negative }\end{array}$ \\
\hline
\end{tabular}




\begin{tabular}{|c|c|c|c|c|c|c|c|c|}
\hline \multirow[b]{2}{*}{ 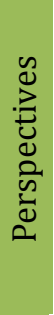 } & \multirow[b]{2}{*}{ : } & \multirow[b]{2}{*}{ 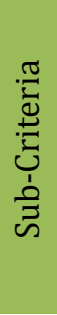 } & \multirow[b]{2}{*}{ Title } & \multicolumn{5}{|c|}{ Siting Technologies } \\
\hline & & & & 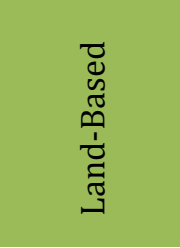 & 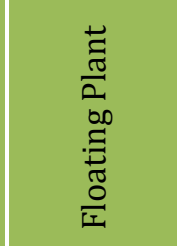 & 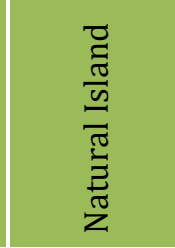 & 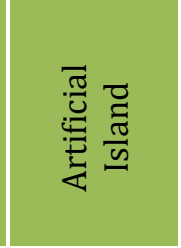 & 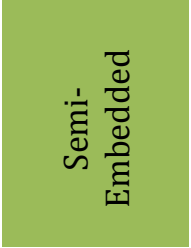 \\
\hline & & & & impact & impact & impact & impact & impact \\
\hline & N3 & & $\begin{array}{l}\text { Operation-Related } \\
\text { Impacts }\end{array}$ & average & very low & low & very low & high \\
\hline & N4 & & $\begin{array}{l}\text { Land Availability and } \\
\text { Utilization }\end{array}$ & poor & very good & fair & good & very good \\
\hline & N5 & & Site Recovery & difficult & easy & somewhat & somewhat & easy \\
\hline $\mathbf{P}$ & & & Political & & & & & \\
\hline & $\mathrm{P} 1$ & & Government Perception & good & fair & very good & fair & very good \\
\hline & P2 & & Government Support & $\begin{array}{c}\text { average } \\
\text { opposition }\end{array}$ & $\begin{array}{l}\text { average } \\
\text { support }\end{array}$ & $\begin{array}{l}\text { strong } \\
\text { support }\end{array}$ & $\begin{array}{l}\text { average } \\
\text { support }\end{array}$ & $\begin{array}{l}\text { average } \\
\text { support }\end{array}$ \\
\hline & P3 & & $\begin{array}{l}\text { Political Side of Tech. } \\
\text { Transfer }\end{array}$ & supportive & neutral & $\begin{array}{c}\text { collaborati } \\
\text { ve }\end{array}$ & neutral & neutral \\
\hline & P4 & & Laws and Agreements & $\begin{array}{l}\text { highly } \\
\text { permit }\end{array}$ & indifferent & indifferent & indifferent & $\begin{array}{l}\text { mostly } \\
\text { permit }\end{array}$ \\
\hline & P5 & & $\begin{array}{l}\text { Rules/Regulations } \\
\text { Availability }\end{array}$ & available & $\begin{array}{c}\text { under } \\
\text { developme } \\
\text { nt }\end{array}$ & available & $\begin{array}{c}\text { under } \\
\text { developme } \\
\text { nt }\end{array}$ & $\begin{array}{c}\text { under } \\
\text { developmen } \\
\mathrm{t}\end{array}$ \\
\hline
\end{tabular}

In a further step, the performance level of a certain criterion/sub-criterion was then converted to a desirable value using the criterion/sub-criterion's desirability curve. For example, the performance level "low acceptance" of the S1 criterion of the Land-Based siting was converted to a desirable value of 0.38 and the performance level "high acceptance" of S1 criterion of the Natural Island was converted to a desirable value of 0.98 . The conversion from performance levels to desirability values using the desirability curves was done for all criteria and subcriteria, as shown in Table 8.9. The general model was then created. 
Table 8.9 Desirability Values Corresponding to the Decision Model's Criteria and Sub-Criteria for each Siting technology

\begin{tabular}{|c|c|c|c|c|c|c|c|c|c|c|c|}
\hline \multirow[b]{2}{*}{ 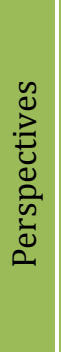 } & \multirow[b]{2}{*}{ } & \multirow[b]{2}{*}{ 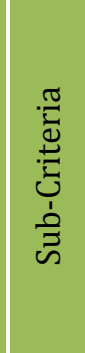 } & \multirow[b]{2}{*}{ Title } & \multicolumn{3}{|c|}{ Relative Values } & \multicolumn{5}{|c|}{ Siting Technologies } \\
\hline & & & & 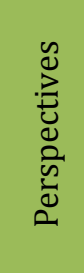 & 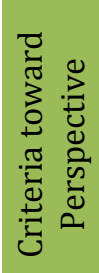 & 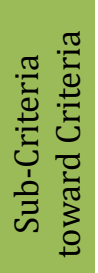 & 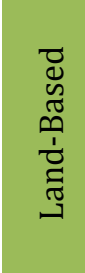 & 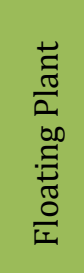 & 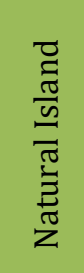 & 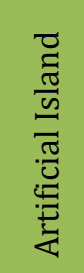 & 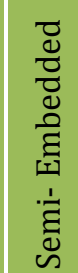 \\
\hline \multirow[t]{8}{*}{$\mathbf{S}$} & & & Social & 0.15 & & & & & & & \\
\hline & S1 & & Public Acceptance \& Attitude & & 0.27 & & 0.39 & 0.68 & 0.98 & 0.68 & 0.39 \\
\hline & S2 & & People Health and Safety & & 0.35 & & & & & & \\
\hline & & S2.1 & - Public & & & 0.66 & 0.75 & 1.00 & 0.85 & 1.00 & 0.85 \\
\hline & & S2.2 & - Workers & & & 0.34 & 1.00 & 0.69 & 0.87 & 0.69 & 0.52 \\
\hline & S3 & & Social Life and Activities & & 0.10 & & 0.35 & 0.60 & 0.83 & 0.60 & 0.60 \\
\hline & S4 & & Visual Impact & & 0.07 & & 0.45 & 0.84 & 0.72 & 0.84 & 0.45 \\
\hline & S5 & & Experts Availability & & 0.21 & & 0.94 & 0.35 & 0.94 & 0.35 & 0.57 \\
\hline \multirow[t]{17}{*}{$\mathbf{T}$} & & & Technical & 0.23 & & & & & & & \\
\hline & $\mathrm{T} 1$ & & Maturity & & 0.14 & & & & & & \\
\hline & & T1.1 & - Applicability & & & 0.32 & 1.00 & 0.12 & 0.46 & 0.12 & 0.46 \\
\hline & & $\mathrm{T} 1.2$ & - Reliability & & & 0.49 & 0.91 & 0.66 & 0.91 & 0.66 & 0.45 \\
\hline & & $\mathrm{T} 1.3$ & - Competency & & & 0.19 & 0.95 & 0.41 & 0.95 & 0.62 & 0.62 \\
\hline & $\mathrm{T} 2$ & & Flexibility & & 0.13 & & & & & & \\
\hline & & $\mathrm{T} 2.1$ & - Scalability & & & 0.40 & 0.58 & 0.96 & 0.58 & 0.96 & 0.12 \\
\hline & & $\mathrm{T} 2.2$ & - Mobility & & & 0.18 & 0.40 & 0.95 & 0.40 & 0.55 & 0.40 \\
\hline & & $\mathrm{T} 2.3$ & - Modularity & & & 0.42 & 0.46 & 0.95 & 0.46 & 0.95 & 0.46 \\
\hline & T3 & & Safety and Security & & 0.25 & & & & & & \\
\hline & & T3.1 & - Resistance & & & 0.33 & 0.21 & 0.72 & 0.45 & 0.45 & 1.00 \\
\hline & & T3.2 & - Containment & & & 0.50 & 0.22 & 0.67 & 0.41 & 0.41 & 0.98 \\
\hline & & T3.3 & - Evacuation & & & 0.17 & 0.91 & 0.47 & 0.47 & 0.47 & 0.11 \\
\hline & $\mathrm{T} 4$ & & Power Generation Capacity & & 0.13 & & 0.91 & 0.55 & 0.71 & 0.71 & 0.55 \\
\hline & T5 & & Plant Life Span & & 0.11 & & 0.85 & 0.38 & 0.85 & 0.61 & 0.61 \\
\hline & T6 & & Used Fuel Storage Capacity & & 0.12 & & 0.70 & 0.50 & 0.88 & 0.88 & 0.97 \\
\hline & $\mathrm{T} 7$ & & Decommission \& Site Cleanup & & 0.12 & & 0.38 & 0.73 & 0.38 & 0.52 & 0.73 \\
\hline \multirow[t]{2}{*}{$\mathbf{E}$} & & & Economic & 0.26 & & & & & & & \\
\hline & E1 & & Site Development Costs & & 0.16 & & & & & & \\
\hline
\end{tabular}




\begin{tabular}{|c|c|c|c|c|c|c|c|c|c|c|c|}
\hline \multirow[b]{2}{*}{ 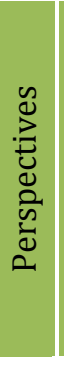 } & \multirow[b]{2}{*}{ 节 } & \multirow[b]{2}{*}{ 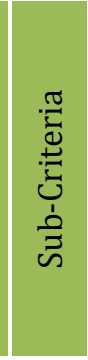 } & \multirow[b]{2}{*}{ Title } & \multicolumn{3}{|c|}{ Relative Values } & \multicolumn{5}{|c|}{ Siting Technologies } \\
\hline & & & & 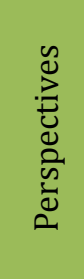 & 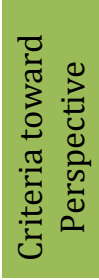 & 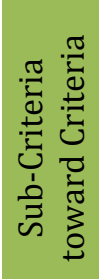 & 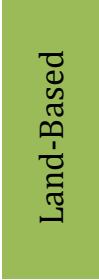 & 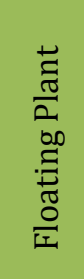 & 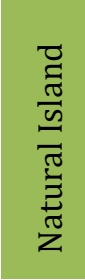 & 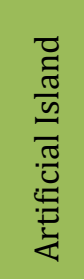 & 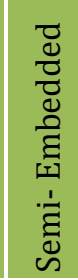 \\
\hline & & E1.1 & - Exploration Cost & & & 0.25 & 0.42 & 0.62 & 0.30 & 0.42 & 0.23 \\
\hline & & E1.2 & - Acquisition Cost & & & 0.34 & 0.18 & 0.94 & 0.59 & 0.59 & 0.38 \\
\hline & & E1.3 & - Preparation Cost & & & 0.41 & 0.41 & 0.78 & 0.27 & 0.41 & 0.13 \\
\hline & E2 & & Plant Development Costs & & 0.23 & & & & & & \\
\hline & & E2.2 & - Construction \& Inst. & & & 0.47 & 0.80 & 0.55 & 0.69 & 0.34 & 0.34 \\
\hline & & E2.3 & - Operation \& Maintenance & & & 0.32 & 0.73 & 0.55 & 0.55 & 0.55 & 0.33 \\
\hline & & E2.4 & - Decommissioning Cost & & & 0.21 & 0.51 & 0.37 & 0.73 & 0.21 & 0.88 \\
\hline & E3 & & $\begin{array}{l}\text { Plant Supplementary Sys. } \\
\text { Cost }\end{array}$ & & 0.16 & & & & & & \\
\hline & & E3.1 & - Water Delivery System & & & 0.22 & 0.33 & 0.71 & 0.50 & 0.71 & 0.15 \\
\hline & & E3.2 & - Grid Connection System & & & 0.18 & 0.90 & 0.36 & 0.50 & 0.36 & 0.72 \\
\hline & & E3.3 & - Ventilation System & & & 0.16 & 0.55 & 0.72 & 0.72 & 0.72 & 0.42 \\
\hline & & E3.4 & - Protection \& Isolation Sys. & & & 0.27 & 0.51 & 0.36 & 0.74 & 0.16 & 0.88 \\
\hline & & E3.5 & - Transportation System & & & 0.17 & 0.90 & 0.24 & 0.42 & 0.24 & 0.66 \\
\hline & $\mathrm{E} 4$ & & Technology Outsourcing Cost & & 0.14 & & 0.87 & 0.33 & 0.87 & 0.14 & 0.58 \\
\hline & E5 & & Return on Investment & & 0.31 & & 0.83 & 0.33 & 0.83 & 0.33 & 0.62 \\
\hline $\mathbf{N}$ & & & Environmental & 0.18 & & & & & & & \\
\hline & N1 & & Site Preparation Impact & & 0.16 & & 0.27 & 0.86 & 0.78 & 0.66 & 0.27 \\
\hline & $\mathrm{N} 2$ & & Construction-Related Impacts & & 0.20 & & 0.77 & 0.90 & 0.77 & 0.60 & 0.22 \\
\hline & N3 & & Operation-Related Impacts & & 0.27 & & 0.61 & 0.92 & 0.78 & 0.92 & 0.22 \\
\hline & N4 & & Land Availability \& Utilization & & 0.17 & & 0.18 & 0.89 & 0.44 & 0.67 & 0.89 \\
\hline & N5 & & Site Recovery & & 0.20 & & 0.21 & 0.78 & 0.38 & 0.38 & 0.78 \\
\hline $\mathbf{P}$ & & & Political & 0.18 & & & & & & & \\
\hline & P1 & & Government Perception & & 0.15 & & 0.57 & 0.37 & 0.79 & 0.37 & 0.79 \\
\hline & P2 & & Government Support & & 0.25 & & 0.34 & 0.72 & 0.95 & 0.72 & 0.72 \\
\hline & P3 & & Political Side of Tech. Trans. & & 0.12 & & 0.86 & 0.57 & 0.73 & 0.57 & 0.57 \\
\hline & $\mathrm{P} 4$ & & Laws \& Agreements & & 0.20 & & 0.99 & 0.62 & 0.62 & 0.62 & 0.81 \\
\hline & P5 & & $\begin{array}{l}\text { Rules/Regulations } \\
\text { Availability }\end{array}$ & & 0.28 & & 1.00 & 0.42 & 1.00 & 0.42 & 0.42 \\
\hline
\end{tabular}


According to the new values (desirability values) of the model's criteria and sub-criteria, the model was implemented and the results were obtained. The output from implementing the general model was the same as for the base model in terms of choosing the best siting technologies, their ranks, and percentage values relative to the best technology. However, their technology values were not the same because their calculation was based on desirability values not relative importance values.

Table 8.10 shows the General Model outputs and table 8.11 shows the comparison between the two models.

Table 8.10 Evaluation of Siting Technologies by Using Desirability Values

\begin{tabular}{|c|c|c|c|c|c|c|c|}
\hline \multirow[b]{2}{*}{$\begin{array}{l}\bar{\delta} \\
\text { हो } \\
\text { के }\end{array}$} & \multirow[b]{2}{*}{ Perspective } & \multirow[b]{2}{*}{$\begin{array}{l}\text { Relati } \\
\text { ve } \\
\text { Value }\end{array}$} & \multicolumn{5}{|c|}{ Siting Technologies } \\
\hline & & & $\begin{array}{l}\text { Land } \\
\text { Based }\end{array}$ & $\begin{array}{l}\text { Floating } \\
\text { Plant }\end{array}$ & $\begin{array}{l}\text { Natural } \\
\text { Island }\end{array}$ & $\begin{array}{l}\text { Artificial } \\
\text { Island }\end{array}$ & $\begin{array}{l}\text { Semi- } \\
\text { Embedded }\end{array}$ \\
\hline S & Social & 0.15 & 0.0992 & 0.1034 & 0.1343 & 0.1034 & 0.0862 \\
\hline $\mathrm{T}$ & Technical & 0.23 & 0.1432 & 0.1402 & 0.1453 & 0.1336 & 0.1521 \\
\hline $\mathrm{E}$ & Economic & 0.26 & 0.1805 & 0.1218 & 0.1778 & 0.0751 & 0.1318 \\
\hline $\mathrm{E}$ & Environmental & 0.18 & 0.0784 & 0.1571 & 0.1151 & 0.1193 & 0.0716 \\
\hline $\mathrm{P}$ & Political & 0.18 & 0.1457 & 0.0980 & 0.1425 & 0.0980 & 0.1164 \\
\hline & Total & 1.00 & 0.6470 & 0.6205 & 0.7150 & 0.5294 & 0.5581 \\
\hline & Technology Value & & 0.65 & 0.62 & 0.72 & 0.53 & 0.56 \\
\hline & Technology Rank & & 2 & 3 & 1 & 5 & 4 \\
\hline & $\begin{array}{l}\text { Relative to the Best } \\
\text { Technology }\end{array}$ & & $91 \%$ & $86 \%$ & $100 \%$ & $74 \%$ & $78 \%$ \\
\hline
\end{tabular}


Table 8.11 Comparison of Siting Technology Ranks in the Generalized Model vs. the Base Model

\begin{tabular}{|c|c|c|c|c|c|}
\hline \multicolumn{6}{|c|}{ Siting Technologies (Generalized Model) } \\
\hline Criteria & $\begin{array}{l}\text { Land } \\
\text { Based }\end{array}$ & $\begin{array}{l}\text { Floating } \\
\text { Plant }\end{array}$ & $\begin{array}{l}\text { Natural } \\
\text { Island }\end{array}$ & $\begin{array}{l}\text { Artificial } \\
\text { Island }\end{array}$ & $\begin{array}{l}\text { Semi- } \\
\text { Embedded }\end{array}$ \\
\hline $\begin{array}{c}\text { Technology Relative } \\
\text { Value }\end{array}$ & 0.65 & 0.62 & 0.72 & 0.53 & 0.56 \\
\hline Technology Rank & 2 & 3 & 1 & 5 & 4 \\
\hline $\begin{array}{l}\text { Relative to the Best } \\
\text { Technology }\end{array}$ & $91 \%$ & $86 \%$ & $100 \%$ & $74 \%$ & $78 \%$ \\
\hline \multicolumn{6}{|c|}{ Siting Technologies (Base Model) } \\
\hline Criteria & $\begin{array}{l}\text { Land } \\
\text { Based }\end{array}$ & $\begin{array}{l}\text { Floating } \\
\text { Plant }\end{array}$ & $\begin{array}{l}\text { Natural } \\
\text { Island }\end{array}$ & $\begin{array}{l}\text { Artificial } \\
\text { Island }\end{array}$ & $\begin{array}{c}\text { Semi- } \\
\text { Embedded }\end{array}$ \\
\hline $\begin{array}{c}\text { Technology } \\
\text { Relative Value } \\
\end{array}$ & 0.21 & 0.20 & 0.23 & 0.17 & 0.18 \\
\hline Technology Rank & 2 & 3 & 1 & 5 & 4 \\
\hline $\begin{array}{l}\text { Relative to the Best } \\
\text { Technology }\end{array}$ & $91 \%$ & $86 \%$ & $100 \%$ & $74 \%$ & $78 \%$ \\
\hline
\end{tabular}

\subsubsection{General Model Assessment and Technology Improvements}

The general model is identical to the base model in terms of providing similar results of choosing the best siting technologies in same ranks. However, the general model is more reliable and practical than the base model because it can evaluate any other siting technology, either one of the identified siting technologies or a completely new siting technology, with no need to do the calculations of pairwise comparisons for all technologies under evaluation. Thus, to evaluate an additional siting technology, real or estimated desirability values of the new technology's 
criteria and sub-criteria should be provided. The general model will then be used to calculate the new technology value.

Considering the general model's readiness to accommodate additional siting technologies encouraged us to study its flexibility in placing another siting technology in first place. Therefore, four scenarios were developed to test the general model to see what improvements would be needed for each of the siting technologies ranked 2 nd to 5 th to become the highest ranked technology. The intention in each testing scenario was to improve the desirability values of the selected technology under study to match or exceed the Natural Island's desirability values to bring the lower ranked technology to first place, as explained in the following steps:

1. Each siting technology's desirability values corresponding to the criteria and sub-criteria in the generalized model were listed and compared to those of the current best technology (i.e., Natural Island), as shown in Table 8.12.

2. Radar graphs were drawn (Figures 8.7, 8.8, 8.9, and 8.10) to illustrate the differences between the desirability values of the two technologies under study, corresponding to the criteria and sub-criteria, and to focus on the most significant differences.

3. The difference $(\Delta)$ between the weighted desirability value of each criterion/sub-criterion of the lower ranked technology and the highest- 
ranked technology (i.e., Natural Island) was calculated. The sum of all differences was also computed (Table 8.13).

4. For any siting technology to move to the first rank (i.e., improve), the sum of the difference $(\Delta)$ between the weighted desirability values of the lower ranked technology minus those of Natural Island should be greater than zero.

5. The improvement process was completed by incrementally changing each technology's desirability values one by one until that technology became the preferred one.

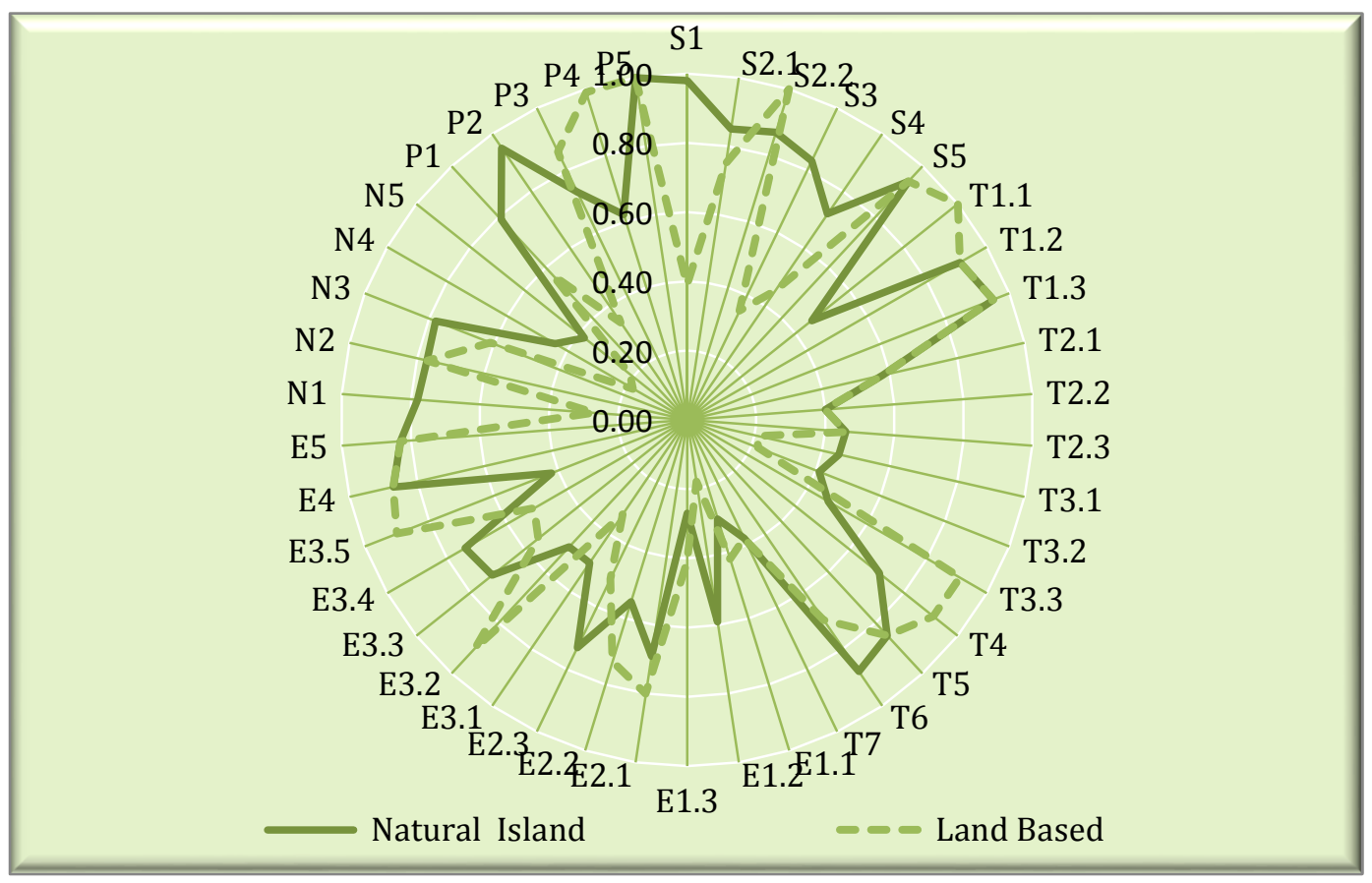

Figure 8.7 Differences Between the Desirability Values of Natural Island and Land-Based Siting Technologies 
Table 8.12 The Differences Between the Natural Island and Land-Based Siting Technologies
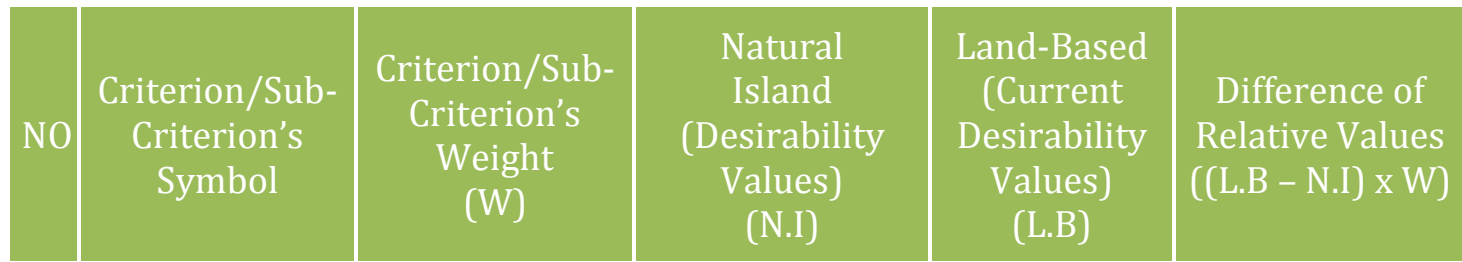

\begin{tabular}{|c|c|c|}
\hline 1 & S1 & \\
\hline 2 & S2.1 & \\
\hline 3 & S2.2 & \\
\hline 4 & S3 & \\
\hline 5 & S4 & \\
\hline 6 & S5 & \\
\hline
\end{tabular}

\begin{tabular}{l}
7 \\
\hline 8 \\
\hline 9
\end{tabular}

T1.1

0.0405

0.0347

0.98

0.0179

0.85

0.0150

0.87

0.0105

0.83

0.0315

0.72

0.0103

0.94

T1.2

0.0158

0.46

T1.3

0.0061

0.91

T2.1

0.0120

T2.2

0.0039

0.95

0.39

0.39
0.75

$-0.0239$

T2.3

0.0141

T3.1

0.0190

0.58

0.40

1.00

$-0.0035$

T3.2

0.0288

T3.3

0.0098

0.0299

T4

0.0299

0.46

T5

0.0276

0.45

0.0023

0.35

$-0.0072$

T6

T7

0.0276

0.41

0.47

0.71

0.85

0.45

$-0.0028$

0.94

0.0000

1.00

0.0056

0.91

0.0000

0.95

0.0000

0.58

0.0000

0.40

0.0000

0.46

0.0000

0.21

$-0.0046$

E1.1

0.0104

0.88

0.38

0.22

$-0.0055$

E1.2

0.0141

0.30

E1.3

0.0171

0.59

E2.1

0.0281

0.27

0.91

0.0043

0.91

0.0060

0.85

0.0000

0.70

$-0.0050$

0.38

0.0000

0.42

0.0012

0.18

$-0.0058$

0.41

0.0024

E2.2

0.0191

0.69

0.80

0.0031

E2.3

0.0126

0.55

0.73

0.0034

E3.1

0.0092

0.73

0.51

$-0.0028$

E3.2

0.0075

0.50

0.33

$-0.0016$

E3.3

0.0065

0.50

0.90

0.0030

E3.4

0.0111

0.72

0.55

$-0.0011$

E3.5

0.0069

0.74

0.51

$-0.0025$

0.42

0.90

0.0033 


\begin{tabular}{|c|c|c|c|c|c|}
\hline NO & $\begin{array}{l}\text { Criterion/Sub- } \\
\text { Criterion's } \\
\text { Symbol }\end{array}$ & $\begin{array}{l}\text { Criterion/Sub- } \\
\text { Criterion's } \\
\text { Weight } \\
\text { (W) }\end{array}$ & $\begin{array}{l}\text { Natural } \\
\text { Island } \\
\text { (Desirability } \\
\text { Values) } \\
\text { (N.I) }\end{array}$ & $\begin{array}{l}\text { Land-Based } \\
\text { (Current } \\
\text { Desirability } \\
\text { Values) } \\
\text { (L.B) }\end{array}$ & $\begin{array}{l}\text { Difference of } \\
\text { Relative Values } \\
((\text { L.B - N.I) x W) }\end{array}$ \\
\hline 31 & E4 & 0.0364 & 0.87 & 0.87 & 0.0000 \\
\hline 32 & E5 & 0.0806 & 0.83 & 0.83 & 0.0000 \\
\hline 33 & N1 & 0.0282 & 0.78 & 0.27 & -0.0144 \\
\hline 34 & $\mathrm{~N} 2$ & 0.0368 & 0.77 & 0.77 & 0.0000 \\
\hline 35 & N3 & 0.0482 & 0.78 & 0.61 & -0.0082 \\
\hline 36 & N4 & 0.0306 & 0.44 & 0.18 & -0.0080 \\
\hline 37 & N5 & 0.0360 & 0.38 & 0.21 & -0.0061 \\
\hline 38 & $\mathrm{P} 1$ & 0.0273 & 0.79 & 0.57 & -0.0060 \\
\hline 39 & P2 & 0.0443 & 0.95 & 0.34 & -0.0270 \\
\hline 40 & P3 & 0.0212 & 0.73 & 0.86 & 0.0027 \\
\hline 41 & P4 & 0.0365 & 0.62 & 0.99 & 0.0135 \\
\hline 42 & P5 & 0.0509 & 1.00 & 1.00 & 0.0000 \\
\hline & \multicolumn{4}{|c|}{$\begin{array}{c}\text { Sum of the Difference }(\Delta) \text { Between the Weighted Desirability } \\
\text { Values of lower-ranked technology (Land-Based) minus those of } \\
\text { highest-ranked technology (Natural Island) }\end{array}$} & -0.0849 \\
\hline
\end{tabular}

Several different approaches could have been used to obtain the required value of the difference $(\Delta)$ greater than zero. For example, the improvement process could focus on the most critical criteria or sub-criteria (i.e., those with high weights). Then their desirability values could be changed/improved promptly to the upper possible levels and the researcher could watch for when the sum of the differences becomes greater than zero. Another approach is to focus on one/more group(s) of criteria under specific perspective(s) and the changes made for the desirability values within the group(s) to study the impacts. In addition, any random combinations of criteria and/or sub-criteria could be used to change their desirability values to achieve the value of $(\Delta)$ greater than zero. 
Table 8.13 Land-Based Improvements for the First Place as Best Siting Technology

\begin{tabular}{|c|c|c|c|c|c|c|c|}
\hline NO & $\begin{array}{c}\text { Criterion/ } \\
\text { Sub- } \\
\text { Criterion' } \\
\text { s } \\
\text { Symbol }\end{array}$ & $\begin{array}{l}\text { Criterion/ } \\
\text { Sub- } \\
\text { Criterion's } \\
\text { Weight } \\
\text { (W) }\end{array}$ & $\begin{array}{l}\text { Natural } \\
\text { Island } \\
\text { (Desirability } \\
\text { Values) } \\
\text { (N.I) }\end{array}$ & $\begin{array}{l}\text { Land-Based } \\
\text { (Current } \\
\text { Desirability } \\
\text { Values) } \\
\text { (L.Bc) }\end{array}$ & $\begin{array}{l}\text { Land-Based } \\
\text { (Improved } \\
\text { Desirability } \\
\text { Values) } \\
\text { (L.Bi) }\end{array}$ & $\begin{array}{c}\text { Difference } \\
\text { of Current } \\
\text { Relative } \\
\text { Values } \\
((\text { L.Bc - N.I) } \\
\text { x W })\end{array}$ & $\begin{array}{c}\text { Difference } \\
\text { of Improved } \\
\text { Relative } \\
\text { Values } \\
((\text { L.Bi - N.I }) \\
\text { x W })\end{array}$ \\
\hline 1 & E5 & 0.0806 & 0.83 & 0.83 & $\longrightarrow 0.94$ & 0.0000 & 0.0089 \\
\hline 2 & N3 & 0.0482 & 0.78 & 0.61 & $\longrightarrow 0.78$ & -0.0082 & 0.0000 \\
\hline 3 & P2 & 0.0443 & 0.95 & 0.34 & $\longrightarrow 0.53$ & -0.0270 & -0.0186 \\
\hline 4 & S1 & 0.0405 & 0.98 & 0.39 & $\rightarrow 0.68$ & -0.0239 & -0.0122 \\
\hline 5 & $\mathrm{~N} 2$ & 0.0368 & 0.77 & 0.77 & $\longrightarrow 0.90$ & 0.0000 & 0.0048 \\
\hline 6 & E4 & 0.0364 & 0.87 & 0.87 & $\rightarrow \quad 1.00$ & 0.0000 & 0.0047 \\
\hline 7 & N5 & 0.0360 & 0.38 & 0.21 & $\rightarrow 0.38$ & -0.0061 & 0.0000 \\
\hline 8 & S2.1 & 0.0347 & 0.85 & 0.75 & $\rightarrow \quad 0.85$ & -0.0035 & 0.0000 \\
\hline 9 & N4 & 0.0306 & 0.44 & 0.18 & $\rightarrow 0.44$ & -0.0080 & 0.0000 \\
\hline 10 & $\mathrm{~T} 4$ & 0.0299 & 0.71 & 0.91 & $\rightarrow 0.97$ & 0.0060 & 0.0078 \\
\hline 11 & T3.2 & 0.0288 & 0.41 & 0.22 & $\rightarrow \quad 0.41$ & -0.0055 & 0.0000 \\
\hline 12 & $\mathrm{~N} 1$ & 0.0282 & 0.78 & 0.27 & $\rightarrow 0.66$ & -0.0144 & -0.0034 \\
\hline 13 & E2.1 & 0.0281 & 0.69 & 0.80 & $\rightarrow 0.93$ & 0.0031 & 0.0067 \\
\hline \multicolumn{6}{|c|}{$\begin{array}{l}\text { Sum of the Difference }(\Delta) \text { Between the Weighted Desirability } \\
\text { Values of lower-ranked technology (Land-Based) minus those of } \\
\text { highest-ranked technology (Natural Island) }\end{array}$} & $-0.0849 \longrightarrow$ & 0.0013 \\
\hline
\end{tabular}

The results of the other three scenarios are shown in Tables 8.14, 8.15, and 8.16 for Floating Plant, Semi-Embedded Plant, and Artificial Island siting technologies, respectively. Land-Based siting technology needed 13 performance dimensions corresponding to criteria/sub-criteria to move to the next higher value to become the best technology. Floating plant, Semi-Embedded, and Artificial Island siting technologies needed 6 , 9, and 7 performance dimensions, respectively, to move one step closer to first place. 


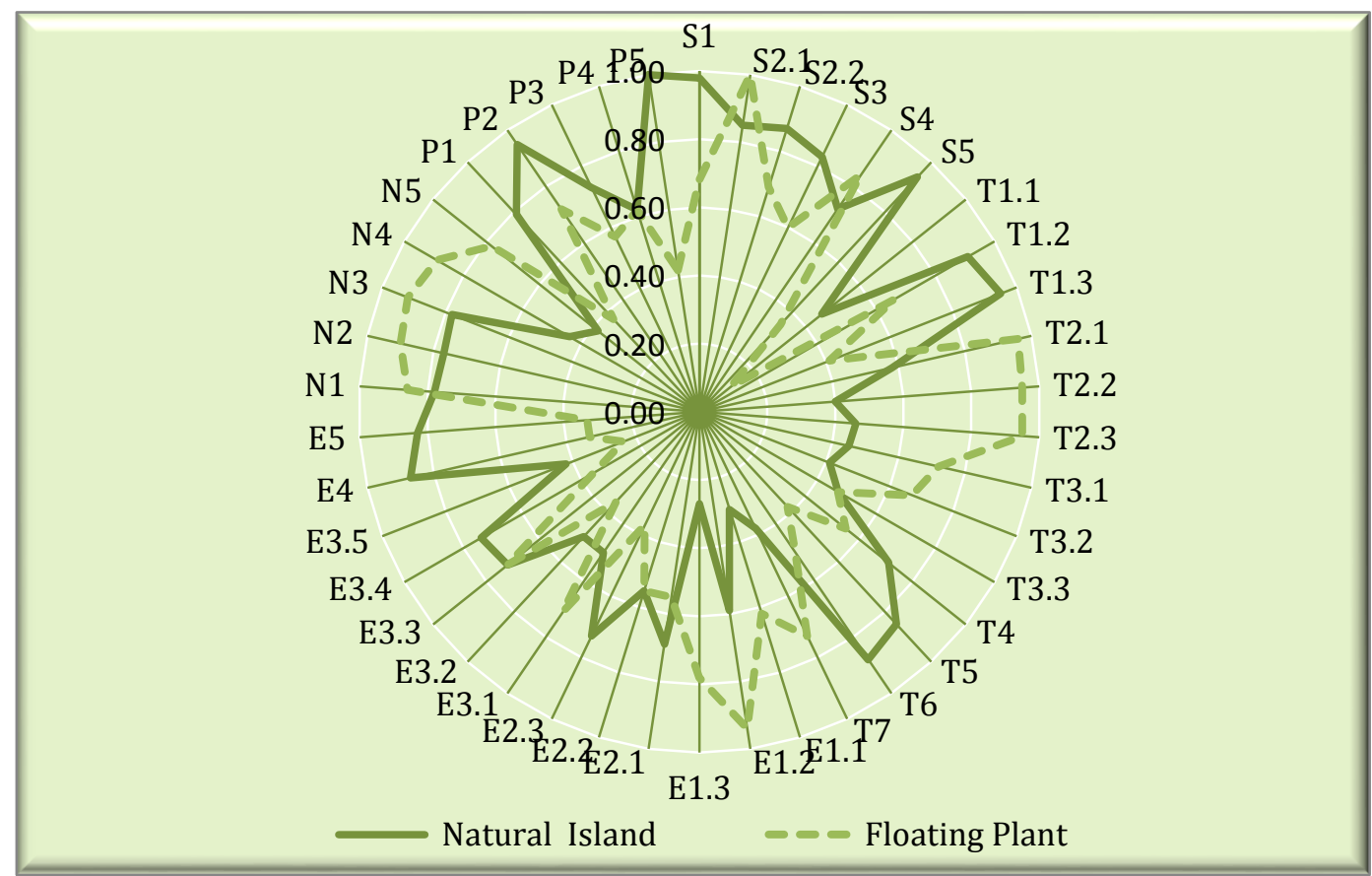

Figure 8.8 Differences Between the Desirability Values of Natural Island and Floating Plant Siting Technologies

Table 8.14 Floating Plant Improvements for the First Place as Best Siting Technology

\begin{tabular}{|c|c|c|c|c|c|c|c|}
\hline z & $\begin{array}{c}\text { Criterion/ } \\
\text { Sub- } \\
\text { Criterion's } \\
\text { Symbol }\end{array}$ & $\begin{array}{l}\text { Criterion/ } \\
\text { Sub- } \\
\text { Criterion's } \\
\text { Weight } \\
\text { (W) }\end{array}$ & $\begin{array}{l}\text { Natural } \\
\text { Island } \\
\text { (Desirability } \\
\text { Values) } \\
\text { (N.I) }\end{array}$ & $\begin{array}{l}\text { Floating } \\
\text { Plant } \\
\text { (Current } \\
\text { Desirability } \\
\text { Values) } \\
\text { (F.Pc) }\end{array}$ & $\begin{array}{l}\text { Floating } \\
\text { Plant } \\
\text { (Improved } \\
\text { Desirability } \\
\text { Values) } \\
\text { (F.Pi) }\end{array}$ & $\begin{array}{c}\text { Difference } \\
\text { of Current } \\
\text { Relative } \\
\text { Values } \\
\text { ((F.Pc- N.I) } \\
\text { x W) }\end{array}$ & $\begin{array}{c}\text { Difference } \\
\text { of Improved } \\
\text { Relative } \\
\text { Values } \\
\text { ((F.Pi - N.I) } \\
\text { x W) }\end{array}$ \\
\hline 1 & E5 & 0.0806 & 0.83 & 0.33 & $\Rightarrow \quad 0.62$ & -0.0403 & -0.0169 \\
\hline 2 & P5 & 0.0509 & 1.00 & 0.42 & $\rightarrow \quad 1.00$ & -0.0295 & 0.0000 \\
\hline 3 & N3 & 0.0482 & 0.78 & 0.92 & $\Rightarrow \quad 1.00$ & 0.0067 & 0.0106 \\
\hline 4 & P2 & 0.0443 & 0.95 & 0.72 & $\longrightarrow \quad 0.95$ & -0.0102 & 0.0000 \\
\hline 5 & S1 & 0.0405 & 0.98 & 0.68 & $\longrightarrow 0.98$ & -0.0122 & 0.0000 \\
\hline 6 & $\mathrm{~N} 2$ & 0.0368 & 0.77 & 0.90 & $\longrightarrow \quad 1.00$ & 0.0048 & 0.0085 \\
\hline & um of th & fference & Betweel & leighte & $\begin{array}{l}\text { Desirability } \\
\text { J minus those }\end{array}$ & -0.1016 & $\rightarrow 0.0021$ \\
\hline
\end{tabular}




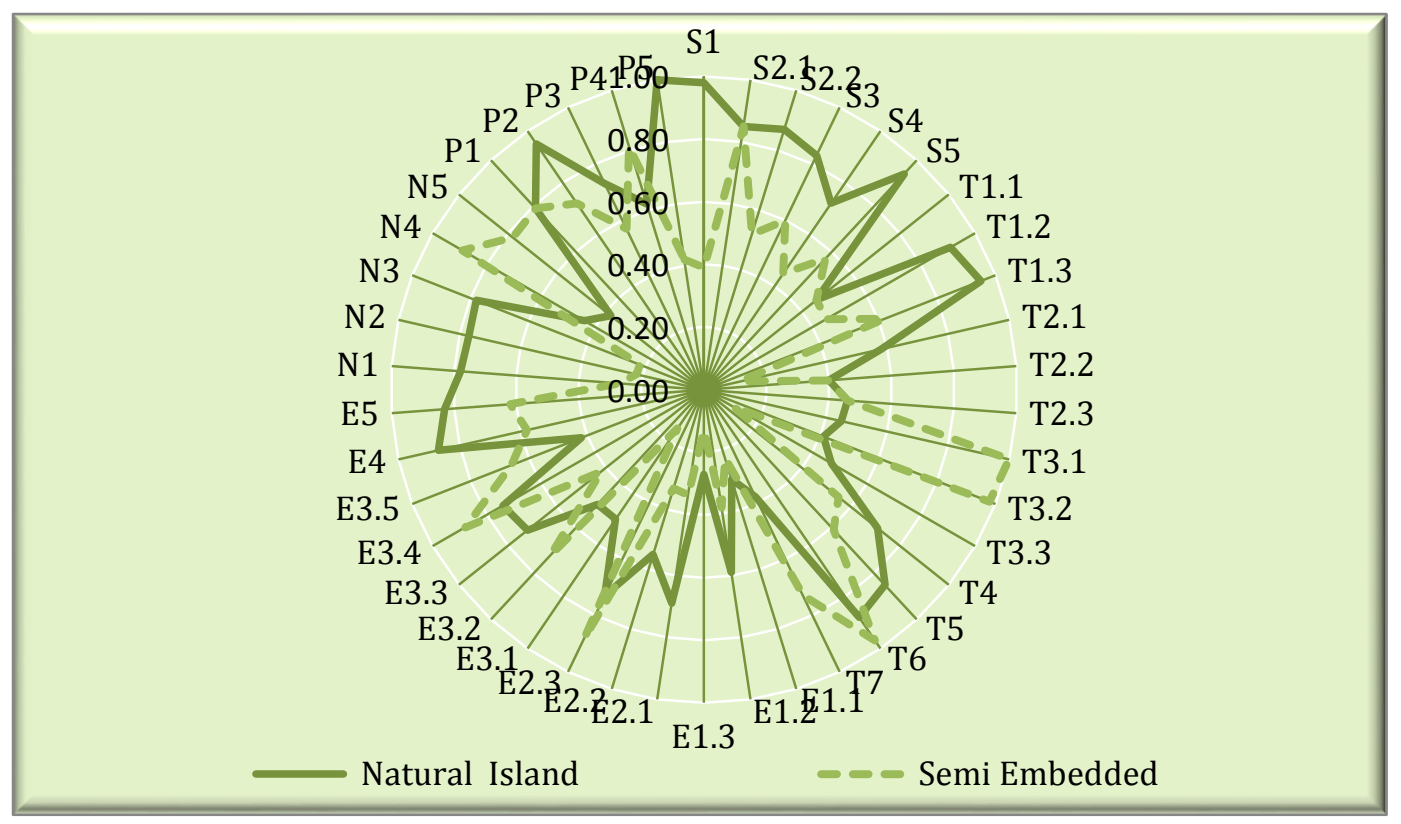

Figure 8.9 Differences Between the Desirability Values of Natural Island and Semi-Embedded Plant Siting Technologies

Table 8.15 Semi-Embedded Plant Improvements for the First Place as Best Siting Technology

\begin{tabular}{|c|c|c|c|c|c|c|c|c|}
\hline ㅇ & $\begin{array}{l}\text { Criterion/ } \\
\text { Sub- } \\
\text { Criterion's } \\
\text { Symbol }\end{array}$ & $\begin{array}{c}\text { Criterion/ } \\
\text { Sub- } \\
\text { Criterion's } \\
\text { Weight } \\
\text { (W) }\end{array}$ & $\begin{array}{l}\text { Natural } \\
\text { Island } \\
\text { (Desirability } \\
\text { Values) } \\
\text { (N.I) }\end{array}$ & $\begin{array}{c}\text { Semi- } \\
\text { Embedded } \\
\text { (Current } \\
\text { Desirability } \\
\text { Values) } \\
\text { (S.Ec) }\end{array}$ & & $\begin{array}{l}\text { Semi- } \\
\text { Embedded } \\
\text { (Improved } \\
\text { Desirability } \\
\text { Values) } \\
\text { (S.Ei) }\end{array}$ & $\begin{array}{c}\text { Difference } \\
\text { of Current } \\
\text { Relative } \\
\text { Values } \\
((\text { S.Ec - N.I) } \\
\text { x W })\end{array}$ & $\begin{array}{c}\text { Difference } \\
\text { of Improved } \\
\text { Relative } \\
\text { Values } \\
\text { ((S.Ei - N.I) } \\
\text { x W) }\end{array}$ \\
\hline 1 & E5 & 0.0806 & 0.83 & 0.62 & $\rightarrow$ & 0.83 & -0.0169 & 0.0000 \\
\hline 2 & P5 & 0.0509 & 1.00 & 0.42 & $\longrightarrow$ & 1.00 & -0.0295 & 0.0000 \\
\hline 3 & N3 & 0.0482 & 0.78 & 0.22 & $\rightarrow$ & 0.61 & -0.0270 & -0.0082 \\
\hline 4 & P2 & 0.0443 & 0.95 & 0.72 & $\rightarrow$ & 0.95 & -0.0102 & 0.0000 \\
\hline 5 & S1 & 0.0405 & 0.98 & 0.39 & $\rightarrow$ & 0.68 & -0.0239 & -0.0122 \\
\hline 6 & $\mathrm{~N} 2$ & 0.0368 & 0.77 & 0.22 & $\rightarrow$ & 0.60 & -0.0203 & -0.0063 \\
\hline 7 & $\mathrm{P} 4$ & 0.0365 & 0.62 & 0.81 & $\rightarrow$ & 0.99 & 0.0069 & 0.0135 \\
\hline 8 & E4 & 0.0364 & 0.87 & 0.58 & $\rightarrow$ & 0.87 & -0.0106 & 0.0000 \\
\hline 9 & N5 & 0.0360 & 0.38 & 0.78 & $\Longrightarrow$ & 0.93 & 0.0144 & 0.0198 \\
\hline & $\begin{array}{l}\text { ues of lowe } \\
\text { of hi }\end{array}$ & $\begin{array}{l}\text { Jifterence } \\
\text { r-ranked te } \\
\text { ghest-ranke }\end{array}$ & $\begin{array}{l}\text { J between t } \\
\text { chnology (Se) } \\
\text { ed technology }\end{array}$ & Natural I: & Desil & ability & \multicolumn{2}{|l|}{$-0.1539 \rightarrow$} \\
\hline
\end{tabular}




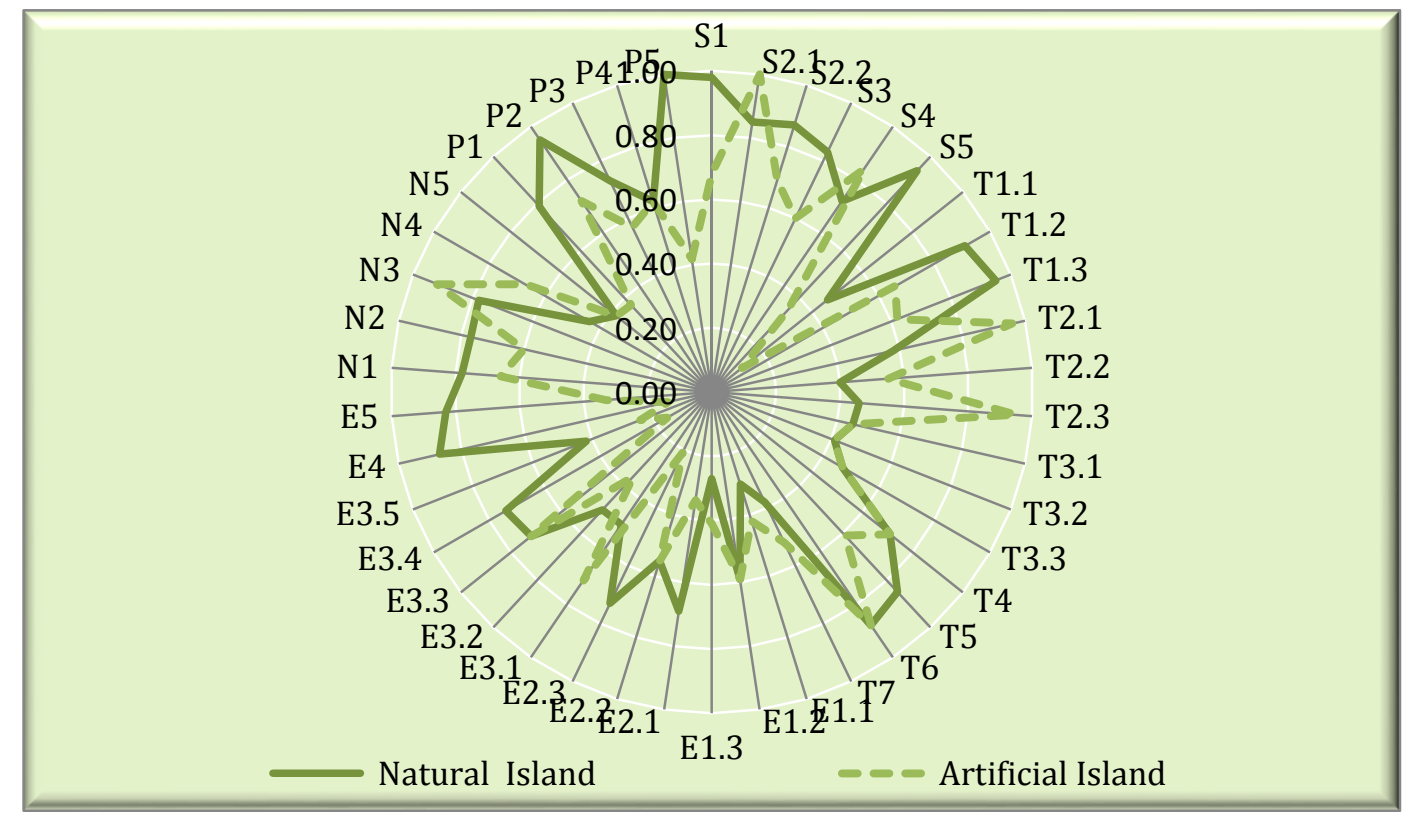

Figure 8.10 Differences Between the Desirability Values of Natural Island and Artificial Island Siting Technologies

Table 8.16 Artificial Island Improvements for the First Place as Best Siting Technology

\begin{tabular}{|c|c|c|c|c|c|c|c|}
\hline z & $\begin{array}{c}\text { Criterion/ } \\
\text { Sub- } \\
\text { Criterion's } \\
\text { Symbol }\end{array}$ & $\begin{array}{l}\text { Criterion/ } \\
\text { Sub- } \\
\text { Criterion's } \\
\text { Weight } \\
\text { (W) }\end{array}$ & $\begin{array}{l}\text { Natural } \\
\text { Island } \\
\text { (Desirability } \\
\text { Values) } \\
\text { (N.I) }\end{array}$ & $\begin{array}{c}\text { Artificial } \\
\text { Island } \\
\text { (Current } \\
\text { Desirability } \\
\text { Values) } \\
\text { (A.Ic) }\end{array}$ & $\begin{array}{c}\text { Artificial } \\
\text { Island } \\
\text { (Improved } \\
\text { Desirability } \\
\text { Values) } \\
\text { (A.Ii) }\end{array}$ & $\begin{array}{c}\text { Difference } \\
\text { of Current } \\
\text { Relative } \\
\text { Values } \\
\text { ((A.Ic - N.I) } \\
\text { x W) }\end{array}$ & $\begin{array}{c}\text { Difference } \\
\text { of Improved } \\
\text { Relative } \\
\text { Values } \\
\text { ((A.Ii - N.I) } \\
\text { x W) }\end{array}$ \\
\hline 1 & E5 & 0.0806 & 0.83 & 0.33 & $\Rightarrow 0.62$ & -0.0403 & -0.0169 \\
\hline 2 & P5 & 0.0509 & 1.00 & 0.42 & $\rightarrow 1.00$ & -0.0295 & 0.0000 \\
\hline 3 & N3 & 0.0482 & 0.78 & 0.92 & $\longrightarrow \quad 1.00$ & 0.0067 & 0.0106 \\
\hline 4 & P2 & 0.0443 & 0.95 & 0.72 & $\longrightarrow 0.95$ & -0.0102 & 0.0000 \\
\hline 5 & S1 & 0.0405 & 0.98 & 0.68 & $\longrightarrow 0.98$ & -0.0122 & 0.0000 \\
\hline 6 & $\mathrm{~N} 2$ & 0.0368 & 0.77 & 0.60 & $\longrightarrow 0.90$ & -0.0063 & 0.0048 \\
\hline 7 & P4 & 0.0365 & 0.62 & 0.62 & $\longrightarrow 0.81$ & 0.0000 & 0.0069 \\
\hline \multicolumn{6}{|c|}{$\begin{array}{c}\text { Sum of the Difference }(\Delta) \text { Between the Weighted Desirability } \\
\text { Values of lower-ranked technology (Artificial Island) minus } \\
\text { those of highest-ranked technology (Natural Island) }\end{array}$} & -0.1674 & 0.0054 \\
\hline
\end{tabular}




\section{CHAPTER 9: RESEARCH DISCUSSIONS AND CONCLUSIONS}

\subsection{Research Discussions}

In this research, a decision model was developed and used to evaluate several alternatives in nuclear power plant (NPP) siting technology. The evaluation process ended in choosing the Natural Island as the best siting technology among five other technologies, including Land-Based. Selection of the Natural Island contradicts the usual choice of Land-Based siting technology as the best for nuclear power plants. Thus, what is the reason for such a decision? Is it the domination of Land-Based siting over other alternatives, the influence of the current decision model's configuration, or the influence of the experts involved in the evaluation process?

\subsubsection{Land-Based vs. the Alternatives}

Land-Based siting technology is the best known option for building a nuclear power plant. Since the first assembled nuclear power plant and to date, Land-Based technology has been virtually the only siting technology used to build the existing

operational nuclear power plants despite the availability of many other siting technologies.

Siting technologies such as offshore and underground technologies have been considered in several studies and different projects, but they have never been 
used in real commercial large-scale nuclear power projects. Chapter 2 of this research (Literature Review) summarizes these studies.

Thus, why is Land-Based the dominant siting technology while many other options are available for building nuclear power plants? To answer this question, we must consider the following points:

- The concept of alternative sitings for nuclear power plants such as offshore and underground was introduced in the early 1970s when there was both rapid growth in the demand for electricity from nuclear power plants and growing concern about limited resources of suitable lands and large quantities of water. However, in just a few years, the demand for electricity fell dramatically in conjunction with the economic recession and the changing social attitudes toward nuclear power after the first nuclear accident at Three Mile Island in 1979. Consequently, many reactor orders and a major nuclear plant project offshore of New Jersey were canceled.

- From 1980 until about 2002, several new nuclear power plants were constructed, using Land-Based siting technology, where the land availability was not a concern and, accordingly, there was no need to consider the offshore or underground alternatives. The Land-Based technology remained dominant. 
- $\quad$ Most of the research papers in the literature focus on the site selection issue of the best location for nuclear power plants, not the best siting technology. As defined in this research, siting selection is a pre-step in site selection. Thus, we can infer that siting technology was not an issue to consider as long as the Land-Based was the best known technology, with more than 50 years of experience and in excess of 400 implementations.

- According to the World Nuclear Association (WNA), 45 countries are planning to build their first nuclear power plant by the end of 2030. In addition to the existing and operating 430 nuclear power reactors (NPRs), many new installations of NPRs (66 are under construction) are taking place almost everywhere in the world. For example, China alone is planning a massive expansion of nuclear energy and aims to have 110 NPRs in operation by 2030. (Note: This point and the next one were the motivations to conduct this research, as explained in Chapter 3)

- The history of nuclear power plant accidents, the calamity of Fukushima (Japan, 2011), the occurence of Hurricane Sandy (USA, 2012) and their extreme impacts on the industry of nuclear power raised the bar with respect to installing new NPPs in safer and more secure places, such as offshore and underground. 
- $\quad$ Most identified siting technologies are still merely concepts because they have never been used in real commercial applications. However, the world's first floating offshore nuclear power plant will be launched in September 2016 from Russia.

- The main purposes of this research and the developed decision model were to re-introduce these siting technologies, promote their advantages, and call for more investigations to improve their level of acceptance and implementation. For example, the selection of Natural Island as the best siting technology would not have been realized without such research and development of the decision model.

Therefore, the lack of such a research that has re-introduced these alternatives was the main reason for the dominance of Land-Based siting technology and the neglect of the alternatives.

\subsubsection{Influence of the Current Decision Model}

To the best of the author's knowledge, only one study in the literature is similar to this research where several siting technologies have been considered and evaluated to choose the best among them. That case was conducted in 1974, when the new siting alternatives were introduced, to study the available alternative sitings for electric power-generating plants in California [103]. The study 
considered several offshore and underground options in addition to the Land-Based option.

That study and this research were both conducted with the same objective. However, the results differed. The other study selected Land-Based and our model selected Natural Island.

The domination of Land-Based was justified in the previous section, so what does it mean that the current model selected the Natural Island as the best siting technology?

- The Natural Island concept considered in this research is defined as a suitable area of land surrounded entirely by water, isolated, and an acceptable distance from the mainland. The concept of Natural Island siting for nuclear power plants is identical to Land-Based siting from a technical perspective because no special technical arrangements are required to implement Natural Island siting. Thus, the two can technically be considered as one siting technology. However, the literature treats them as two different siting technologies because of differences in their natures and advantages/ disadvantages of one over the other. The differences between them were characterized by the different values/weights of the criteria and sub-criteria of our decision model. 
- The current model considered the 5-STEEP perspectives as the domain of the identified and validated criteria and sub-criteria used to evaluate the alternative siting technologies. In contrast, the older study considered three categories of criteria: cost (i.e., economic), environmental impacts, and feasibility and risk (i.e., technical). Social and political criteria were not part of the older study. The influnce of social and political criteria and subcriteria were noticeable and significant in our model. For example, when the social perspective was given the highest priority value of 0.96 , as explained in section 7.3.2 of Chapter 7 to understand its importance within the model, the Natural Island was selected as the best siting technology. The same thing happened when the political perspective was given the highest priority value of 0.96 . Thus, the existence of the two perspectives in the current decision model with their criteria and sub-criteria added a comprehensiveness feature to the model and improved the model's output. Our model differentiated between the two siting technologies as the literature and the experts did.

- On the other hand, when the social and political perspectives were excluded from the general decision model, both siting technologies, Land-Based and Natural Island, obtained equal technology values, which put them in first place as best and for being considered as one siting technology. Tabel 9.1 shows the results of excluding both perspectives from the model. 
Table 9.1 Results of Excluding the Social and Political Perspectives from the Base Decision Model

\begin{tabular}{|c|c|c|c|c|c|c|c|}
\hline \multirow[b]{2}{*}{$\begin{array}{l}\overline{8} \\
\text { हे } \\
\text { हे }\end{array}$} & \multirow[b]{2}{*}{ Perspective } & \multirow[b]{2}{*}{$\begin{array}{c}\text { Relative } \\
\text { Value }\end{array}$} & \multicolumn{5}{|c|}{ Siting Technologies } \\
\hline & & & $\begin{array}{l}\text { Land } \\
\text { Based } \\
\text { (L.B) }\end{array}$ & $\begin{array}{l}\text { Floating } \\
\text { Plant } \\
\text { (F.P) }\end{array}$ & $\begin{array}{l}\text { Natural } \\
\text { Island } \\
\text { (N.I) }\end{array}$ & $\begin{array}{l}\text { Artificial } \\
\text { Island } \\
\text { (A.I) }\end{array}$ & $\begin{array}{c}\text { Semi } \\
\text { Embedded } \\
\text { (S.E) }\end{array}$ \\
\hline S & Social & 0.00 & 0.00000 & 0.00000 & 0.00000 & 0.00000 & 0.00000 \\
\hline $\mathrm{T}$ & Technical & 0.23 & 0.04578 & 0.04247 & 0.04248 & 0.04468 & 0.05151 \\
\hline $\mathrm{E}$ & Economic & 0.26 & 0.07178 & 0.04511 & 0.06202 & 0.03413 & 0.04253 \\
\hline E & Environmental & 0.18 & 0.02357 & 0.04224 & 0.03719 & 0.03591 & 0.03001 \\
\hline $\mathrm{P}$ & Political & 0.00 & 0.00000 & 0.00000 & 0.00000 & 0.00000 & 0.00000 \\
\hline & Total & & 0.14113 & 0.13182 & 0.14169 & 0.11472 & 0.12405 \\
\hline & Technology Value & & 0.14 & 0.13 & 0.14 & 0.11 & 0.12 \\
\hline & Technology Rank & & 1 & 2 & 1 & 4 & 3 \\
\hline & Technology Value (Was) & & 0.21 & 0.20 & 0.23 & 0.17 & 0.18 \\
\hline & Technology Rank (Was) & & 2 & 3 & 1 & 5 & 4 \\
\hline
\end{tabular}

Therefore, in terms of structure and elements, the current model made a major difference in evaluating several siting technologies and in selecting the best among them.

\subsubsection{The Experts and Their Influence on Selecting the Natural Island}

As explained in Chapter 7, the comparisons among the five siting technologies were done for pairs, meaning that each siting technology was compared to another technology on one criterion/sub-criterion at a time. This technique allowed the experts to focus their evaluation on two technologies at once and assign a proper weight (relative importance value) for each technology. Thus, 
each pair of siting technologies (e.g., Land-Based and Natural Island, Land-Based and Floating Plant) was compared one-to-one 42 times as per the total number of criteria and sub-criteria in the upper immediate level and the comparisons were repeated more than 10 times as per the average number of experts per panel. Therefore, the total technology value of each siting technology was the average output of more than 420 comparisons between each two technologies, which indicates and ensures that each siting technology was evaluated fairly and properly by the experts..

We can assure that selection of the Natural Island siting over Land-Based was realistic and acceptable and the biased influence of the experts was at minimum because:

- The experts worked independently with no direct connections among them during the evaluation process.

- The experts answered the questionnaires and performed the pairwise comparisons through private and individual links to web-based tools. Thus, the experts' inputs mainly represented their own judgments.

- The 53 experts were from different countries, affiliations, and backgrounds, which means the decision was based on a large diversity of knowledge and the average inputs of 53 experiences. 
- $\quad$ Most of the experts are highly educated (96\% PhDs). More than $80 \%$ were from academia and the remaining came from consultation and research firms.

Therefore, the influence of the expert on the decision was unbiased and fair.

\subsubsection{Model's Applicability for other Energy Technologies}

The current decision model was built on the HDM structure, which is characterized by its flexibility. HDM flexibility is represented in its potential to accommodate any number of evaluation elements, at any number of levels, and for any number of alternatives. Thus, using the model to evaluate additional siting technologies for nuclear power plants would not become an issue.

This model was built and its elements were identified based on the special characteristics of nuclear power plants. The most prominent characteristic is NPPs' independence from fuel/energy sources. Other energy technologies such as solar, wind, fossil, geothermal, and hydropower are mainly fuel source dependent. For example, solar and wind power stations cannot be built underground where sun light and winds are not available. Hydropower and geothermal are clear examples of fuel/energy source dependence. Solar power stations can be built offshore, either on floating plants or natural islands, but require a huge area of land or space, which is unrealistic. Thus, using the current model to evaluate siting technologies of other 
energy technologies is possible but the model would need major modifications in terms of elements and alternatives identification.

However, the general structure of the model can be used as is with minor modifications of the criteria and sub-criteria to evaluate several type of energies (i.e., solar, wind, geothermal, biomass, and nuclear) to choose the best one for a specific power station project.

\subsection{Research Conclusions}

A unique HDM was developed to evaluate different nuclear power plant siting technologies. The main purpose of the developed decision model was to help decision makers in deciding what siting technology among all potential technologies is best for a specific nuclear power plant.

The developed decision model was built gradually in several sequential steps. Each step was considered carefully and completed under the supervision of the research's committee chair. The model was developed at first as a base model and then generalized. The base model was tested to prove its reliability and readiness to achieve its objective and then generalized to form the holistic model.

The model's elements were identified from the literature and then validated by the experts. The experts came from different countries, affiliations, and backgrounds. 


\subsubsection{Research Contributions}

The main contribution of this research is the development of a holistic, robust, and usable decision model for evaluating alternative siting technologies for building nuclear power plants. The developed model is unique because siting technologies have never been evaluated based on the 5-STEEP perspectives, with a large number and well-identified criteria and sub-criteria, and the model can accommodate any number of available or future alternatives.

In addition to the main contribution, the research and developed decision model make several important additions to the body of knowledge and the nuclear power industry. These additions are:

- The research will encourage the nuclear industry, energy utilities, investors, governments, and society in general to consider the novel unused siting technologies (i.e., offshore and underground) and their sub-sitings in future installations.

- $\quad$ The research will open up possibilities to consider different siting solutions that will reduce people's fear of having a nuclear power plants "in my backyard."

- $\quad$ The model will help in planning and designing an entire nuclear power plant project in terms of location, required land/space, reactor and coolant 
technologies, safety and protection systems, waste management possibilities, public acceptance, and regulatory approvals.

- $\quad$ The model will make the important criteria for siting decisions explicit under the five perspectives.

- $\quad$ The model will support the trend of building more nuclear power plants to satisfy the increased need for clean energy.

- The model will mitigate the restrictions of land availability and safety requirements.

- $\quad$ The model will help the nuclear industry consider a wide range of nuclear energy-related issues that have not been examined in serious studies and take actions to address and resolve them.

- $\quad$ The model will promote the idea of building similar decision models for other energy issues.

- The model is an addition to the hierarchical decision methodology and represents one of its genuine applications.

\subsubsection{Research Limitations:}

- The model was developed to evaluate nuclear power plant siting technologies. Thus, to evaluate siting technologies of any energy other than 
nuclear, some sort of modification is required in the model in terms of decision elements and potential alternatives.

- $\quad$ The decision model was developed to help policy makers choose the best siting technology by considering the relative importance values of the 5STEEP perspectives. However, any other beneficiaries, such as power utilities, investors, and consumers, the model's objective, and the values of the 5-STEEP perspectives must be defined accordingly.

- $\quad$ The base model was developed by using pairwise comparisons (i.e., comparing each two technologies with respect to one criterion/sub-criterion at a time) because no real data were available for the technologies to be used in the evaluation process except for Land-Based technology. However, the launching of the new floating nuclear power plant at the end of this year (i.e., 2016) will provide real data on floating siting technology, which might change the decision entirely.

- $\quad$ The model was developed based on the subjective judgments of the involved group of experts. Thus, any other group of experts might affect the model development or the final output.

\subsubsection{Future Work}

The completion of this research and the development of the decision model provide the base for future research such as: 
- $\quad$ Developing a similar model for selecting the best location for a nuclear power plant after selecting best siting technology. In other words, while the current model will select the best siting technology among the potential technologies, the future model would choose the most suitable site or actual position out of the potential available sites.

- $\quad$ Other future work can investigate adapting the model to select the best siting for nuclear waste.

- A third potential future work is to modify the model for use in evaluating various renewable energy sources such as solar, wind, geothermal, and biomass to select the best among them for a specific energy project.

- $\quad$ One additional work can be the investigation of reducing the current number of decision elements from 27 criteria and 22 sub-criteria to a reasonable number and analyzing the influenec on the decision results. 


\section{REFERENCES}

[01] N. Colonna, F. Belloni, E. Berthoumieux, M. Calviani, C. Domingo-Pardo, C. Guerrero, D. Karadimos, C. Lederer, C. Massimi, C. Paradela, R. Plag, J. Praena, and R. Sarmento, "Advanced nuclear energy systems and the need of accurate nuclear data: The n-TOF project at CERN," Energy and Environmental Science, vol. 3, no. 12, pp. 1910-1917, 2010.

[02] "The Greenhouse Theory of Climate Change: A Test by an Inadvertent Global Experiment."[Online].Available:http://www.sciencemag.org/content/240/4 850/293.Short. [Accessed: 02-Jan-2012].

[03] The definition of renewable energy. (n.d.). Retrieved April 12, 2011, from http://www.dictionary.com/browse/renewable-energy

[04] "game changers for nuclear energy - Google Search." [Online]. Available: http://www. google.com.proxy.lib.pdx.edu/search [Accessed: 07-Jan-2012].

[05] REN21, the Renewable Energy Policy Network for the 21st Century, (2011). "Renewables 2011: Global Status Report". p. 18. http://www.ren21.net/ Portals/97/documents/GSR /GSR2011 Master18.pdf. [Accessed 23-Dec2011]

[06] A. M. Omer, "Energy, environment and sustainable development," Renewable and Sustainable Energy Reviews, vol. 12, no. 9, pp. 2265-2300, 2008.

[07] H. Y. Jeong, Y. I. Kim, Y. B. Lee, K. S. Ha, B. C. Won, D. U. Lee, and D. Hahn, “A 'must-go path' scenario for sustainable development and the role of nuclear energy in the 21st century," Energy Policy, vol. 38, no. 4, pp. 1962-1968, 2010 .

[08] K. Menyah and Y. Wolde-Rufael, "CO2 emissions, nuclear energy, renewable energy and economic growth in the US," Energy Policy, vol. 38, no. 6, pp. 2911-2915, 2010.

[09] Dittmar M, Nuclear energy: Status and future limitations, Energy (2011), doi:10.1016/j. energy. 2011.05.040

[10] J. V. Spadaro, L. Langlois and B. Hamilton, IAEA bulletin 42/2/2000. 
[11] H. Janssens, "Nuclear as part of Sustainable Development: an Introduction," Final Report on the Round Tables.

[12] S. B. Alam, H. M. D. Kabir, A. B. M. R. Sazzad, K. Redwan, I. Aziz, I. K. Chowdhury, and M. A. Matin, "Can gen-4 nuclear power and reactor technology be safe and reliable future energy for developing countries?," in Power and Energy (PECon), 2010 IEEE International Conference on, 2010, pp. 113-118.

[13] A. White, "Global nuclear energy: A GE perspective," in 29th World Nuclear Association, WNA Annual Symposium 2004, September 8, 2004 - September 10, 2004, London, United kingdom, 2004, pp. 25-29.

[14] J. C. Kemeny, "Saving American Democracy: The lessons of Three Mile Island.," Technology review, vol. 83, no. 7, pp. 65-75, 1980.

[15] N. Meshkati, "Lessons of the Chernobyl nuclear accident for sustainable energy generation: Creation of the safety culture in nuclear power plants around the world," Energy Sources, Part A: Recovery, Utilization and Environmental Effects, vol. 29, no. 9, pp. 807-815, 2007.

[16] Z. Jiang, "Fukushima nuclear accident implications for the nuclear power development in China," in 2011 International Conference on Energy, Environment and Sustainable Development, ICEESD 2011, October 21, 2011 October 23, 2011, Shanghai, China, 2012, vol. 347-353, pp. 3810-3814

[17] “design basis and severe accidents - Google Search." [Online]. Available: http://www. google .com/search? [Accessed: 23-Jan-2012].

[18] E. Upuras, A. Kaliatka, J. Augutis, S. Rimkevicius, E. Urbonavicius, and V. Kopustinskas, "Safety analysis of beyond design basis accidents in RBMK1500 reactors," Annals of Nuclear Energy, vol. 34, no. 5, pp. 356-373, 2007.

[19] G. Saji, "Management of ultimate risk of nuclear plants by source terms Lessons learned from the Chernobyl accident," in Fourteenth International Conference on Nuclear Engineering 2006, ICONE 14, July 17, 2006 - July 20, 2006, Miami, FL, United states, 2006, vol. 2006.

[20] Z. Jiang, "Fukushima nuclear accident implications for the nuclear power development in China," in 2011 International Conference on Energy, 
Environment and Sustainable Development, ICEESD 2011, October 21, 2011 October 23, 2011, Shanghai, China, 2012, vol. 347-353, pp. 3810-3814.

[21] A. Roshan, P. Shylamoni, and S. Acharya, "SITING OF NUCLEAR POWER PLANTS."

[22] D. Voivontas, D. Assimacopoulos, and E. Koukios, "Aessessment of biomass potential for power production: a GIS based method," Biomass and Bioenergy, vol. 20, no. 2, pp. 101-112, 2001.

[23] A. R. Abbas, K. S. Low, I. M. N. Ahmad, J. H. Chan, A. Sasekumar, F. A. Ghaffar, K. O. Salleh, K. R. John, A. Y. Saad, W. A. W. Zahari, Y. T. Phua, Y. N. Phua, Y. Y. Wong, I. M. Jamaludin, M. N. Mohammed, S. Jaafar, and P. H. Yau, "Assessment parameters for coal-fired generation plant site selection," International Energy Journal, vol. 6, no. 1, pp. 445-454, 2005.

[24] J. D. Calvert Jr. and W. L. Heilman, "NEW APPROACH TO POWER PLANT SITING.," American Society of Civil Engineers, Journal of the Power Division, vol. 98, no. P01, pp. 93-102, 1972.

[25] A. D. Bhanarkar, C. V. Chalapati Rao, and V. I. Pandit, "Air pollution modeling for power plant site selection," International Journal of Environmental Studies, vol. 62, no. 5, pp. 527-534, 2005.

[26] W. J. Rusert, R. P. Kummerle, F. L. Mitchell, and O. Reeves, "ENVIRONMENTAL CONDITIONS PREDOMINANT IN POWER PLANT SITE SELECTION - IMPACT ON DESIGN, CONSTRUCTION AND OPERATION.," in Proceedings of the American Power Conference., Chicago, IL, USA, 1985, vol. 47, pp. 354-357.

[27] L. T. Klein, "POWER PLANT SITE SELECTION.," Greater Los Angeles Area Energy Symp, Proc, April 3, 1975 - April 3, 1975, pp. 98-103, 1975.

[28] A. Beavis and R. Charlier, "SITE SELECTION STUDIES FOR LAND-BASED OTEC POWER PLANTS.," in Papers Presented at the 3rd International Symposium on Wave, Tidal, OTEC, and Small Scale Hydro Energy: Water for Energy., Brighton, Engl, 1986, pp. 217-238.

[29] H. Z. Kennon, "Power facility site selection in the 1990s," in Proceedings of the 55th Annual Meeting of the American Power Conference. Part 1 (of 2), April 1, 1993 - April 1, 1993, Chicago, IL, USA, 1993, vol. 55, pp. 453-455. 
[30] "Common power plant siting - Google Search." [Online]. Available: http://www. google.com/search? [Accessed: 19-Jan-2012].

[31] N. Jain, "NUCLEAR ENERGY Technology from Hell." Accessed via Google search engine on $02 / 19 / 2012$.

[32] R. P. Hammond and A. P. Zechella, "FLOATING NUCLEAR POWER PLANTS PRESENT AND FUTURE.," World Energy Conf, 9th, Trans, Pap and Discuss, September 23, 1974 - September 27, 1974, pp. 557-568, 1975.

[33] J. C. Kemeny, "SAVING AMERICAN DEMOCRACY: THE LESSONS OF THREE MILE ISLAND.," Technology review, vol. 83, no. 7, pp. 65-75, 1980.

[34] B. Borko and J. E. Just, "Legal and institutional problems in power plant siting," Nuclear Safety, vol. 18, no. 2, pp. 127-133, 1977.

[35] "Guideline for site selection for nuclear power plant- Google Search." [Online] Available:http://www.aelb.gov.my/aelb/malay/dokumen/panduan.pdf [Accessed: 04-April-2012].

[36] G. Yadigaroglu and S. O. Andersen, "Novel siting solutions for nuclear power plants," Nuclear. Safety., v. 15, no. 6, pp. 651-664, vol. 15, no. 6, 1974.

[37] R. Noyes, "Offshore and underground power plants," Park Ridge, NJ, Noyes Data Corp. (Energy Technology Review, No. 19; Ocean Technology Review, No. 6), p 319, vol. 1, 1977.

[38] J. Holmes and C. Fink, "Tuned floating platform for offshore power facilities," Sanders Nuclear Corp., Nashua, NH, 1972.

[39] T. Kokusho, K. Kishi, H. Kawai, and K. Goto, "State-of-the art on research and development of advanced siting technology in Japan," in International Conference on Design and Safety of Advanced Nuclear Power Plants. Proceedings, 25-29 Oct. 1992, Tokyo, Japan, 1992, pp. 1-14.

[40] R. P. Hammond and A. P. Zechella, "Floating nuclear power plants - Present and future," World Energy Conf, 9th, Trans, Pap and Discuss, September 23, 1974 - September 27, 1974, pp. 557-568, 1975.

[41] Anon, "Floating nuclear power plants will flow from assembly line," Engineering News-Record, vol. 199, no. 21, pp. 22-23, 1977. 
[42] J. A. Fischer and H. Singh, "Role of offshore nuclear power plants," American Society of Civil Engineers, Journal of the Power Division, vol. 101, no. 1, pp. 1-9, 1975.

[43] J. W. Kindt, "Offshore siting of nuclear power plants," Ocean Development \& International Law, vol. 8, no. 1, pp. 57-103, 1980.

[44] O. H. Klepper and T. D. Anderson, "Siting considerations for future offshore nuclear energy stations," Nuclear Technology, vol. 22, no. 2, pp. 160-169, 1974.

[45] R. S. Orr and C. Dotson, "Offshore nuclear power plants," Nuclear Engineering and Design, vol. 25, no. 3, pp. 334-349, 1973.

[46] J. Turner, "Manufacturing plans, concepts, and facilities for floating nuclear plants," Nuclear Engineering International, v. 18, no. 205, pp. 487-490, vol. 18, no. 205, 1973.

[47] M. Kennemuyi and R. Lochbaum, "Offshore nuclear power plants," 1973.

[48] R. C. Nichols, “Floating Nuclear Plants,” Thermal Power Conf., Pullman, 1975.

[49] G. D. Friedlander, "Floating reactor: Crisis solution?" vol. 10, no. 2, pp. 44-51, 1973.

[50] A. R. Collier and R. C. Nichols, "Floating nuclear plant design," Nuclear Engineering International, vol. 18, no. 205, pp. 478-483, 1973.

[51] V. Riggi and P. R. Ramsay, "Floating nuclear power plants - A New Approach To Energy Generation," Am Eng Model Soc Semin '77, Scale Models in Eng and Des, October 24-27, 1977, p. 67, 1977.

[52] D. P. Maniago, "Offshore power systems - Its answer to the energy crisis," Am Inst of Plant Eng (AIPE) Annual Conv., Conf Proc, June 12, 1978 - June 14, 1978, 1978.

[53] A. P. Zechella, "Floating nuclear power plants," Military Engineer, vol. 69, no. 451, pp. 306-309, 1977.

[54] P. V. Thangam Babu and D. V. Reddy, "Existing methodologies in the design and analysis of offshore floating nuclear power plants," Nuclear Engineering 
and Design, vol. 48, no. 1, pp. 167-205, Jun. 1978.

[55] A. R. Collier and R. C. Nichols, "Floating nuclear power plants for offshore siting," Westinghouse Engineer, vol. 32, no. 6, pp. 162-169, 1972.

[56] A. R. Collier and R. C. Nichols, "Floating nuclear power plants for offshore siting," vol. 14, no. 2, pp. 42-46, 1973.

[57] W. J. F. Standring, M. Dowdall, I. Amundsen, and P. Strand, "Floating nuclear power plants: Potential implications for radioactive pollution of the northern marine environment," Marine Pollution Bulletin, vol. 58, no. 2, pp. 174-178, 2009.

[58] J. Woodliffe, "Offshore nuclear power stations: putting pressure on the Law of the Sea," Int'l J. Estuarine \& Coastal L., vol. 3, p. 138, 1988.

[59] L. Van Broekhoven, A. Bastin, and S. J. Lefevere, "Ecological problems of a nuclear power station: A basis for comparing offshore sites," in SEME: Symposium Engineering in Marine Environment, Brugges, Belg, 1982, p. 4. 37-4. 46.

[60] H. M. Busey, "Floating plants for seismic protection," Nuclear Applications, vol. 6, no. 6, pp. 533-543, 1969.

[61] R. E. Caines, "Exposure fire protection for floating nuclear power plants," Fire Technology, vol. 11, no. 3, pp. 175-183, 1975.

[62] A.K. Larsson, "Environmental impact from an offshore plant," Wind Engineering, vol. 18, no. 5, pp. 213-218, 1994.

[63] C. Bookman, "Offshore nuclear power plants-spectacle or spectre," Rhode Island Univ., Kingston (USA), 1974.

[64] E. J. Baker, S. G. West, D. J. Moss, and J. M. Weyant, "Impact of offshore nuclear power plants," Environment and Behavior, vol. 12, no. 3, pp. 367-407, 1980.

[65] J. N. Barkenbus, "Prospects for offshore nuclear power production," Proceedings of the Gas Conditioning Conference, pp. 231-233, 1979.

[66] J. Rodd, "Offshore power plants for developing countries," in First International Conference on Technology for Development, 1980: Preprints of 
Papers, 1980, p. 154.

[67] K. Motohashi, "Position control of a floating nuclear power plant," 1993.

[68] M. Ikeno, H. Tanaka, and M. Matsuyama, "3-D dynamic behavior of moored floating structure of a nuclear power plant due to tsunami based on nondistorted model tests•," in ISOPE-2001: Eleventh International Offshore and Polar Engineering Conference; Stavenger, 2001, pp. 339-346.

[69] P. V. Thangam Babu and D. V. Reddy, "Fluid-structure interaction response analysis of floating nuclear plants including the effects of mooring," Ocean Engineering, vol. 7, no. 6, pp. 707-741, 1980.

[70] F. E. Bonsack, "Siting alternatives for floating nuclear plants: An update," OCEAN 75 Conference, vol., no., pp.643,651, 22-25 Sept. 1975

[71] J. T. Dette and L. E. Stahl, "Site investigations for an offshore nuclear power plant," Siting Considerations for Offshore Nuclear Power Plants, Seminar Proceedings, Apr 19 1974, 1974.

[72] A. Golovin, V. Abramov, K. Kovalenko, G. Merzlikin, Y. A. Sergeev, G. Sosenkov, A. Suvorov, P. Sukhoruchenkov, and V. Shmakov, "Utilization of floating nuclear power plants in Northern regions," Atomic Energy, vol. 51, no. 2, pp. 497-501, 1981.

[73] Usher, E F. "Islands for nuclear power stations." Industrial Islands"; International Conference (1981): 23-29. Print.

[74] R. Kajima, T. Kokusho, and K. Nishi, "Structural concept of offshore NPPs and their characteristics," in International Conference on Design and Safety of Advanced Nuclear Power Plants. Proceedings, 25-29 Oct. 1992, Tokyo, Japan, 1992, pp. 14-2.

[75] "Concerns on floating and submerged nuclear power plants - Google Search." [Online] Available: http://www.nuclearpolicy.info/docs/news/KIMO_OSPAR_Sellafield_FNPP.pd f [Accessed: 11-Dec-2011]

[76] "Underwater power plants- Google Search." [Online] Available: https://netfiles.uiuc.edu/mragheb/www/NPRE\%20402\%20ME\%20405\%2 
0Nuclear\%20Power\%20Engineering/Underwater\%20Power\%20Plants.pdf [Accessed: 19-Dec-2011]

[77] Flynn, T A. "Why not an underwater nuclear power plant?" Combustion 39.3,1967, 19-20.

[78] V. I. Vasjukov, D. M. Klyikov, V. L. Podbereznyi, and V. Y. Shipilov, "Floating nuclear desalination plant AFWS-40," Desalination, vol. 89, no. 1, pp. 21-32, 1992

[79] V. Kostin, Y. K. Panov, V. Polunichev, and I. Shamanin, "Floating powergenerating unit with a KLT-40S reactor system for desalinating sea water," Atomic Energy, vol. 102, no. 1, pp. 31-35, 2007.

[80] E. Iignatenko, D. M. Klykov, V. K. Kovalenko, F. M. Mitenkov, and A. K. Polushkin, "Buoyant new market? Floating nuclear plants for remote regions" Nuclear Engineering International, vol. 42, no. 514, pp. 28-31, 1997.

[81] "Floating nuclear power plants bellona reprot 2011- Google Search." [Online] Available http://bellona.org/filearchive/fil_fnpp_report.pdf [Accessed: 25Feb-2011]

[82] D. Fitriyani, Z. Su'ud, B. Epung Saepul, and others, "Design and safety optimization of ship-based small nuclear power reactors," Progress in Nuclear Energy, vol. 50, no. 2, pp. 299-303, 2008.

[83] A. A. Sarkisov, V. L. Vysotskii, V. P. Bilashenko, V. N. Barinov, A. E. Kiselev, V. G. Markarov, I. N. Kulakov, A. N. Lepekhin, V. V. Petrunin, A. V. Pichugin, and S. V. Krysov, "Expected radiological and radioecological consequences of operating floating nuclear heat and power plants," Atomic Energy, vol. 104, no. 3, pp. 237-249, 2008.

[84] Y. E. Gorlinskii, V. A. Kut'kov, V. N. Lystsov, V. I. Makarov, N. V. Murzin, and V. D. Pavlov, "Securing the radiological safety of people and the environment at all stages of the life cycle of floating nuclear heat-and-power plants," Atomic energy, vol. 107, no. 2, pp. 122-129, 2009.

[85] J. P. Franklin, "10-MW barge-mounted nuclear power plant being built by U.S. army," Power Engineering, vol. 67, no. 8, pp. 57-59, 1963. 
[86] Y. N. Kuznetsov, B. Gabaraev, V. Reshetov, and V. Moskin, "Leasing of nuclear power plants with using floating technologies," The ASME Foundation, Inc., Three Park Avenue, New York, NY 10016-5990 (United States), 2002.

[87] "Coastal effects of offshore energy systems- Google Search." [Online] Available: http://www.fas.org/ota/reports/7615.pdf [Accessed: 13-Apr2011]

[88] J. H. Crowley, P. L. Doan, and D. R. McCreath, "Underground nuclear plant siting: A technical and safety assessment," Nuclear Safety, vol. 15, no. 5, pp. 519-534, 1974

[89] M. B. Watson, W. A. Kammer, N. P. Langley, L. A. Selzer, and R. L. Beck, "Underground nuclear power plant siting.," Nuclear Engineering and Design, vol. 33, no. 3, pp. 269-307, 1975.

[90] "Prospects of development of small underground nuclear reactors in Singapore- Google Search." [Online] Available: http://www.scicet.ru/ uploads/assets/file/presentation 02.pdf on Nov. 03, [Accessed: 5-Mar-2011]

[91] S. Pinto, "Underground construction of nuclear power reactors," Nuclear Engineering and Design, vol. 61, no. 3, pp. 441-458, 1980.

[92] C. W. Myers, J. M. Mahar, J. F. Kunze, and N. Z. Elkins, "Underground nuclear parks: New approach for the deployment of nuclear energy systems," in 1st International Conference on Underground Spaces - Design, Engineering and Environmental Aspects, Underground Spaces 2008, Sep. 8-10, 2008, New Forest, United kingdom, 2008, vol. 102, pp. 63-70.

[93] "Underground nuclear parks and the continental super-grid- Googel Search." [Online] Available:http://www.w2agz.com/SG\%202\%20Proceedings/7\%20 Myers\%20Nuclear\%20SG2 \%20Presentation\%200ct\%2018.pdf [Accessed: 20-Feb-2012]

[94] W. Myers and N. Elkins, "Siting nuclear power plants underground: Old idea, new circumstances," Nuclear News, vol. 47, no. 13, pp. 33-38, 2004.

[95] M. Watson, W. Kammer, N. Langley, L. Selzer, and R. Beck, "Underground nuclear power plant siting," Nuclear Engineering and Design, vol. 33, no. 3, pp. 269-307, 1975. 
[96] W. A. Kammer and M. B. Watson, "Underground nuclear power plants with surface turbine generator," Nuclear Engineering and Design, vol. 33, no. 3, pp. 308-335, 1975.

[97] F. Buchhardt, "Some comments on the concept of 'underground siting of nuclear power plants'-a critical review of the recently elaborated numerous studies" Nuclear Engineering and Design, vol. 59, no. 2, pp. 217-30, 1980.

[98] D. Reddy, O. Moselhi, and S. Sheha, "Dynamic structure-medium interaction of underground nuclear reactor containments'," in Proc. Sixth World Conf. on Earthquake Engineering, New Delhi, India, 1977.

[99] H. Takahashi, "The deep underground nuclear park concept: Issues of safety, economy, and nonproliferation," in Abstracts of the 14th Pacific Basin Nuclear Conference, March 21, 2004 - March 25, 2004, Honolulu, HI, United states, 2004, pp. 158-159.

[100] A. Palmer, S. Ramakrishna, and H. M. Cheema, "Nuclear power in Singapore," IES Journal Part A: Civil and Structural Engineering, vol. 3, no. 1, pp. 65-69, 2010.

[101] A. Chew, "Underground nuclear power plant: why not?," 2009.

[102] "Site evaluation for new nuclear power plants", Google Search [online] accessed at http://nuclearsafety.gc.ca/pubs_catalogue/uploads/RD346_Draft2_e.pdf

[103] H. F. Perla, "Are there alternatives to present concepts for power-plant siting?," Energy Sources, vol. 1, no. 2, pp. 223-35, Winter 1974.

[104] C. C. Warnick, "Methodology and criteria for siting energy plants in Idaho," University of Idaho, Moscow, ID, 1976.

[105] A. Macintosh, Siting nuclear power plants in Australia: where would they go? Australia Institute, 2007.

[106] "Siting new nuclear power stations" Google Search [online] accessed at Jun, 13, 2011 at www.jacksonconsult.com/content pdf/NuclearSitingReport.pdf

[107] E. Rodwell, "Siting guide: site selection and evaluation criteria for an early site permit Application, 1006878, Final Report," Electric Power Research 
Institute, (March 2002)

[108] U. N. R. C. O. of N. R. Research, General site suitability criteria for nuclear power stations. US Nuclear Regulatory Commission, Office of Nuclear Regulatory Research, 92.

[109] "Fundamentals of power reactors: Site selection- Google Search." [Online] Available: $\underline{\text { https://canteach.candu.org/Content\%20Library/19930203.pdf }}$ [Accessed: 02-Feb-2011]

[110] "Nuclear power plant siting study-Google Search." [Online] Available: http://www.dtic.mil/cgi-bin/GetTRDoc?AD=ADA030730 [Accessed: 15-Jan2011]

[111] Salman. B. A., "Nuclear power plant site selection', - Google Search." [Online] Available: http://www. google.com.proxy.lib.pdx.edu/search [Accessed: 07Jan-2012].

[112] Roshan A.D, Shylamoni P., Sourav A., "Monograph on siting of nuclear power plants", Google Search [online]. Available: http://www. google.com.proxy.lib.pdx.edu/search

[113] "Selecting sites for nuclear centres- Google Search." [Online] Available: http://www.iaea.org/Publications/Magazines/Bulletin/Bull053/053047025 29.pdf [Accessed: 18-Jan-2011]

[114] "Siting and safety of nuclear plant." Nuclear Power; the Journal of British Nuclear Engineering 4.40 (1959): 82-83. Print.

[115] G. Greenhalgh, "The safety and siting of nuclear power plants," Nuclear Engineering International, vol. 19, no. 223, pp. 1015-21, Dec. 1974.

[116] Farmer, S R. "Siting criteria - A new approach." Journal of the British Nuclear Energy Society 6.3 (1967): 219-228. Print.

[117] G. Thompson, Design and Siting Criteria for Nuclear Power Plants. January, 2008.

[118] M. O. Lamble, "Environmental aspects of siting nuclear power stations," Electronic Progress, vol. 17, no. 4, pp. 21-26, 1975. 
[119] "The environment- siting nuclear power plants- Google Search." [Online] Available:http://www.iaea.org/Publications/Magazines/Bulletin/Bull151/ 15104704652.pdf

[120] "Safety criteria for siting a Nuclear Power Plant- Google Search." [Online] Available: http://www.finlex.fi/data/normit/6143-YVL1-10e.pdf [Accessed: 10-Jan-2011]

[121] R. B. Matthiesen, G. Howard, and C. B. Smith, "Seismic considerations in siting and design of power plants," Nuclear Engineering and Design, vol. 25, no. 1, pp. 3-16, 1973.

[122] G. E. Howard, P. Ibáñez, and C. B. Smith, "Seismic design of nuclear power plants-an assessment," Nuclear Engineering and Design, vol. 38, no. 3, pp. 385-461, 1976.

[123] J. Fischer, D. Maniago, and I. Watson, "Macro-engineering aspects of floating nuclear power plant siting," in OCEAN 75 Conference, 1975, pp. 634-642.

[124] C. W. Kirkwood, "A case history of nuclear power plant site selection," Journal of the Operational Research Society, pp. 353-363, 1982.

[125] R. L. Keeney and K. Nair, "Nuclear siting using decision analysis," Energy Policy, vol. 5, no. 3, pp. 223-231, 1977.

[126] HARTOG, G., HINLOOPEN, E., and NIJKAMP, P., 1989. "A sensitivity analysis of multicriteria choice-methods" Energy Economics, October, 293-300.

[127] Y. Lugasi, A. Mehrez, and Z. Sinuany-Stern, "Nuclear power plant site selection: a case study," Nuclear Technology.;(United States), vol. 69, no. 1, 1985.

[128] Need for New Nuclear Facilities. (n.d.). Retrieved October 08, 2012, from http://www.nei.org/keyissues/newnuclearplants/needfornewnuclearplants/

[129] Emerging Nuclear Energy Countries (n.d). Retrieved August 23, 2013, from http://www.world-nuclear.org/information-library/country-profiles/others emerging-nuclear-energy-countries.aspx

[130] E. Løken, "Use of multicriteria decision analysis methods for energy planning problems," Renewable and Sustainable Energy Reviews, vol. 11, no. 7, pp. 
1584-1595, 2007.

[131] S. Theodorou, G. Florides, and S. Tassou, "The use of multiple criteria decision making methodologies for the promotion of RES through funding schemes in Cyprus, A review," Energy policy, vol. 38, no. 12, pp. 7783-7792, 2010.

[132] H. Chen and J. Li, "A sensitivity analysis algorithm for the constant sum pairwise comparison judgments in hierarchical decision models," in Portland International Center for Management of Engineering and Technology Technology Management in the Energy-Smart World, PICMET'11, July 31, 2011 - August 4, 2011, 2011, p. Portland State University; PSU Office of Information Technologies; IKON Office Solutions.

[133] H. Chen, D. F. Kocaoglu, and J. Ho, "Applying sensitivity analysis to the strategic evaluation of emerging technologies in Taiwan semiconductor foundry industry," in Technology Management: A unifying discipline for melting the boundaries, 2005, pp. 166-173.

[134] H. Chen and D. F. Kocaoglu, "A sensitivity analysis algorithm for hierarchical decision models," European Journal of Operational Research, vol. 185, no. 1, pp. 266-288, 2008.

[135] A. Mahmood, "Software implementation of hierarchical decision modeling and hierarchical decision modeling sensitivity analysis," 2011. [Online]. Available: http://purl.umn.edu/120150. [Accessed: 02-June-2013].

[136] Abbas, Mustafa Sulaiman, "Consistency Analysis for Judgment Quantification in Hierarchical Decision Model" (2016). Dissertations and Theses. Paper 2699. http://pdxscholar.library.pdx.edu/open_access_etds/2699

[137] Phan, Kenny, "Innovation Measurement: A Decision Framework to Determine Innovativeness of a Company" (2013). Dissertations and Theses. Paper 1017. http://pdxscholar.library.pdx.edu/open access etds/1017

[138] Sheikh, Nasir Jamil, "Assessment of Solar Photovoltaic Technologies Using Multiple Perspectives and Hierarchical Decision Modeling" (2013).

Dissertations and Theses. Paper 978.

http://pdxscholar.library.pdx.edu/open access etds/978

[139] Dalkey, N. C., \& Helmer, O. (1963). An experimental application of the Delphi 
method to the use of experts. Management Science 9, 458-467.

[140] G. Rowe and G. Wright, "The Delphi Technique as a Forecasting Tool: Issues and Analysis," International Journal of Forecasting, vol. 15, no. 4, pp. 353375, 99AD.

[141] D. M. Kingman, A. M. Yoder, N. S. Hodge, R. Ortega, and W. E. Field, "Utilizing expert panels in agricultural safety and health research," Journal of agricultural safety and health, vol. 11, no. 1, pp. 61-74, 2005.

[142] Steyaert, Stef, and Hervé Lisoir. "Participatory Methods Toolkit: A Practitioner's Manual." King Baudouin Foundation and Flemish Institute for Science and Technology (2005).

[143] Expert Panel; [online] Available: http://ec.europa.eu/europeaid/ evaluation /methodology/ examples/too pan res en.pdf [Accessed 05-April-2013]

[144] "Criteria for selecting expert group members under the program for scaling up renewable energy in low income countries," Climate Investment Fund, 26March-2010[Online]Available: http://www.climateinvestmentfunds.org/cif/ sites/climateinvestmentfunds.org/files/criteria\%20for\%20selecting\%20Exp erts final022410.pdf [Accessed: 22-May-2013]

[145] P. Slottje, J. P. van der Sluijs, and A. B. Knol, "Expert Elicitation: Methodological suggestions for its use in environmental health impact assessments," 2008.

[146] "Example of an Expert Panel Criteria and Procedure Chosen for the Selection of Experts Call for Toxicology Experts to Serve as Members and Temporary Advisers." FAO/WHO Joint Secretariat To JECFA 15/04, 15 Apr. 2002. Web. [Online] Available http://ec.europa.eu/europeaid/evaluation/methodology/examples/exp_too _pan_two_en.pdf [Accessed 10-April-2013]

[147] "Seven Criteria for Selecting a Product Liability Expert." ExpertPages. N.p., n.d. Reteived 14/04/2013 World Wide Web, http://expertpages.com/news/Seven _Criteria_for_Selecting_a_Product_Liability_Expert.htm>.

[148] Harper, Robin J. "Selecting Your Expert: Criteria to Determine the "Right" 
Expert for Your Case." Dives, Grauer \& Harper, Vancouver, BC, For The, May 2009. Retrieved 23/05/ 2013. Web, http://www.cle.bc.ca/PracticePoints /LIT/expert choice.pdf

[149] "Selection Procedure and Criteria for Selecting Experts for the Review Teams of the KAA, Selection Procedure." Retreived 21/05/2013. World Wide Web, http://www. Ak reditimi-ks.org/sq/?Guidelines_for_Experts: Selection_ Procedure_and_Criteria for Selecting_Experts_for_the_Review_Teams_of the -KAA

[150] P. Shah, "Expert Finding Using Social Networking," Master's Projects, no. 48, pp. 1-68, 2009.

[151] Fu, Yupeng, Rongjing Xiang, Yiqun Liu, Min Zhang, and Shaoping Ma. "Finding experts using social network analysis." In Proceedings of the IEEE/WIC/ACM International Conference on Web Intelligence, pp. 77-80. IEEE Computer Society, 2007.

[152] Atkinson, R and Flint, J, "Snowball Sampling”, The SAGE Encyclopedia of Social Science Research Methods, Lweis-Beck, M., Bryman, A and Futing Liao, T. (ed), London (2004)

[153] Bogers, Toine, Klaas Kox, and Antal van den Bosch. "Using citation analysis for finding experts in workgroups." In Proc. DIR, pp. 21-28. 2008.

[154] Albar, F. M., \& Kocaoglu, D. F. (2009). Few or More Attributes: Deleting Criteria Using Sensitivity Analysis . PICMET 2009 Proceedings, 564-570. URL: http://ieeexplore.ieee.org.proxy.lib.pdx.edu/stamp/stamp.jsp?tp=\&ar number $=5262117$ \&isnumber $=5261733$

[155] Baker, D., Bridges, D., Hunter, R., Johnson, G., Krupa, J., Murphy, J. and Sorenson, K. (2002) Guidebook to Decision Making Methods, WSRC-IM-200200002, Department of Energy, USA.

[156] Public Attitudes to Nuclear Power. (2010). [Available Online] http://www.oecd-nea.org/ndd/reports/2010/nea6859-public-attitudes.pdf.

[157] The definition of validate. (n.d.). Retrieved June 22, 2013, from https://www.vocabulary.com/dictionary/validate

[158] The definition of evaluation. (n.d.). Retrieved June 22, 2013, from 
https://www.vocabulary.com/dictionary/evaluation

[159] World's largest nuclear reactor being built by Chinese firm. (2103, August 26). Retrieved from http://asian-power.com/project/news/world \%E2\%80 \%99s-largest-nuclear-reactor-being-built-chinese-firm

[160] Nuclear Power Reactors. (2016, January). Retrieved from http://www.worldnuclear.org/information-library/nuclear-fuel-cycle/nuclear-powerreactors/nuclear-power-reactors.aspx

[161] Safely Managing Used Nuclear Fuel. (2104, August). Retrieved from http://www.nei.org/Master-Document-Folder/Backgrounders/FactSheets/Safely-Managing-Used-Nuclear-Fuel\#

[162] Samseth, Jon, et al. "Closing and Decommissioning Nuclear Power Reactors." UNEP Year book (2012): 35-49. Retrieved from http://www.unep. org/yearbook/2012/pdfs/uyb 2012 ch 3.pdf

[163] Brownfield Nuclear Power Plant Siting Report. (2009, August). Retrieved from https://art.inl.gov/NGNP/Subcontractors\%20Documents/Entergy/ Brownfield\%20Nuclear\%20Power\%20Plant\%20Siting\%20Report.pd

[164] Woite, G. (1978). Capital Investment Costs of Nuclear Power Plants. Retrieved from https://www.iaea.org/sites/default/files/publications/magazines/ bulletin/bull20-1/20104781123.pdf

[165] Assessment of the Nuclear Power Industry -Final Repor. (2013, June). Retrieved from http://docplayer.net/8662279-Assessment-of-the-nuclearpower-industry-final-report-june-2013.html

[166] Black, Veatch. "Cost and Performance Data for Power Generation Technologies." Prepared for the National Renewable Energy Laboratory (2012).Retrieved from http://bv.com/docs/reports-studies/nrel-costreport.pdf

[167] Lund, Ingemar. "DECOMMISSIONING OF NUCLEAR POWER PLANTS: POLICIES, STRATEGIES AND COSTS." Strategy Selection for the Decommissioning of Nuclear Facilities (2004): 67. Retrieved from http://www.oecd-nea.org/rwm/pubs/2004/RWM 2004 5300-strategyselection.pdf\#page $=67$ 
[168] Barak, A., et al. "Nuclear desalination: Experience, needs, and prospects." IAEA Bulletin 32.3 (1990): 43-48. Retrieved from http://iaealive-liv.sites.ac/sites/ default/files/32304794348.pdf

[169] Interfacing Nuclear Power Plants with the Electric Grid: the Need for Reliability amid Complexity. (n.d.). Retrieved from https://www.iaea.org/ About/Policy/GC/GC53/GC53InfDocuments/English/gc53inf-3-att5 en.pdf

[170] Cadwallader, Lee Charles. "Ventilation Systems Operating Experience Review for Fusion Applications." INEEL Report, INEEL/EXT-99-01318(1999). Retrieved form https://inldigitallibrary.inl.gov/sti/3318120.pdf 


\section{APPENDICES}

\section{Appendix A: Common Criteria for Selecting Experts}

\begin{tabular}{|c|c|}
\hline Criterion & Description \\
\hline Academic Degree & $\begin{array}{l}\text { Education is the key element of an expert's curriculum vitae. } \\
\text { University/college degree in one of the disciplines that are directly } \\
\text { related to the research area or decision model's elements is required. } \\
\text { Typically, a well-educated expert will be more ready to do his/her task } \\
\text { efficiently specially with unexpected issues/events that might be } \\
\text { occurred. Expert's knowledge is highly regarded as a source of power. } \\
\text { University/college degree in relevant subject(s) will give an expert some } \\
\text { measure of credibility. If the expert has one or more advanced degrees, } \\
\text { that is will be an advantage. }\end{array}$ \\
\hline Experience & $\begin{array}{l}\text { Experience generally complements education. In some situations certain } \\
\text { knowledge can only be gained through experience. It is commonly known } \\
\text { that where an expert has been employed can say a lot about an expert as } \\
\text { where he or she went to school. A significant history of work experience } \\
\text { at a university, government research labs, or employment with top or } \\
\text { well-known organizations lends credibility to the expert's curriculum } \\
\text { vitae. So, long-term, at least } 10 \text { years, relevant experience generally } \\
\text { complements education. }\end{array}$ \\
\hline License & $\begin{array}{l}\text { Licensing, by official office or state board, usually not essential for an } \\
\text { expert, but certainly enhances his/her credibility. A license identifies the } \\
\text { expert as one who regards himself or herself as a professional in a chosen } \\
\text { field. A license is not an automatic outcome of education, but a credential } \\
\text { that requires additional and continuing effort and expenditures by the } \\
\text { expert to be achieved and maintained. }\end{array}$ \\
\hline
\end{tabular}




\begin{tabular}{|c|c|}
\hline Participation & $\begin{array}{l}\text { Active involvement in technical societies or committees is an excellent } \\
\text { means for an expert to keep abreast with state-of-the-art in a particular } \\
\text { industry or technology. Membership and participations in national or } \\
\text { international scientific bodies, professional societies, and other expert } \\
\text { advisory committees would enhance expert's knowledge. }\end{array}$ \\
\hline $\begin{array}{c}\text { Methods/Tools } \\
\text { Knowledge }\end{array}$ & $\begin{array}{l}\text { The larger or the variety of decision making tools or methods that expert } \\
\text { is knowledgeable of, the greater the chance that he/she will be selected } \\
\text { or the better chance that he/she will act efficiently. Knowledge of } \\
\text { different decision methods would also enhance the possibility of having } \\
\text { an expert to work in a decision panel. Beyond that, the expert's } \\
\text { knowledge and ability to deal with state-of-the-art tools, technologies, } \\
\text { hardware, or software will enhance and leverage the expert's analytical } \\
\text { and judgmental skills. }\end{array}$ \\
\hline $\begin{array}{l}\text { Communication } \\
\text { Skills }\end{array}$ & $\begin{array}{l}\text { It is very important that a selected expert has a competent means of } \\
\text { communication with others either face to face or remotely. The impact of } \\
\text { an expert's opinions will only be as powerful as the expert is effective in } \\
\text { communicating the meaning and relevance of his or her opinions. Along } \\
\text { the way, the expert should be mindful that members of the panel may } \\
\text { need a variety of different kinds of explanations to ultimately grasp the } \\
\text { facts of the case, and so the effective expert will be open to and actively } \\
\text { seek non-verbal means such as diagrams, animations, models and } \\
\text { functional, physical demonstrative aids to help convey the substance of } \\
\text { his or her opinions. }\end{array}$ \\
\hline $\begin{array}{c}\text { Independence and } \\
\text { Impartiality }\end{array}$ & $\begin{array}{l}\text { The independency and impartiality would open-mind and encourage the } \\
\text { expert to provide fair, confident, and strong feedback. Independency is } \\
\text { an important criterion that allows the expert to state and deliver his/her } \\
\text { opinions or judgments with no conflicts of interest or influence of the } \\
\text { case under evaluation or other experts. }\end{array}$ \\
\hline $\begin{array}{c}\text { Research and } \\
\text { Teaching }\end{array}$ & $\begin{array}{l}\text { Research and teaching are indictors of an active and updated expert. } \\
\text { Research and teaching on the part of an expert tend to enhance his or her } \\
\text { credibility and help an expert to comment on the research, method, }\end{array}$ \\
\hline
\end{tabular}




\begin{tabular}{|c|c|}
\hline & $\begin{array}{l}\text { criteria, and alternatives; or recommend something different for the } \\
\text { benefit of study. To an extent, who knows the requirements of an } \\
\text { academic research, how to deal with graduate students, and how to } \\
\text { support a research with current information and data is a helpful expert. }\end{array}$ \\
\hline $\begin{array}{c}\text { Willingness and } \\
\text { Availability }\end{array}$ & $\begin{array}{l}\text { Experts should have the interest and the time to act as an active part of } \\
\text { the case he/she has been selected for, as well the passion to involve in } \\
\text { making the decision and sharing knowledge and experience. Expert } \\
\text { should have the eager to participate more than once and repeat his/her } \\
\text { role, discuss the results, and make changes. Reluctant experts who are } \\
\text { pushed into assisting may not ultimately give the best or right opinion. } \\
\text { An expert who has little availability time may not be the best choice. }\end{array}$ \\
\hline Publications & $\begin{array}{l}\text { Scientific publications in peer-reviewed journals, in particular, relevant } \\
\text { publications within the most recent years would improve and support } \\
\text { expert nomination or selection within an expert panel. Published papers } \\
\text { in a well known journals or scientific magazines are a key factor that } \\
\text { distinguishes and helps in identifying a suitable expert for the research. } \\
\text { Number of publications, related topics, detailed information, and updated } \\
\text { data show expert's level of interest, experience, and knowledge that one } \\
\text { can expect or ask for. }\end{array}$ \\
\hline Locality & $\begin{array}{l}\text { Locality is an important criterion to be considered in selecting experts. } \\
\text { Locality could be the field of study (discipline) or the place where the } \\
\text { case belongs (city/country). Local experts are having an advantage over } \\
\text { nonlocal. They are more aware about the nature and conditions of the } \\
\text { case under study or evaluation. Locality of disciplines is highly required } \\
\text { in most cases, while locality of city/country is recommended since local } \\
\text { experts might not available for all cases in all times. Expert in the same } \\
\text { region of the research will be easy to communicate in terms of language, } \\
\text { means of communication, or time difference for responses. }\end{array}$ \\
\hline
\end{tabular}




\section{Appendix B: Common Methods for Selecting Experts}

\begin{tabular}{|c|c|}
\hline Method & Description \\
\hline Social Network & $\begin{array}{l}\text { The social network analysis (SNA) provides an excellent method for finding } \\
\text { experts. Social network is a collection of people with similar profession, } \\
\text { background, or interest. Nowadays, the existing of the Internet has helped } \\
\text { in building well structured virtual relationships among people in networks } \\
\text { such as Facebook, LinkedIn, and Google+. The main use of social networks } \\
\text { includes posting personal information, sharing knowledge or opinions in a } \\
\text { particular area of interest, helping others within the network, or having a } \\
\text { casual interaction [146]. People, especially experts, are not isolated but } \\
\text { connected, so when we find one expert, those who are connected or have } \\
\text { strong relationship with him/her are highly possible to be experts too } \\
\text { [147]. The idea of using social network in order to identify an expert is the } \\
\text { way that people (experts) of the same network are connected to each } \\
\text { other. A person might have few or several connections with others, those } \\
\text { others mostly have their own connections too. This style of connections } \\
\text { provides a sizable number of people as much as the size of the network. } \\
\text { Reaching or accessing these networks is a valuable and an efficient } \\
\text { approach to identify and select experts. }\end{array}$ \\
\hline Snowball & $\begin{array}{l}\text { Snowball Sampling or chain sampling is another technique that is so } \\
\text { helpful in finding expert people within a specific field. It can be placed } \\
\text { within a wider set of methodologies that takes advantage of the social } \\
\text { networks of identified respondents, which can be used to provide a } \\
\text { researcher with an escalating set of potential contacts. It could be defined } \\
\text { as a technique for gathering research subjects through the identification of } \\
\text { an initial subject who is used to provide the names of other actors. These } \\
\text { actors may themselves open possibilities for an expanding web of contact } \\
\text { and inquiry [148]. Snowball Sampling is based on the cooperation of one } \\
\text { expert and the collaboration of other experts. The technique starts by } \\
\text { identifying an expert or few experts, who in turn will do the same thing to } \\
\text { identify or name other experts - the snowball will roll and become bigger. }\end{array}$ \\
\hline
\end{tabular}




\begin{tabular}{|l|l|}
\hline The later will do the same and locate more experts (chain referral \\
sampling) until a good size of sample is obtained. It is so efficient because \\
one connection could generate several others with no prior arrangements \\
or direct connection with other experts. Researchers use this technique to \\
obtain knowledge or data from extended associations that have been \\
developed overtime and where there is no easy direct access \\
Citation is a kind of relationship between the cited paper(s) and the citing \\
one. Citation analysis is the study of the impact and assumed quality of an \\
article, an author or an institution based on the number of times works \\
and/or authors have been cited by others. The approach uses the scholarly \\
works to set up connections to other works or researchers. A general \\
concept in citation analysis is that the degree to which a paper is cited, to \\
be a good indicator of expertise. Thus, a highly cited paper is a good \\
indicator too of an expert or a group of experts (authors) in the paper's \\
topic. Citation analysis involves assessing the research performance of \\
individual scholars, scholarly journal, and research group, departments, \\
and institutions [149]. The main uses of citation analysis are a) to find out \\
how much impact a particular article has had, by showing which other \\
authors based some work upon it or cited it as an example within their own \\
papers. b) to find out more about a field or topic; i.e. by reading the papers \\
that cites a seminal work in that area. c) to determine how much impact a \\
particular author has had by looking at his/her total number of citations.ee \\
well known citation analysis tools are 1) Web of Science (composed of 3 \\
citation indexes: Science Citation index Expanded, Social Sciences Citation \\
Index, and Arts and Humanities Citation Index), 2) Scopus, and 3) Google \\
Scholar. These three tools are in different in their subject focus but they are \\
in common for science, technology, and arts \& humanities. \\
Citation Analysis
\end{tabular}


Appendix C: Experts Invitation Questionnaire

\begin{tabular}{|c|c|c|}
\hline \multicolumn{3}{|c|}{ Please Select One of the Options Below: } \\
\hline \multirow{2}{*}{\multicolumn{3}{|c|}{$\begin{array}{l}\text { I will join your Expert Panel(s) } \\
\text { I will not be able to join your Expert Panel(s) }\end{array}$}} \\
\hline & & \\
\hline \multicolumn{3}{|c|}{ I suggest the following colleagues as potential Expert Panelists } \\
\hline & Expert's Name & Email Address \\
\hline \multicolumn{3}{|l|}{ Expert 1} \\
\hline \multicolumn{3}{|l|}{ Expert 2} \\
\hline \multicolumn{3}{|l|}{ Expert 3} \\
\hline \multicolumn{3}{|l|}{ Expert 4} \\
\hline Expert 5 & & \\
\hline
\end{tabular}




\section{Appendix D: Siting Technologies Validation Questionnaire}

Default Question Block

The literature of nuclear power plant siting technologies has identified 13 different offshore and underground siting options in addition to the land-based option.

Below is the 13 siting technologies, please click either Yes or No to indicate if the option is one of the most potential and applicable options and should be used in developing the essential decision model.

\begin{tabular}{l|cc}
\hline & Yes & No \\
\hline 1. Floating Plant & 0 & \\
\hline 2. Ocean Floor Plant & 0 & \\
\hline 3. Under the Ocean Floor & & \\
\hline 4. Natural Island & & \\
\hline 5. Artificial Island & & \\
\hline 6. Pre-Stressed Concrete Barge & 0 \\
\hline 7. Steel-Hull vessel Plant & 0 \\
\hline 8. Tuned Sphere Plant & 0 \\
\hline 9. Surface Mounded Plant & \\
\hline 10. Hillside Plant & \\
\hline 11. Deep Below the Surface & \\
\hline 12. Semi Embedded Plant & \\
\hline 13. Totally Embedded Plant &
\end{tabular}

Please add your comments here 
Appendix E: Model's Criteria and Sub-Criteria Validation Questionnaire

SurveyHead

Questionnaire to Validate the Decision Elements in the Evaluation Model for Siting of Nuclear Power Plants

Please select your areas of expertise below to indicate the expert panels which you will join.

Please note that Strategic option includes all 5 major panels/perspectives. If you select it, you will join all panels.

$\square$ Strategic

$\square$ Social

$\square$ Technical

$\square$ Economic

$\square$ Environmental

$\square$ Political

Social

\section{Social Criteria:}

Please click "Yes" or "No" for each criterion to indicate if the criterion is appropriate and should be used in the model.

If you want to add comments, add new criterion, or modify criterion's title or definition, please do it in the comments space.

(Note: if a criterion has sub-criteria, they will show up below if the criterion is selected as Yes.)

\begin{tabular}{l|c}
\hline & Yes \\
\hline S1. Public Acceptance and Attitude & No \\
\hline $\begin{array}{l}\text { Public acceptance refers to the level of public readiness to accept the nuclear } \\
\text { power plant }\end{array}$ & \\
\hline $\begin{array}{l}\text { S2. People Health and Safety (Level of Protection) } \\
\text { Provide during the construction and operation phases. }\end{array}$ &
\end{tabular}


S3. Social Life and Activities

The impact of a power plant technology with its large structures on the daily life and occasional activities of the locals.

S4. Visual Impact (Aesthetics)

The visual effect of a plant is the physical appearance of the facility relative to the landscape.

\section{S5. Manpower Availability (Experts)}

Skillful people are required to work for designing, implementing, and constructing a siting technology for a nuclear power plant.

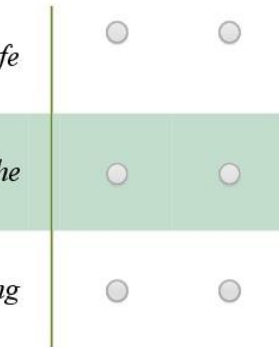

\section{- Social criteria comments and suggested additions, if any}

\section{- $\underline{\text { S2. People Health and Safety Sub-Criteria }}$}

\begin{tabular}{l|c}
\hline & Yes \\
\hline S2.1 Public & \\
\hline Inhabitants living within permissible boundaries & \\
S2.2 Workers &
\end{tabular}

\section{- Social sub-criteria comments and suggested additions, if any}

\section{Technical}

\section{Technical Criteria:}

Please click "Yes" or "No" for each criterion to indicate if the criterion is appropriate and should be used in the model.

If you want to add comments, add new criterion, or modify criterion's title or definition, please do it in the comments space. 
(Note: if a criterion has sub-criteria, they will show up below if the criterion is selected as Yes.)

\begin{tabular}{|c|c|c|}
\hline & Yes & No \\
\hline $\begin{array}{l}\text { T1. Maturity } \\
\text { Maturity is a term that defines the degree of readiness of a technology for } \\
\text { implementation. }\end{array}$ & 0 & 0 \\
\hline $\begin{array}{l}\text { T2. Flexibility } \\
\text { Flexibility is the ability of a technology to respond to potential internal or external } \\
\text { changes and needs that affect its current function, in timely and cost-effective } \\
\text { manner. }\end{array}$ & 0 & 0 \\
\hline $\begin{array}{l}\text { T3. Safety \& Security } \\
\text { The potential to prevent any external attacks, avoid any internal accidents, resist } \\
\text { severe seismic activities, limit any leakage of radioactive materials, and provide } \\
\text { high level of protection to people during construction, operation, and evacuation }\end{array}$ & 0 & 0 \\
\hline $\begin{array}{l}\text { T4. Power Generation Capacity } \\
\text { Nuclear power plants power generation capacities ranging from several hundred } \\
\text { megawatts to several thousand megawatts. The required power capacity would } \\
\text { directly affect the selection of a siting technology. }\end{array}$ & 0 & 0 \\
\hline $\begin{array}{l}\text { T5. Average Life Time } \\
\text { Nuclear power plants are built to serve for a certain minimum life span in order to } \\
\text { be economic. Some of the identified siting technologies have the potential to } \\
\text { exceed their average life time, while others might have limited life time based on } \\
\text { the design, location, or application }\end{array}$ & 0 & 0 \\
\hline $\begin{array}{l}\text { T6. Waste Storage Capacity } \\
\text { In general, wastes are stored at plant's site for a period of time and then } \\
\text { transferred to a permanent secure location to rest forever. The site capacity to store } \\
\text { more radioactive materials for very long time is a positive characteristic. }\end{array}$ & 0 & 0 \\
\hline $\begin{array}{l}\text { T7. Decommissioning and Site Cleanup } \\
\text { Decommissioning is a technical process that includes clean-up of radioactive } \\
\text { materials and progressive demolition of the plant. }\end{array}$ & 0 & 0 \\
\hline
\end{tabular}

\section{- Technical criteria comments and suggested additions, if any}

\section{- T1. Maturity Sub-Criteria}

T1.1 Applicability

The level of practical application 
T1.2 Reliability (subcriterion)

The level of dependability or trustworthiness

T1.3 Efficiency (subcriterion)

The ratio of useful output to the total input (productivity)

\section{- T.2 Flexibility Sub-Criteria}

T2.1 Scalability
The ability of a plant to be expanded in size, number of units, or space to
accommodate more reactors or auxiliary systems for future plans
accommodate more reactors or auxiliary systems for future plans

\section{T2.2 Mobility}

The feature that would allow a plant to be relocated at different sites in order to supply the power for remote areas or in case of emergencies, or to be sited at totally different location

T2.3 Modularity

The possibility of a plant to be built on smaller standard units (modules) to ease or standardize the construction and installation processes

\begin{tabular}{cc} 
Yes & No \\
\hline & 0 \\
0 & \\
& \\
& \\
&
\end{tabular}

\section{- T3. Safety \& Security Sub-Criteria}

\begin{tabular}{l|c}
\hline & Yes \\
\hline T3.1 Resistance \\
\hline $\begin{array}{l}\text { The ability to resist any external phenomenon (e.g., storms, earthquake, floods, } \\
\text { attacks, etc. }\end{array}$ \\
$\begin{array}{l}\text { T3.2 Containment } \\
\text { The ability to contain any internal malfunction or radioactive leakage }\end{array}$ \\
$\begin{array}{l}\text { T3.3 Evacuation } \\
\text { The ability to provide safe, secure, and fast process to transfer workers or people to } \\
\text { a better place }\end{array}$ & \\
\end{tabular}

- Technical sub-criteria comments and suggested additions, if any

Economic 


\section{Economic Criteria:}

Please click "Yes" or "No" for each criterion to indicate if the criterion is appropriate and should be used in the model.

If you want to add comments, add new criterion, or modify criterion's title or definition, please do it in the comments space.

(Note: if a criterion has sub-criteria, they will show up below if the criterion is selected as Yes.)

E1. Site Development Cost
Site development is an initial stage for setting up nuclear power plant. In order to
select a plant location either inland, underground, or offshore; three consecutive
actions are needed at an early stage: Exploration, Acquisition, and Preparation.
Site development cost is the cost of theses actions
E2. Plant Development Cost
Developing a muclear power plant starts with plant's design, contimues with
construction and installation, follows with operation and maintenance, and ends
with decommission.

\section{E3. Plant Supplementary Systems Cost}

A miclear power plant requires several additional systems to support its operation and continuation. These systems differ in their functionalities but work together to enhance the plant's overall functionality

\section{E4. Technology Transfer Cost}

Exchanging knowledge (i.e., Know-how) or acquiring experiences (i.e., hiring experts) from others (locally or internationally) will involve some cost, which could be defined as technology transfer cost.

\section{E5. Return on Investment}

Total cost could not be the sole factor. Some of these sitings could cost more at the beginning but justify the high cost by the output on the long run of plant's lifecycle operation. Return on investment (ROI) is the ratio of net output over the total investment.

\section{E6. Site Sharing Benefits}

Site sharing could be a positive factor in siting technology selection process. Some power plants could save or generate money by sharing the ground surface with other industrial.

Yes No

\section{- Economic criteria comments and suggested additions, if any}




\section{- E1. Site Development Cost Sub-Criteria}

\begin{tabular}{l|c}
\hline & Yes \\
\hline E1.1 Exploration Cost & \\
\hline To investigate the suitability of subsurface materials & \\
E1.2 Acquisition Cost & \\
\hline To obtain and control the site for a long period of time & \\
E1.3 Preparation Cost & \\
To make the site suitable for plant construction and operation &
\end{tabular}

\section{- E2. Plant Development Cost Sub-Criteria}

\begin{tabular}{l|c}
\hline E2.1 Design Cost & Yes \\
\hline Cost of desiging the plant's main components. & \\
\hline E2.2 Construction and Installation Cost & \\
\hline Cost of the process of building and setting up the plant. & \\
\hline E2.3 Operation and Maintenance Cost & \\
\hline Cost of the plant's frequent and continuous activities. & \\
E2.4 Decommissioning Cost & \\
\hline Cost of the process of withdrawing the plant from service. &
\end{tabular}

\section{- E3. Plant Supplementary Systems Cost}

E3.1 Water Delivery System Cost
Cost of providing the required usable water resources for steam generation and
plant cooling.

\section{E3.2 Grid Connection System Cost}

Cost of electrical transmission and distribution channels to connect plant to the grid.

\section{E3.3 Ventilation System Cost}

Cost of providing fresh air circulation for a highly sealed environment.

\section{E3.4 Protection and Isolation System Cost}

Cost of pProviding the required level of protection for the plant and from the plant.

E3.5 Transportation System Cost

Cost of providing appropriate means to transfer people and materials from and to the plant.

\begin{tabular}{|c|cc}
\hline & Yes & No \\
\hline & 0 \\
0 & 0 \\
0 & 0 \\
0 & 0 \\
0 & 0
\end{tabular}

\section{- Economic sub-criteria comments and suggested additions, if any}


Environmental

\section{Environmental Criteria:}

Please click "Yes" or "No" for each criterion to indicate if the criterion is appropriate and should be used in the model.

If you want to add comments, add new criterion, or modify criterion's title or definition, please do it in the comments space.

(Note: if a criterion has sub-criteria, they will show up below if the criterion is selected as Yes.)

\begin{tabular}{l|l}
\hline & Yes No \\
\hline N1. Site Preparation-Related Impacts (Disruption) &
\end{tabular}

Some changes in the site will take place in accordance with site preparation works, which in turn will alter the site's ecological system.

\section{N2. Construction-Related Impacts}

All activities during the construvtion phase (i.e. transportation, accommodation, construction, etc.) will impact directly the nature of the site in terms of daily site reformation and waste generation. Construction phase makes permanent changes in the ecosystem.

\section{N3. Opeartion-Related Impacts}

Massive quantities of usable water are to be extracted from lakes, rivers, seas, ocean, or underground. This practice can negatively affect water sources either by discharging highly heated water or by small amounts of radionuclide back into the water source.

\section{N4. Land Consumption and Utilization}

An environmental feature that would support siting technology selection is the wise use of available land/space. In most countries, land is a scarce commodity and there are usually many options for its utilization.

\section{N5. Site Recovery}

Most nuclear power plants mostly are decommissioned at the end of their functional lives. The ability to return the site to its natural state at retirement is a key factor for choosing environment friendly siting technology.

$\begin{array}{ll}0 & 0 \\ 0 & 0 \\ 0 & 0 \\ 0 & \\ 0 & \end{array}$

\section{- Environmental criteria comments and suggested additions, if any}




\section{Political Criteria:}

Please click "Yes" or "No" for each criterion to indicate if the criterion is appropriate and should be used in the model.

If you want to add comments, add new criterion, or modify criterion's title or definition, please do it in the comments space.

(Note: if a criterion has sub-criteria, they will show up below if the criterion is selected as Yes.)

\begin{tabular}{|c|c|c|}
\hline & Yes & No \\
\hline $\begin{array}{l}\text { P1. Government Perception } \\
\text { Governments need to be aware of the advantages and disadvantages of the new } \\
\text { siting technologies. The level of government perception of these new siting } \\
\text { technologies could support or hinder the decision of selecting the proper one. }\end{array}$ & 0 & 0 \\
\hline $\begin{array}{l}\text { P2. Government Support } \\
\text { Governments have excellent mechanisms to promote a new technology. These } \\
\text { mechanisms include raising public awareness, implementing stringent or flexible } \\
\text { regulations and standards, licensing, tax exemption, subsidies and loans. }\end{array}$ & 0 & 0 \\
\hline $\begin{array}{l}\text { P3. Political Side of Technology Transfer } \\
\text { The political side of technology transfer is critical because many of the technical } \\
\text { and economic obstacles could be lessened or amplified depending on whether } \\
\text { collaboration exists among governments. }\end{array}$ & 0 & 0 \\
\hline $\begin{array}{l}\text { P4. National/International Laws and Agreements } \\
\text { A potential accident in a nuclear power plant can lead to consequences that can } \\
\text { extend many miles. A site near an international border raises the problem of } \\
\text { appropriate treaties with the neighboring state/country. }\end{array}$ & 0 & 0 \\
\hline $\begin{array}{l}\text { P5. Rules and Regulations Availability } \\
\text { It is important to refer to existing rules and regulations in considering any siting } \\
\text { technology. In the absence of relevant rules and regulations, developing new rules } \\
\text { and waiting for new legislations are time consuming. }\end{array}$ & 0 & 0 \\
\hline
\end{tabular}

\section{- Political criteria comments and suggested additions, if any}


Appendix F: Tables of Pairwise Comparison Results for All Perspectives, Criteria, and Sub-Criteria

Table F-1 Social Criteria Relative Values

\begin{tabular}{|c|c|c|c|c|c|c|}
\hline & \multicolumn{6}{|c|}{ Social Criteria } \\
\cline { 1 - 5 } Experts & $\begin{array}{c}\text { Public } \\
\text { Acceptance and } \\
\text { Attitude }\end{array}$ & $\begin{array}{c}\text { People } \\
\text { Health and } \\
\text { Safety }\end{array}$ & $\begin{array}{c}\text { Social Life } \\
\text { and } \\
\text { Activities }\end{array}$ & $\begin{array}{c}\text { Visual } \\
\text { Impact }\end{array}$ & $\begin{array}{c}\text { Experts } \\
\text { Availability }\end{array}$ & Inconsistency \\
\hline EXP01 & 0.14 & 0.53 & 0.05 & 0.03 & 0.26 & 0.09 \\
\hline EXP02 & 0.29 & 0.25 & 0.16 & 0.17 & 0.13 & 0.01 \\
\hline EXP03 & 0.36 & 0.18 & 0.08 & 0.08 & 0.31 & 0.01 \\
\hline EXP04 & 0.20 & 0.36 & 0.07 & 0.05 & 0.31 & 0.01 \\
\hline EXP05 & 0.40 & 0.31 & 0.17 & 0.07 & 0.05 & 0.03 \\
\hline EXP06 & 0.54 & 0.24 & 0.10 & 0.07 & 0.05 & 0.01 \\
\hline EXP07 & 0.34 & 0.33 & 0.07 & 0.05 & 0.21 & 0.09 \\
\hline EXP08 & 0.14 & 0.43 & 0.17 & 0.09 & 0.18 & 0.05 \\
\hline EXP09 & 0.09 & 0.45 & 0.07 & 0.06 & 0.33 & 0.03 \\
\hline EXP10 & 0.35 & 0.42 & 0.10 & 0.08 & 0.05 & 0.02 \\
\hline EXP11 & 0.16 & 0.45 & 0.06 & 0.05 & 0.28 & 0.04 \\
\hline EXP12 & 0.14 & 0.36 & 0.11 & 0.04 & 0.35 & 0.00 \\
\hline EXP13 & 0.30 & 0.25 & 0.15 & 0.10 & 0.20 & 0.03 \\
\hline Mean & 0.27 & 0.35 & 0.1 & 0.07 & 0.21 & \\
\hline Disagreement & & & & & & 0.08 \\
\hline
\end{tabular}

Table F-2 People Health and Safety Sub-Criteria Relative Values

\begin{tabular}{|c|c|c|c|}
\hline \multirow{2}{*}{ Experts } & \multicolumn{2}{|c|}{ People Health and Safety Sub-Criteria } & \multirow{2}{*}{ Inconsistency } \\
\hline & Public & Workers & \\
\hline EXP01 & 0.41 & 0.59 & 0.00 \\
\hline EXP02 & 0.50 & 0.50 & 0.00 \\
\hline EXP03 & 0.95 & 0.05 & 0.00 \\
\hline EXP04 & 0.60 & 0.40 & 0.00 \\
\hline EXP05 & 0.80 & 0.20 & 0.00 \\
\hline EXP06 & 0.65 & 0.35 & 0.00 \\
\hline EXP07 & 0.40 & 0.60 & 0.00 \\
\hline EXP08 & 0.80 & 0.20 & 0.00 \\
\hline EXP09 & 0.75 & 0.25 & 0.00 \\
\hline EXP10 & 0.65 & 0.35 & 0.00 \\
\hline EXP11 & 0.68 & 0.32 & 0.00 \\
\hline EXP12 & 0.70 & 0.30 & 0.00 \\
\hline EXP13 & 0.65 & 0.35 & 0.00 \\
\hline Mean & 0.66 & 0.34 & 0.10 \\
\hline Disagreement & & & \\
\hline
\end{tabular}


Table F-3 Technical Criteria Relative Values

\begin{tabular}{|c|c|c|c|c|c|c|c|c|}
\hline \multirow[b]{2}{*}{ Experts } & \multicolumn{7}{|c|}{ Technical Criteria } & \multirow[b]{2}{*}{ Inconsistency } \\
\hline & Maturity & Flexibility & $\begin{array}{l}\text { Safety } \\
\text { and } \\
\text { Security }\end{array}$ & $\begin{array}{l}\text { Power } \\
\text { Generation } \\
\text { Capacity }\end{array}$ & $\begin{array}{l}\text { Plant } \\
\text { Life } \\
\text { Span }\end{array}$ & $\begin{array}{l}\text { Fuel Used } \\
\text { Storage } \\
\text { Capacity }\end{array}$ & $\begin{array}{l}\text { Decommission } \\
\text { and Clean Up }\end{array}$ & \\
\hline EXP01 & 0.05 & 0.02 & 0.55 & 0.10 & 0.11 & 0.09 & 0.09 & 0.05 \\
\hline EXP02 & 0.10 & 0.18 & 0.19 & 0.15 & 0.17 & 0.12 & 0.08 & 0.02 \\
\hline EXP03 & 0.14 & 0.14 & 0.14 & 0.14 & 0.15 & 0.14 & 0.14 & 0.07 \\
\hline EXP04 & 0.06 & 0.06 & 0.54 & 0.06 & 0.06 & 0.06 & 0.18 & 0.11 \\
\hline EXP05 & 0.02 & 0.02 & 0.21 & 0.05 & 0.02 & 0.33 & 0.34 & 0.07 \\
\hline EXP06 & 0.14 & 0.07 & 0.35 & 0.22 & 0.08 & 0.08 & 0.06 & 0.08 \\
\hline EXP07 & 0.08 & 0.16 & 0.24 & 0.13 & 0.05 & 0.23 & 0.10 & 0.10 \\
\hline EXP08 & 0.17 & 0.23 & 0.19 & 0.09 & 0.10 & 0.09 & 0.14 & 0.06 \\
\hline EXP09 & 0.15 & 0.26 & 0.14 & 0.10 & 0.11 & 0.09 & 0.16 & 0.02 \\
\hline EXP10 & 0.26 & 0.08 & 0.07 & 0.21 & 0.17 & 0.14 & 0.06 & 0.06 \\
\hline EXP11 & 0.07 & 0.17 & 0.26 & 0.13 & 0.17 & 0.10 & 0.09 & 0.01 \\
\hline EXP12 & 0.25 & 0.19 & 0.25 & 0.11 & 0.08 & 0.07 & 0.06 & 0.03 \\
\hline EXP13 & 0.26 & 0.20 & 0.15 & 0.18 & 0.08 & 0.07 & 0.06 & 0.01 \\
\hline EXP14 & 0.21 & 0.19 & 0.20 & 0.10 & 0.13 & 0.10 & 0.07 & 0.06 \\
\hline EXP15 & 0.10 & 0.05 & 0.18 & 0.18 & 0.18 & 0.15 & 0.15 & 0.02 \\
\hline Mean & 0.14 & 0.13 & 0.24 & 0.13 & 0.11 & 0.12 & 0.12 & \\
\hline Disagree & & & & & & & & 0.07 \\
\hline
\end{tabular}

Table F-4 Maturity Sub-Criteria Relative Values

\begin{tabular}{|c|c|c|c|c|}
\hline & \multicolumn{3}{|c|}{ Maturity Sub-Criteria } \\
\hline Experts & Applicability & Reliability & Competency & \\
\hline EXP01 & 0.11 & 0.75 & 0.14 & 0.01 \\
\hline EXP02 & 0.24 & 0.52 & 0.24 & 0.00 \\
\hline EXP03 & 0.13 & 0.85 & 0.02 & 0.05 \\
\hline EXP04 & 0.21 & 0.51 & 0.28 & 0.00 \\
\hline EXP05 & 0.98 & 0.01 & 0.01 & 0.00 \\
\hline EXP06 & 0.10 & 0.69 & 0.21 & 0.00 \\
\hline EXP07 & 0.14 & 0.68 & 0.18 & 0.00 \\
\hline EXP08 & 0.43 & 0.43 & 0.14 & 0.00 \\
\hline EXP09 & 0.28 & 0.44 & 0.28 & 0.00 \\
\hline EXP10 & 0.33 & 0.34 & 0.33 & 0.00 \\
\hline EXP11 & 0.20 & 0.44 & 0.36 & 0.02 \\
\hline EXP12 & 0.44 & 0.30 & 0.26 & 0.00 \\
\hline EXP13 & 0.32 & 0.50 & 0.18 & 0.01 \\
\hline EXP14 & 0.32 & 0.49 & 0.19 & 0.00 \\
\hline EXP15 & 0.50 & 0.33 & 0.10 & 0.04 \\
\hline Mean & 0.32 & 0.49 & 0.19 & \\
\hline Disagreement & & & & 0.07 \\
\hline
\end{tabular}


Table F-5 Flexibility Sub-Criteria Relative Values

\begin{tabular}{|c|c|c|c|c|}
\hline & \multicolumn{3}{|c|}{ Flexibility Sub-Criteria } \\
\hline Experts & Scalability & Mobility & Modularity & \\
\hline EXP01 & 0.50 & 0.01 & 0.50 & 0.02 \\
\hline EXP02 & 0.31 & 0.20 & 0.49 & 0.01 \\
\hline EXP03 & 0.20 & 0.20 & 0.60 & 0.00 \\
\hline EXP04 & 0.39 & 0.10 & 0.50 & 0.02 \\
\hline EXP05 & 0.26 & 0.10 & 0.64 & 0.05 \\
\hline EXP06 & 0.58 & 0.04 & 0.38 & 0.10 \\
\hline EXP07 & 0.18 & 0.41 & 0.41 & 0.00 \\
\hline EXP08 & 0.33 & 0.33 & 0.33 & 0.00 \\
\hline EXP09 & 0.16 & 0.58 & 0.26 & 0.00 \\
\hline EXP10 & 0.72 & 0.07 & 0.22 & 0.01 \\
\hline EXP11 & 0.60 & 0.15 & 0.25 & 0.06 \\
\hline EXP12 & 0.43 & 0.23 & 0.34 & 0.03 \\
\hline EXP13 & 0.45 & 0.10 & 0.45 & 0.09 \\
\hline EXP14 & 0.35 & 0.05 & 0.60 & 0.02 \\
\hline EXP15 & 0.60 & 0.20 & 0.20 & 0.00 \\
\hline Mean & 0.40 & 0.19 & 0.41 & \\
\hline Disagreement & & & & 0.10 \\
\hline
\end{tabular}

Table F-6 Plant Safety and Security Sub-Criteria Relative Values

\begin{tabular}{|c|c|c|c|c|}
\hline \multirow{2}{*}{ Experts } & \multicolumn{3}{|c|}{ Plant Safety and Security Sub-Criteria } & \multirow{2}{*}{ Inconsistency } \\
\hline & Resistance & Containment & Evacuation & \\
\hline EXP01 & 0.37 & 0.54 & 0.09 & 0.04 \\
\hline EXP02 & 0.22 & 0.59 & 0.19 & 0.04 \\
\hline EXP03 & 0.38 & 0.49 & 0.13 & 0.00 \\
\hline EXP04 & 0.37 & 0.45 & 0.18 & 0.00 \\
\hline EXP05 & 0.35 & 0.60 & 0.05 & 0.09 \\
\hline EXP06 & 0.29 & 0.55 & 0.16 & 0.00 \\
\hline EXP07 & 0.32 & 0.55 & 0.13 & 0.06 \\
\hline EXP08 & 0.33 & 0.33 & 0.33 & 0.00 \\
\hline EXP09 & 0.39 & 0.49 & 0.12 & 0.00 \\
\hline EXP10 & 0.28 & 0.51 & 0.21 & 0.04 \\
\hline EXP11 & 0.33 & 0.46 & 0.21 & 0.05 \\
\hline EXP12 & 0.35 & 0.55 & 0.10 & 0.00 \\
\hline EXP13 & 0.25 & 0.60 & 0.15 & 0.02 \\
\hline EXP14 & 0.30 & 0.50 & 0.20 & 0.06 \\
\hline EXP15 & 0.33 & 0.33 & 0.33 & 0.00 \\
\hline Mean & 0.32 & 0.50 & 0.17 & \\
\hline Disagreement & & & & 0.06 \\
\hline
\end{tabular}


Table F-7 Economic Criteria Relative Values

\begin{tabular}{|c|c|c|c|c|c|c|}
\hline & \multicolumn{7}{|c|}{ Economic Criteria } \\
\cline { 1 - 5 } & $\begin{array}{c}\text { Experts } \\
\text { Site } \\
\text { Development }\end{array}$ & $\begin{array}{c}\text { Plant } \\
\text { Development }\end{array}$ & $\begin{array}{c}\text { Supplementary } \\
\text { Systems }\end{array}$ & $\begin{array}{c}\text { Technology } \\
\text { Outsourcing }\end{array}$ & $\begin{array}{c}\text { Return on } \\
\text { Investment }\end{array}$ & \\
\hline EXP01 & 0.16 & 0.34 & 0.21 & 0.12 & 0.17 & 0.05 \\
\hline EXP02 & 0.09 & 0.25 & 0.20 & 0.26 & 0.21 & 0.06 \\
\hline EXP03 & 0.14 & 0.23 & 0.18 & 0.07 & 0.37 & 0.12 \\
\hline EXP04 & 0.20 & 0.31 & 0.18 & 0.17 & 0.14 & 0.02 \\
\hline EXP05 & 0.13 & 0.29 & 0.20 & 0.16 & 0.21 & 0.02 \\
\hline EXP06 & 0.16 & 0.18 & 0.13 & 0.11 & 0.42 & 0.06 \\
\hline EXP07 & 0.24 & 0.16 & 0.12 & 0.10 & 0.38 & 0.04 \\
\hline EXP08 & 0.14 & 0.18 & 0.07 & 0.23 & 0.37 & 0.09 \\
\hline EXP09 & 0.12 & 0.19 & 0.21 & 0.17 & 0.31 & 0.02 \\
\hline EXP10 & 0.10 & 0.16 & 0.10 & 0.05 & 0.6 & 0.14 \\
\hline EXP11 & 0.27 & 0.21 & 0.17 & 0.13 & 0.21 & 0.02 \\
\hline EXP12 & 0.19 & 0.19 & 0.16 & 0.11 & 0.35 & 0.06 \\
\hline Mean & & & & & & \\
\hline Disagreement & & & & & & 0.08 \\
\hline
\end{tabular}

Table F-8 Site Development Cost Sub-Criteria Relative Values

\begin{tabular}{|c|c|c|c|c|}
\hline \multirow{2}{*}{ Experts } & \multicolumn{3}{|c|}{ Site Development Cost Sub-Criteria } & \multirow{2}{*}{ Inconsistency } \\
\cline { 2 - 4 } & Exploration & Acquisition & Preparation & \\
\hline EXP01 & 0.17 & 0.53 & 0.30 & 0.04 \\
\hline EXP02 & 0.22 & 0.21 & 0.54 & 0.03 \\
\hline EXP03 & 0.22 & 0.28 & 0.50 & 0.00 \\
\hline EXP04 & 0.16 & 0.38 & 0.46 & 0.02 \\
\hline EXP05 & 0.34 & 0.33 & 0.33 & 0.00 \\
\hline EXP06 & 0.16 & 0.38 & 0.46 & 0.02 \\
\hline EXP07 & 0.18 & 0.41 & 0.41 & 0.00 \\
\hline EXP08 & 0.25 & 0.41 & 0.34 & 0.05 \\
\hline EXP09 & 0.35 & 0.27 & 0.38 & 0.01 \\
\hline EXP10 & 0.28 & 0.33 & 0.39 & 0.00 \\
\hline EXP11 & 0.33 & 0.25 & 0.42 & 0.02 \\
\hline EXP12 & 0.29 & 0.27 & 0.44 & 0.02 \\
\hline Mean & 0.25 & 0.34 & 0.41 & \\
\hline Disagreement & & & & 0.10 \\
\hline
\end{tabular}


Table F-9 Plant Development Cost Sub-Criteria Relative Values

\begin{tabular}{|c|c|c|c|c|}
\hline & \multicolumn{2}{|c|}{ Plant Development Cost Sub-Criteria } & \\
\hline & Experts & Construction & Operation & Decommission \\
\hline & EXP01 & 0.47 & 0.33 & 0.03 \\
\hline EXP02 & 0.31 & 0.44 & 0.25 & 0.03 \\
\hline EXP03 & 0.58 & 0.33 & 0.09 & 0.10 \\
\hline EXP04 & 0.45 & 0.31 & 0.24 & 0.02 \\
\hline EXP05 & 0.33 & 0.33 & 0.33 & 0.00 \\
\hline EXP06 & 0.49 & 0.19 & 0.32 & 0.03 \\
\hline EXP07 & 0.55 & 0.28 & 0.17 & 0.09 \\
\hline EXP08 & 0.44 & 0.29 & 0.27 & 0.04 \\
\hline EXP09 & 0.37 & 0.49 & 0.14 & 0.06 \\
\hline EXP10 & 0.60 & 0.31 & 0.09 & 0.04 \\
\hline EXP11 & 0.47 & 0.31 & 0.22 & 0.07 \\
\hline EXP12 & 0.54 & 0.25 & 0.21 & \\
\hline Mean & 0.47 & 0.32 & 0.21 & 0.08 \\
\hline Disagreement & & & & \\
\hline
\end{tabular}

Table F-10 Supplementary Systems Cost Sub-Criteria Relative Values

\begin{tabular}{|c|c|c|c|c|c|c|}
\hline \multirow{2}{*}{ Experts } & \multicolumn{5}{|c|}{$\begin{array}{l}\text { Economic } \\
\text { Supplementary Systems Cost Sub-Criteria }\end{array}$} & \multirow{2}{*}{ Inconsistency } \\
\hline & $\begin{array}{l}\text { Water } \\
\text { Delivery }\end{array}$ & $\begin{array}{c}\text { Grid } \\
\text { Connection }\end{array}$ & $\begin{array}{l}\text { Ventilation } \\
\text { System }\end{array}$ & $\begin{array}{l}\text { Protection } \\
\text { \& Isolation }\end{array}$ & $\begin{array}{l}\text { Transportation } \\
\text { System }\end{array}$ & \\
\hline EXP01 & 0.21 & 0.24 & 0.16 & 0.19 & 0.20 & 0.01 \\
\hline EXP02 & 0.20 & 0.20 & 0.20 & 0.23 & 0.17 & 0.01 \\
\hline EXP03 & 0.29 & 0.14 & 0.26 & 0.25 & 0.06 & 0.03 \\
\hline EXP04 & 0.27 & 0.26 & 0.14 & 0.19 & 0.14 & 0.02 \\
\hline EXP05 & 0.20 & 0.20 & 0.20 & 0.20 & 0.20 & 0.00 \\
\hline EXP06 & 0.29 & 0.14 & 0.14 & 0.29 & 0.14 & 0.00 \\
\hline EXP07 & 0.35 & 0.19 & 0.12 & 0.12 & 0.22 & 0.02 \\
\hline EXP08 & 0.21 & 0.16 & 0.17 & 0.30 & 0.16 & 0.04 \\
\hline EXP09 & 0.18 & 0.20 & 0.12 & 0.29 & 0.21 & 0.01 \\
\hline EXP10 & 0.04 & 0.08 & 0.03 & 0.66 & 0.19 & 0.04 \\
\hline EXP11 & 0.22 & 0.19 & 0.15 & 0.28 & 0.16 & 0.03 \\
\hline EXP12 & 0.25 & 0.16 & 0.20 & 0.22 & 0.17 & 0.02 \\
\hline Mean & 0.23 & 0.18 & 0.16 & 0.27 & 0.17 & \\
\hline Disagreement & & & & & & 0.05 \\
\hline
\end{tabular}


Table F-11 Environmental Criteria Relative Values

\begin{tabular}{|c|c|c|c|c|c|c|}
\hline & \multicolumn{7}{|c|}{ Environmental Criteria } & \\
\cline { 1 - 3 } & $\begin{array}{c}\text { Experts } \\
\text { Preparation } \\
\text { Impacts }\end{array}$ & $\begin{array}{c}\text { Sonstruction } \\
\text { Impacts }\end{array}$ & $\begin{array}{c}\text { Operation } \\
\text { Impacts }\end{array}$ & $\begin{array}{c}\text { Land } \\
\text { Availability }\end{array}$ & $\begin{array}{c}\text { Site } \\
\text { Recovery }\end{array}$ & Inconsistency \\
\hline EXP01 & 0.19 & 0.15 & 0.27 & 0.22 & 0.16 & 0.03 \\
\hline EXP02 & 0.14 & 0.40 & 0.14 & 0.06 & 0.26 & 0.01 \\
\hline EXP03 & 0.07 & 0.10 & 0.22 & 0.47 & 0.15 & 0.05 \\
\hline EXP04 & 0.23 & 0.14 & 0.42 & 0.10 & 0.11 & 0.08 \\
\hline EXP05 & 0.10 & 0.09 & 0.17 & 0.23 & 0.41 & 0.06 \\
\hline EXP06 & 0.12 & 0.16 & 0.34 & 0.11 & 0.27 & 0.00 \\
\hline EXP07 & 0.13 & 0.21 & 0.42 & 0.16 & 0.08 & 0.05 \\
\hline EXP08 & 0.21 & 0.21 & 0.23 & 0.21 & 0.13 & 0.00 \\
\hline EXP09 & 0.16 & 0.25 & 0.39 & 0.08 & 0.12 & 0.01 \\
\hline EXP10 & 0.23 & 0.23 & 0.23 & 0.23 & 0.08 & 0.00 \\
\hline EXP11 & 0.21 & 0.40 & 0.11 & 0.09 & 0.17 & 0.01 \\
\hline EXP12 & 0.19 & 0.24 & 0.09 & 0.13 & 0.35 & 0.03 \\
\hline EXP13 & 0.06 & 0.08 & 0.45 & 0.12 & 0.29 & 0.06 \\
\hline Mean & 0.16 & 0.20 & 0.27 & 0.17 & 0.20 & \\
\hline Disagreement & & & & & & 0.10 \\
\hline
\end{tabular}

Table F-12 Political Criteria Relative Values

\begin{tabular}{|c|c|c|c|c|c|c|}
\hline \multirow[b]{2}{*}{ Experts } & \multicolumn{5}{|c|}{ Political Criteria } & \multirow[b]{2}{*}{ Inconsistency } \\
\hline & $\begin{array}{c}\text { Government } \\
\text { Perception }\end{array}$ & $\begin{array}{l}\text { Government } \\
\text { Support }\end{array}$ & $\begin{array}{l}\text { Political } \\
\text { side of } \\
\text { Technology } \\
\text { Transfer }\end{array}$ & $\begin{array}{l}\text { National/ } \\
\text { International } \\
\text { Laws and } \\
\text { Agreements }\end{array}$ & $\begin{array}{c}\text { Rules \& } \\
\text { Regulations } \\
\text { Availability }\end{array}$ & \\
\hline EXP01 & 0.09 & 0.36 & 0.10 & 0.17 & 0.28 & 0.03 \\
\hline EXP02 & 0.18 & 0.26 & 0.12 & 0.17 & 0.27 & 0.02 \\
\hline EXP03 & 0.07 & 0.06 & 0.10 & 0.45 & 0.31 & 0.06 \\
\hline EXP04 & 0.27 & 0.18 & 0.25 & 0.16 & 0.14 & 0.01 \\
\hline EXP05 & 0.14 & 0.41 & 0.07 & 0.08 & 0.29 & 0.05 \\
\hline EXP06 & 0.23 & 0.20 & 0.12 & 0.20 & 0.25 & 0.03 \\
\hline EXP07 & 0.14 & 0.26 & 0.09 & 0.23 & 0.28 & 0.02 \\
\hline EXP08 & 0.15 & 0.25 & 0.08 & 0.25 & 0.27 & 0.03 \\
\hline EXP09 & 0.21 & 0.18 & 0.11 & 0.13 & 0.38 & 0.02 \\
\hline EXP10 & 0.20 & 0.40 & 0.10 & 0.09 & 0.22 & 0.02 \\
\hline EXP11 & 0.09 & 0.26 & 0.13 & 0.20 & 0.32 & 0.06 \\
\hline EXP12 & 0.05 & 0.13 & 0.14 & 0.30 & 0.38 & 0.02 \\
\hline Mean & 0.15 & 0.25 & 0.12 & 0.20 & 0.28 & \\
\hline isagreemen & & & & & & 0.07 \\
\hline
\end{tabular}


Appendix G: Desirability Tables and Curves of All 42 Decision Model's Criteria and Sub-Criteria

Table G-1 Desirability Values of Public Acceptance and Attitude Criterion

\begin{tabular}{|l|c|c|c|c|c|c|c|}
\hline \multicolumn{2}{|c|}{ Social: (S1) Public Acceptance and Attitude } \\
\hline \multicolumn{1}{|c|}{ Metrics } & EXP01 & EXP02 & EXP03 & EXP04 & EXP05 & Avg. & $\%$ \\
\hline no acceptance & 0 & 10 & 10 & 0 & 0 & 4 & 0.04 \\
\hline neutral acceptance & 10 & 50 & 50 & 25 & 10 & 29 & 0.29 \\
\hline low acceptance & 10 & 60 & 60 & 40 & 25 & 39 & 0.39 \\
\hline average acceptance & 60 & 80 & 75 & 75 & 50 & 68 & 0.68 \\
\hline high acceptance & 100 & 100 & 100 & 90 & 100 & 98 & 0.98 \\
\hline
\end{tabular}

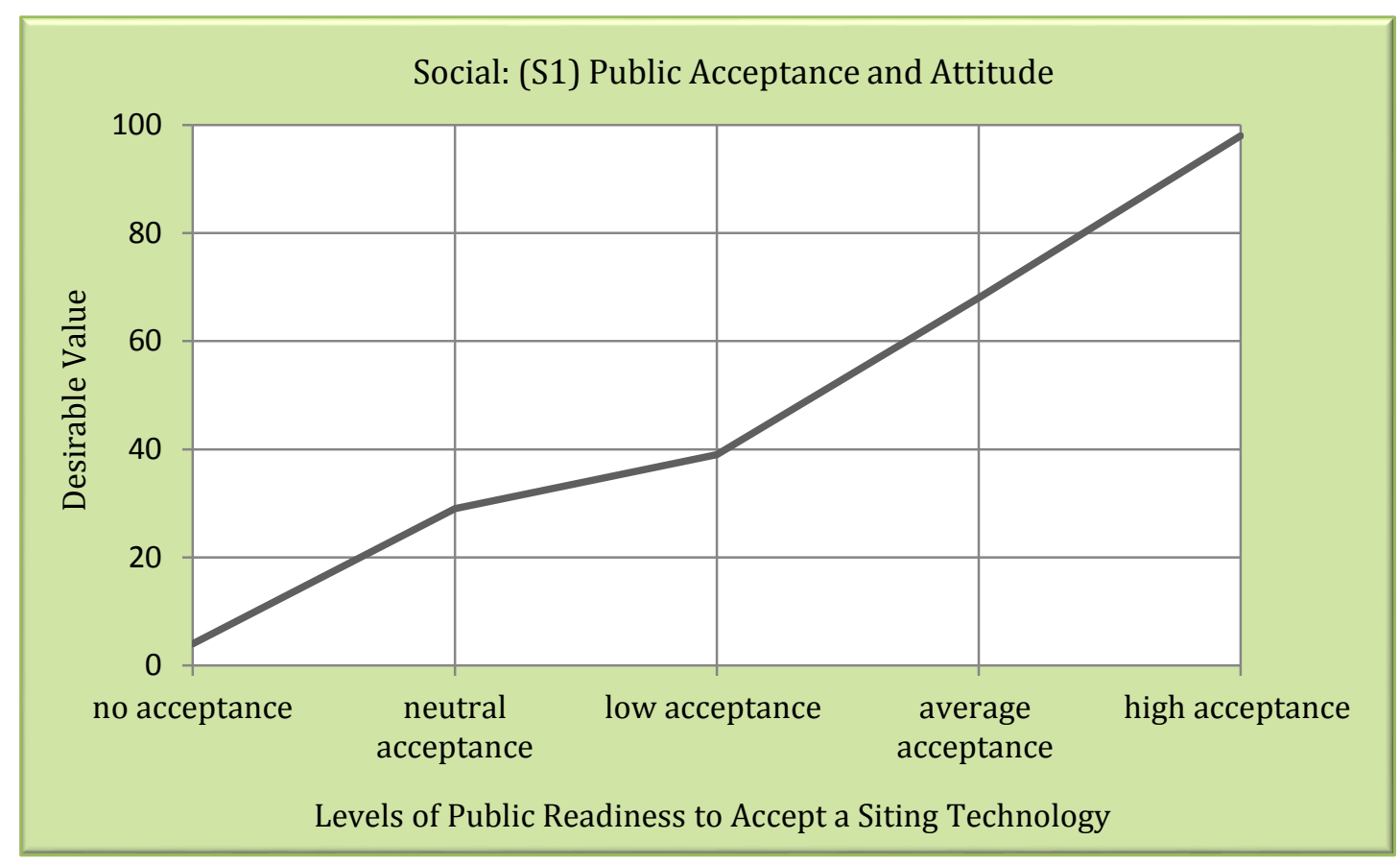

Figure G-1 Desirability Curve of Public Acceptance and Attitude Criterion 
Table G-2 Desirability Values of Public Health and Safety Sub-Criterion

\begin{tabular}{|l|c|c|c|c|c|c|c|}
\hline \multicolumn{2}{c|}{ Social: (S2.1) Health and Safety/Public } \\
\hline \multicolumn{1}{|c|}{ Metrics } & EXP01 & EXP02 & EXP03 & EXP04 & EXP05 & Avg. & $\%$ \\
\hline high negative impact & 0 & 0 & 0 & 0 & 0 & 0 & 0.00 \\
\hline average negative impact & 50 & 75 & 60 & 70 & 40 & 59 & 0.59 \\
\hline low negative impact & 75 & 80 & 70 & 90 & 60 & 75 & 0.75 \\
\hline trivial negative impact & 80 & 95 & 80 & 90 & 80 & 85 & 0.85 \\
\hline no negative impact & 100 & 100 & 100 & 100 & 100 & 100 & 1.00 \\
\hline
\end{tabular}

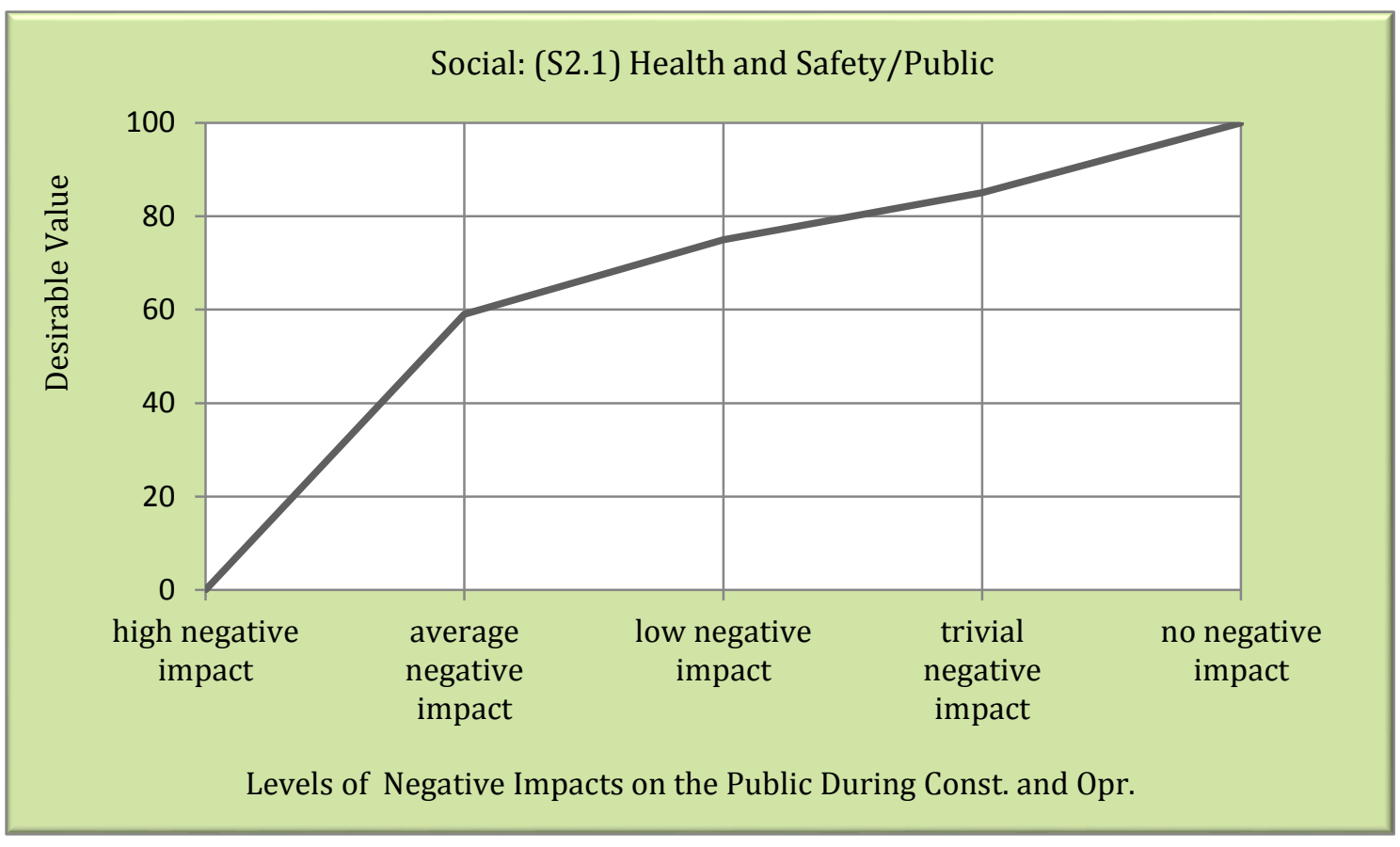

Figure G-2 Desirability Curve of Public Health and Safety Sub-Criterion 
Table G-3 Desirability Values of Workers Health and Safety Sub-Criterion

\begin{tabular}{|l|c|c|c|c|c|c|c|}
\hline \multicolumn{7}{|c|}{ Social: (S2.1) Health and Safety/Workers } \\
\hline \multicolumn{1}{|c|}{ Metrics } & EXP01 & EXP02 & EXP03 & EXP04 & EXP05 & Avg. & $\%$ \\
\hline high negative impact & 0 & 0 & 0 & 0 & 0 & 0 & 0.00 \\
\hline average negative impact & 85 & 50 & 50 & 50 & 25 & 52 & 0.52 \\
\hline low negative impact & 90 & 75 & 70 & 60 & 50 & 69 & 0.69 \\
\hline trivial negative impact & 95 & 95 & 90 & 80 & 75 & 87 & 0.87 \\
\hline no negative impact & 100 & 100 & 100 & 100 & 100 & 100 & 1.00 \\
\hline
\end{tabular}

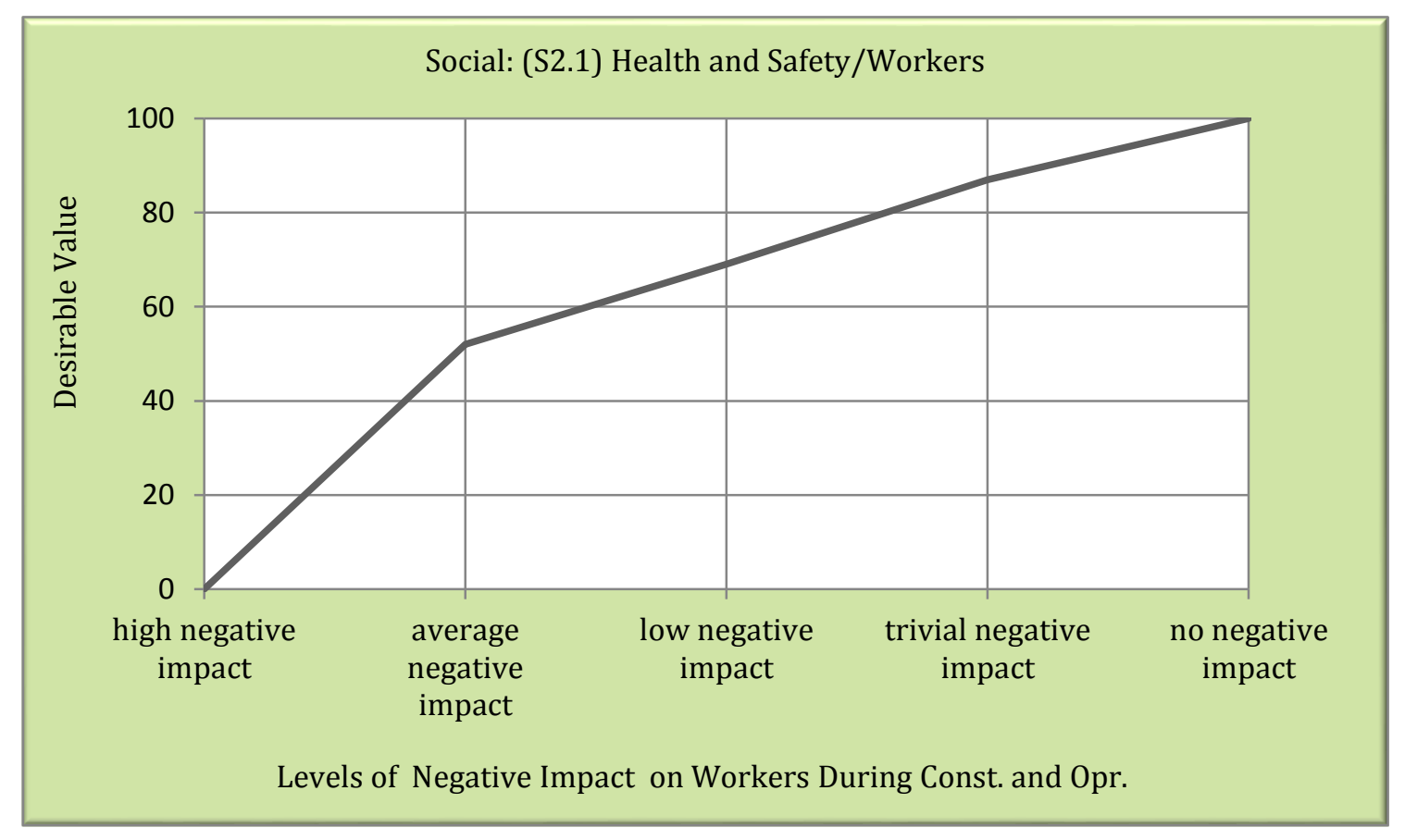

Figure G-3 Desirability Curve of Workers Health and Safety Sub-Criterion 
Table G-4 Desirability Values of Social Life and Activities Criterion

Social: (S3) Social Life and Activities

\begin{tabular}{|l|c|c|c|c|c|c|c|}
\hline \multicolumn{1}{|c|}{ Metrics } & EXP01 & EXP02 & EXP03 & EXP04 & EXP05 & Avg. & $\%$ \\
\hline high negative impact & 0 & 0 & 0 & 0 & 0 & 0 & 0.00 \\
\hline average negative impact & 25 & 20 & 45 & 35 & 50 & 35 & 0.35 \\
\hline low negative impact & 50 & 60 & 65 & 55 & 70 & 60 & 0.60 \\
\hline very low negative impact & 75 & 90 & 85 & 75 & 90 & 83 & 0.83 \\
\hline no negative impact & 100 & 100 & 100 & 100 & 100 & 100 & 1.00 \\
\hline
\end{tabular}

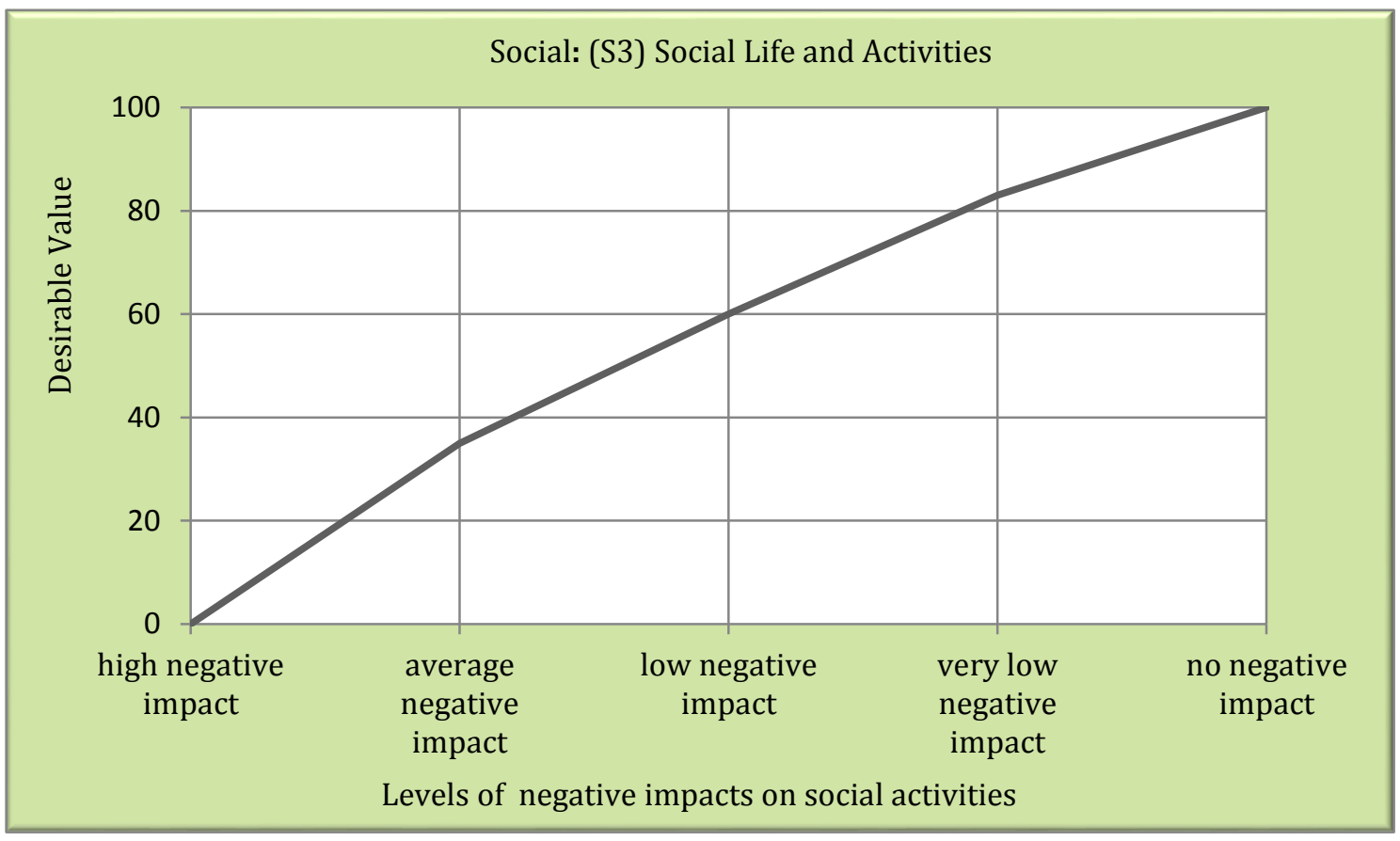

Figure G-4 Desirability Curve of Social Life and Activities Criterion 
Table G-5 Desirability Values of Visual Impact Criterion

\begin{tabular}{|l|c|c|c|c|c|c|c|c|}
\hline \multicolumn{7}{c|}{ Social: (S4) Visual Impact } \\
\hline \multicolumn{1}{|c|}{ Metrics } & EXP01 & EXP02 & EXP03 & EXP04 & EXP05 & Avg. & $\%$ \\
\hline highly disturbing & 0 & 0 & 0 & 0 & 0 & 0 & 0.00 \\
\hline moderately disturbing & 50 & 60 & 40 & 25 & 50 & 45 & 0.45 \\
\hline slightly disturbing & 90 & 80 & 60 & 50 & 80 & 72 & 0.72 \\
\hline barely disturbing & 95 & 90 & 80 & 75 & 80 & 84 & 0.84 \\
\hline not disturbing & 100 & 100 & 100 & 100 & 100 & 100 & 1.00 \\
\hline
\end{tabular}

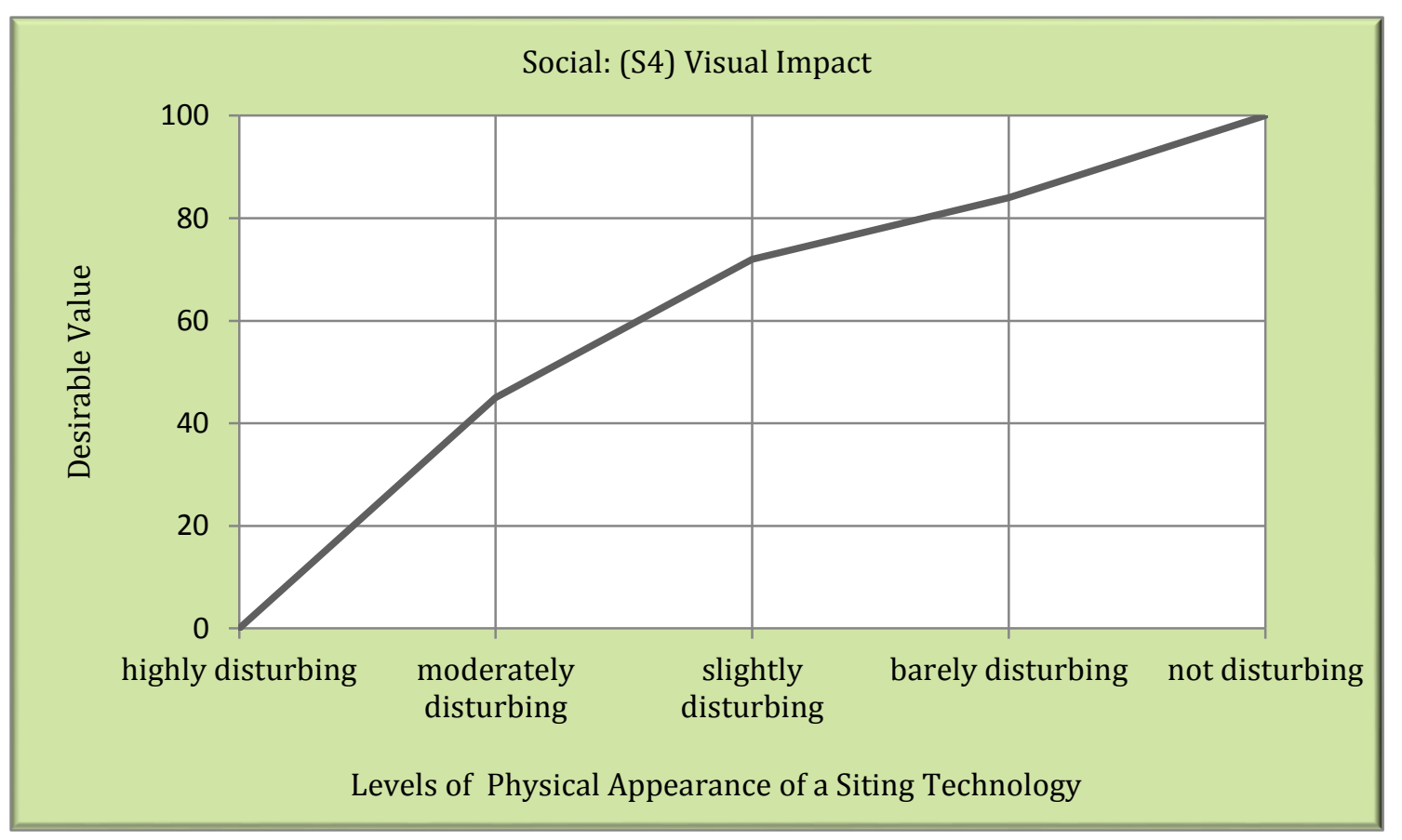

Figure G-5 Desirability Curve of Visual Impact Criterion 
Table G-6 Desirability Values of Experts Availability Criterion

\begin{tabular}{|l|c|c|c|c|c|c|c|}
\hline \multicolumn{7}{c|}{ Social: (S5) Experts Availability } \\
\hline \multicolumn{1}{|c|}{ Metrics } & EXP01 & EXP02 & EXP03 & EXP04 & EXP05 & Avg. & $\%$ \\
\hline highly disturbing & 0 & 0 & 0 & 0 & 0 & 0 & 0.00 \\
\hline moderately disturbing & 50 & 60 & 40 & 25 & 50 & 45 & 0.45 \\
\hline slightly disturbing & 90 & 80 & 60 & 50 & 80 & 72 & 0.72 \\
\hline barely disturbing & 95 & 90 & 80 & 75 & 80 & 84 & 0.84 \\
\hline not disturbing & 100 & 100 & 100 & 100 & 100 & 100 & 1.00 \\
\hline
\end{tabular}

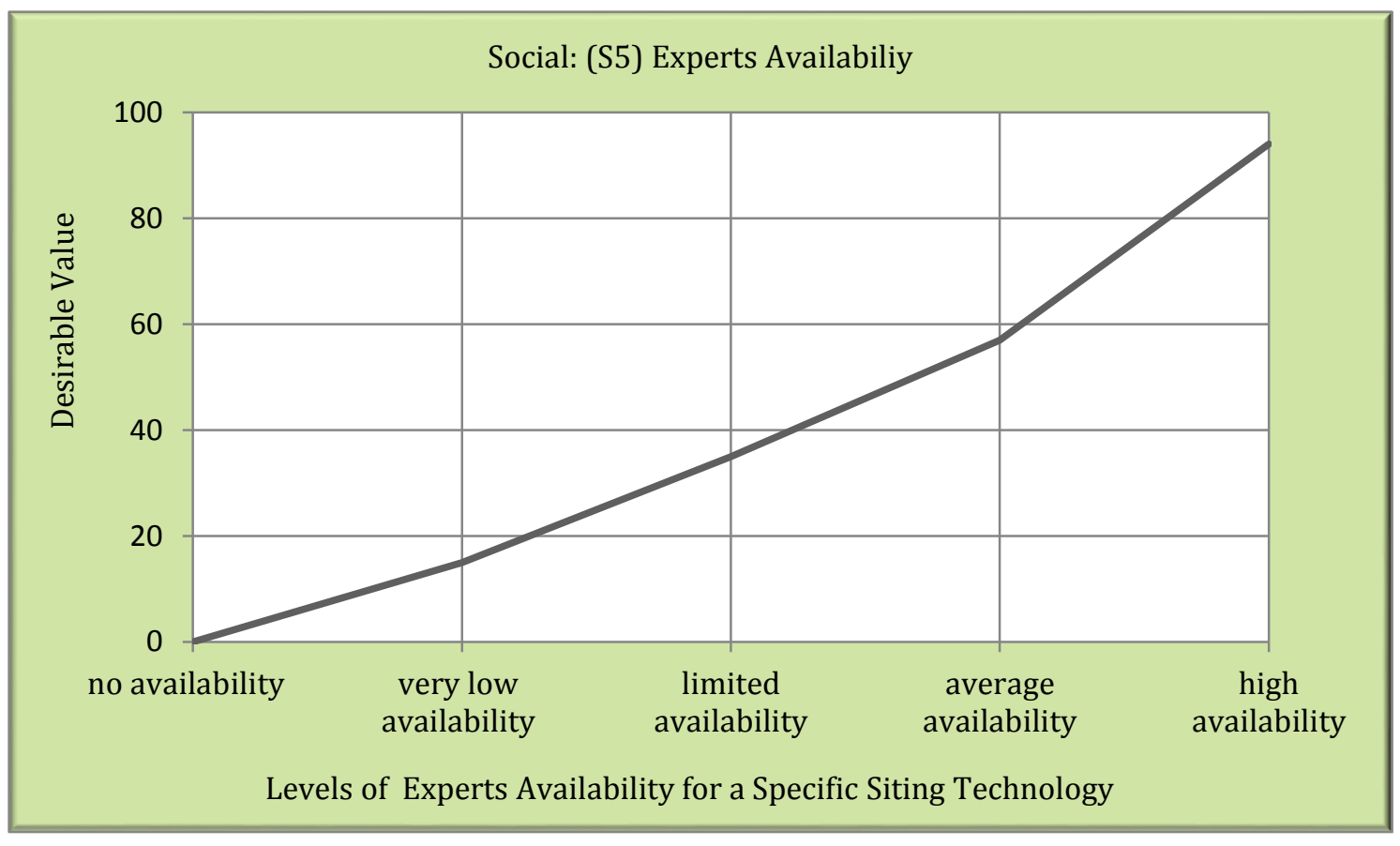

Figure G-6 Desirability Curve of Experts Availability Criterion 
Table G-7 Desirability Values of Maturity/Applicability Sub-Criterion

Technical: (T1.1) Maturity/Applicability

\begin{tabular}{|l|c|c|c|c|c|c|c|}
\hline \multicolumn{1}{|c|}{ Metrics } & EXP01 & EXP02 & EXP03 & EXP04 & EXP05 & Avg. & $\%$ \\
\hline none $(\mathrm{AP}=0)$ & 10 & 0 & 0 & 5 & 0 & 3 & 0.03 \\
\hline once $(\mathrm{AP}=1)$ & 20 & 10 & 5 & 15 & 10 & 12 & 0.12 \\
\hline twice $(\mathrm{AP}=2)$ & 30 & 20 & 15 & 30 & 20 & 23 & 0.23 \\
\hline few $(2<\mathrm{AP} \leq 5)$ & 60 & 30 & 40 & 50 & 50 & 46 & 0.46 \\
\hline several $(5<\mathrm{AP} \leq 10)$ & 70 & 70 & 85 & 80 & 90 & 79 & 0.79 \\
\hline
\end{tabular}

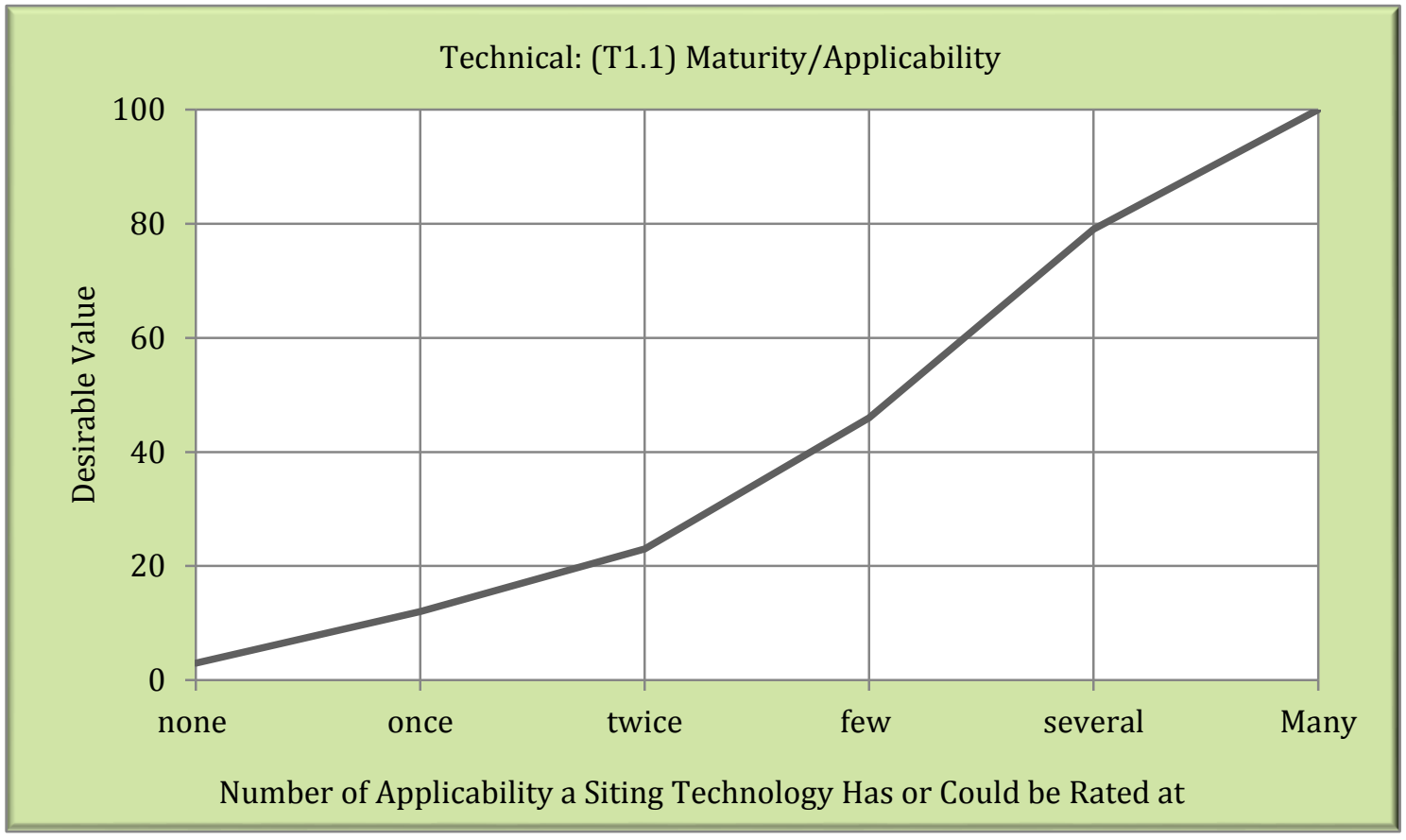

Figure G-7 Desirability Curve of Maturity/Applicability Sub-Criterion 
Table G-8 Desirability Values of Maturity/Reliability Sub-Criterion

Technical: (T1.2) Maturity/Reliability

\begin{tabular}{|l|c|c|c|c|c|c|c|}
\hline \multicolumn{1}{|c|}{ Metrics } & EXP01 & EXP02 & EXP03 & EXP04 & EXP05 & Avg. & $\%$ \\
\hline $\mathrm{RE}=0 \%$ & 0 & 0 & 0 & 0 & 0 & 0 & 0.00 \\
\hline $0<\mathrm{RE} \leq 20 \%$ & 10 & 20 & 5 & 0 & 15 & 10 & 0.10 \\
\hline $20<\mathrm{RE} \leq 40 \%$ & 30 & 40 & 15 & 20 & 25 & 26 & 0.26 \\
\hline $40<\mathrm{RE} \leq 60 \%$ & 50 & 60 & 30 & 40 & 45 & 45 & 0.45 \\
\hline $60<\mathrm{RE} \leq 80 \%$ & 70 & 80 & 50 & 60 & 70 & 66 & 0.66 \\
\hline
\end{tabular}

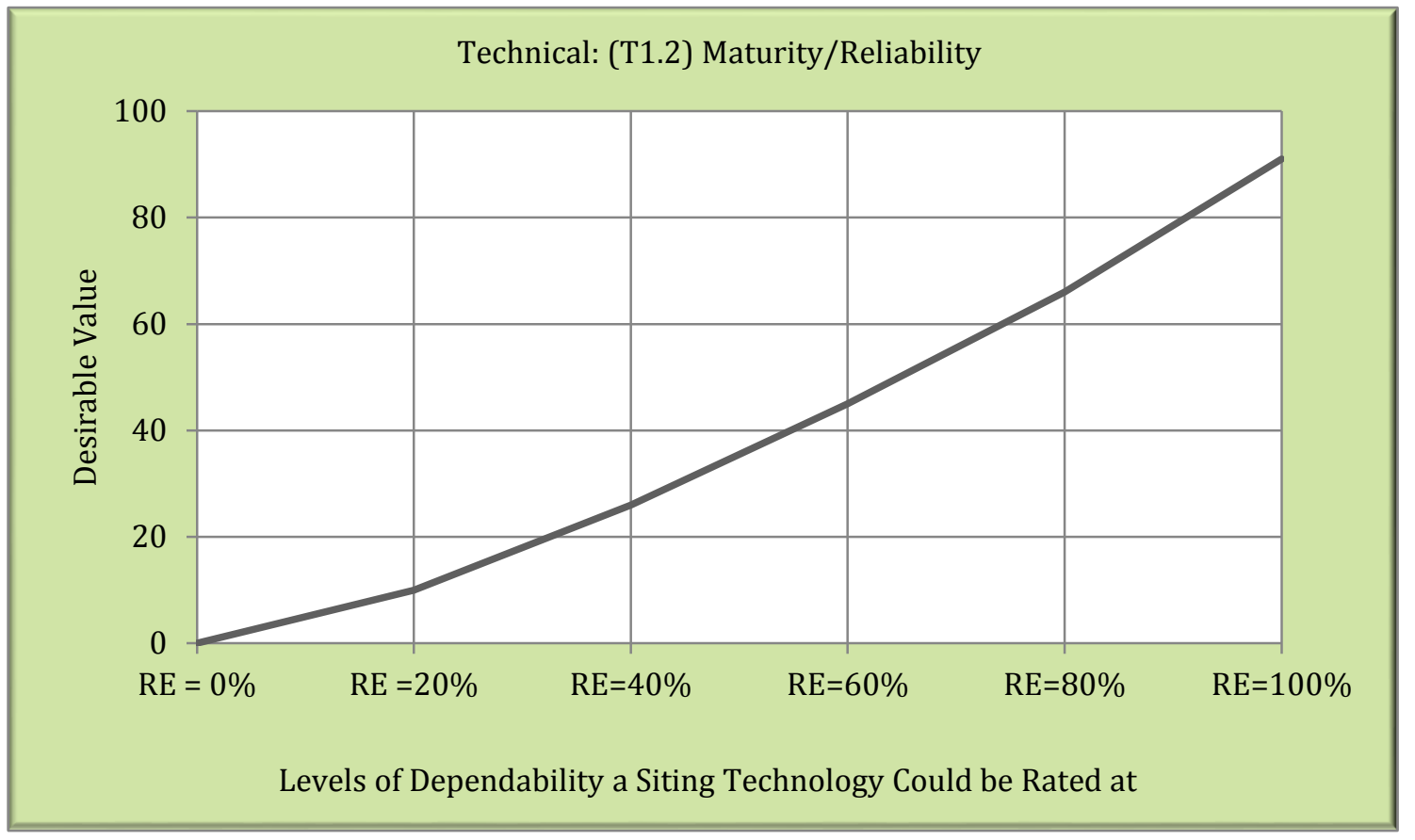

Figure G-8 Desirability Curve of Maturity/Reliability Sub-Criterion 
Table G-9 Desirability Values of Maturity/Competency Sub-Criterion

Technical: (T1.3) Maturity/Competency

\begin{tabular}{|l|c|c|c|c|c|c|c|}
\hline \multicolumn{1}{|c|}{ Metrics } & EXP01 & EXP02 & EXP03 & EXP04 & EXP05 & Avg. & $\%$ \\
\hline $\mathrm{CO}=0 \%$ & 0 & 0 & 0 & 0 & 0 & 0 & 0.00 \\
\hline $0<\mathrm{CO} \leq 20 \%$ & 10 & 25 & 20 & 10 & 5 & 14 & 0.14 \\
\hline $20<\mathrm{CO} \leq 40 \%$ & 20 & 40 & 40 & 10 & 10 & 24 & 0.24 \\
\hline $40<\mathrm{CO} \leq 60 \%$ & 40 & 65 & 60 & 20 & 20 & 41 & 0.41 \\
\hline $60<\mathrm{CO} \leq 80 \%$ & 60 & 80 & 80 & 50 & 40 & 62 & 0.62 \\
\hline
\end{tabular}

Technical: (T1.3) Maturity/Competency

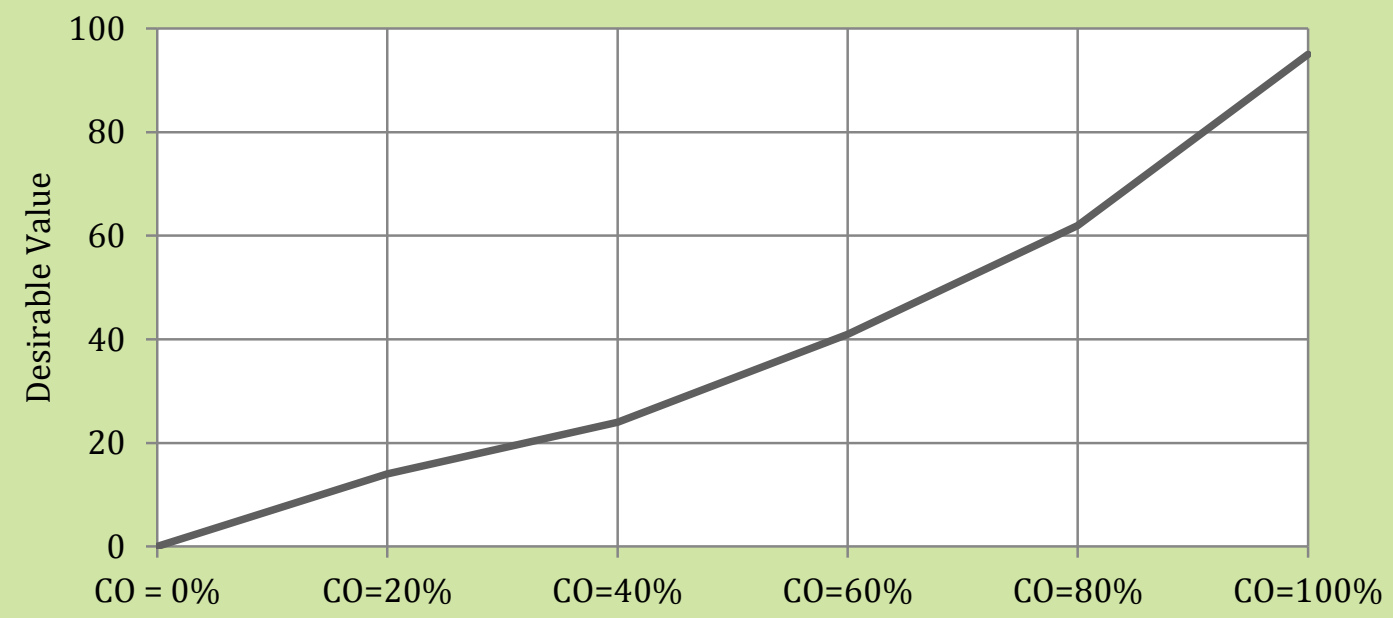

Levels of Competency a Siting Technology Has or Could be Rated at

Figure G-9 Desirability Curve of Maturity/Competency Sub-Criterion 
Table G-10 Desirability Values of Flexibility/Scalability Sub-Criterion

\begin{tabular}{|l|c|c|c|c|c|c|c|}
\hline \multicolumn{7}{|c|}{ Technical: (T2.1) Flexibility/Scalability } \\
\hline \multicolumn{1}{|c|}{ Metrics } & EXP01 & EXP02 & EXP03 & EXP04 & EXP05 & Avg. & $\%$ \\
\hline unscalable & 25 & 20 & 10 & 0 & 5 & 12 & 0.12 \\
\hline possible & 75 & 50 & 40 & 50 & 75 & 58 & 0.58 \\
\hline totally scalable & 100 & 80 & 100 & 100 & 100 & 96 & 0.96 \\
\hline
\end{tabular}

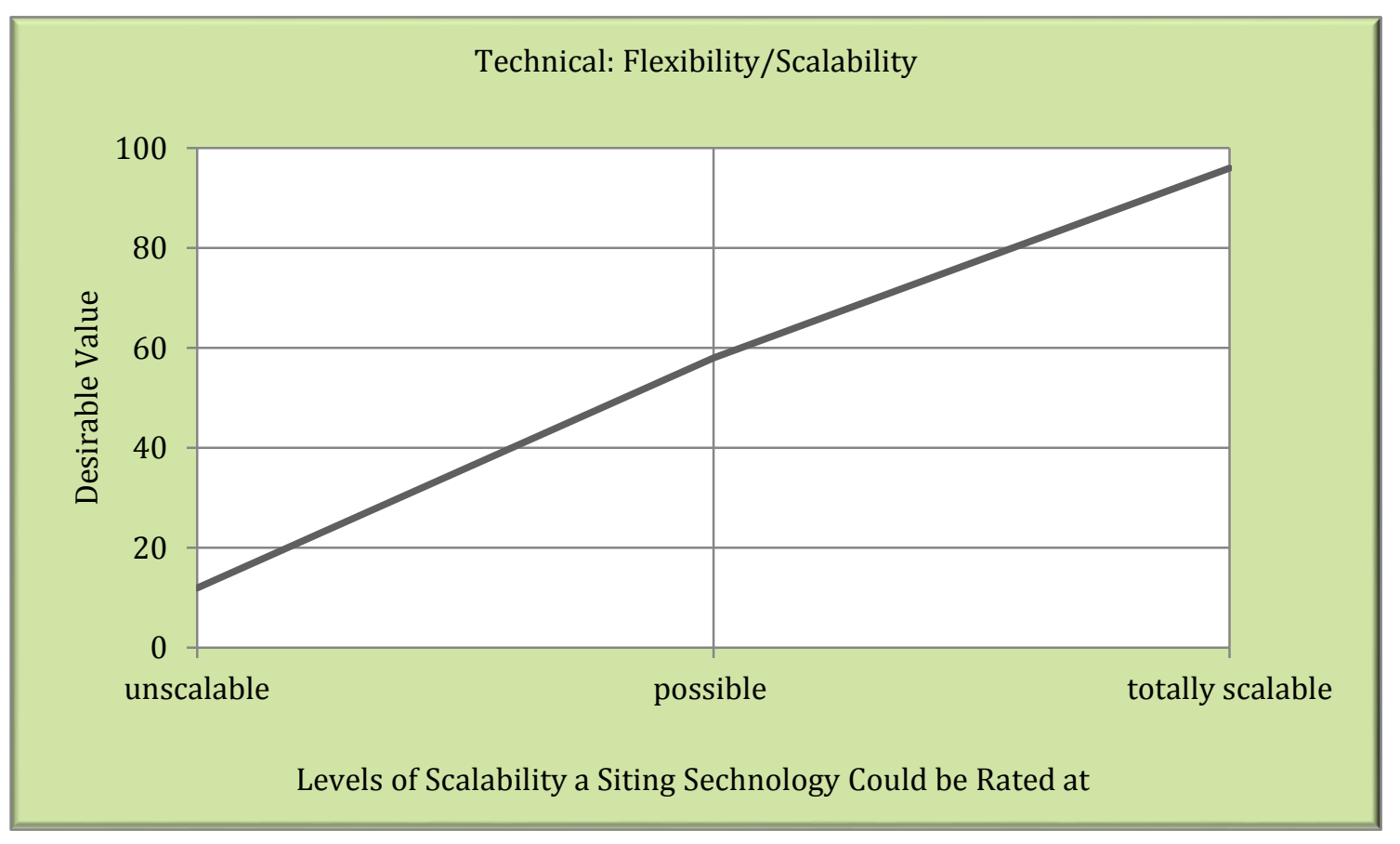

Figure G-10 Desirability Curve of Flexibility/Scalability Sub-Criterion 
Table G-11 Desirability Values of Flexibility/Mobility Sub-Criterion

\begin{tabular}{|l|c|c|c|c|c|c|c|}
\hline \multicolumn{7}{|c|}{ Technical: (T2.1) Flexibility/Mobility } \\
\hline \multicolumn{1}{|c|}{ Metrics } & EXP01 & EXP02 & EXP03 & EXP04 & EXP05 & Avg. & $\%$ \\
\hline fixed & 100 & 50 & 50 & 0 & 0 & 40 & 0.40 \\
\hline possible & 50 & 50 & 75 & 50 & 50 & 55 & 0.55 \\
\hline totally mobile & 100 & 100 & 100 & 75 & 100 & 95 & 0.95 \\
\hline
\end{tabular}

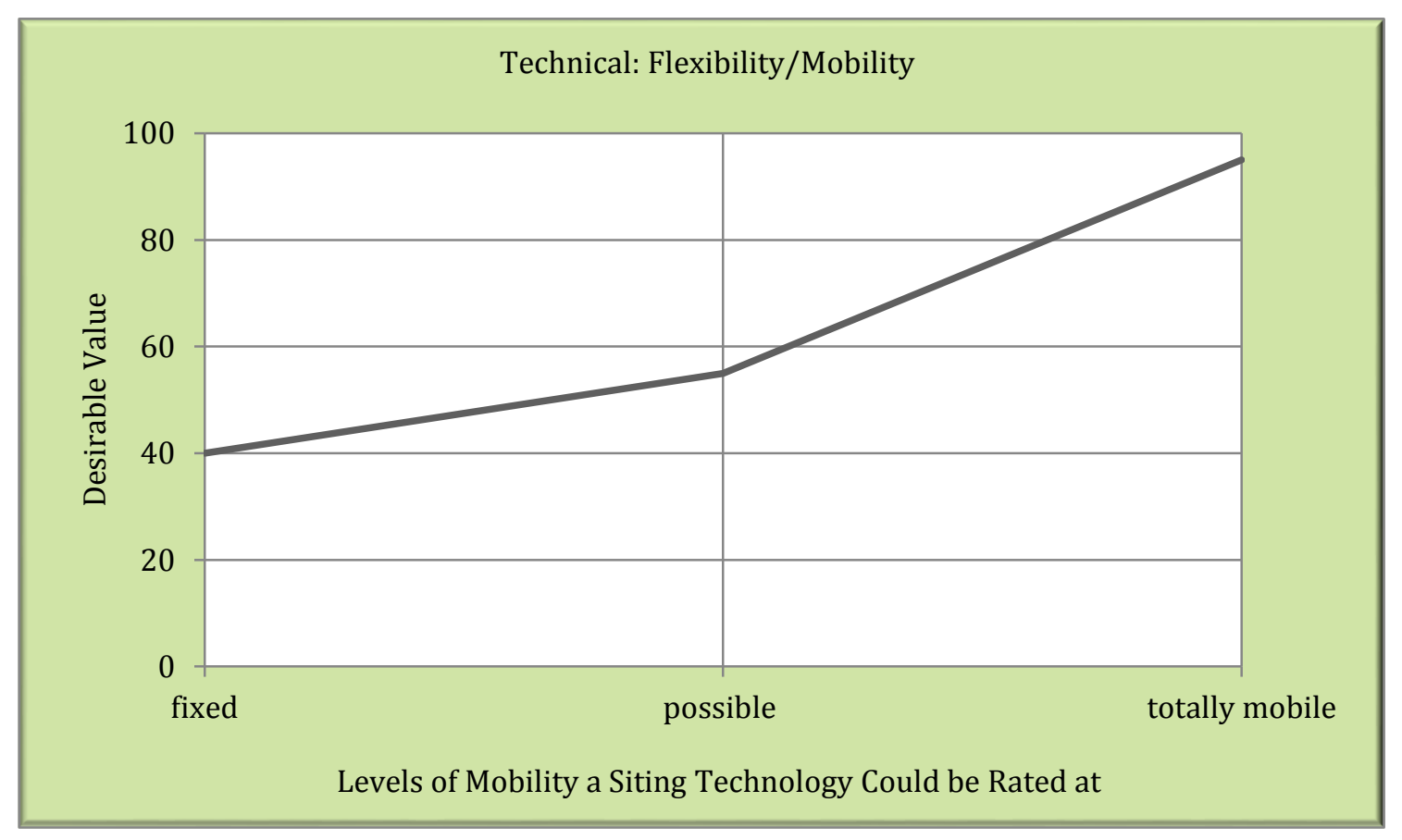

Figure G-11 Desirability Curve of Flexibility/Mobility Sub-Criterion 
Table G-12 Desirability Values of Flexibility/Modularity Sub-Criterion

Technical: (T2.1) Flexibility/Modularity

\begin{tabular}{|l|c|c|c|c|c|c|c|}
\hline \multicolumn{1}{|c|}{ Metrics } & EXP01 & EXP02 & EXP03 & EXP04 & EXP05 & Avg. & $\%$ \\
\hline nonstandard & 25 & 10 & 25 & 20 & 0 & 16 & 0.16 \\
\hline possible & 50 & 20 & 50 & 60 & 50 & 46 & 0.46 \\
\hline standard & 100 & 100 & 75 & 100 & 100 & 95 & 0.95 \\
\hline
\end{tabular}

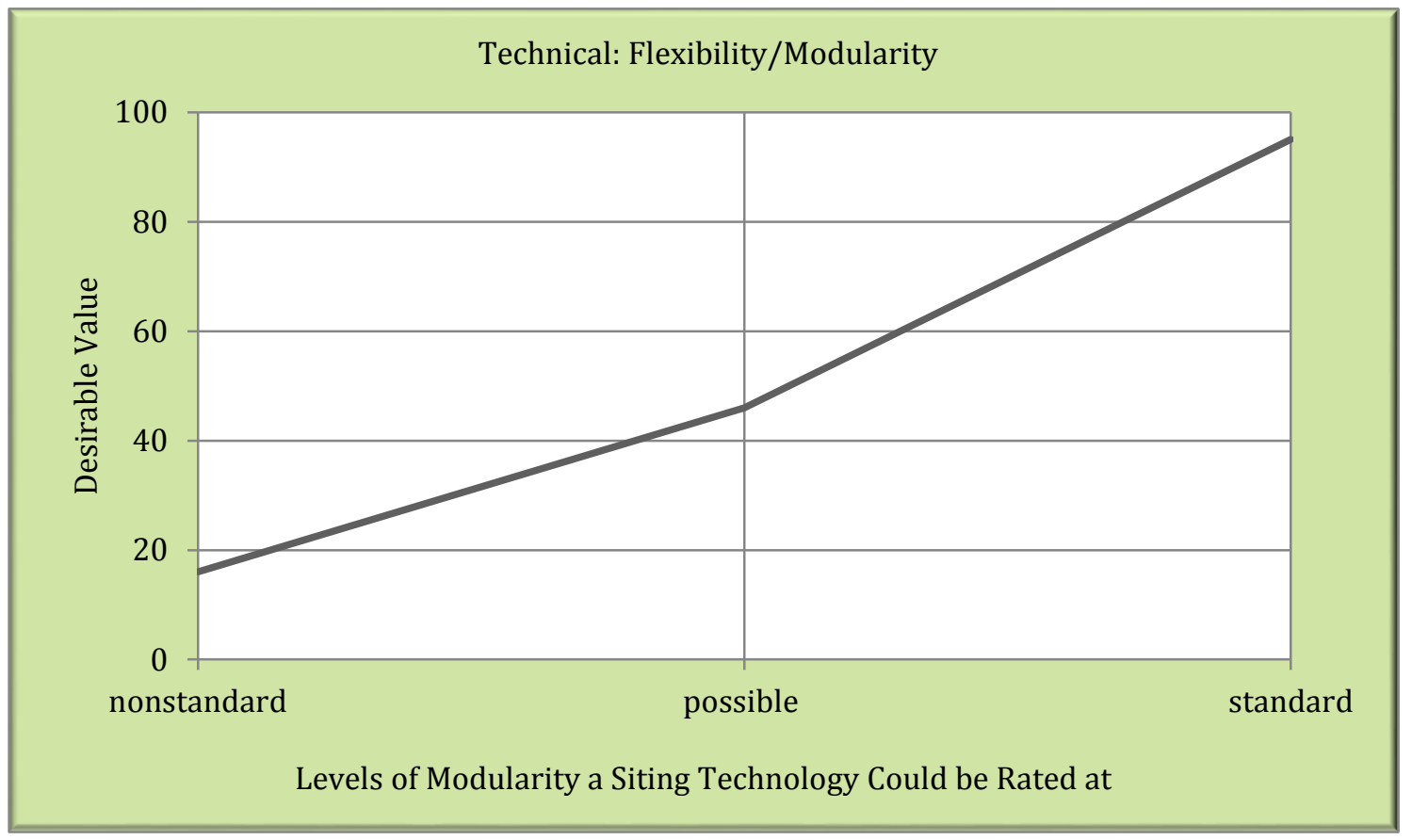

Figure G-12 Desirability Curve of Flexibility/Modularity Sub-Criterion 
Table G-13 Desirability Values of Safety and Security/Resistance Sub-Criterion

\begin{tabular}{|l|c|c|c|c|c|c|c|c|}
\hline \multicolumn{7}{|c|}{ Technical: (T3.1) Safety \& Security/Resistance } \\
\hline \multicolumn{1}{|c|}{ Metrics } & EXP01 & EXP02 & EXP03 & EXP04 & EXP05 & Avg. & $\%$ \\
\hline no resistance & 0 & 0 & 0 & 0 & 0 & 0 & 0.00 \\
\hline very low resistance & 5 & 20 & 10 & 0 & 0 & 7 & 0.07 \\
\hline low resistance & 10 & 40 & 20 & 25 & 10 & 21 & 0.21 \\
\hline medium resistance & 25 & 60 & 30 & 50 & 60 & 45 & 0.45 \\
\hline high resistance & 75 & 80 & 50 & 75 & 80 & 72 & 0.72 \\
\hline very high resistance & 100 & 100 & 100 & 100 & 100 & 100 & 1.00 \\
\hline
\end{tabular}

Technical: (T3.1) Safety \& Security/Resistance

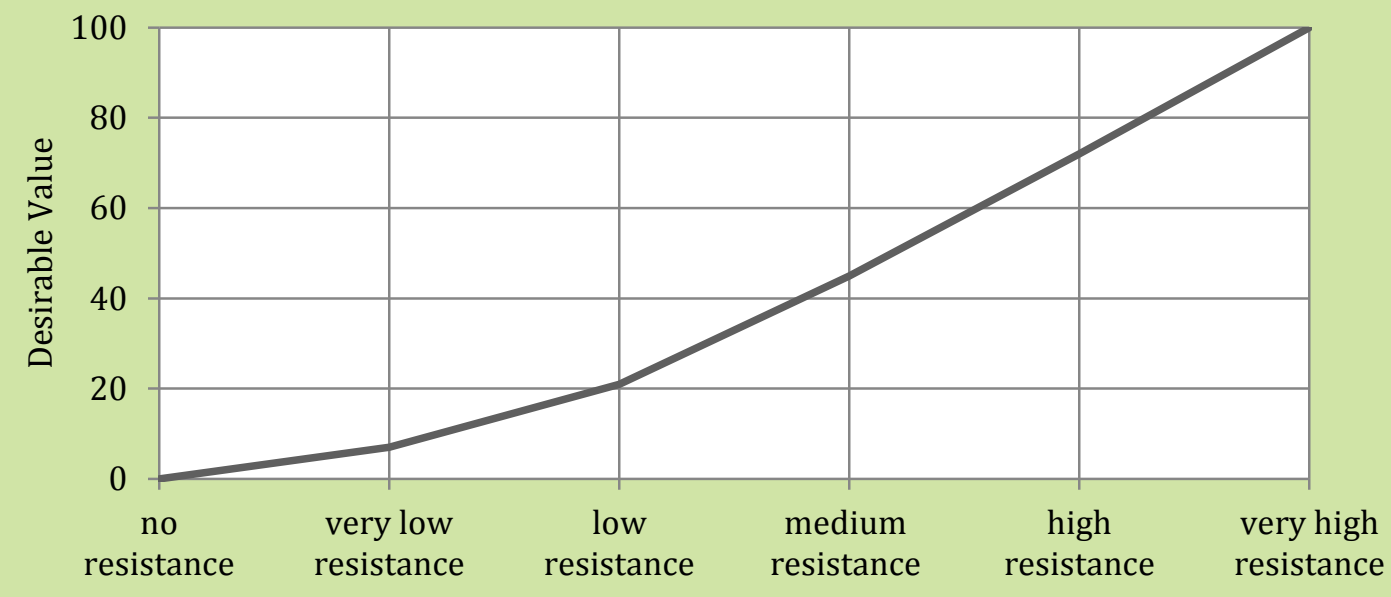

Levels of Resistance a Siting Technology Could be Rated at

Figure G-13 Desirability Curves of Safety and Security/Resistance Sub-Criterion 
Table G-14 Desirability Values of Safety and Security/Containment Sub-Criterion

Technical: (T3.2) Safety \& Security/Containment

\begin{tabular}{|l|c|c|c|c|c|c|c|}
\hline \multicolumn{1}{|c|}{ Metrics } & EXP01 & EXP02 & EXP03 & EXP04 & EXP05 & Avg. & $\%$ \\
\hline no containment & 0 & 0 & 0 & 0 & 0 & 0 & 0.00 \\
\hline very low containment & 10 & 15 & 5 & 20 & 5 & 11 & 0.11 \\
\hline low containment & 15 & 35 & 10 & 40 & 10 & 22 & 0.22 \\
\hline medium containment & 25 & 65 & 27 & 60 & 30 & 41.4 & 0.41 \\
\hline high containment & 50 & 85 & 70 & 80 & 50 & 67 & 0.67 \\
\hline very high containment & 100 & 99 & 90 & 100 & 100 & 97.8 & 0.98 \\
\hline
\end{tabular}

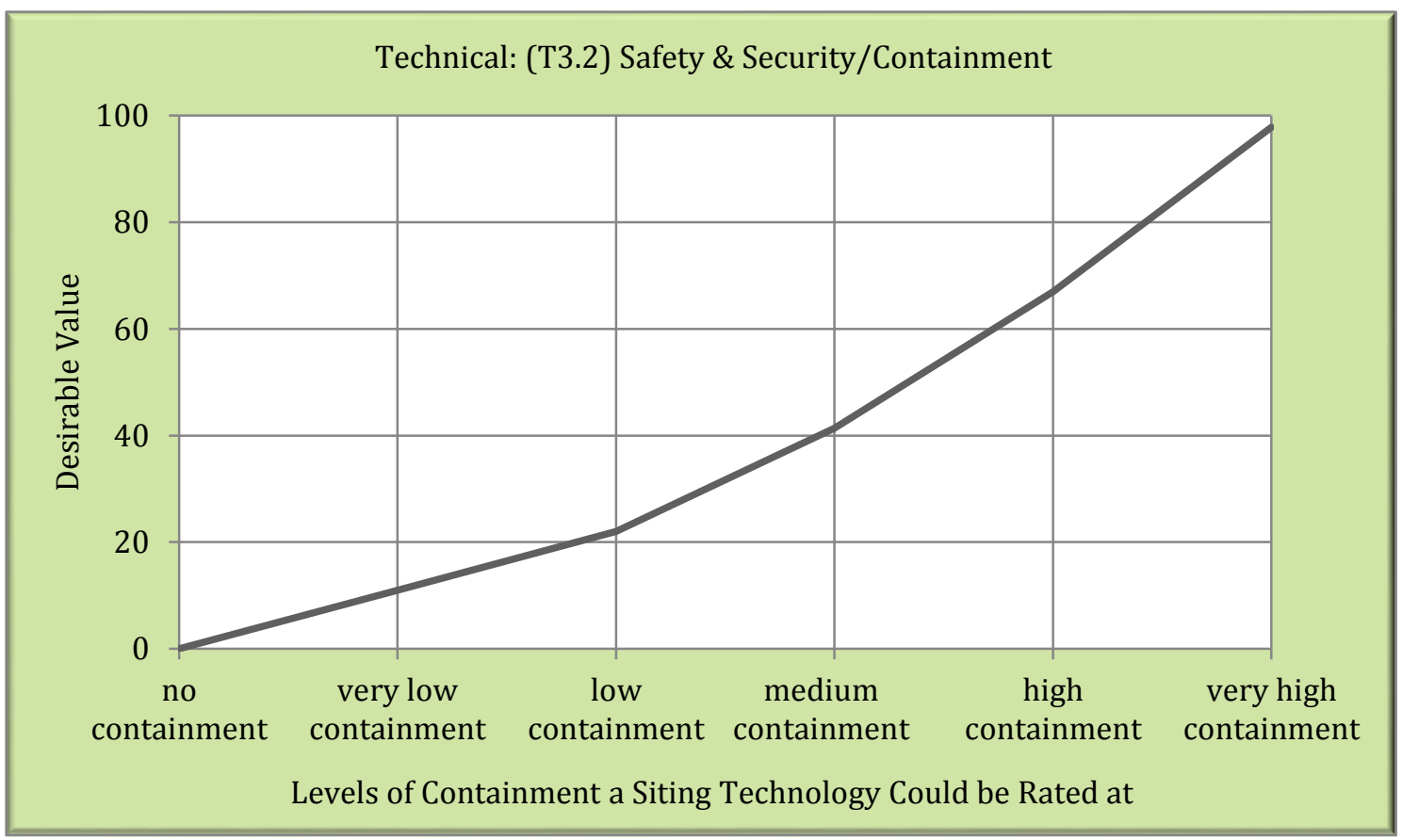

Figure G-14 Desirability Curve of Safety and Security/Containment Sub-Criterion 
Table G-15 Desirability Values of Safety and Security/Evacuation Sub-Criterion

Technical: (T3.3) Safety \& Security/Evacuation

\begin{tabular}{|l|c|c|c|c|c|c|c|}
\hline \multicolumn{1}{|c|}{ Metrics } & EXP01 & EXP02 & EXP03 & EXP04 & EXP05 & Avg. & $\%$ \\
\hline zero evacuation level & 0 & 0 & 0 & 0 & 0 & 0 & 0.00 \\
\hline very low evacuation level & 5 & 5 & 10 & 10 & 10 & 8 & 0.08 \\
\hline low evacuation level & 10 & 10 & 0 & 20 & 15 & 11 & 0.11 \\
\hline medium evacuation level & 45 & 35 & 30 & 75 & 50 & 47 & 0.47 \\
\hline high evacuation level & 85 & 90 & 95 & 90 & 95 & 91 & 0.91 \\
\hline very high evacuation level & 100 & 100 & 100 & 100 & 100 & 100 & 1.00 \\
\hline
\end{tabular}

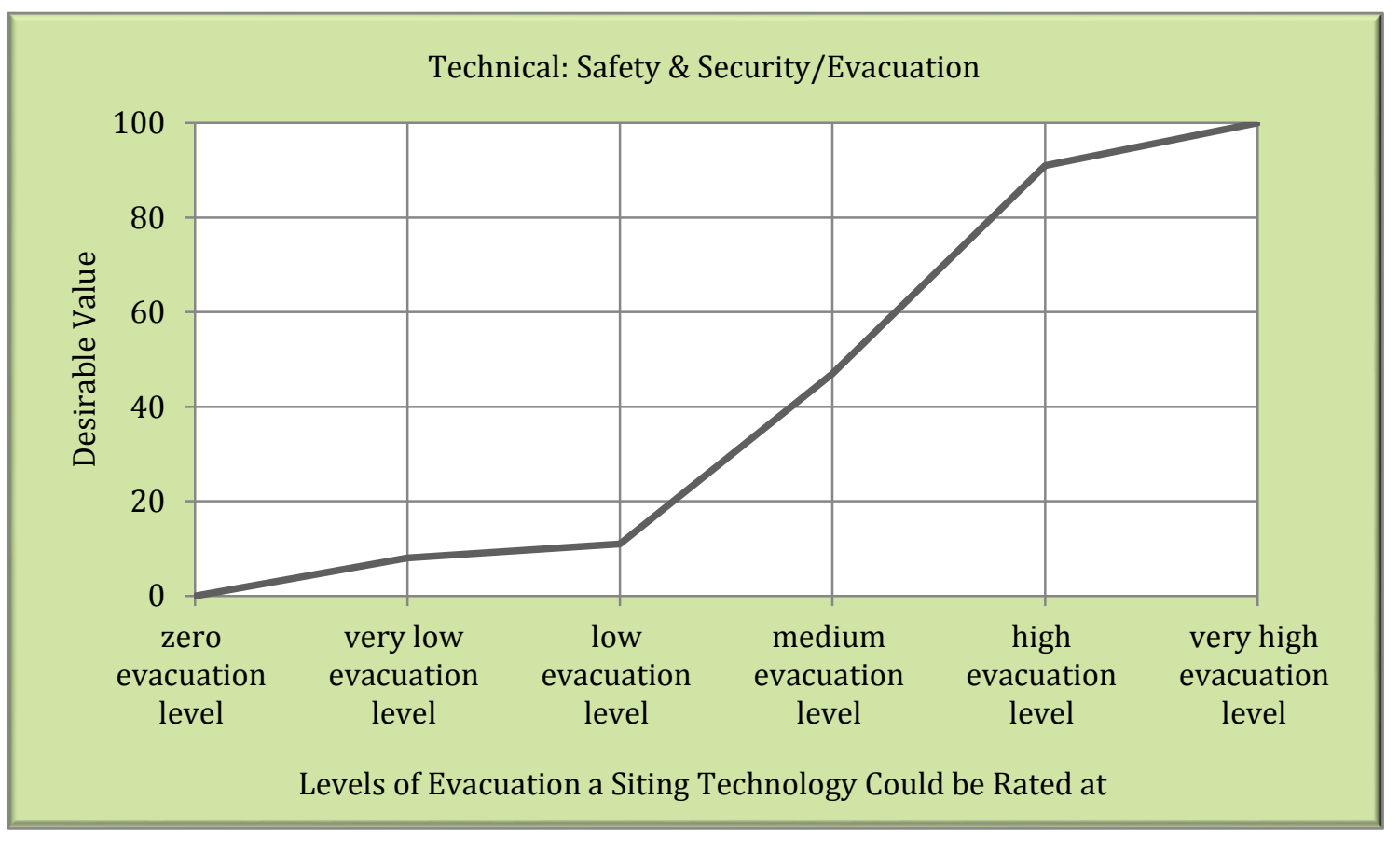

Figure G-15 Desirability Curve of Safety and Security/Evacuation Sub-Criterion 
Table G-16 Desirability Values of Power Generation Capacity Criterion

Technical: (T4) Power Generation Capacity (MWe)

\begin{tabular}{|l|c|c|c|c|c|c|c|}
\hline \multicolumn{1}{|c|}{ Metrics } & EXP01 & EXP02 & EXP03 & EXP04 & EXP05 & Avg. & $\%$ \\
\hline $\mathrm{PG}=0 \mathrm{MWe}$ & 0 & 0 & 0 & 0 & 0 & 0 & 0.00 \\
\hline $1<\mathrm{PG} \leq 500$ & 40 & 25 & 10 & 50 & 75 & 40 & 0.40 \\
\hline $500<\mathrm{PG} \leq 1000$ & 70 & 65 & 0 & 60 & 80 & 55 & 0.55 \\
\hline $1000<\mathrm{PG} \leq 1500$ & 80 & 86 & 30 & 70 & 90 & 71.2 & 0.71 \\
\hline $1500<\mathrm{PG} \leq 2000$ & 90 & 95 & 95 & 80 & 95 & 91 & 0.91 \\
\hline $2000<\mathrm{PG} \leq 2500$ & 95 & 99 & 100 & 90 & 100 & 96.8 & 0.97 \\
\hline $\mathrm{PG}>2500 \mathrm{MWe}$ & 100 & 100 & 100 & 100 & 100 & 100 & 1.00 \\
\hline
\end{tabular}

Technical: (T4) Power Generation Capacity (MWe)

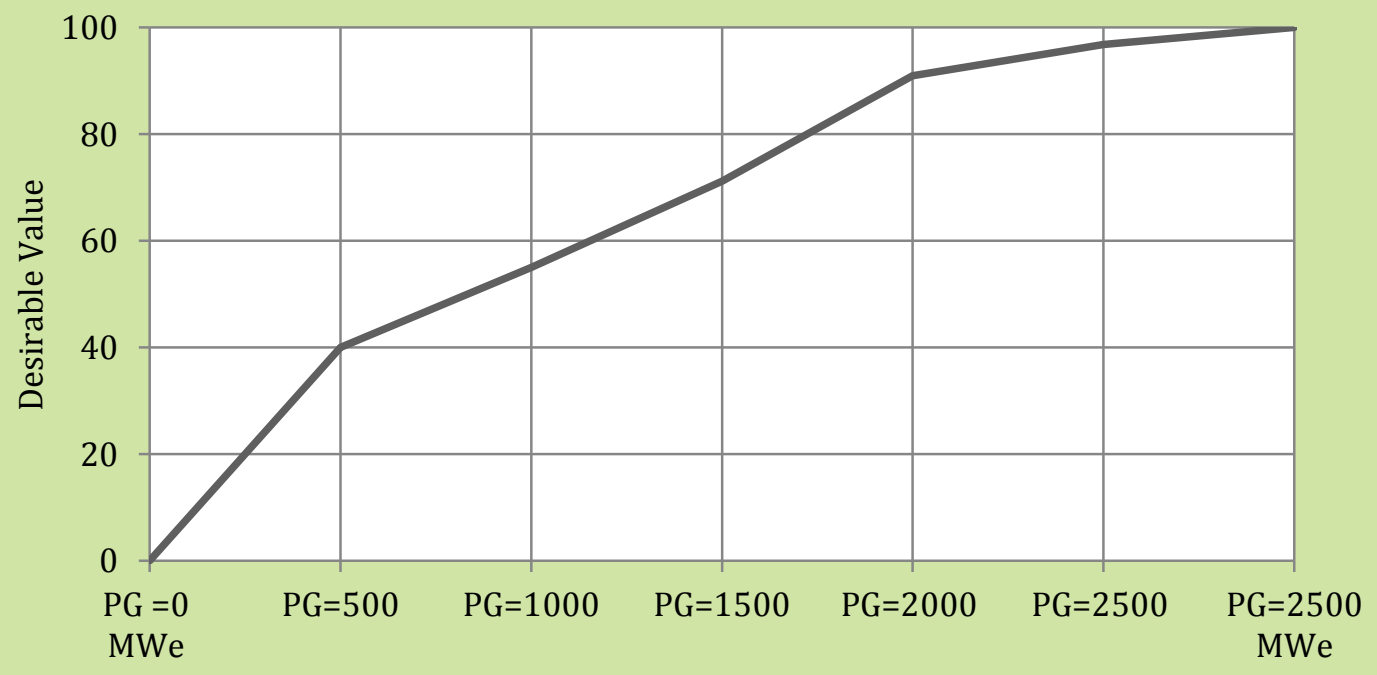

Ranges of Power Generation a Siting Technology Could be Rated at

Figure G-16 Desirability Curve of Power Generation Capacity Criterion 
Table G-17 Desirability Values of Plant Life Span Criterion

\begin{tabular}{|c|c|c|c|c|c|c|c|}
\hline \multicolumn{8}{|c|}{ Technical: (T5) Plant Life Span (Years) } \\
\hline Metrics & EXP01 & EXP02 & EXP03 & EXP04 & EXP05 & Avg. & $\%$ \\
\hline $\mathrm{LT}=0$ year & 0 & 0 & 0 & 0 & 0 & 0 & 0.00 \\
\hline $0<\mathrm{LT} \leq 20$ & 20 & 10 & 5 & 30 & 25 & 18 & 0.18 \\
\hline $20<\mathrm{LT} \leq 40$ & 40 & 30 & 10 & 50 & 60 & 38 & 0.38 \\
\hline $40<\mathrm{LT} \leq 60$ & 60 & 60 & 25 & 80 & 80 & 61 & 0.61 \\
\hline $60<\mathrm{LT} \leq 80$ & 80 & 80 & 70 & 100 & 95 & 85 & 0.85 \\
\hline $80<\mathrm{LT} \leq 100$ & 90 & 100 & 95 & 100 & 100 & 97 & 0.97 \\
\hline LT > 100 years & 100 & 100 & 100 & 100 & 100 & 100 & 1.00 \\
\hline
\end{tabular}

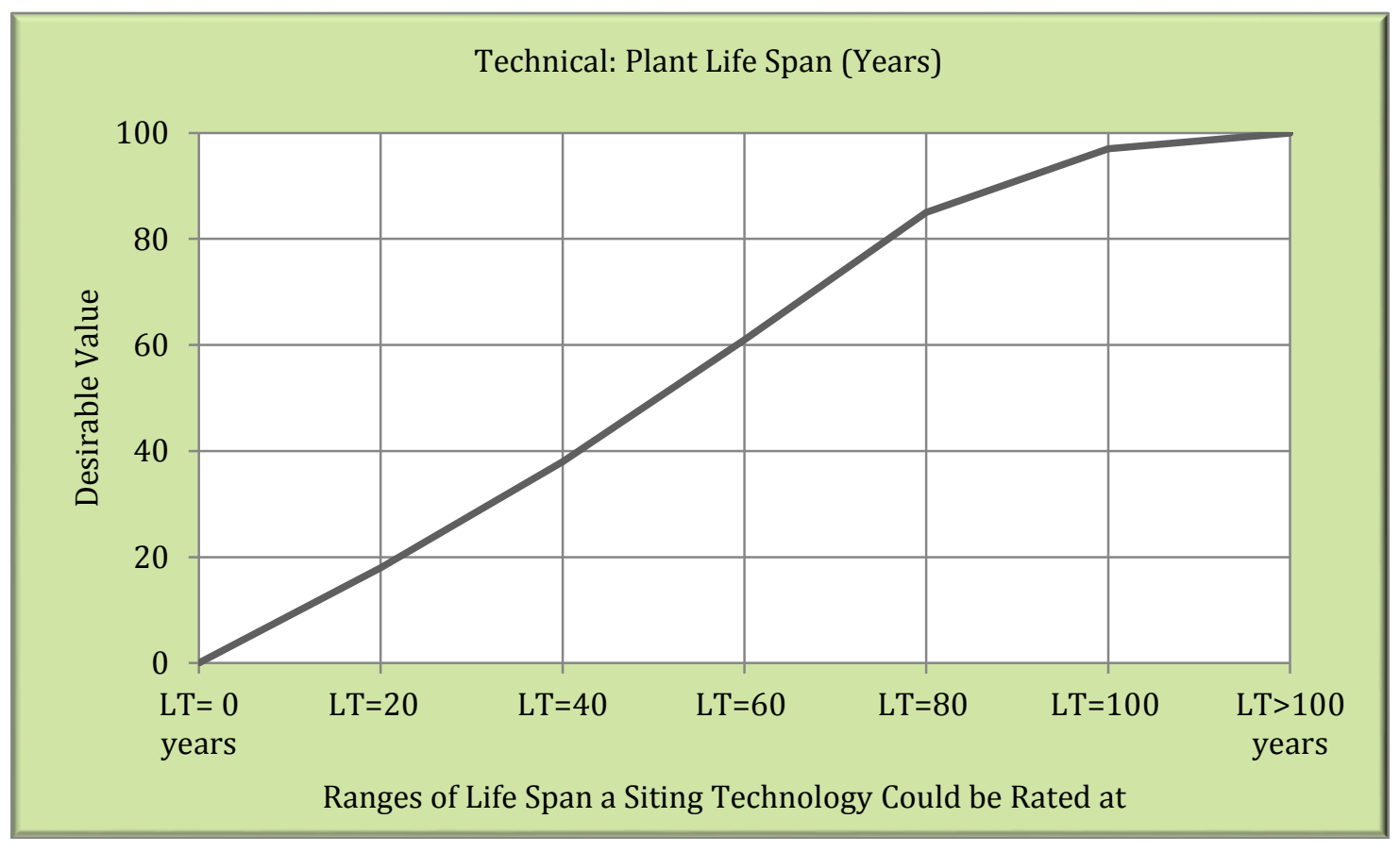

Figure G-17 Desirability Curve of Plant Life Span Criterion 
Table G-18 Desirability Values of Used Fuel Storage Capacity Criterion

Technical: (T6) Used Fuel Storage Capacity (Metric Tons)

\begin{tabular}{|l|c|c|c|c|c|c|c|}
\hline \multicolumn{1}{|c|}{ Metrics } & EXP01 & EXP02 & EXP03 & EXP04 & EXP05 & Avg. & $\%$ \\
\hline FS $=0$ & 0 & 0 & 0 & 0 & 0 & 0 & 0.00 \\
\hline $1<$ FS $\leq 500$ & 50 & 25 & 10 & 25 & 50 & 32 & 0.32 \\
\hline $500<$ FS $\leq 1000$ & 60 & 50 & 25 & 45 & 70 & 50 & 0.50 \\
\hline $1000<$ FS $\leq 1500$ & 70 & 75 & 50 & 65 & 90 & 70 & 0.70 \\
\hline $1500<$ FS $\leq 2000$ & 80 & 100 & 75 & 85 & 100 & 88 & 0.88 \\
\hline $2000<$ FS $\leq 2500$ & 90 & 100 & 100 & 95 & 100 & 97 & 0.97 \\
\hline FS $>2500$ metric tons & 100 & 100 & 100 & 100 & 100 & 100 & 1.00 \\
\hline
\end{tabular}

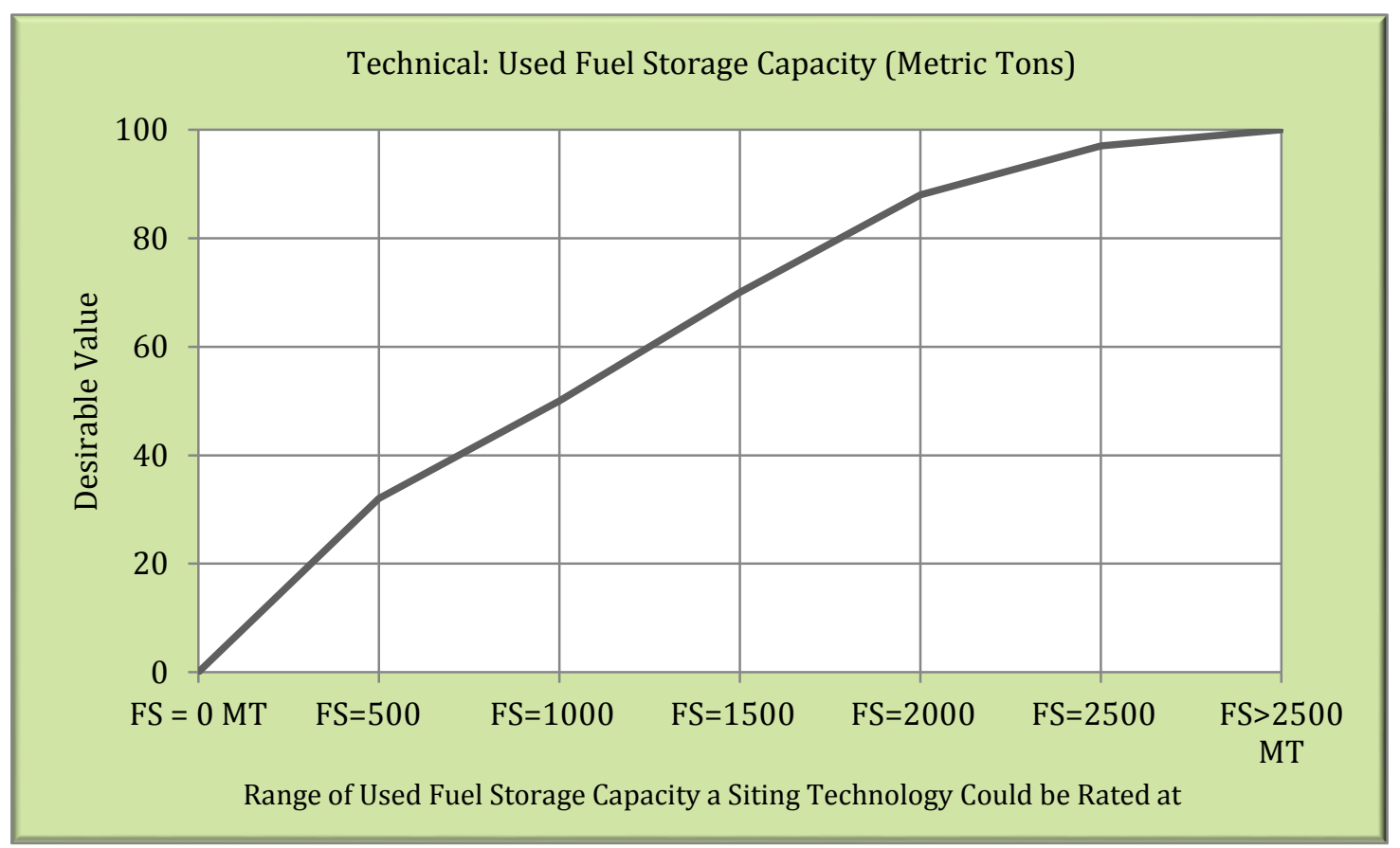

Figure G-18 Desirability Curve of Used Fuel Storage Capacity Criterion 
Table G-19 Desirability Values of Decommission and Site Cleanup Time Criterion

Technical: (T7) Decommissioning \& Cleanup Time (Years)

\begin{tabular}{|l|c|c|c|c|c|c|c|}
\hline \multicolumn{1}{|c|}{ Metrics } & EXP01 & EXP02 & EXP03 & EXP04 & EXP05 & Avg. & $\%$ \\
\hline DT $=0$ year & 100 & 100 & 100 & 100 & 100 & 100 & 1.00 \\
\hline $0<$ DT $\leq 10$ & 50 & 75 & 80 & 70 & 90 & 73 & 0.73 \\
\hline $10<$ DT $\leq 20$ & 30 & 40 & 60 & 50 & 80 & 52 & 0.52 \\
\hline $20<$ DT $\leq 30$ & 25 & 15 & 40 & 40 & 70 & 38 & 0.38 \\
\hline $30<$ DT $\leq 40$ & 20 & 10 & 20 & 30 & 60 & 28 & 0.28 \\
\hline $40<$ DT $\leq 50$ & 15 & 5 & 10 & 20 & 30 & 16 & 0.16 \\
\hline DT $>50$ years & 10 & 0 & 0 & 5 & 0 & 3 & 0.03 \\
\hline
\end{tabular}

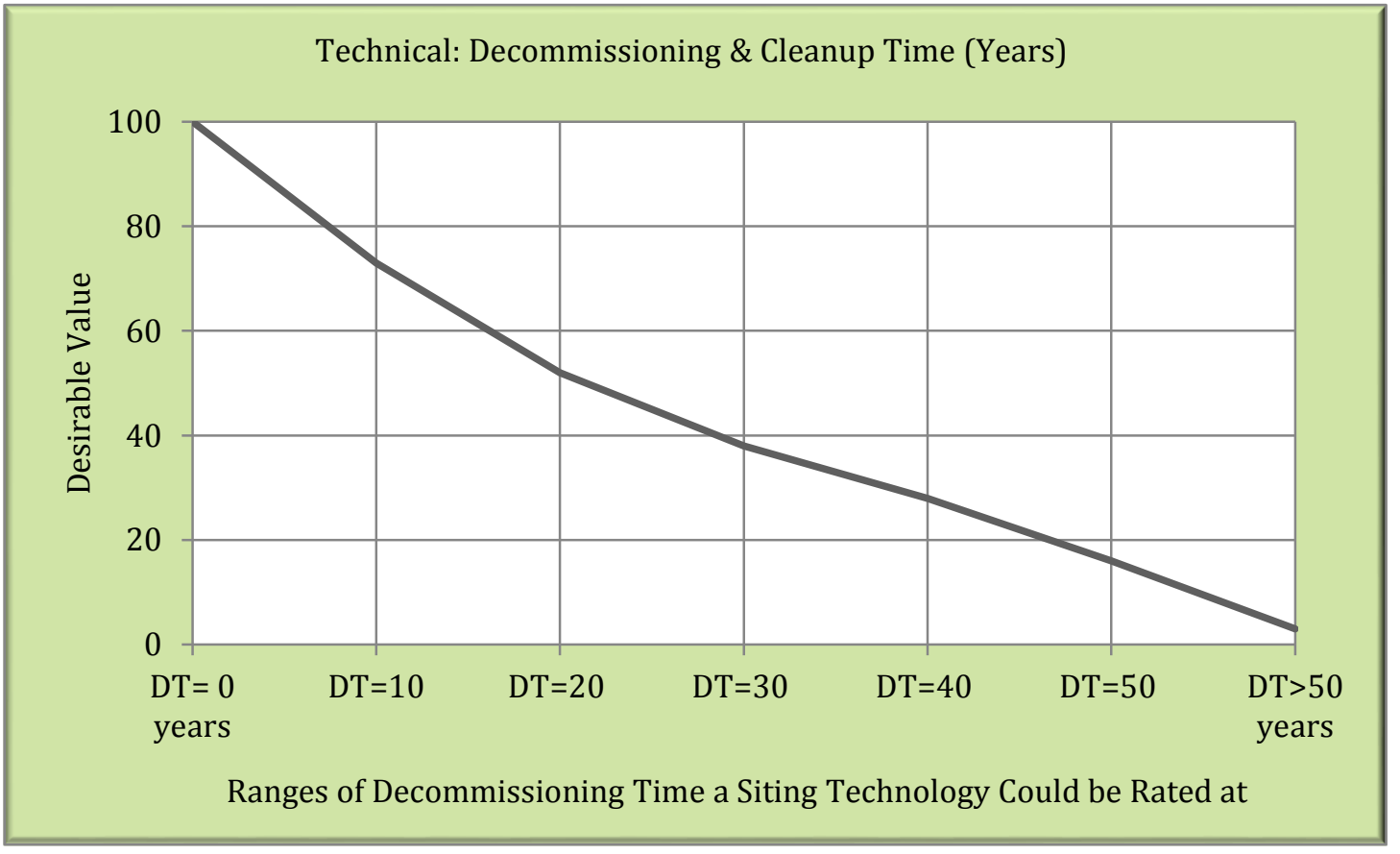

Figure G-19 Desirability Curve of Decommission and Site Cleanup Time Criterion 
Table G-20 Desirability Values of Site Exploration Cost Sub-Criterion

Economic: (E1.1) Site Development/Site Exploration Cost (\$ Millions)

\begin{tabular}{|l|c|c|c|c|c|c|c|}
\hline \multicolumn{1}{|c|}{ Metrics } & EXP01 & EXP02 & EXP03 & EXP04 & EXP05 & Avg. & $\%$ \\
\hline $\mathrm{SE}=\$ 0$ & 100 & 100 & 100 & 100 & 100 & 100 & 1.00 \\
\hline $0<\mathrm{SE} \leq 2$ & 90 & 70 & 95 & 80 & 75 & 82 & 0.82 \\
\hline $2<\mathrm{SE} \leq 4$ & 70 & 40 & 90 & 60 & 50 & 62 & 0.62 \\
\hline $4<\mathrm{SE} \leq 6$ & 50 & 10 & 85 & 40 & 25 & 42 & 0.42 \\
\hline $6<\mathrm{SE} \leq 8$ & 30 & 5 & 80 & 20 & 15 & 30 & 0.30 \\
\hline $8<\mathrm{SE} \leq 10$ & 20 & 1 & 75 & 10 & 10 & 23.2 & 0.23 \\
\hline $\mathrm{SE}>10$ & 10 & 0 & 25 & 0 & 0 & 7 & 0.07 \\
\hline
\end{tabular}

Economic: (E1.1) Site Development/Site Exploration Cost (\$ Millions)

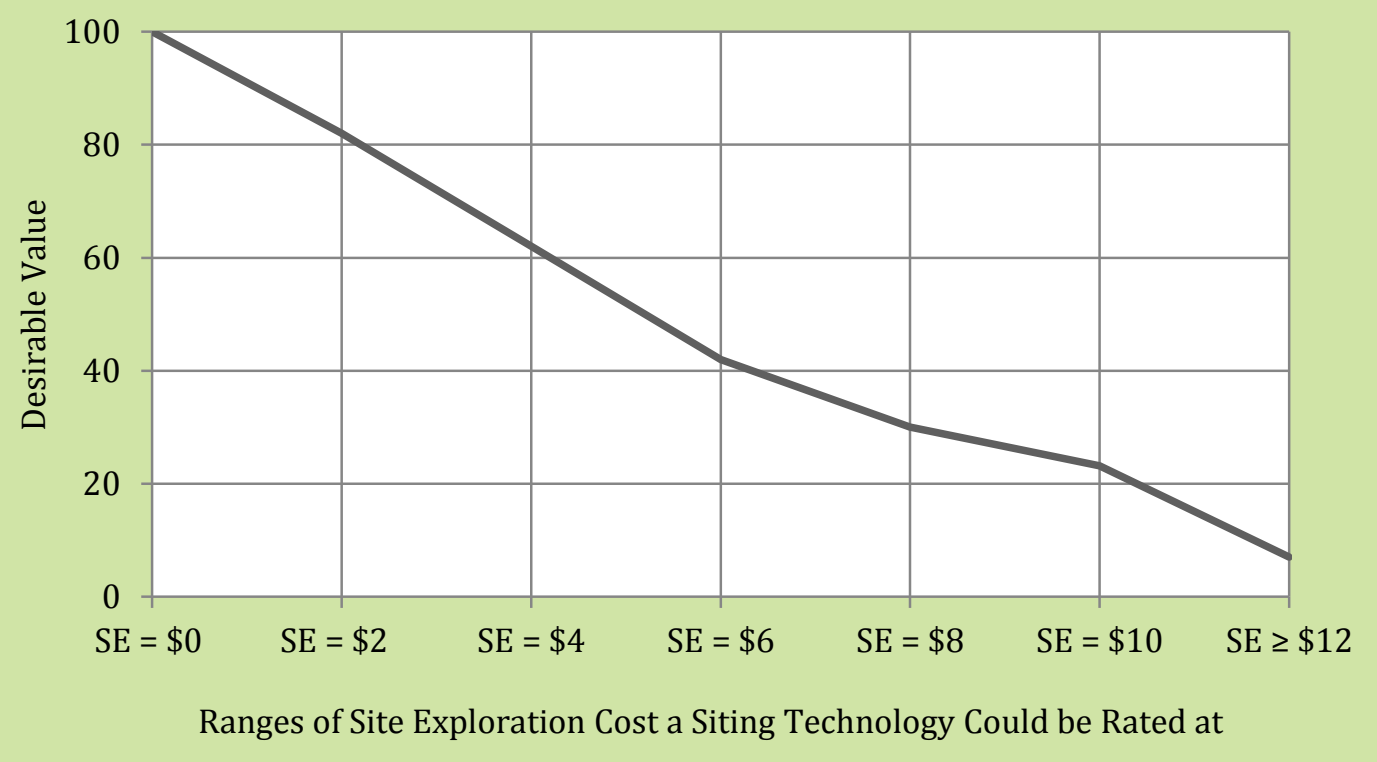

Figure G-20 Desirability Cure of Site Exploration Cost Sub-Criterion 
Table G-21 Desirability Values of Site Acquisition Cost Sub-Criterion

Economic: (E1.2) Site Development/Site Acquisition Cost (\$ Millions)

\begin{tabular}{|l|c|c|c|c|c|c|c|}
\hline \multicolumn{1}{|c|}{ Metrics } & EXP01 & EXP02 & EXP03 & EXP04 & EXP05 & Avg. & $\%$ \\
\hline $\mathrm{SA}=0$ & 100 & 100 & 100 & 100 & 100 & 100 & 1.00 \\
\hline $0<\mathrm{SA} \leq 5$ & 100 & 90 & 99 & 85 & 95 & 93.8 & 0.94 \\
\hline $5<\mathrm{SA} \leq 10$ & 75 & 80 & 90 & 65 & 85 & 79 & 0.79 \\
\hline $10<\mathrm{SA} \leq 15$ & 50 & 50 & 75 & 45 & 75 & 59 & 0.59 \\
\hline $15<\mathrm{SA} \leq 20$ & 25 & 35 & 50 & 25 & 55 & 38 & 0.38 \\
\hline $20<\mathrm{SA} \leq 25$ & 5 & 20 & 30 & 10 & 25 & 18 & 0.18 \\
\hline $\mathrm{SA}>25$ & 0 & 0 & 0 & 0 & 0 & 0 & 0.00 \\
\hline
\end{tabular}

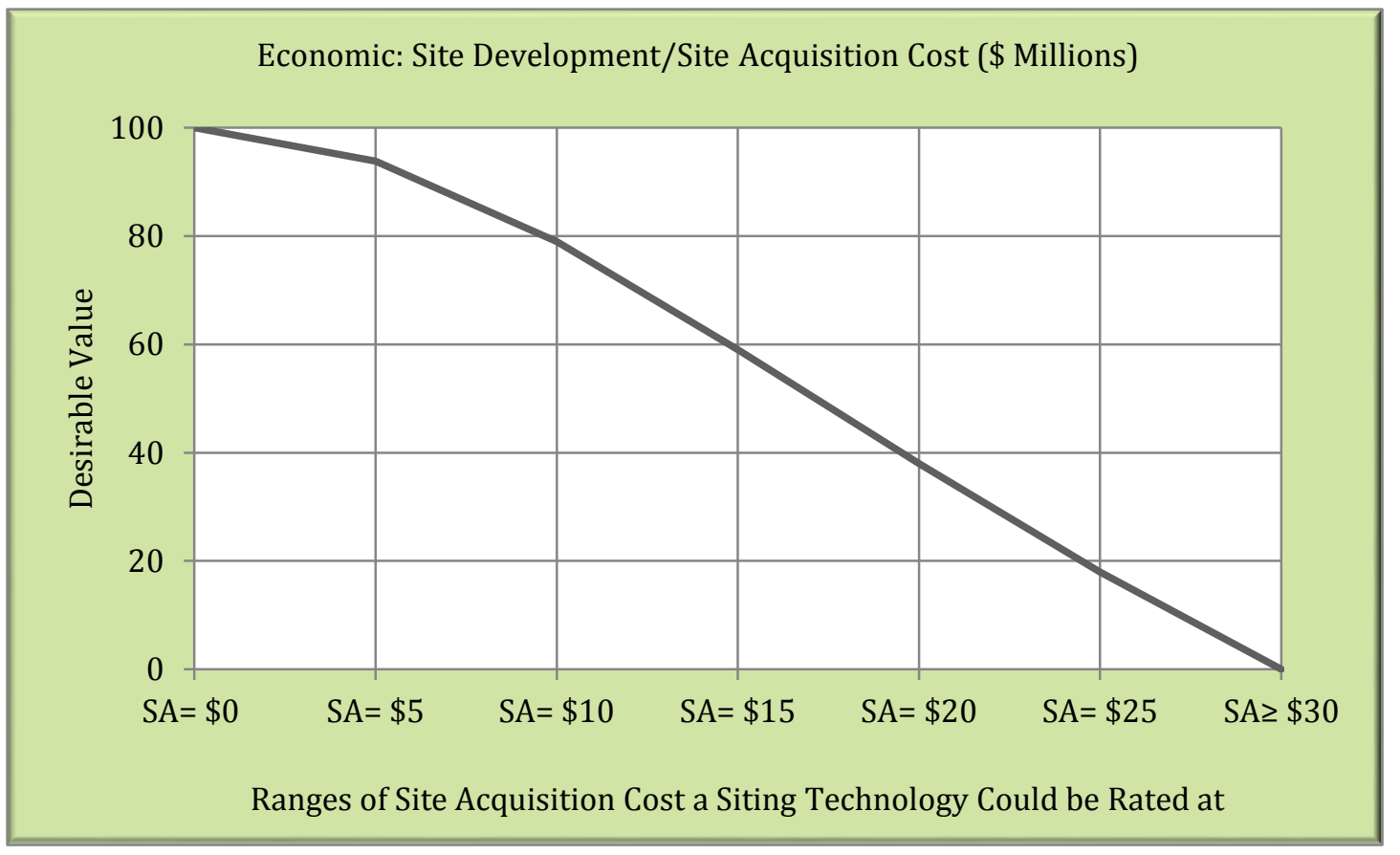

Figure G-21 Desirability Curve of Site Acquisition Cost Sub-Criterion 
Table G-22 Desirability Values of Site Preparation Cost Sub-Criterion

Economic: (E1.3) Site Development/Site Preparation Cost (\$ Millions)

\begin{tabular}{|l|c|c|c|c|c|c|c|}
\hline \multicolumn{1}{|c|}{ Metrics } & EXP01 & EXP02 & EXP03 & EXP04 & EXP05 & Avg. & $\%$ \\
\hline $\mathrm{SP}=0$ & 100 & 100 & 100 & 100 & 100 & 100 & 1.00 \\
\hline $0<\mathrm{SP} \leq 10$ & 50 & 75 & 90 & 85 & 90 & 78 & 0.78 \\
\hline $10<\mathrm{SP} \leq 20$ & 40 & 55 & 70 & 50 & 85 & 60 & 0.60 \\
\hline $20<\mathrm{SP} \leq 30$ & 30 & 35 & 40 & 40 & 60 & 41 & 0.41 \\
\hline $30<\mathrm{SP} \leq 40$ & 20 & 25 & 20 & 30 & 40 & 27 & 0.27 \\
\hline $40<\mathrm{SP} \leq 50$ & 10 & 15 & 10 & 20 & 10 & 13 & 0.13 \\
\hline $\mathrm{SP}>50$ & 0 & 0 & 0 & 0 & 0 & 0 & 0.00 \\
\hline
\end{tabular}

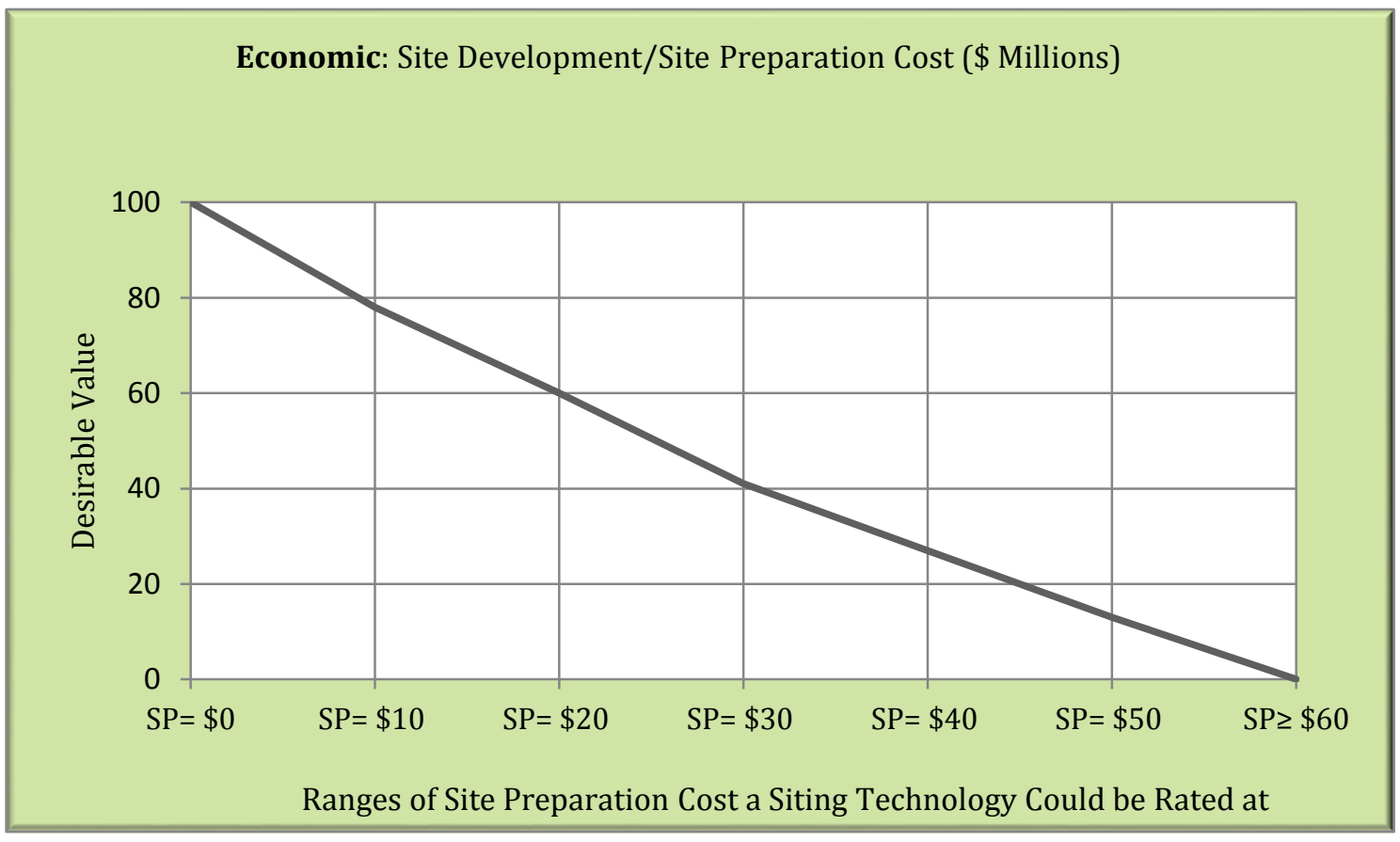

Figure G-22 Desirability Curve of Site Preparation Cost Sub-Criterion 
Table G-23 Desirability Values of Construction and Installation Cost Sub-Criterion

\begin{tabular}{|l|c|c|c|c|c|c|c|}
\hline \multicolumn{7}{|c|}{ Economic: (E2.1)Plant Development/Construction and Installation Cost } \\
(\$ Millions/MW) \\
\hline \multicolumn{1}{|c|}{ Metrics } & EXP01 & EXP02 & EXP03 & EXP04 & EXP05 & Avg. & $\%$ \\
\hline EPC $=0$ & 100 & 100 & 100 & 100 & 100 & 100 & 1.00 \\
\hline $0<$ EPC $\leq 2$ & 95 & 80 & 95 & 95 & 100 & 93 & 0.93 \\
\hline $2<$ EPC $\leq 4$ & 90 & 60 & 80 & 80 & 90 & 80 & 0.80 \\
\hline $4<\mathrm{EPC} \leq 6$ & 80 & 40 & 65 & 70 & 90 & 69 & 0.69 \\
\hline $6<\mathrm{EPC} \leq 8$ & 75 & 20 & 45 & 65 & 70 & 55 & 0.55 \\
\hline $8<\mathrm{EPC} \leq 10$ & 50 & 10 & 25 & 35 & 50 & 34 & 0.34 \\
\hline $\mathrm{EPC}>10$ & 0 & 0 & 0 & 0 & 0 & 0 & 0.00 \\
\hline
\end{tabular}

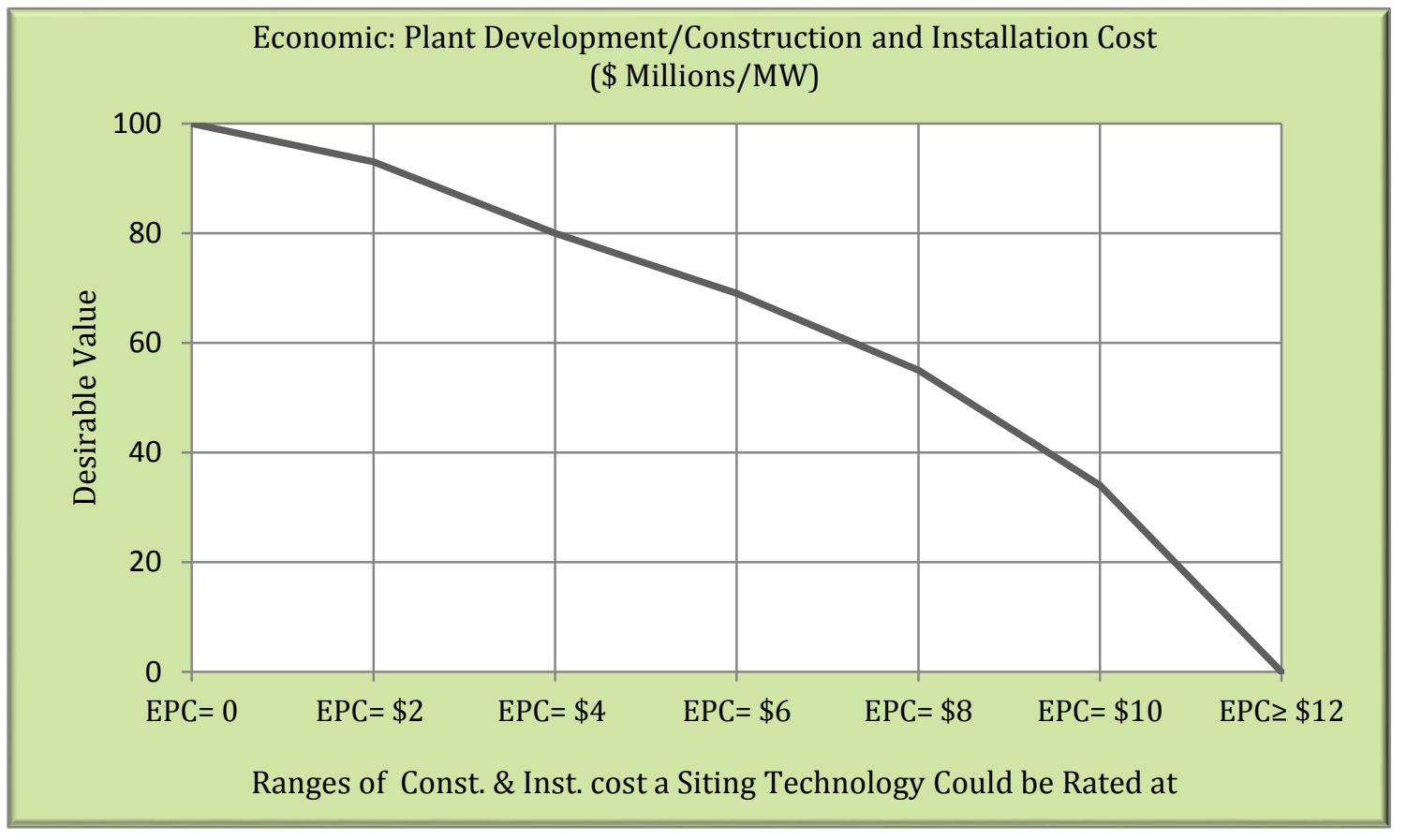

Figure G-23 Desirability Curve of Construction and Installation Cost Sub-Criterion 
Table G-24 Desirability Values of Operation and Maintenance Cost Sub-Criterion

Economic: (E2.2) Plant Development/Operation and Maintenance Cost (\$/MWh)

\begin{tabular}{|l|c|c|c|c|c|c|c|}
\hline \multicolumn{1}{|c|}{ Metrics } & EXP01 & EXP02 & EXP03 & EXP04 & EXP05 & Avg. & $\%$ \\
\hline $0 \& \mathrm{M}=\$ 0$ & 100 & 100 & 100 & 100 & 100 & 100 & 1.00 \\
\hline$\$ 0<0 \& \mathrm{M} \leq \$ 10$ & 90 & 95 & 95 & 80 & 85 & 89 & 0.89 \\
\hline $10<0 \& \mathrm{M} \leq 20$ & 85 & 80 & 75 & 60 & 65 & 73 & 0.73 \\
\hline $20<0 \& \mathrm{M} \leq 30$ & 60 & 75 & 55 & 40 & 45 & 55 & 0.55 \\
\hline $30<0 \& \mathrm{M} \leq 40$ & 45 & 40 & 35 & 20 & 25 & 33 & 0.33 \\
\hline $40<0 \& \mathrm{M} \leq 50$ & 25 & 15 & 15 & 10 & 10 & 15 & 0.15 \\
\hline $0 \& \mathrm{M}>\$ 50$ & 0 & 0 & 0 & 0 & 0 & 0 & 0.00 \\
\hline
\end{tabular}

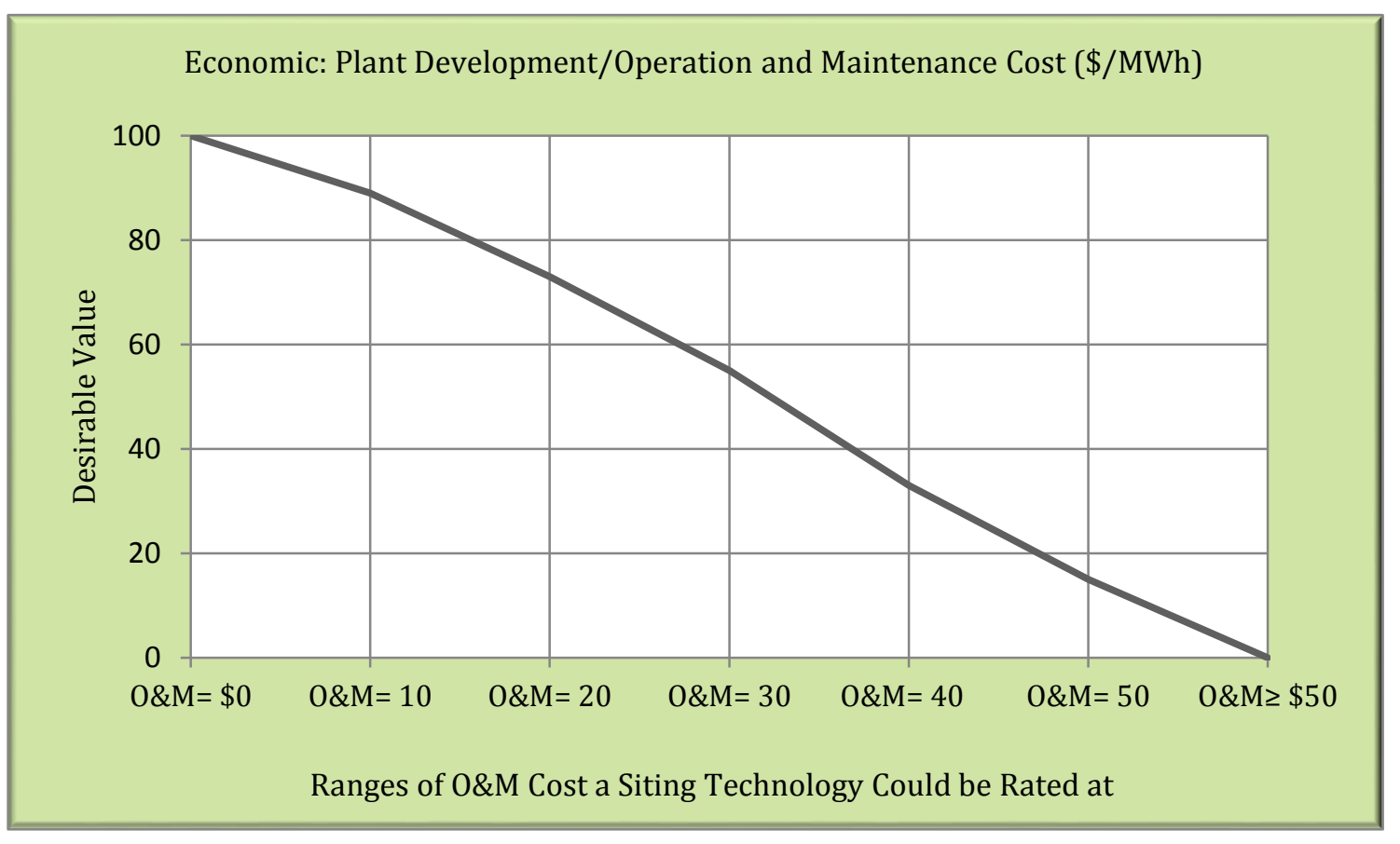

Figure G-24 Desirability Curve of Operation and Maintenance Cost Sub-Criterion 
Table G-25 Desirability Values of Decommission and Cleanup Cost Sub-Criterion

\section{Economic: (E2.3) Plant Development/Decommissioning and Cleanup Cost} (\$ Millions)

\begin{tabular}{|l|c|c|c|c|c|c|c|}
\hline \multicolumn{1}{|c|}{ Metrics } & EXP01 & EXP02 & EXP03 & EXP04 & EXP05 & Avg. & $\%$ \\
\hline $\mathrm{DC}=0$ & 100 & 100 & 100 & 100 & 100 & 100 & 1.00 \\
\hline $0<\mathrm{DC} \leq 200$ & 80 & 90 & 95 & 90 & 85 & 88 & 0.88 \\
\hline $200<\mathrm{DC} \leq 400$ & 60 & 85 & 65 & 80 & 75 & 73 & 0.73 \\
\hline $400<\mathrm{DC} \leq 600$ & 50 & 65 & 35 & 50 & 55 & 51 & 0.51 \\
\hline $600<\mathrm{DC} \leq 800$ & 40 & 55 & 15 & 40 & 35 & 37 & 0.37 \\
\hline $800<\mathrm{DC} \leq 1000$ & 20 & 35 & 5 & 30 & 15 & 21 & 0.21 \\
\hline $\mathrm{DC}>1000$ & 0 & 0 & 0 & 0 & 0 & 0 & 0.00 \\
\hline
\end{tabular}

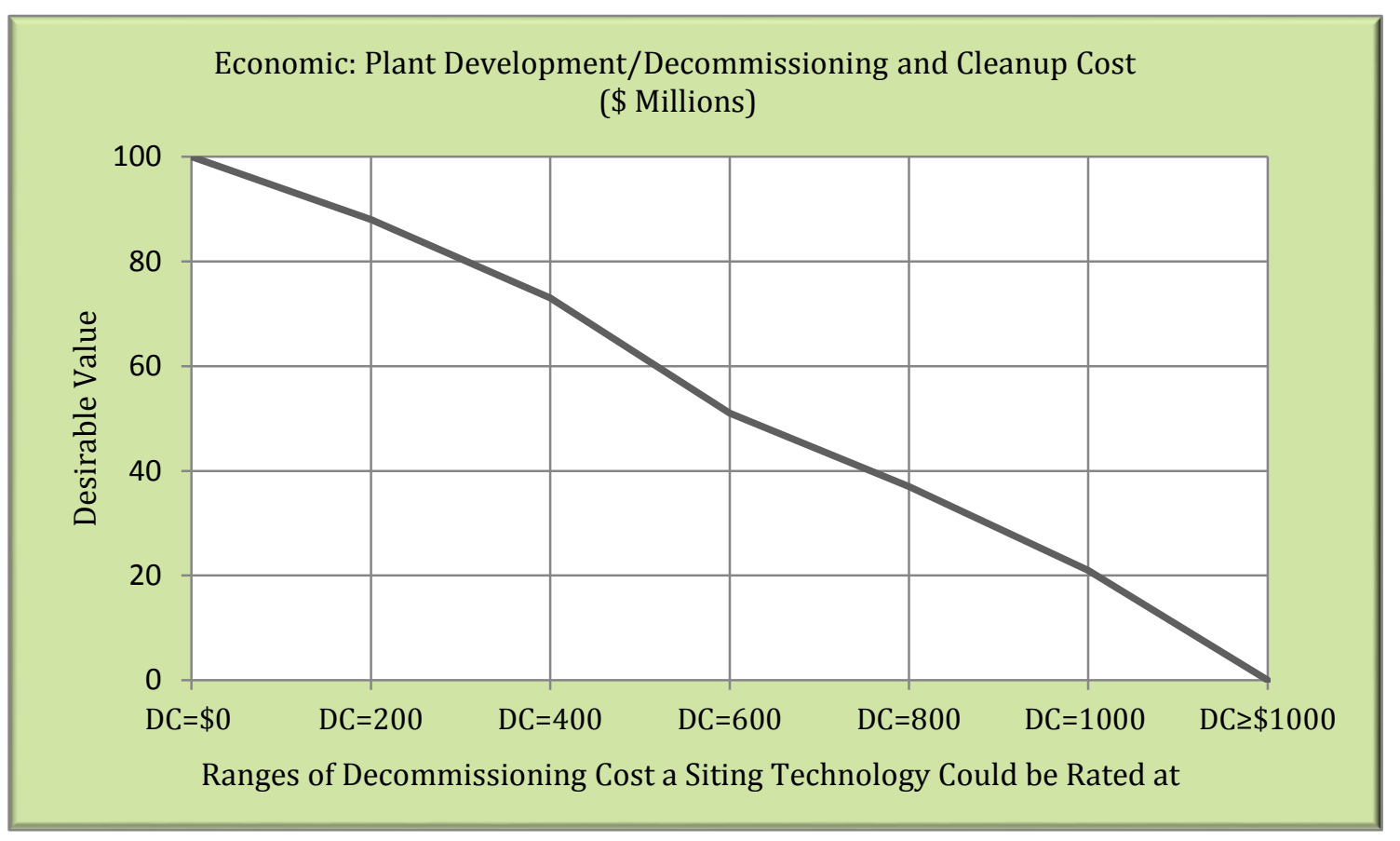

Figure G-25 Desirability Curve of Decommission and Cleanup Cost Sub-Criterion 
Table G-26 Desirability Values of Water Delivery Cost Sub-Criterion

\begin{tabular}{|l|c|c|c|c|c|c|c|}
\multicolumn{7}{|c|}{ Economic: (E3.1) Plant Supplementary Systems: Water Delivery Cost } \\
(\$/MWh) \\
\hline \multicolumn{1}{|c|}{ Metrics } & EXP01 & EXP02 & EXP03 & EXP04 & EXP05 & Avg. & $\%$ \\
\hline $\mathrm{WD}=0$ & 100 & 100 & 100 & 100 & 100 & 100 & 1.00 \\
\hline $0<\mathrm{WD} \leq 1$ & 80 & 96 & 90 & 95 & 70 & 86.2 & 0.86 \\
\hline $1<\mathrm{WD} \leq 2$ & 60 & 88 & 70 & 85 & 50 & 70.6 & 0.71 \\
\hline $2<\mathrm{WD} \leq 3$ & 40 & 67 & 50 & 65 & 30 & 50.4 & 0.50 \\
\hline $3<\mathrm{WD} \leq 4$ & 20 & 50 & 30 & 55 & 10 & 33 & 0.33 \\
\hline $4<\mathrm{WD} \leq 5$ & 5 & 20 & 10 & 35 & 5 & 15 & 0.15 \\
\hline $\mathrm{WD}>5$ & 0 & 0 & 0 & 0 & 0 & 0 & 0.00 \\
\hline
\end{tabular}

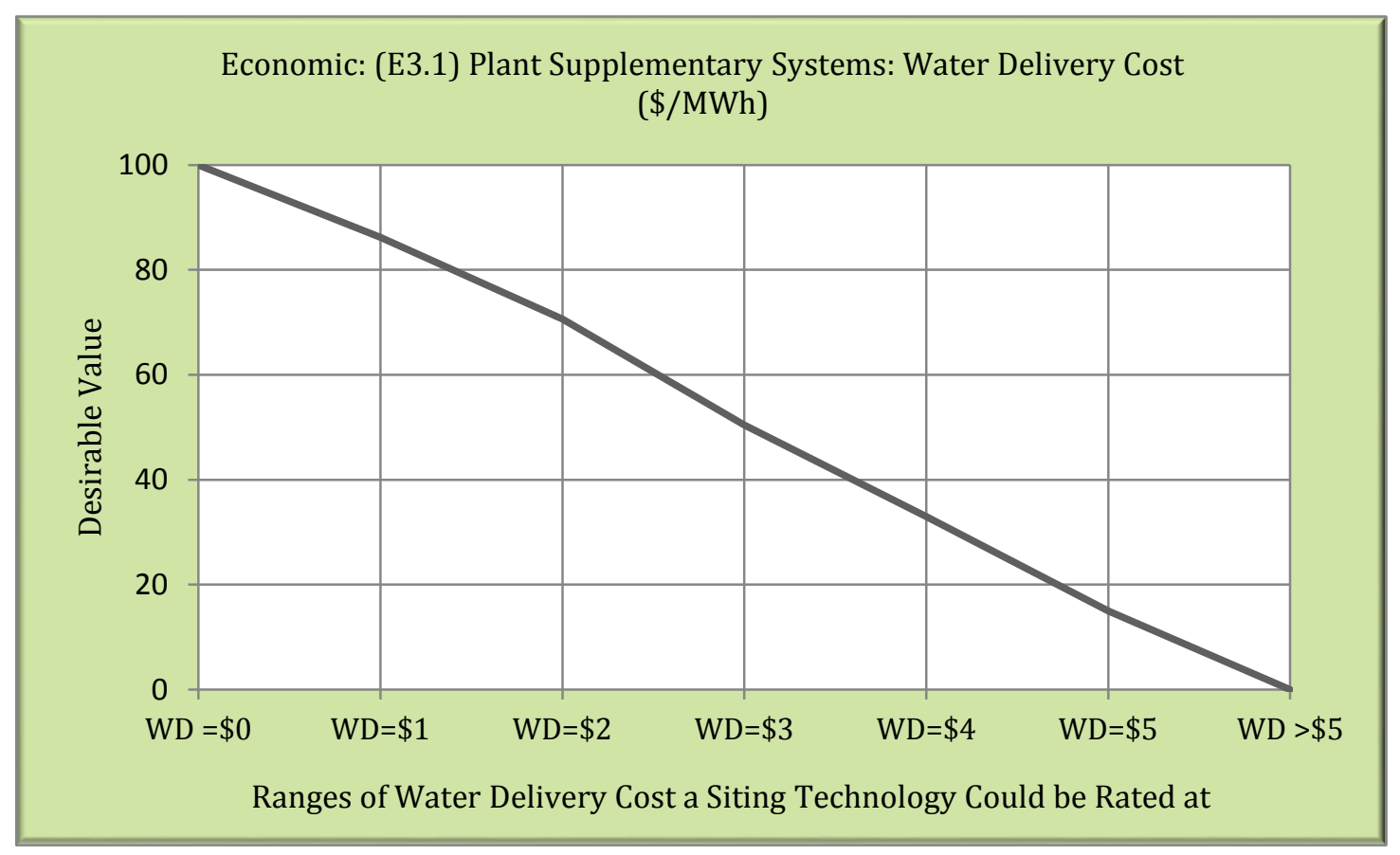

Figure G-26 Desirability Curve of Water Delivery Cost Sub-Criterion 
Table G-27 Desirability Values of Grid Connection Cost Sub-Criterion

\begin{tabular}{|l|c|c|c|c|c|c|c|}
\hline \multicolumn{7}{|c|}{$\begin{array}{c}\text { Economic: (E3.2) Plant Supplementary Systems/Grid Connection Cost } \\
\text { (\$/MWh) }\end{array}$} \\
\hline \multicolumn{1}{|c|}{ Metrics } & EXP01 & EXP02 & EXP03 & EXP04 & EXP05 & Avg. & $\%$ \\
\hline GC $=0$ & 100 & 100 & 100 & 100 & 100 & 100 & 1.00 \\
\hline $0<$ GC $\leq 20$ & 95 & 95 & 90 & 80 & 90 & 90 & 0.90 \\
\hline $20<$ GC $\leq 40$ & 75 & 85 & 80 & 60 & 60 & 72 & 0.72 \\
\hline $40<$ GC $\leq 60$ & 55 & 55 & 40 & 50 & 50 & 50 & 0.50 \\
\hline $60<$ GC $\leq 80$ & 35 & 45 & 30 & 30 & 40 & 36 & 0.36 \\
\hline $80<$ GC $\leq 100$ & 15 & 25 & 10 & 20 & 20 & 18 & 0.18 \\
\hline$G C>100$ & 0 & 0 & 0 & 0 & 0 & 0 & 0.00 \\
\hline
\end{tabular}

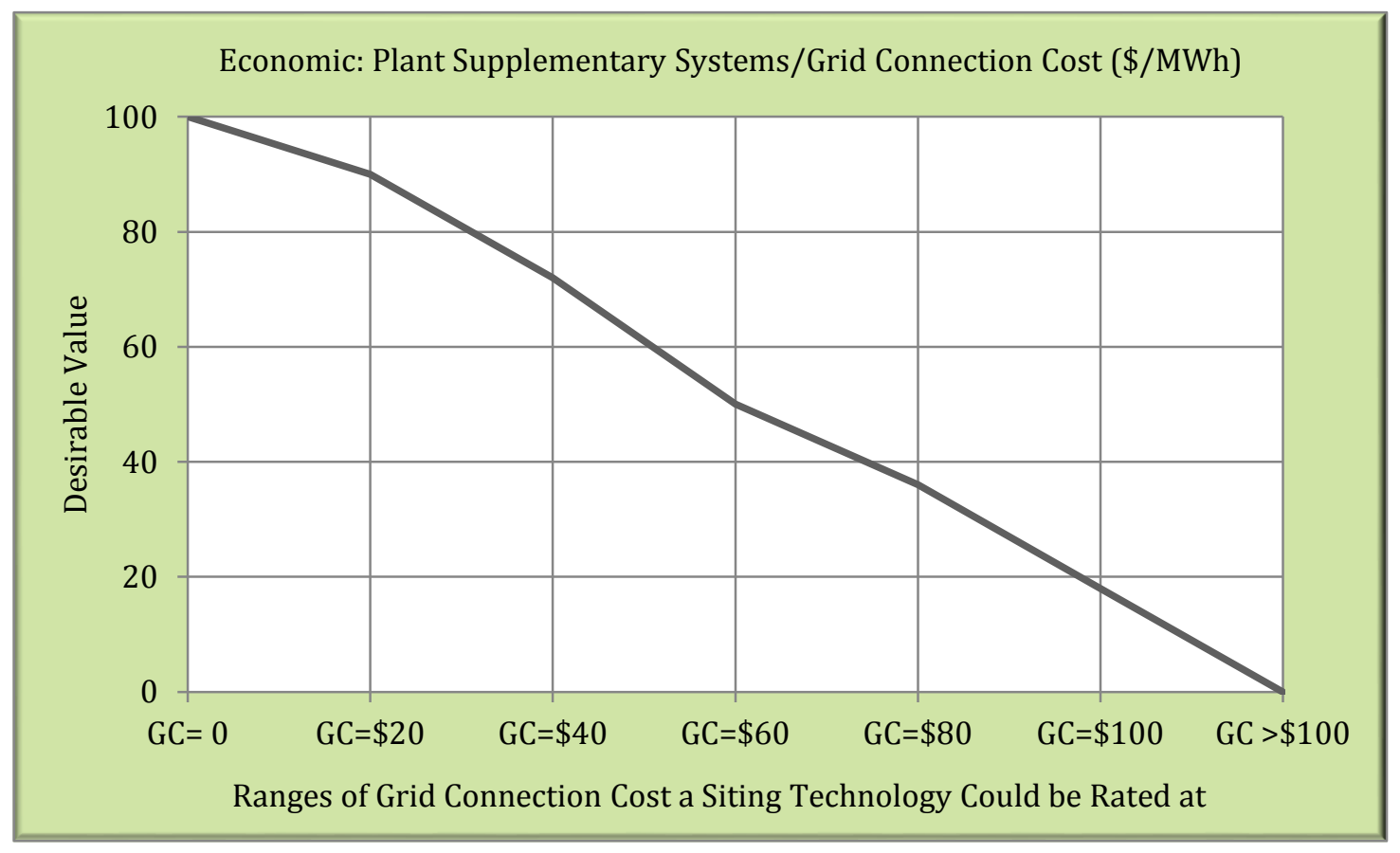

Figure G-27 Desirability Curve of Grid Connection Cost Sub-Criterion 
Table G-28 Desirability Values of Ventilation System Cost Sub- Criterion

\begin{tabular}{|l|c|c|c|c|c|c|c|}
\hline \multicolumn{7}{|c|}{ Economic: (E3.3) Plant Supplementary Systems/Ventilation System Cost } \\
(\$ Millions)
\end{tabular}

Economic: Plant Supplementary Systems/Ventilation System Cost (\$ Millions)

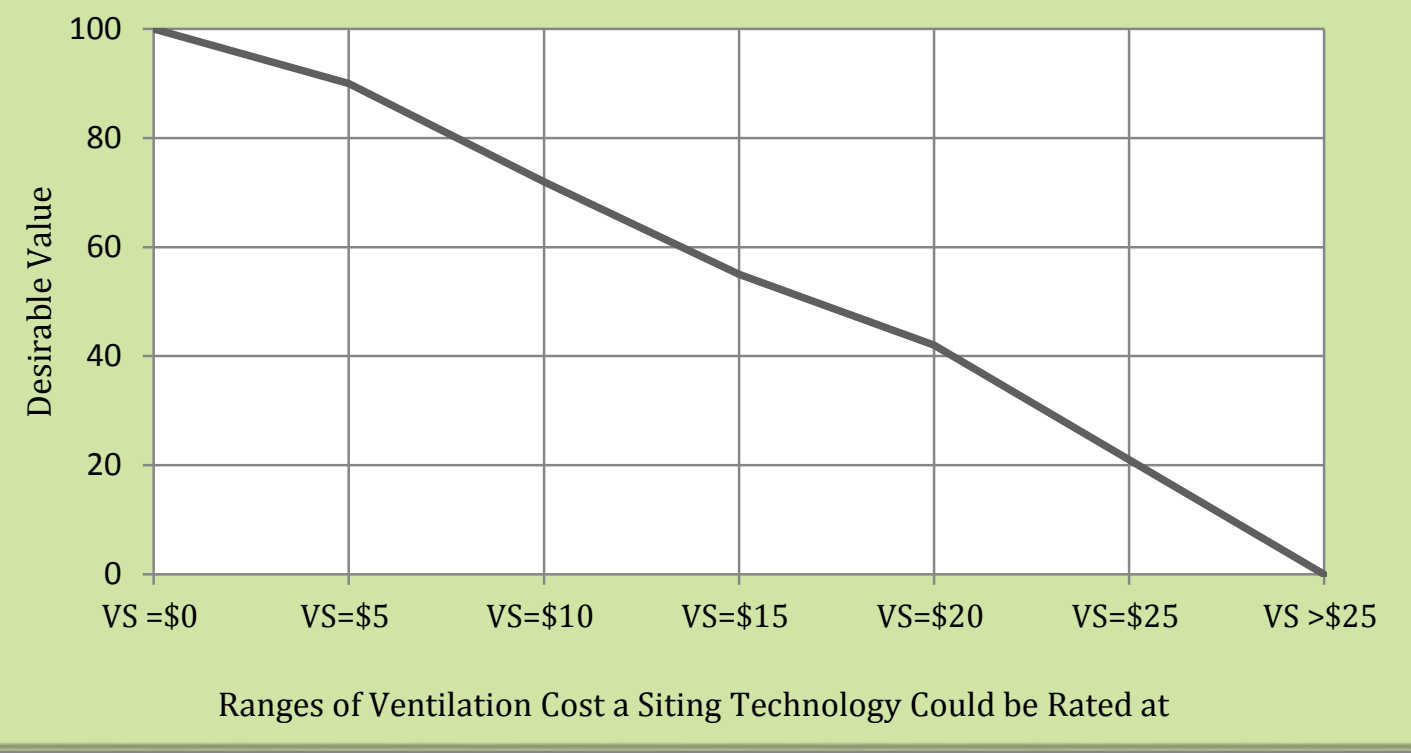

Figure G-28 Desirability Curve of Ventilation System Cost Sub-Criterion 
Table G-29 Desirability Values of Protection and Isolation Cost Sub-Criterion

\begin{tabular}{|l|c|c|c|c|c|c|c|}
\hline \multicolumn{7}{|c|}{$\begin{array}{c}\text { Economic:(E3.4) Plant Supplementary Systems/Protection \& Isolation Cost } \\
\text { (\$ Millions) }\end{array}$} \\
\hline \multicolumn{1}{|c|}{ Metrics } & EXP01 & EXP02 & EXP03 & EXP04 & EXP05 & Avg. & $\%$ \\
\hline $\mathrm{PI}=0$ & 100 & 100 & 100 & 100 & 100 & 100 & 1.00 \\
\hline $0<\mathrm{PI} \leq 5$ & 90 & 95 & 99 & 80 & 75 & 87.8 & 0.88 \\
\hline $5<\mathrm{PI} \leq 10$ & 70 & 85 & 89 & 50 & 75 & 73.8 & 0.74 \\
\hline $10<\mathrm{PI} \leq 15$ & 50 & 65 & 59 & 30 & 50 & 50.8 & 0.51 \\
\hline $15<\mathrm{PI} \leq 20$ & 40 & 55 & 49 & 10 & 25 & 35.8 & 0.36 \\
\hline $20<\mathrm{PI} \leq 25$ & 20 & 25 & 29 & 5 & 0 & 15.8 & 0.16 \\
\hline $\mathrm{PI}>25$ & 0 & 0 & 0 & 0 & 0 & 0 & 0.00 \\
\hline
\end{tabular}

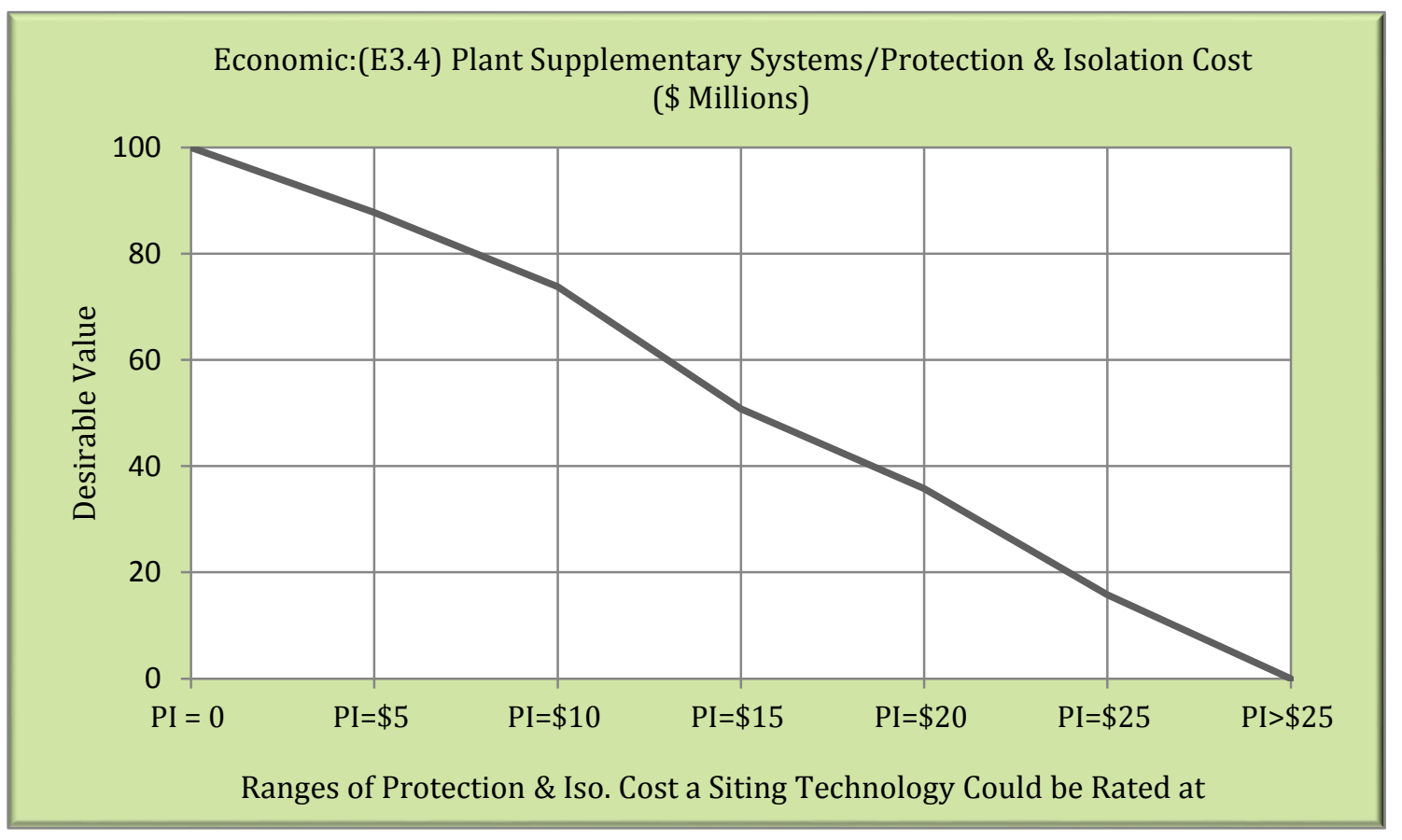

Figure G-29 Desirability Curve of Ventilation System Cost Sub-Criterion 
Table G-30 Desirability Values of Transportation System Cost Sub-Criterion

Economic:(E3.5) Plant Supplementary Systems/Transportation System Cost (\$ Millions)

\begin{tabular}{|l|c|c|c|c|c|c|c|}
\hline \multicolumn{1}{|c|}{ Metrics } & EXP01 & EXP02 & EXP03 & EXP04 & EXP05 & Avg. & $\%$ \\
\hline TS $=0$ & 100 & 100 & 100 & 100 & 100 & 100 & 1.00 \\
\hline $0<\mathrm{TS} \leq 5$ & 95 & 90 & 90 & 80 & 95 & 90 & 0.90 \\
\hline $5<\mathrm{TS} \leq 10$ & 70 & 60 & 70 & 50 & 80 & 66 & 0.66 \\
\hline $10<\mathrm{TS} \leq 15$ & 45 & 50 & 30 & 30 & 55 & 42 & 0.42 \\
\hline $15<\mathrm{TS} \leq 20$ & 25 & 30 & 10 & 10 & 45 & 24 & 0.24 \\
\hline $20<\mathrm{TS} \leq 25$ & 5 & 10 & 0 & 5 & 10 & 6 & 0.06 \\
\hline $\mathrm{TS}>25$ & 0 & 0 & 0 & 0 & 0 & 0 & 0.00 \\
\hline
\end{tabular}

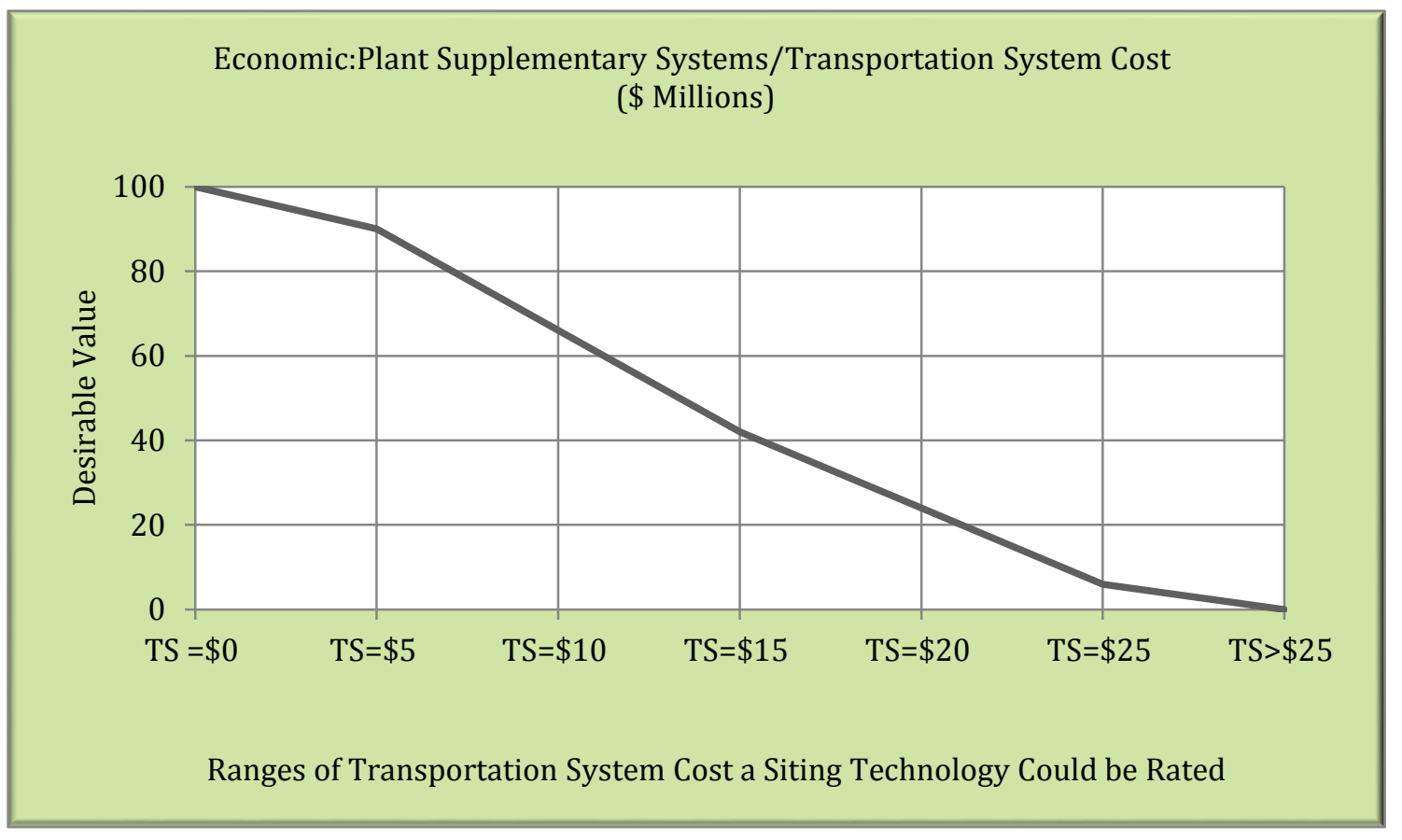

Figure G-30 Desirability Curve of Transportation System Cost Sub-Criterion 
Table G-31 Desirability Values of Technology Outsourcing Cot Criterion

Economic:(E4) Technology Outsourcing Cost (\% of Overnight Capital Cost)

\begin{tabular}{|l|c|c|c|c|c|c|c|}
\hline \multicolumn{1}{|c|}{ Metrics } & EXP01 & EXP02 & EXP03 & EXP04 & EXP05 & Avg. & $\%$ \\
\hline TO $=0 \%$ & 100 & 100 & 100 & 100 & 100 & 100 & 1.00 \\
\hline TO $=20 \%$ & 80 & 90 & 95 & 90 & 80 & 87 & 0.87 \\
\hline TO $=40 \%$ & 60 & 70 & 40 & 70 & 50 & 58 & 0.58 \\
\hline TO $=60 \%$ & 40 & 50 & 20 & 30 & 25 & 33 & 0.33 \\
\hline TO $=80 \%$ & 20 & 30 & 5 & 10 & 5 & 14 & 0.14 \\
\hline TO $=100 \%$ & 0 & 0 & 0 & 0 & 0 & 0 & 0.00 \\
\hline TO $=0 \%$ & 100 & 100 & 100 & 100 & 100 & 100 & 1.00 \\
\hline
\end{tabular}

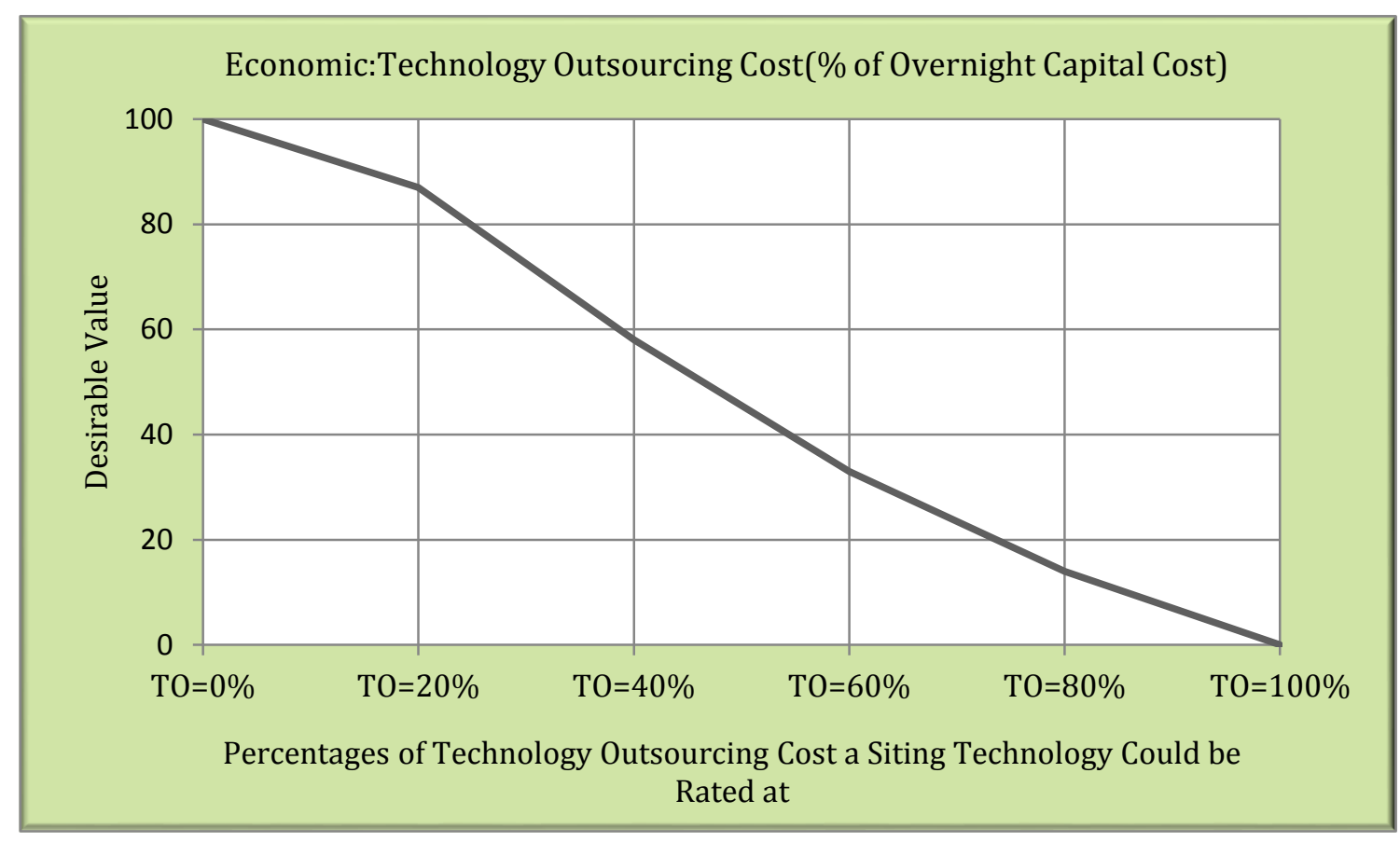

Figure G-31 Desirability Curve of Technology Outsourcing Cost Criterion 
Table G-32 Desirability Values of Return On Investment Criterion

\begin{tabular}{|l|c|c|c|c|c|c|c|}
\hline \multicolumn{7}{|c|}{ Economic: (E5) Return On Investment (\% ) } \\
\hline \multicolumn{1}{|c|}{ Metrics } & EXP01 & EXP02 & EXP03 & EXP04 & EXP05 & Avg. & $\%$ \\
\hline ROI $=0 \%$ & 0 & 0 & 0 & 0 & 0 & 0 & 0.00 \\
\hline ROI $=20 \%$ & 50 & 35 & 15 & 25 & 40 & 33 & 0.33 \\
\hline ROI $=40 \%$ & 70 & 60 & 40 & 80 & 60 & 62 & 0.62 \\
\hline ROI $=60 \%$ & 80 & 90 & 75 & 89 & 80 & 82.8 & 0.83 \\
\hline ROI $=80 \%$ & 90 & 95 & 95 & 99 & 90 & 93.8 & 0.94 \\
\hline ROI $=100 \%$ & 100 & 100 & 100 & 100 & 100 & 100 & 1.00 \\
\hline & & & & & & & \\
\hline
\end{tabular}

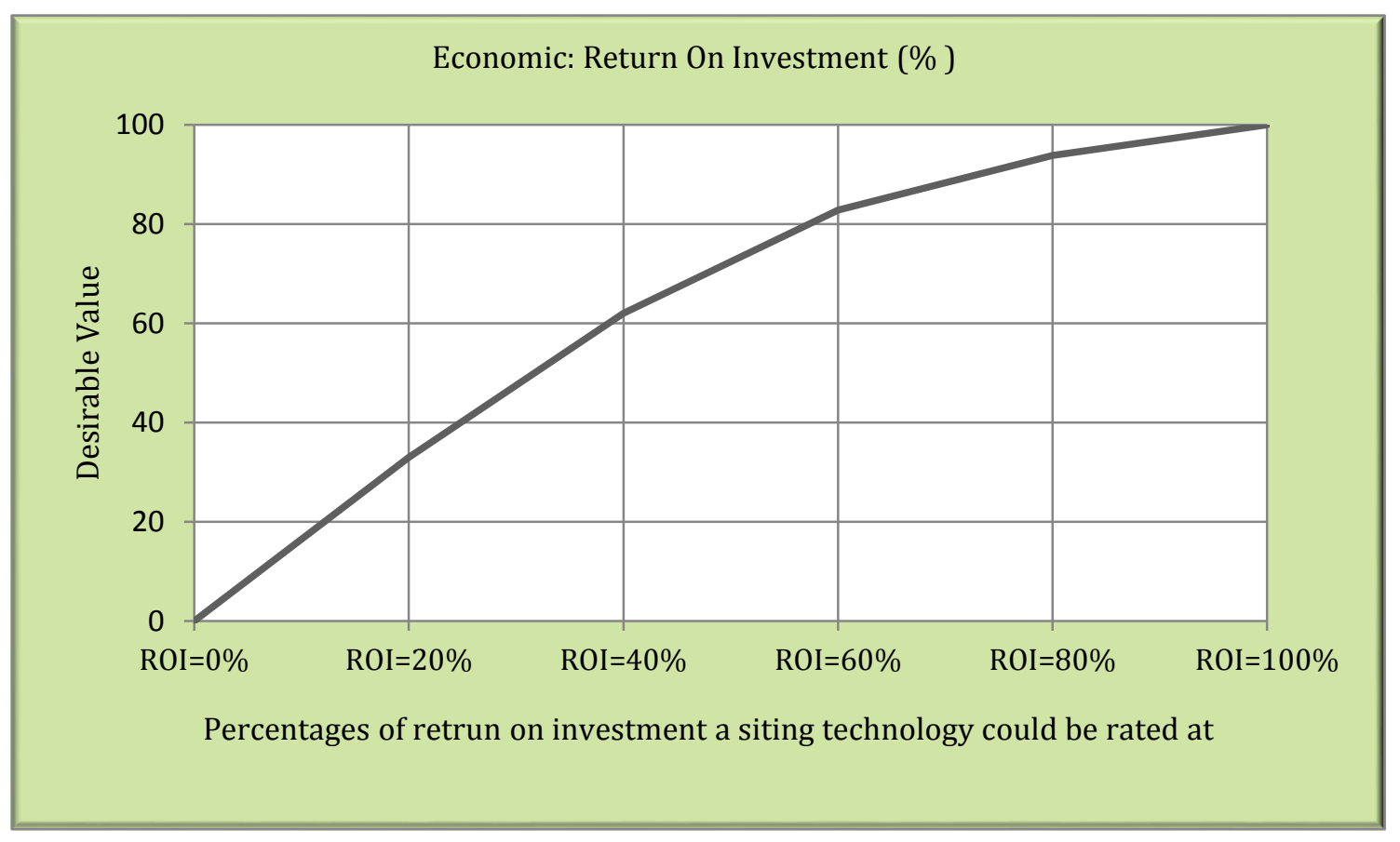

Figure G-32 Desirability Curve of Return On Investment Criterion 
Table G-33 Desirability Values of Site Preparation-Ecological Impacts Criterion

Environmental: (N1) Site Preparation-Ecological Impacts (Disruption)

\begin{tabular}{|l|c|c|c|c|c|c|c|}
\hline \multicolumn{1}{|c|}{ Metrics } & EXP01 & EXP02 & EXP03 & EXP04 & EXP05 & Avg. & $\%$ \\
\hline very high disruption & 10 & 0 & 20 & 0 & 0 & 6 & 0.06 \\
\hline high disruption & 30 & 20 & 50 & 20 & 15 & 27 & 0.27 \\
\hline average disruption & 80 & 35 & 70 & 80 & 65 & 66 & 0.66 \\
\hline low disruption & 90 & 50 & 85 & 90 & 75 & 78 & 0.78 \\
\hline very low disruption & 95 & 70 & 90 & 95 & 80 & 86 & 0.86 \\
\hline no disruption & 100 & 100 & 100 & 100 & 100 & 100 & 1.00 \\
\hline
\end{tabular}

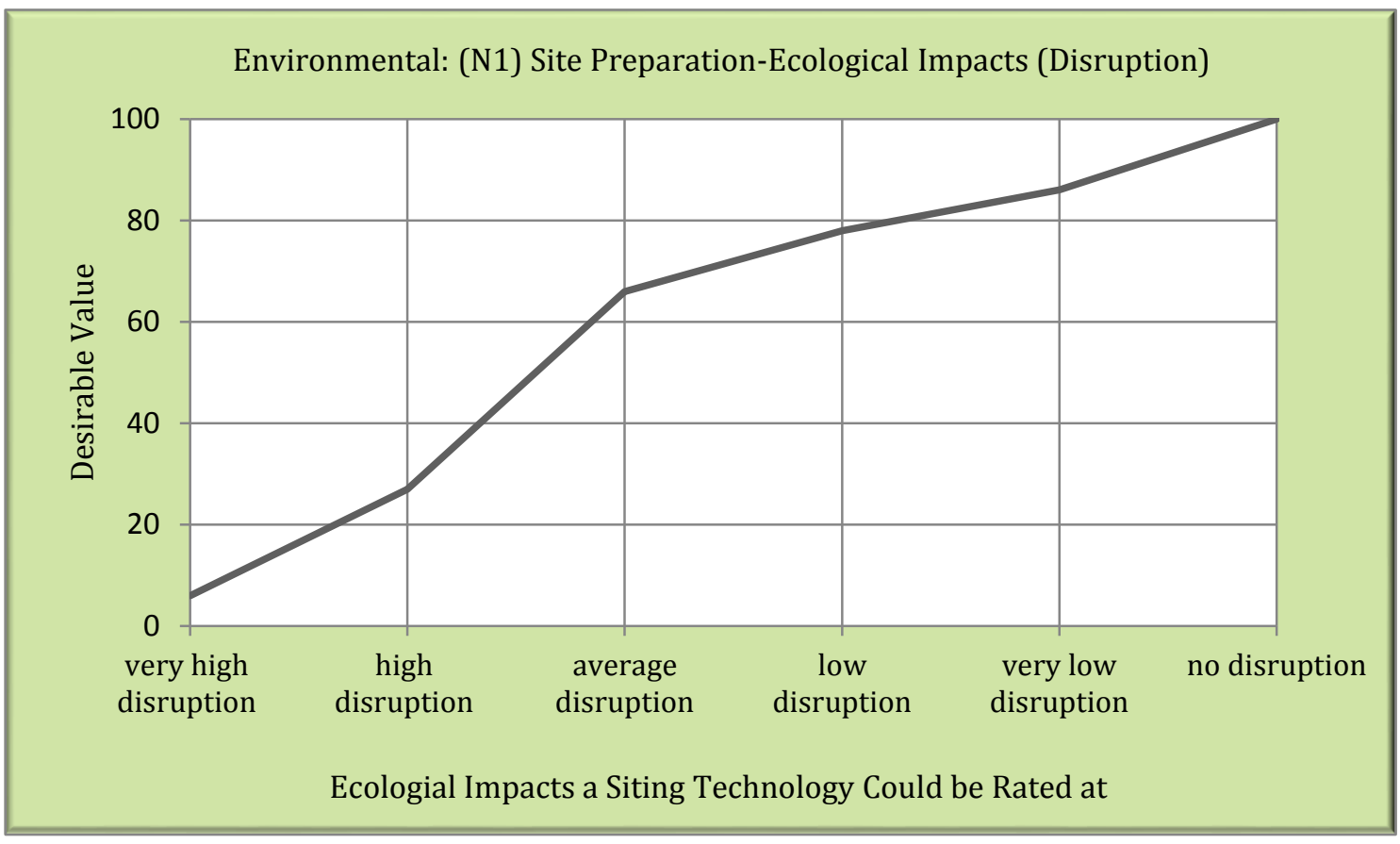

Figure G-33 Desirability Curve of Site Preparation-Ecological Impacts Criterion 
Table G-34 Desirability Values of Construction-Related Negative Impacts Criterion

Environmental:(N2) Construction-Related Negative Impacts

\begin{tabular}{|l|c|c|c|c|c|c|c|}
\hline \multicolumn{1}{|c|}{ Metrics } & EXP01 & EXP02 & EXP03 & EXP04 & EXP05 & Avg. & $\%$ \\
\hline very high negative impact & 5 & 0 & 0 & 0 & 0 & 1 & 0.01 \\
\hline high negative impact & 25 & 10 & 25 & 10 & 40 & 22 & 0.22 \\
\hline average negative impact & 50 & 55 & 75 & 45 & 75 & 60 & 0.60 \\
\hline low negative impact & 80 & 75 & 85 & 55 & 90 & 77 & 0.77 \\
\hline very low negative impact & 90 & 90 & 99 & 75 & 95 & 89.8 & 0.90 \\
\hline no negative impact & 100 & 100 & 100 & 100 & 100 & 100 & 1.00 \\
\hline
\end{tabular}

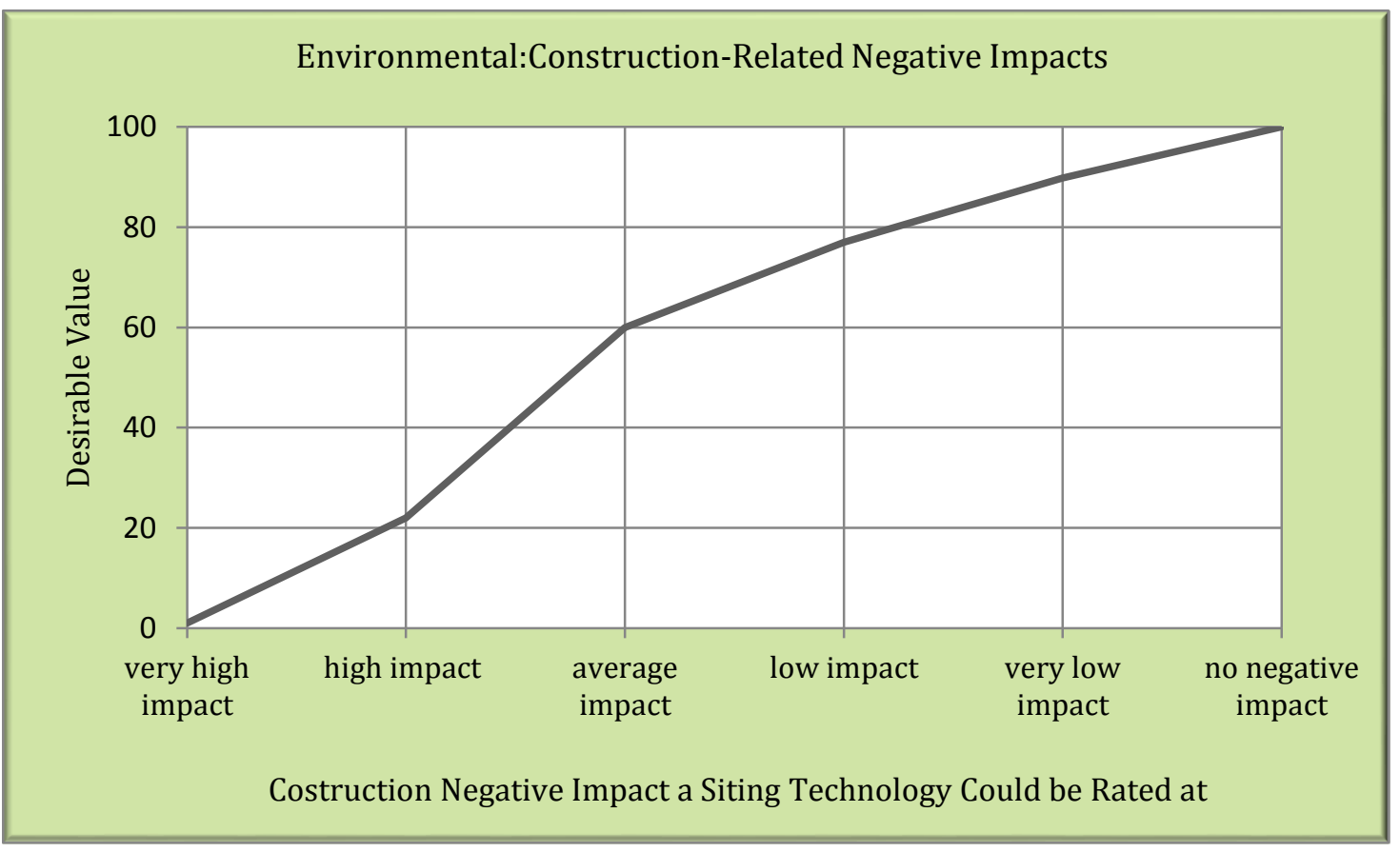

Figure G-34 Desirability Curve of Construction-Related Negative Impacts Criterion 
Table G-35 Desirability Values of Operation-Related Negative Impacts Criterion

\begin{tabular}{|l|c|c|c|c|c|c|c|c|}
\hline \multicolumn{7}{|c|}{ Environmental:(N3) Operation-Related Impacts/(Water Contamination) } \\
\hline \multicolumn{1}{|c|}{ Metrics } & EXP01 & EXP02 & EXP03 & EXP04 & EXP05 & Avg. & $\%$ \\
\hline very high contamination & 25 & 10 & 0 & 0 & 0 & 7 & 0.07 \\
\hline high contamination & 35 & 40 & 10 & 10 & 15 & 22 & 0.22 \\
\hline average contamination & 75 & 60 & 50 & 85 & 35 & 61 & 0.61 \\
\hline low contamination & 90 & 80 & 75 & 90 & 55 & 78 & 0.78 \\
\hline very low contamination & 95 & 90 & 100 & 99 & 75 & 91.8 & 0.92 \\
\hline no contamination & 100 & 100 & 100 & 100 & 100 & 100 & 1.00 \\
\hline
\end{tabular}

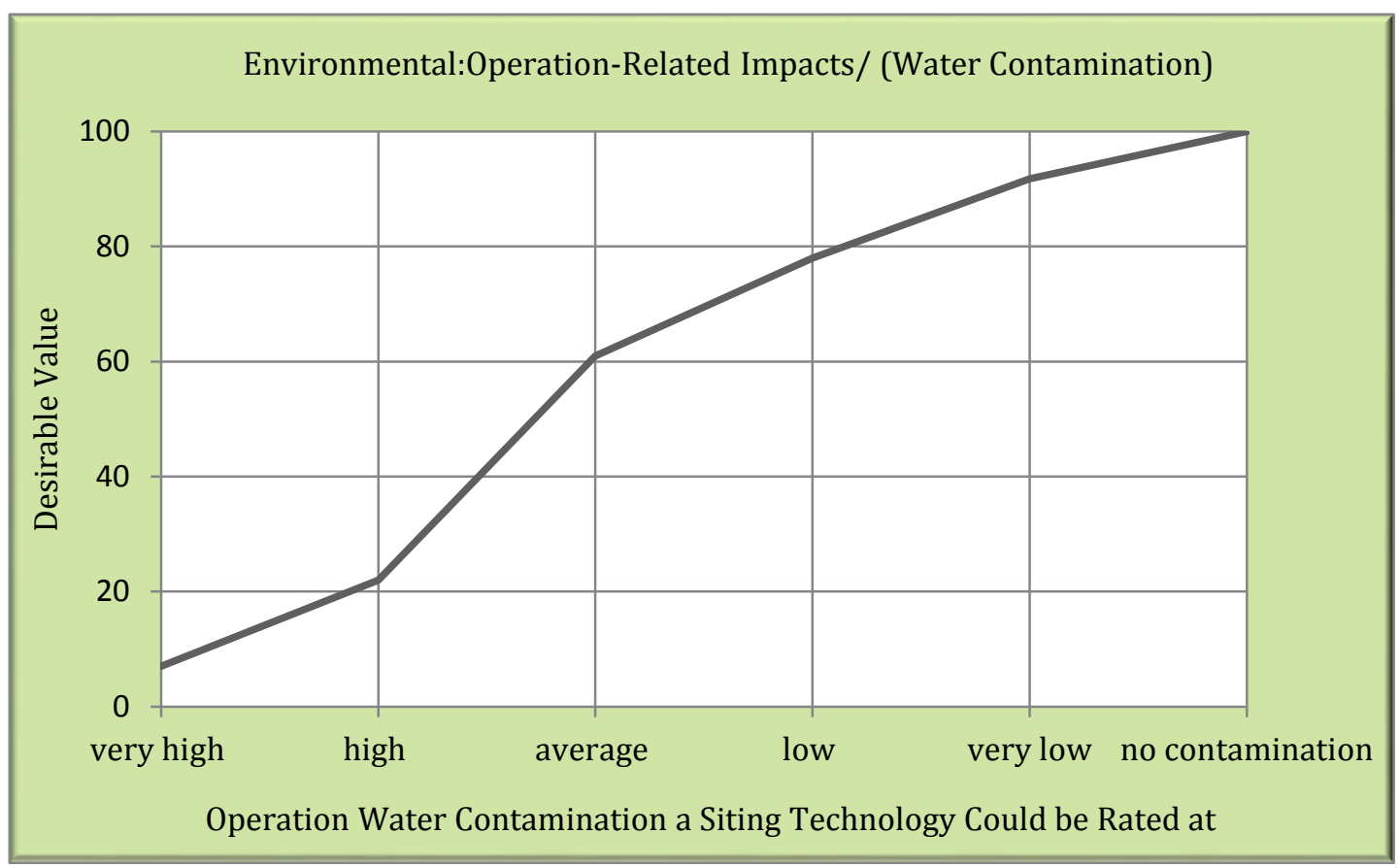

Figure G-35 Desirability Curve of Operation-Related Negative Impacts Criterion 
Table G-36 Desirability Values of Land Availability and Utilization Criterion

Environmental: (N4) Land Availability/Utilization

\begin{tabular}{|l|c|c|c|c|c|c|c|}
\hline \multicolumn{1}{|c|}{ Metrics } & EXP01 & EXP02 & EXP03 & EXP04 & EXP05 & Avg. & $\%$ \\
\hline very poor & 0 & 5 & 0 & 10 & 0 & 3 & 0.03 \\
\hline poor & 25 & 10 & 10 & 40 & 5 & 18 & 0.18 \\
\hline Fair & 55 & 30 & 50 & 60 & 25 & 44 & 0.44 \\
\hline good & 75 & 60 & 80 & 80 & 40 & 67 & 0.67 \\
\hline very good & 90 & 90 & 95 & 100 & 70 & 89 & 0.89 \\
\hline excellent & 100 & 100 & 100 & 100 & 100 & 100 & 1.00 \\
\hline
\end{tabular}

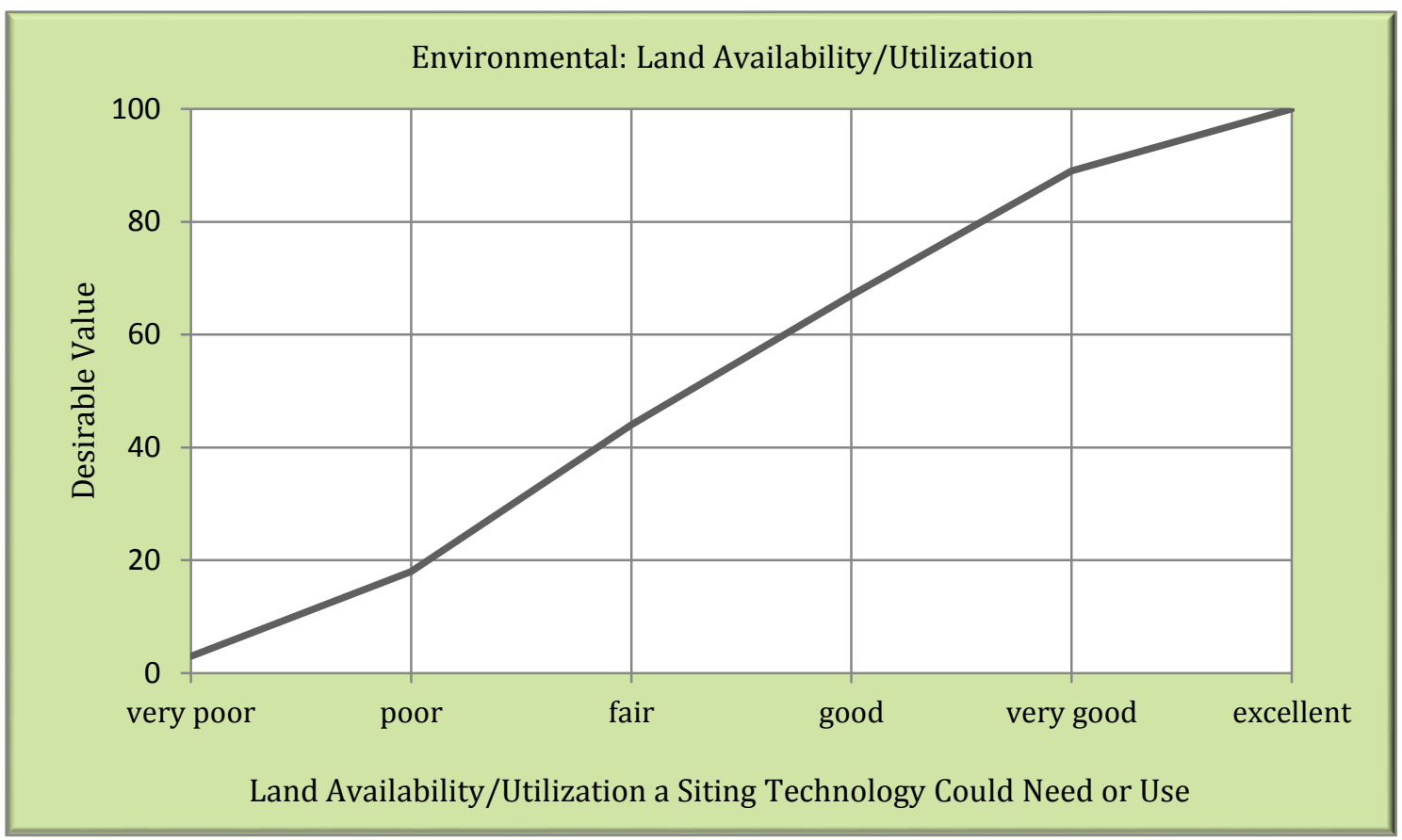

Figure G-36 Desirability Curve of Land Availability and Utilization Criterion 
Table G-37 Desirability Values of Site Recovery Criterion

\begin{tabular}{|l|c|c|c|c|c|c|c|}
\hline \multicolumn{7}{|c|}{ Environmental: (N5) Site Recovery } \\
\hline \multicolumn{1}{|c|}{ Metrics } & EXP01 & EXP02 & EXP03 & EXP04 & EXP05 & Avg. & $\%$ \\
\hline very difficult & 10 & 0 & 20 & 0 & 5 & 7 & 0.07 \\
\hline difficult & 20 & 20 & 30 & 20 & 15 & 21 & 0.21 \\
\hline somewhat & 40 & 35 & 40 & 45 & 30 & 38 & 0.38 \\
\hline neutral & 65 & 50 & 50 & 60 & 70 & 59 & 0.59 \\
\hline easy & 80 & 80 & 70 & 80 & 80 & 78 & 0.78 \\
\hline very easy & 95 & 90 & 90 & 100 & 90 & 93 & 0.93 \\
\hline
\end{tabular}

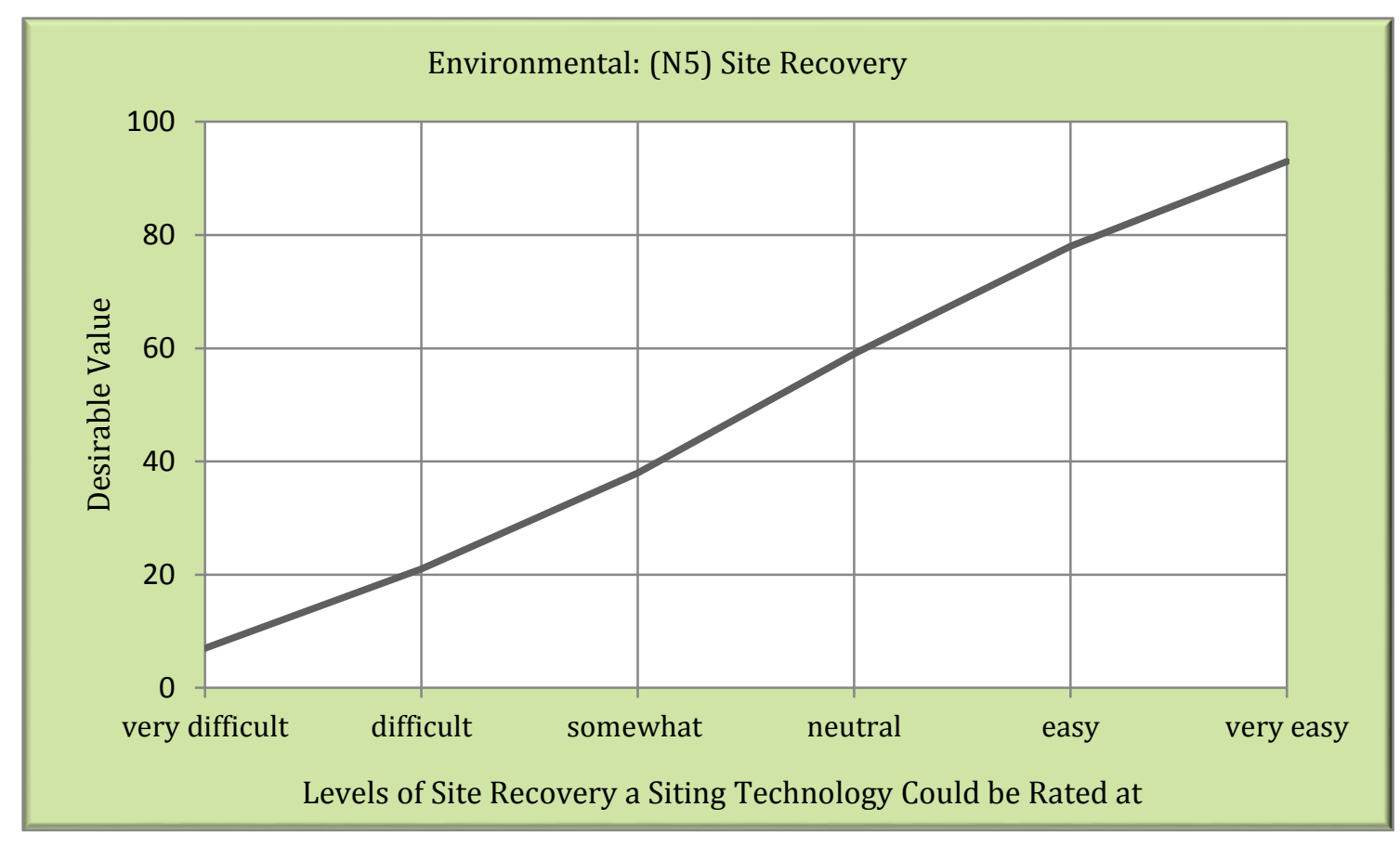

Figure G-37 Desirability Curve of Site Recovery Criterion 
Table G-38 Desirability Values of Government Perception Criterion

\begin{tabular}{|l|c|c|c|c|c|c|c|}
\hline \multicolumn{7}{c|}{ Political: (P1) Government Perception } \\
\hline \multicolumn{1}{|c|}{ Metrics } & EXP01 & EXP02 & EXP03 & EXP04 & EXP05 & Avg. & $\%$ \\
\hline poor & 25 & 0 & 0 & 50 & 0 & 15 & 0.15 \\
\hline fair & 45 & 25 & 30 & 60 & 25 & 37 & 0.37 \\
\hline good & 55 & 50 & 60 & 70 & 50 & 57 & 0.57 \\
\hline very good & 75 & 75 & 90 & 80 & 75 & 79 & 0.79 \\
\hline excellent & 100 & 100 & 100 & 90 & 100 & 98 & 0.98 \\
\hline
\end{tabular}

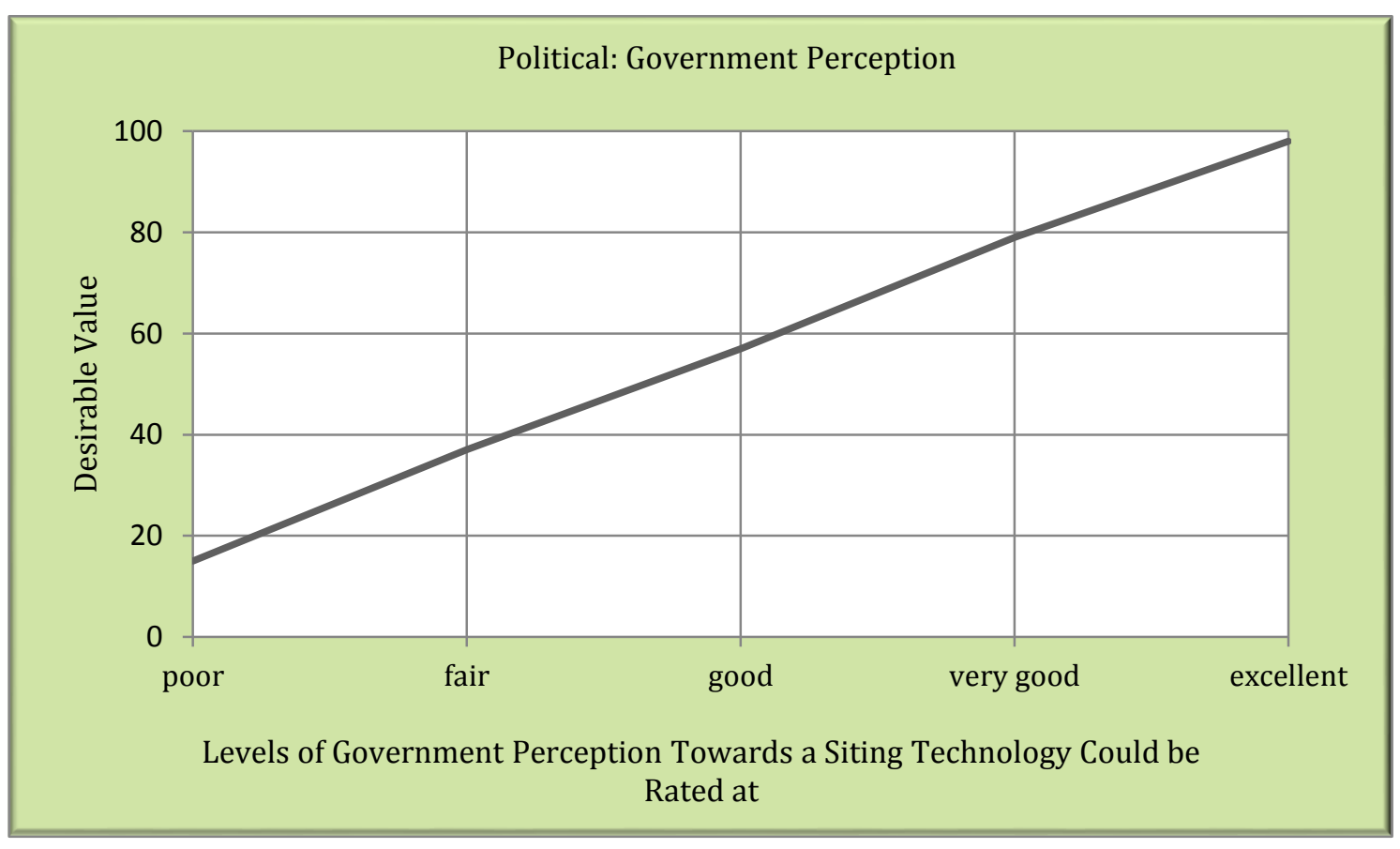

Figure G-38 Desirability Curve of Government Perception Criterion 
Table G-39 Desirability Values of Government Support/Opposition Criterion

\section{Political: (P2) Government Support/Opposition}

\begin{tabular}{|l|c|c|c|c|c|c|c|}
\hline \multicolumn{1}{|c|}{ Metrics } & EXP01 & EXP02 & EXP03 & EXP04 & EXP05 & Avg. & $\%$ \\
\hline strong opposition & 0 & 0 & 10 & 0 & 0 & 2 & 0.02 \\
\hline average opposition & 25 & 35 & 40 & 60 & 10 & 34 & 0.34 \\
\hline no support/opposition & 50 & 50 & 60 & 70 & 35 & 53 & 0.53 \\
\hline average support & 75 & 60 & 85 & 80 & 60 & 72 & 0.72 \\
\hline strong support & 100 & 90 & 95 & 100 & 90 & 95 & 0.95 \\
\hline
\end{tabular}

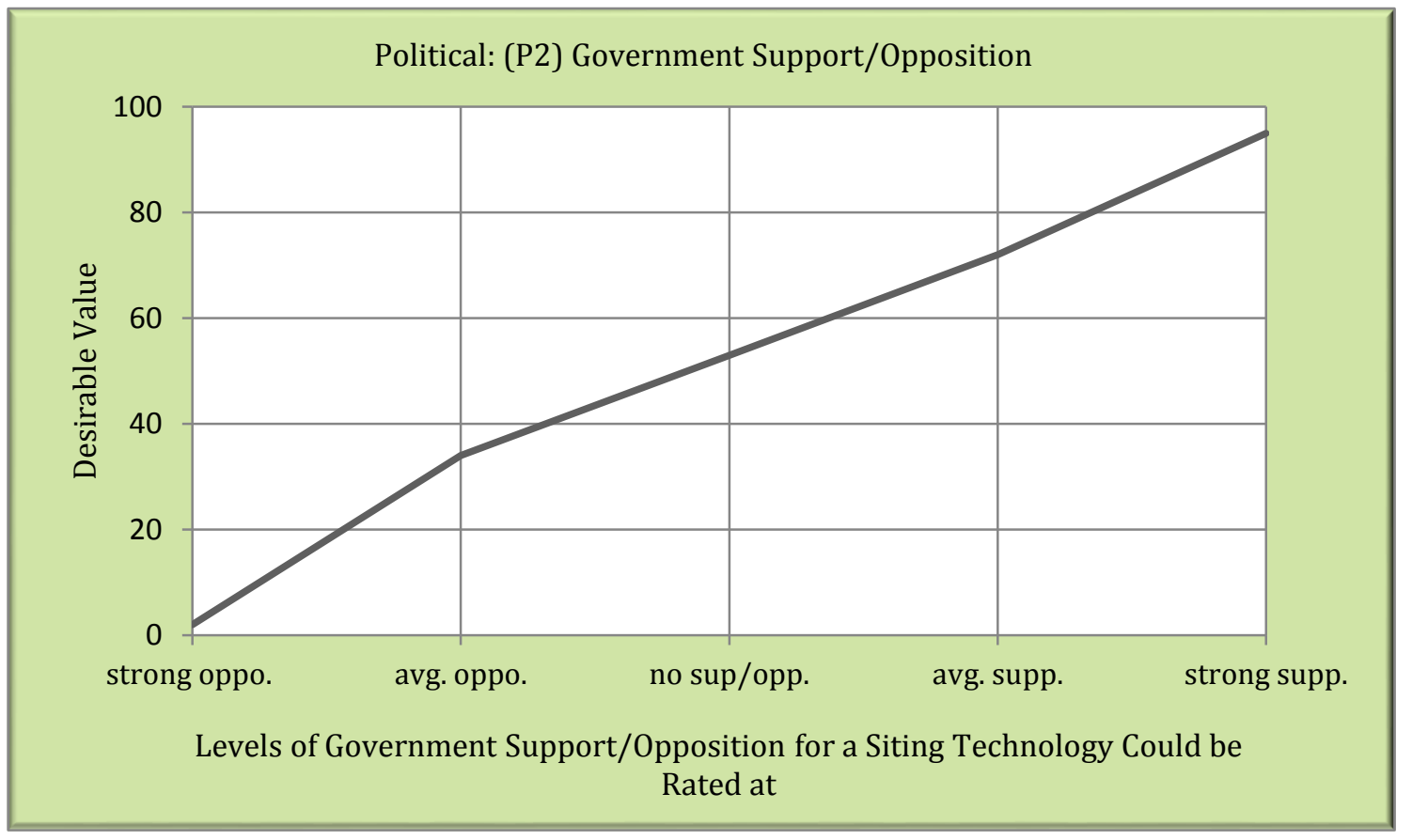

Figure G-39 Desirability Curve of Government Support/Opposition Criterion 
Table G-40 Desirability Values of Political Side of Technology Transfer Criterion Political: (P3) Political Side of Technology Transfer

\begin{tabular}{|l|c|c|c|c|c|c|c|}
\hline \multicolumn{1}{|c|}{ Metrics } & EXP01 & EXP02 & EXP03 & EXP04 & EXP05 & Avg. & $\%$ \\
\hline critical & 10 & 20 & 5 & 0 & 15 & 10 & 0.10 \\
\hline unhelpful & 25 & 45 & 50 & 20 & 45 & 37 & 0.37 \\
\hline neutral & 50 & 65 & 75 & 40 & 55 & 57 & 0.57 \\
\hline collaborative & 75 & 85 & 80 & 60 & 65 & 73 & 0.73 \\
\hline supportive & 80 & 100 & 95 & 80 & 75 & 86 & 0.86 \\
\hline
\end{tabular}

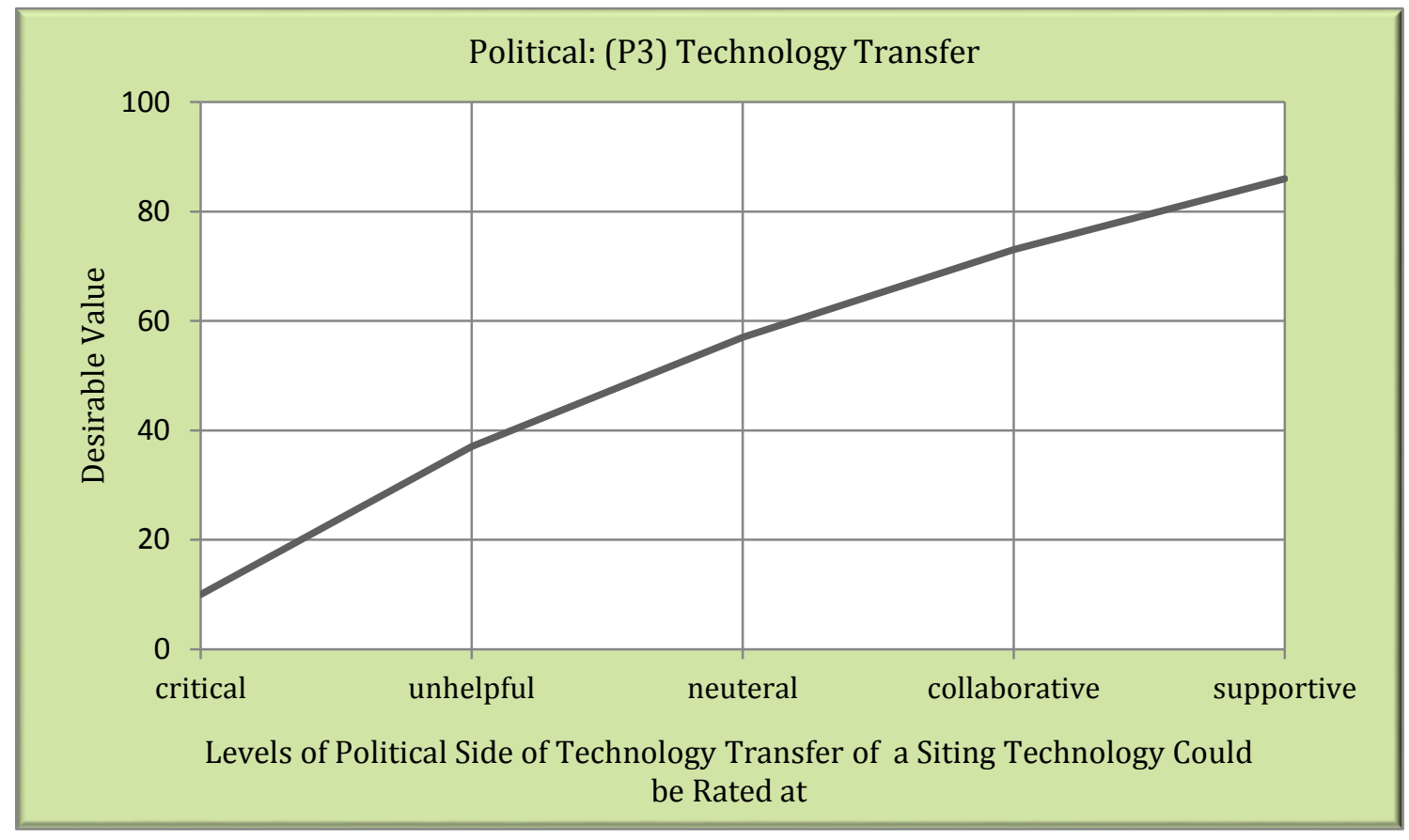

Figure G-40 Desirability Curve of Political Side of Technology Transfer Criterion 
Table G-41 Desirability Values of National/International Laws and Agreements Criterion

Political: (P4) National/International Laws and Agreements

\begin{tabular}{|l|c|c|c|c|c|c|c|}
\hline \multicolumn{1}{|c|}{ Metrics } & EXP01 & EXP02 & EXP03 & EXP04 & EXP05 & Avg. & $\%$ \\
\hline strongly prevent & 0 & 5 & 0 & 10 & 5 & 4 & 0.04 \\
\hline conditionally prevent & 25 & 35 & 40 & 30 & 50 & 36 & 0.36 \\
\hline indifferent & 50 & 75 & 60 & 50 & 75 & 62 & 0.62 \\
\hline mostly permit & 75 & 90 & 80 & 80 & 80 & 81 & 0.81 \\
\hline highly permit & 100 & 100 & 100 & 100 & 95 & 99 & 0.99 \\
\hline
\end{tabular}

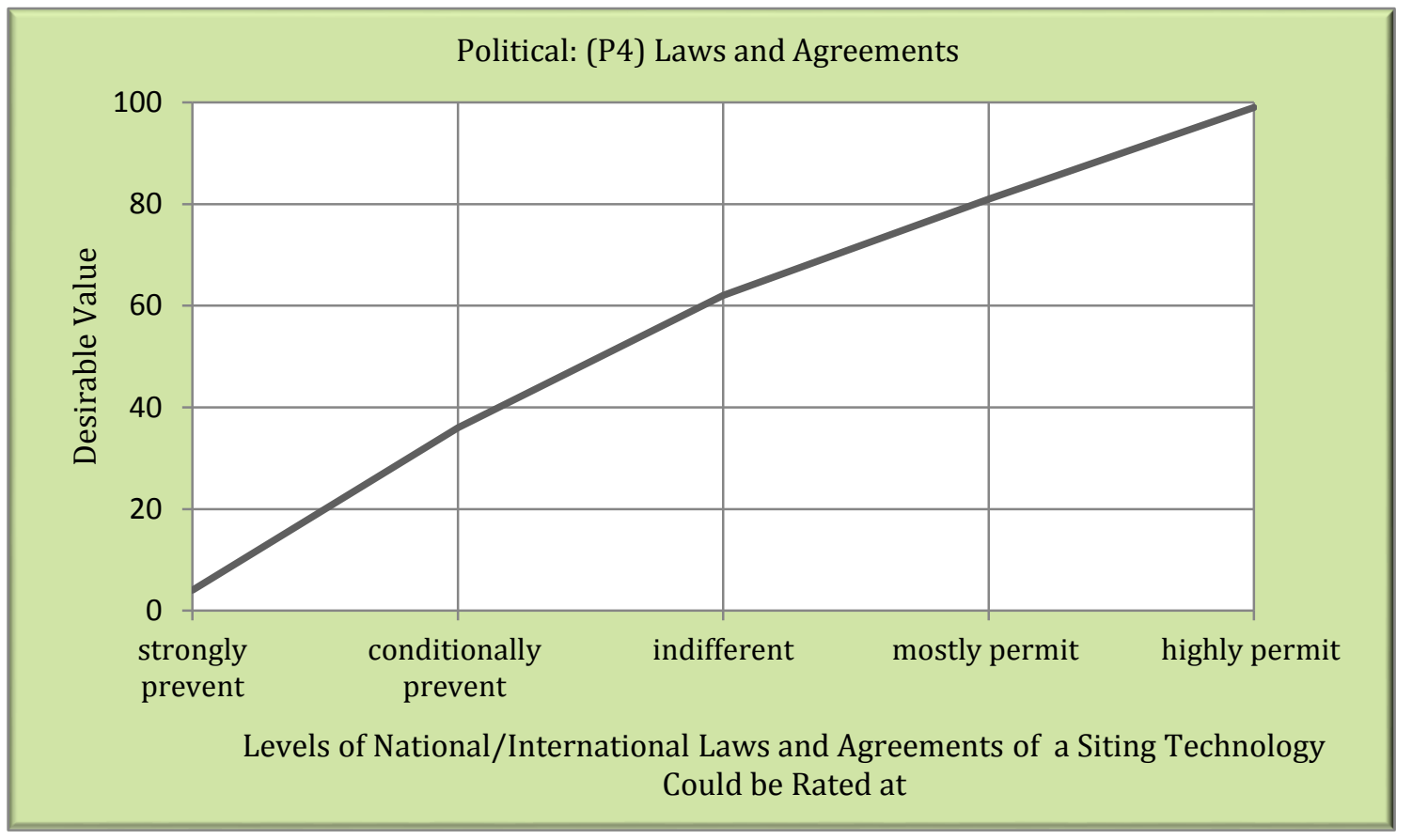

Figure G-41 Desirability Curve of National/International Laws and Agreements Criterion 
Table G-42 Desirability Values of Rules and Regulations Availability Criterion

Political: (P5) Rules and Regulations Availability

\begin{tabular}{|l|c|c|c|c|c|c|c|}
\hline \multicolumn{1}{|c|}{ Metrics } & EXP01 & EXP02 & EXP03 & EXP04 & EXP05 & Avg. & $\%$ \\
\hline not available & 25 & 25 & 0 & 50 & 0 & 20 & 0.20 \\
\hline under development & 50 & 25 & 10 & 75 & 50 & 42 & 0.42 \\
\hline available & 100 & 100 & 100 & 100 & 100 & 100 & 1.00 \\
\hline
\end{tabular}

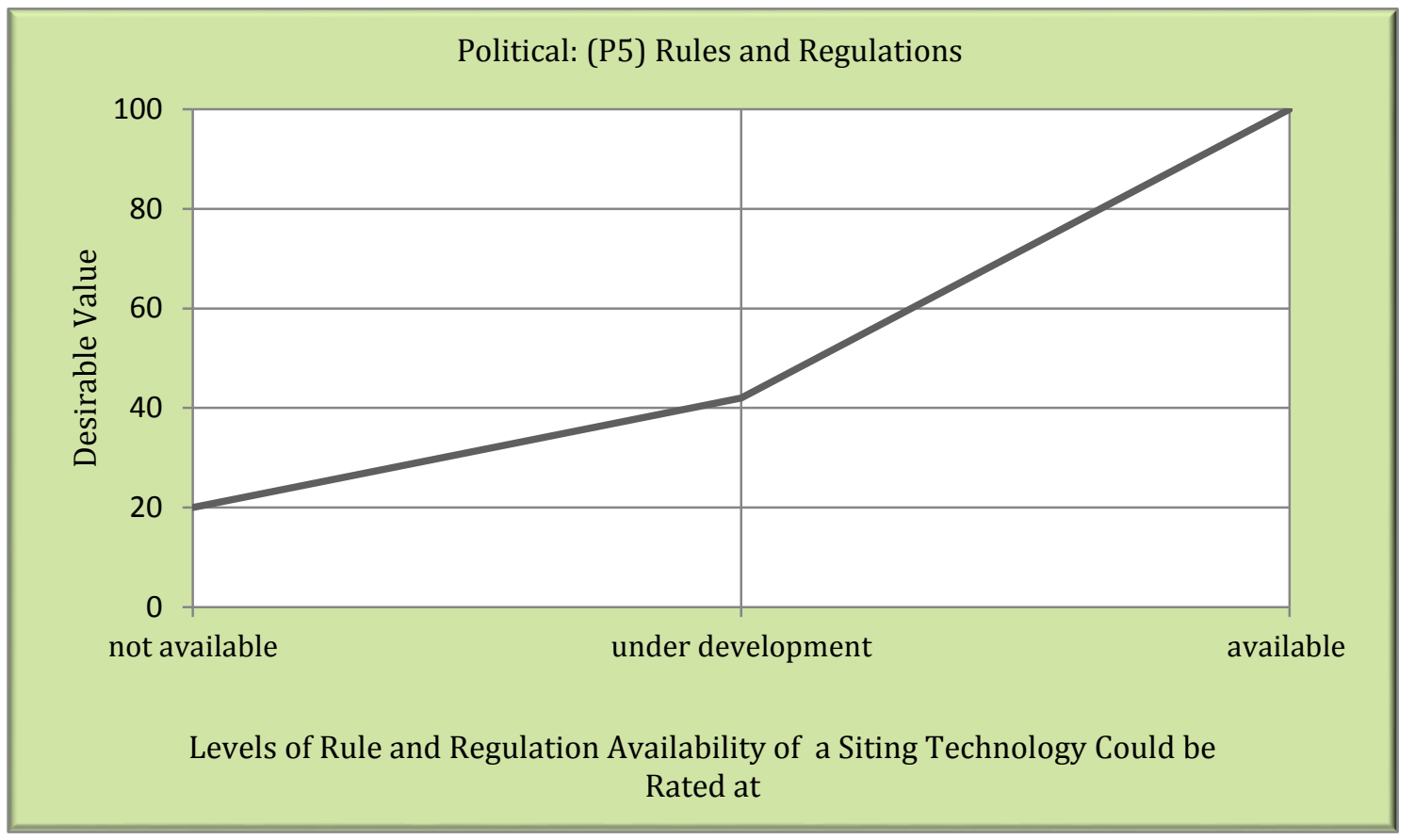

Figure G-42 Desirability Curve of National/International Laws and Agreements Criterion 